NISTIR 8160

\title{
Influence of Fire on the Lateral Load Capacity of Steel-Sheathed Cold-Formed Steel Shear Walls
}

\section{Report of Test}

Matthew S. Hoehler

Christopher M. Smith

This publication is available free of charge from:

https://doi.org/10.6028/NIST.IR.8160 
NISTIR 8160

\section{Influence of Fire on the Lateral Load Capacity of Steel-Sheathed Cold-Formed Steel Shear Walls}

\section{Report of Test}

Matthew S. Hoehler Christopher M. Smith Fire Research Division Engineering Laboratory

This publication is available free of charge from: https://doi.org/10.6028/NIST.IR.8160

December 2016

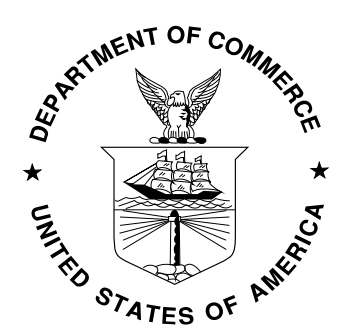

U.S. Department of Commerce

Penny Pritzker, Secretary

National Institute of Standards and Technology Willie May, Under Secretary of Commerce for Standards and Technology and Director 


\begin{abstract}
A series of fourteen experiments on six $9 \mathrm{ft} . \times 12 \mathrm{ft}$. $(2.7 \mathrm{~m} \times 3.7 \mathrm{~m})$ shear wall specimens consisting of cold-formed steel framing sheathed on one side with light-gauge steel adhered to gypsum board and on the opposite side with plain gypsum board were conducted at the National Fire Research Laboratory at the National Institute of Standards and Technology. The specimens were subjected to varying sequences of simulated seismic shear deformation and fire loading to study the influence of structure-fire interactions on the lateral load capacity of the walls. The test program was designed to complement a parallel test series to investigate a full-scale six-story building subjected to earthquakes and fires. The test results showed that the fire loading caused a shift in the failure mode of the walls from local to global bucking of the sheet metal with an accompanying $35 \%$ reduction of load capacity.
\end{abstract}

\title{
Key words
}

cold-formed steel; shear walls; earthquake; fire; fire following earthquake 


\section{Acknowledgements}

In-kind support for this work was provide by CEMCO, Sure-Board, Intermat and MarinolWare. The authors would specifically like to recognize Fernando Sesma, Carlton Elliott, Tyler Elliott and Robert Gilliam, as well as the NIST Fire Research Division staff (Brian Story, Laurean DeLauter, Anthony Chakalis, Michael Selepak, Marco Fernandez, Artur Chernovsky, Doris Reinhardt, Matthew Bundy, and Randal McDermott) who contributed to these experiments. Valuable input to the development of the test setup and plan was provided by Tara Hutchinson and Xiang Wang (University of California, San Diego), Brian Meacham and Praveen Kamath (Worcester Polytechnic Institute) and Benjamin Schafer (Johns Hopkins University). This support is gratefully acknowledged.

\section{Disclaimer}

Certain commercial equipment, instruments, or materials are identified in this report in order to specify the experimental procedure adequately. Such identification is not intended to imply recommendation or endorsement by the National Institute of Standards and Technology, nor is it intended to imply that the materials or equipment identified are necessarily the best available for the purpose.

\section{Note about units}

International System of Units (SI) and U.S. Customary Units are used in this report. Measured or calculated results related to mechanical loading are reported in both systems of units. Construction drawings and product specifications use U.S. Customary Units because this is the prevalent practice in the construction industry in the United States at this time. In these cases, conversion factors to SI are provided. 


\section{Table of Contents}

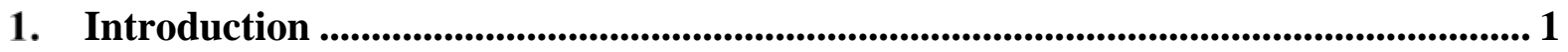

1.1. Background ……………………………………....................................... 1

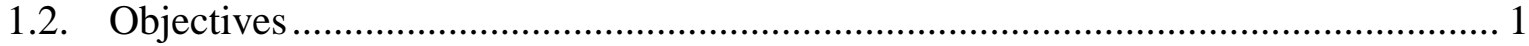

2. Test Program...................................................................................................... 1

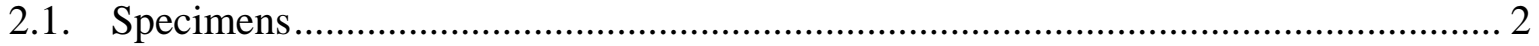

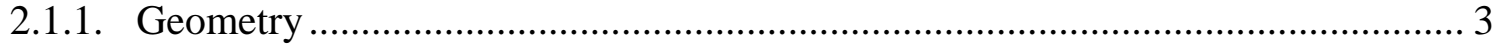

2.1.2. Cold-formed steel framing members................................................................... 4

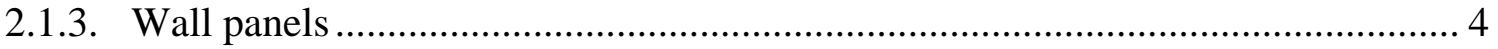

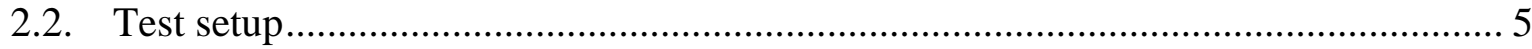

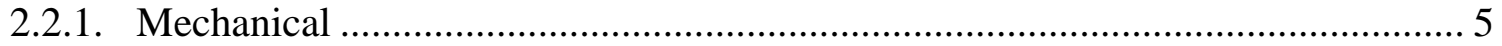

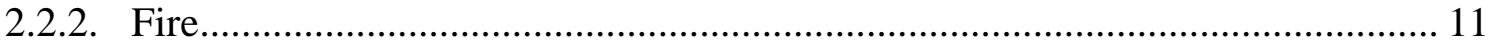

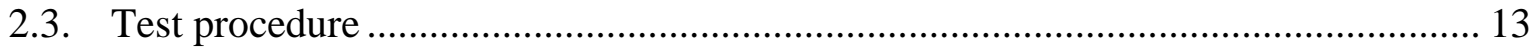

2.3.1. Monotonic loading ……………………………............................................. 13

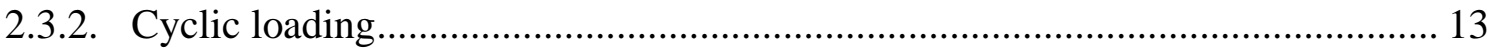

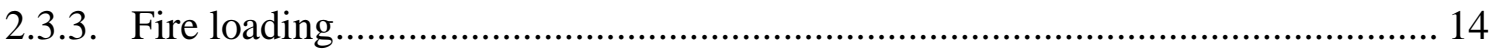

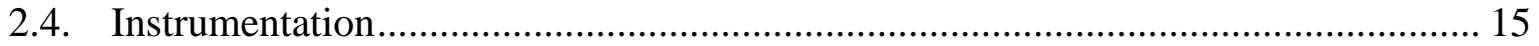

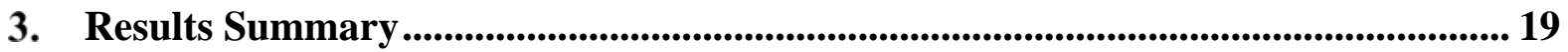

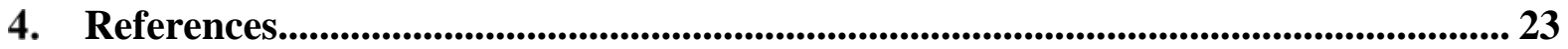

Appendix A. Fabrication Drawings .............................................................................. 24

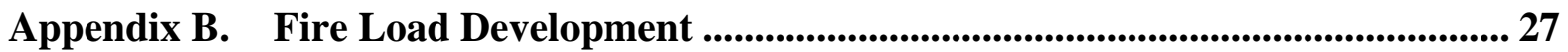

Appendix C. CFS01 Test Data................................................................................... 30

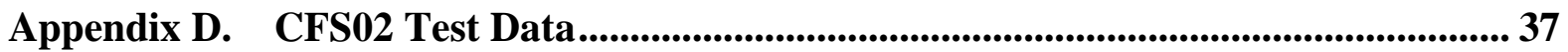

Appendix E. CFS03 Test Data.................................................................................. 41

Appendix F. CFS04 Test Data............................................................................................. 49

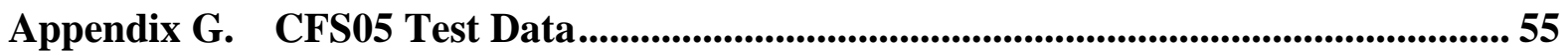

Appendix H. CFS06 Test Data...........................................................................................60 


\section{List of Figures}

Figure 1: Cold-formed steel framed building at the UCSD test facility.............................. 1

Figure 2: Typical floor plan for six-story building after Xiang [1]. ..................................... 2

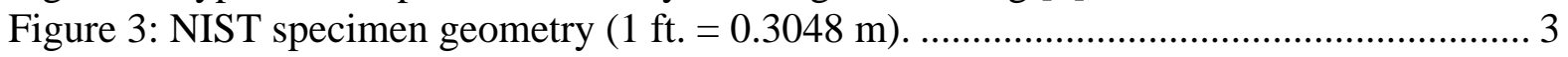

Figure 4: Photograph of specimen framing. ............................................................... 3

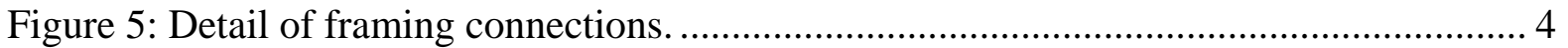

Figure 6: Photograph of test specimen with one gypsum board removed.............................. 5

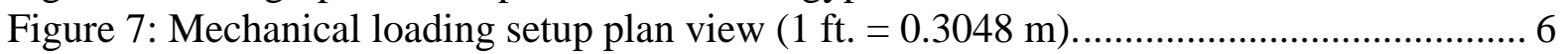

Figure 8: Mechanical loading setup from South $(1 \mathrm{ft} .=0.3048 \mathrm{~m})$............................... 7

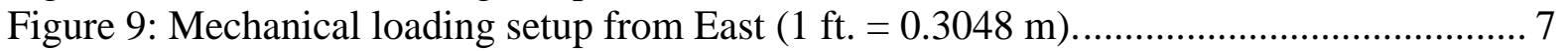

Figure 10: Photograph of mechanical loading setup from the East. ................................... 8

Figure 11: Photograph of mechanical loading setup from the West...................................... 8

Figure 12: Photograph of mechanical loading setup from the South.................................. 9

Figure 13: Photograph of Polytetrafluoroethylene (Teflon) glides at actuator to prevent out-

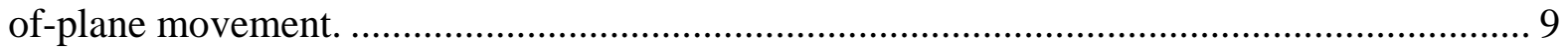

Figure 14: Schematic of attachment of specimen to mechanical loading frame. ................. 10

Figure 15: Photograph of plate washer on bottom of tension tie rods. ................................. 10

Figure 16: Photograph of top loading beam from above. ............................................... 11

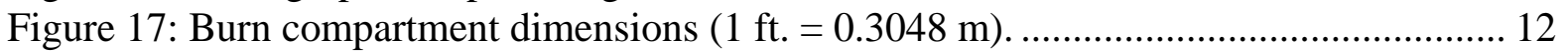

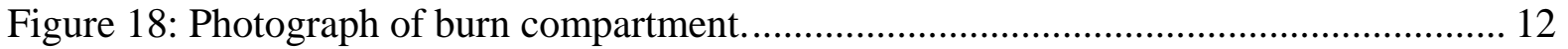

Figure 19: Schematic cross section of burn compartment against wall.............................. 13

Figure 20: Cyclic displacement pattern (Test Method C) from ASTM E2126-11 [4].......... 14

Figure 21: Target upper layer temperature versus time during heating phase predicted by

CFAST for the NIST tests (NIST target). ASTM E119 standard fire curve shown for

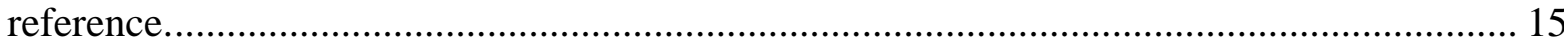

Figure 22: Sensor locations on specimen and loading frame $(1 \mathrm{ft} .=0.3048 \mathrm{~m}) \ldots \ldots \ldots \ldots \ldots \ldots . . . . . .17$

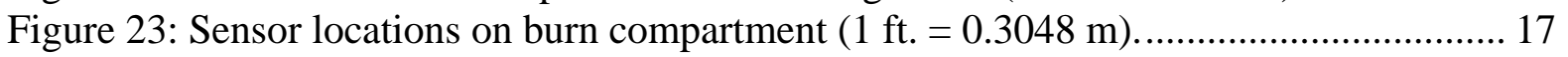

Figure 24: Photographs linear potentiometers to measure wall uplift and slip: (a) North end;

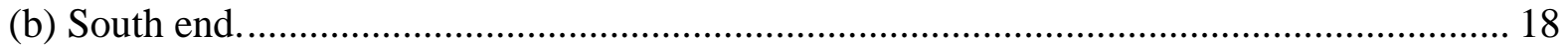

Figure 25: Photograph of string potentiometer to measure top wall drift............................. 18

Figure 26: Photograph of thermocouples in specimen. .................................................. 18

Figure 27: Photograph of GoPro video camera in water bath used to acquire footage during

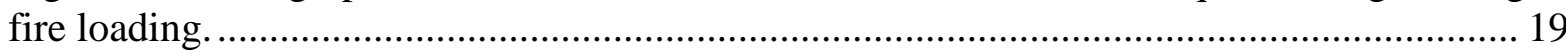

Figure 28: Backbone curves for CFS02 to CFS06 (U.S. Customary Units).......................... 20

Figure 29: Backbone curves for CFS02 to CFS06 (SI Units)........................................... 21

Figure 30: Photograph of back of metal sheathed side of wall after mechanical loading to 2.8

\% drift; nonstructural gypsum removed: (a) unburned wall; (b) wall after burning. ............. 22

Figure 31: Photograph of back of metal sheathed side of wall after fire loading for $26 \mathrm{~m} 40 \mathrm{~s}$

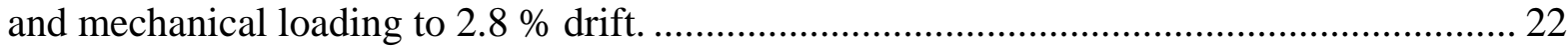

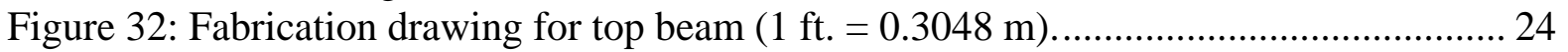

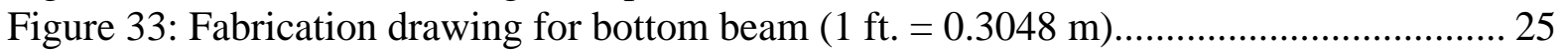

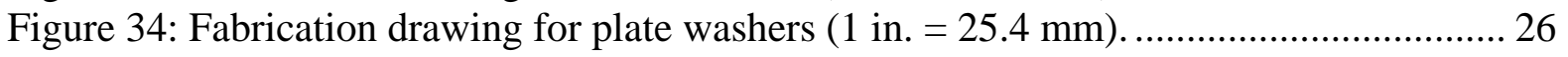

Figure 35: Approximate burn area for NIST investigations after Xiang [1]. ....................... 28

Figure 36: Photo (looking East) of $2^{\text {nd }}$ level showing opening at end of corridor in the sixstory building. 
Figure 37: Upper layer temperature versus time predicted by CFAST for four, five and six pans of heptane in the UCSD corridor along with target curve for the NIST compartment. . 29 Figure 38: Smokeview visualizations of CFAST models: (a) UCSD $2^{\text {nd }}$ floor corridor with 6 pans of heptane; (b) NIST compartment with HRR selected to match UCSD results. .......... 29 Figure 39: CFS01 - Lateral load (Actuator Force) versus drift (Disp_Longitudinal_SP) during

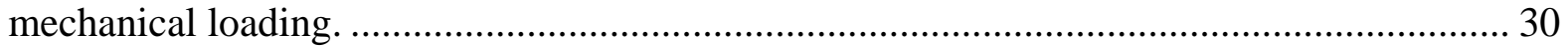
Figure 40: CFS01 - Uplift at bottom of specimen during mechanical loading..................... 31 Figure 41: CFS01 - Ancillary displacement measurements during mechanical loading....... 31 Figure 42: CFS01 - Burner heat release rate and upper layer temperature during fire loading.

Figure 43: CFS01 - Compartment temperatures during fire loading: (a) North thermocouple

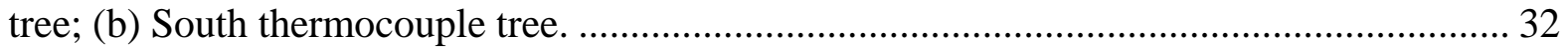
Figure 44: CFS01 - Specimen temperatures during fire loading. ........................................ 33 Figure 45: CFS01 - Photograph of bottom framing beam: (a) during test; (b) retrofit for all

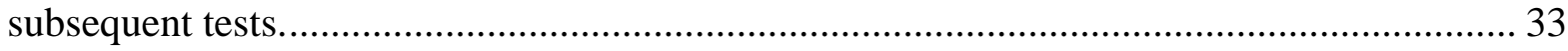
Figure 46: CFS01 - Photograph of metal sheathed side of wall after mechanical loading

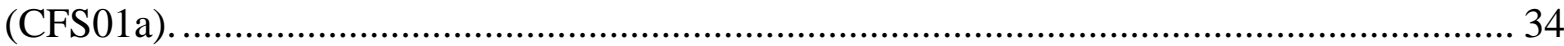
Figure 47: CFS01 - Photograph of gypsum sheathed side of wall after mechanical loading (CFS01a). 34

Figure 48: CFS01 - Photograph of back of metal sheathed side of wall after mechanical

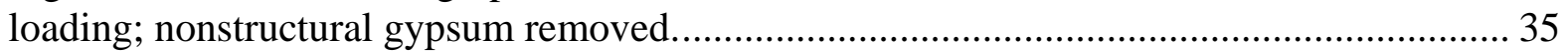
Figure 49: CFS01 - Photograph of back of compartment during fire loading (CFS01b)...... 35 Figure 50: CFS01 - Photograph of metal sheathed side of wall after fire loading (CFS01b). 36 Figure 51: CFS01 - Photograph of joint detail of metal sheathed side of wall after fire loading (CFS01b). 36 Figure 52: CFS02 - Lateral load (Actuator Force) versus drift (Disp_Longitudinal_SP) during

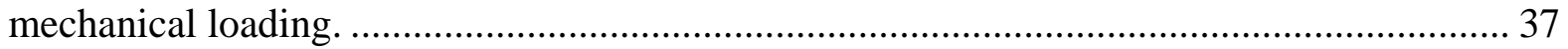
Figure 53: CFS02 - Uplift at bottom of specimen during mechanical loading...................... 38 Figure 54: CFS02 - Ancillary displacement measurements during mechanical loading........ 38 Figure 55: CFS02 - Photograph of metal sheathed side of wall after mechanical loading to 2.8 $\%$ drift (CFS02a). 39 Figure 56: CFS02 - Photograph of gypsum sheathed side of wall after mechanical loading to $2.8 \%$ drift (CFS02a). 39

Figure 57: CFS02 - Photograph of back of metal sheathed side of wall after mechanical loading to $2.8 \%$ drift (CFS02a); nonstructural gypsum removed. 40 Figure 58: CFS02 - Photograph of back of metal sheathed side of wall after mechanical loading to $2.8 \%$ drift (CFS02a) highlighting corner damage. 40 Figure 59: CFS03 - Lateral load (Actuator Force) versus drift (Disp_Longitudinal_SP) during mechanical loading. 41 Figure 60: CFS03 - Uplift at bottom of specimen during mechanical loading: (a) Before fire; (b) After fire. 42 Figure 61: CFS03 - Ancillary displacement measurements during mechanical loading: (a) Before fire; (b) After fire. 42 Figure 62: CFS03 - Burner heat release rate and upper layer temperature during fire loading. 
Figure 63: CFS03 - Compartment temperatures during fire loading: (a) North thermocouple

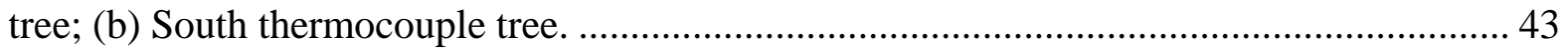
Figure 64: CFS03 - Specimen temperatures during fire loading. ........................................ 44 Figure 65: CFS03 - Photograph of metal sheathed side of wall after mechanical loading to 1.0

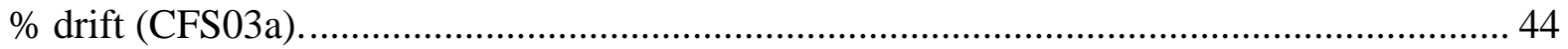
Figure 66: CFS03 - Photograph of back of compartment with redesigned fire protection for reaction frames during fire loading (CFS03b)......................................................... 45 Figure 67: CFS03 - Photograph of metal sheathed side of wall after fire loading (CFS03b).45 Figure 68: CFS03 - Photograph of metal sheathed side of the burned wall after mechanical loading to $2.8 \%$ drift (CFS03c). 46 Figure 69: CFS03 - Photograph of metal sheathed side of the burned wall after mechanical loading to $2.8 \%$ drift (CFS03c) highlighting tearing of sheet metal................................. 46 Figure 70: CFS03 - Photograph of gypsum sheathed side of wall after mechanical loading to $2.8 \%$ drift (CFS03c). 47 Figure 71: CFS03 - Photograph of gypsum sheathed side of wall after mechanical loading to $2.8 \%$ drift (CFS03c) highlighting screw shearing. 47 Figure 72: CFS03 - Photograph of gypsum sheathed side of wall after mechanical loading to $2.8 \%$ drift (CFS03c) highlighting board detachment. 48

Figure 73: CFS03 - Photograph of back of metal sheathed side of the burned wall after mechanical loading to $2.8 \%$ drift (CFS03c); nonstructural gypsum removed...................... 48 Figure 74: CFS04 - Lateral load (Actuator Force) versus drift (Disp_Longitudinal_SP) during

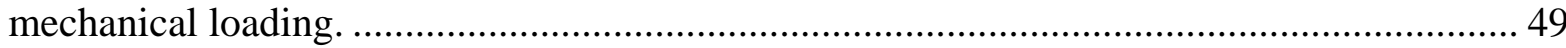
Figure 75: CFS04 - Uplift at bottom of specimen during mechanical loading: (a) Before fire;

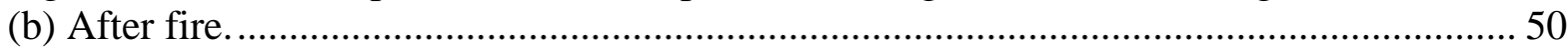
Figure 76: CFS04 - Ancillary displacement measurements during mechanical loading: (a) Before fire; (b) After fire. 50 Figure 77: CFS04 - Burner heat release rate and upper layer temperature during fire loading.

Figure 78: CFS04 - Compartment temperatures during fire loading: (a) North thermocouple

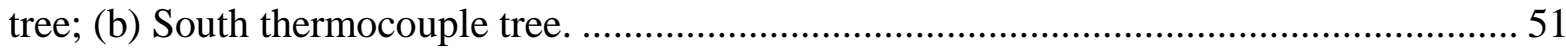
Figure 79: CFS04 - Specimen temperatures during fire loading. ..................................... 52 Figure 80: CFS04 - Photograph of metal sheathed side of wall after mechanical loading to 1.8

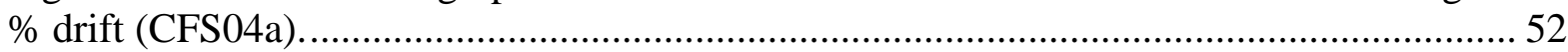
Figure 81: CFS04 - Photograph of metal sheathed side of wall after fire loading (CFS04b).53 Figure 82: CFS04 - Photograph of metal sheathed side of the burned wall after mechanical

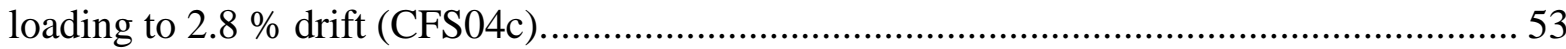
Figure 83: CFS04 - Photograph of gypsum sheathed side of wall after mechanical loading to $2.8 \%$ drift (CFS04c). 54

Figure 84: CFS04 - Photograph of back of metal sheathed side of the burned wall after mechanical loading to $2.8 \%$ drift (CFS04c); nonstructural gypsum removed....................... 54 Figure 85: CFS05 - Burner heat release rate and upper layer temperature during fire loading.

Figure 86: CFS05 - Compartment temperatures during fire loading: (a) North thermocouple

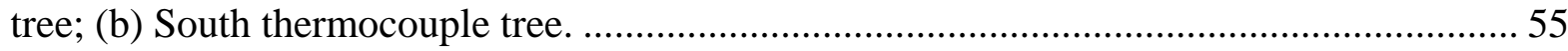
Figure 87: CFS05 - Specimen temperatures during fire loading. ...................................... 56 
Figure 88: CFS05 - Lateral load (Actuator Force) versus drift (Disp_Longitudinal_SP) during

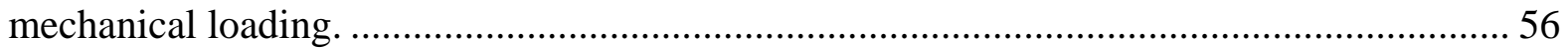

Figure 89: CFS05 - Uplift at bottom of specimen during mechanical loading...................... 57

Figure 90: CFS05 - Ancillary displacement measurements during mechanical loading....... 57

Figure 91: CFS05 - Photograph of metal sheathed side of wall after fire loading (CFS05a). 58

Figure 92: CFS05 - Photograph of metal sheathed side of the burned wall after mechanical

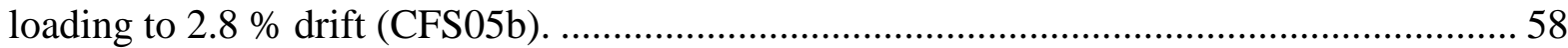

Figure 93: CFS05 - Photograph of metal sheathed side of the burned wall after mechanical

loading to $2.8 \%$ drift (CFS05b) highlighting sheeting damage........................................ 59

Figure 94: CFS05 - Photograph of gypsum sheathed side of wall after mechanical loading to

$2.8 \%$ drift (CFS05b). 59

Figure 95: CFS06 - Lateral load (Actuator Force) versus drift (Disp_Longitudinal_SP) during

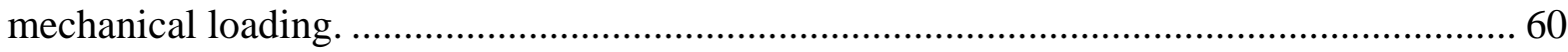

Figure 96: CFS06 - Uplift at bottom of specimen during mechanical loading: (a) Before fire;

(b) After fire. 61

Figure 97: CFS06 - Ancillary displacement measurements during mechanical loading: (a)

Before fire; (b) After fire.

61

Figure 98: CFS06 - Burner heat release rate and upper layer temperature during fire loading.

Figure 99: CFS06 - Compartment temperatures during fire loading: (a) North thermocouple

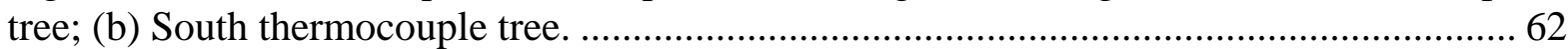

Figure 100: CFS06 - Specimen temperatures during fire loading. .................................... 63

Figure 101: CFS06 - Photograph of metal sheathed side of wall after fire loading (CFS06b).

Figure 102: CFS06 - Photograph of metal sheathed side of the burned wall after mechanical

loading to $2.8 \%$ drift (CFS06c).

Figure 103: CFS06 - Photograph of gypsum sheathed side of wall after mechanical loading

to $2.8 \%$ drift (CFS06c).

Figure 104: CFS06 - Photograph of back of metal sheathed side of the burned wall after

mechanical loading to $2.8 \%$ drift (CFS06c); nonstructural gypsum removed. 65

Figure 105: CFS06 - Photograph of back of metal sheathed side of wall after mechanical loading to $2.8 \%$ drift (CFS06c) highlighting charring of gypsum board. 


\section{List of Tables}

Table 1: Test program..................................................................................................... 2

Table 2: Amplitude of primary cycles and step durations. ............................................... 14

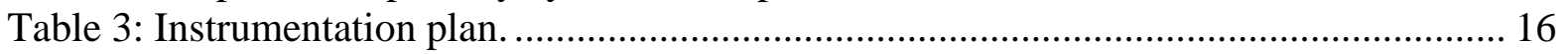

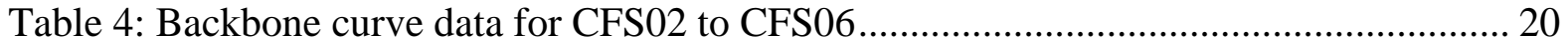

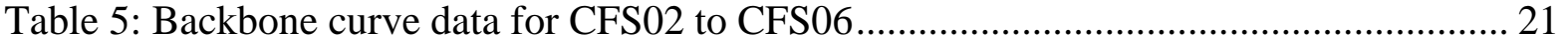

Table 6: Predicted temperature from CFAST models. ...................................................... 29 


\section{Introduction}

\subsection{Background}

Light-gauge construction, e.g. timber or cold-formed steel (CFS), is widely used for low-rise buildings in the western United States. Full-scale experiments are necessary to validate the performance of these construction methods as they are used for taller buildings located in seismic regions. In June of 2016, experimental investigations of the performance of a sixstory, light-gauge cold-formed steel framed building (Figure 1) were conducted on the Large High-

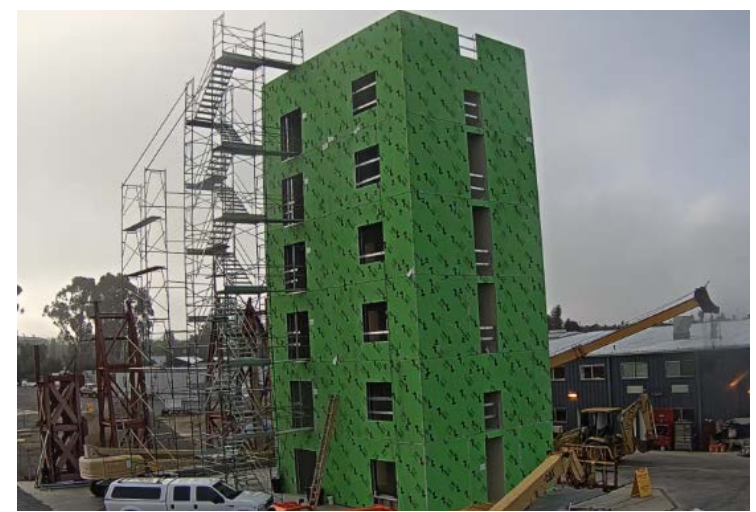

Figure 1: Cold-formed steel framed building at the UCSD test facility.

Performance Outdoor Shake Table at the University of California, San Diego (UCSD). The building's lateral load resistance system consisted of cold-formed steel framing members sheathed by panels of light-gauge steel adhered to gypsum board. The aim was to study the earthquake performance of this construction method for mid-rise structures (five to ten stories), as well as the earthquake-damaged building's response to fire. Subsequent to the fire tests, additional earthquake shaking was planned to study the response of the building to aftershocks. The aftershock test results can help inform decisions about first-responder access to a building in the case of fire following earthquake as well as understanding the impact of fire and aftershocks on structural vulnerability and resiliency. Additional details on the six-story building tests are provided by Xiang [1].

The investigators of the UCSD study collaborated with the authors to better understand how the fire tests might impact the structure's integrity.

\subsection{Objectives}

The objective of the tests reported here was to experimentally determine the influence of the fire load to be used in the tests at UCSD on the lateral load resistance of the investigated light-gauge cold-formed steel shear walls. The findings were intended to help inform the selection of earthquake shaking intensities used in the UCSD tests before and after the fires in order to gain the most value from those unique large-scale experiments, as well as to provide insight into structure-fire interaction for this construction method.

\section{Test Program}

A total of fourteen tests were conducted on six single wall specimens at the National Fire Research Laboratory (NFRL) at the National Institute of Standards and Technology (NIST) in Gaithersburg, Maryland. Table 1 provides an overview of the test program. The specimens were subjected sequentially to varied combinations of mechanical (shear) deformation and thermal (fire) loading. Specimen CFS01 was used to establish the monotonic "pushover" load-displacement capacity of the wall system (CFS01a) and subsequently to shake down the compartment fire test setup (CFS01b). Specimen CFS02 was loaded by fully-reversed cyclic shear deformation to destruction (defined as $2.8 \%$ interstory drift) to establish the cyclic load-displacement response. Specimens CFS03 and 
CFS04 were cycled to deformations just before and after the peak load was achieved, respectively, burned for 13 minutes and 20 seconds and then cycling was continued until destruction of the wall. For specimen CFS05, an undamaged wall was burned for 13 minutes and 20 seconds and then cycled until destruction. Specimen CFS06 was tested similarly to Specimen CFS03, however, the burn duration was doubled. The test program was intended to measure key limit states of the walls.

Table 1: Test program.

\begin{tabular}{|c|c|c|c|}
\hline Test name & Specimen & Description & Loading rate / Amplitude \\
\hline CFS01a & \multirow{2}{*}{ CFS01 } & Monotonic pushover & Push @ 0.1 in./m $(2.54$ mm/m) \\
\hline CFS01b & & $10 \mathrm{~m}$ burn & Multiple steps to $1900 \mathrm{~kW}$ \\
\hline CFSO2 & CFSO2 & Cycling to failure & $0.06 \mathrm{in} . / \mathrm{s}(1.524 \mathrm{~mm} / \mathrm{s})$ \\
\hline CFSO3a & \multirow{3}{*}{ CFSO3 } & Cycling to $1 \% \mathrm{drift}$ & $0.06 \mathrm{in} . / \mathrm{s}(1.524 \mathrm{~mm} / \mathrm{s})$ \\
\hline CFSO3b & & $13 \mathrm{~m} 20 \mathrm{~s}$ burn & Step to $1900 \mathrm{~kW}$ \\
\hline CFS03C & & Continue cycling until failure & $0.06 \mathrm{in} . / \mathrm{s}(1.524 \mathrm{~mm} / \mathrm{s})$ \\
\hline CFS04a & \multirow{3}{*}{ CFSO4 } & Cycling to $1.8 \%$ drift & $0.06 \mathrm{in} . / \mathrm{s}(1.524 \mathrm{~mm} / \mathrm{s})$ \\
\hline CFSO4b & & $13 \mathrm{~m} 20 \mathrm{~s}$ burn & Step to $1900 \mathrm{~kW}$ \\
\hline CFS04c & & Continue cycling until failure & $0.06 \mathrm{in} . / \mathrm{s}(1.524 \mathrm{~mm} / \mathrm{s})$ \\
\hline CFS05a & \multirow{2}{*}{ CFSO5 } & $13 \mathrm{~m} 20 \mathrm{~s}$ burn & Step to $1900 \mathrm{~kW}$ \\
\hline CFS05b & & Cycling to failure & $0.06 \mathrm{in} . / \mathrm{s}(1.524 \mathrm{~mm} / \mathrm{s})$ \\
\hline CFS06a & \multirow{3}{*}{ CFSO6 } & Cycling to $1 \% \mathrm{drift}$ & $0.06 \mathrm{in} . / \mathrm{s}(1.524 \mathrm{~mm} / \mathrm{s})$ \\
\hline CFSO6b & & $26 \mathrm{~m} 40 \mathrm{~s}$ burn & Step to $1900 \mathrm{~kW}$ \\
\hline CFS06c & & Continue cycling until failure & $0.06 \mathrm{in} . / \mathrm{s}(1.524 \mathrm{~mm} / \mathrm{s})$ \\
\hline
\end{tabular}

\subsection{Specimens}

Six $9 \mathrm{ft} . \times 12 \mathrm{ft} .(2.7 \mathrm{~m} \times 3.7 \mathrm{~m})$ shear wall test specimens consisting of cold-formed steel framing sheathed on one side with light-gauge metal adhered to gypsum board and on the opposite side with plain gypsum board were fabricated by Sure-Board/Intermat onsite at the NFRL. The specimens were designed to approximate a longitudinal shear wall along one side of the center corridor on the $2^{\text {nd }}$ floor of the UCSD six-story building (Figure 2).
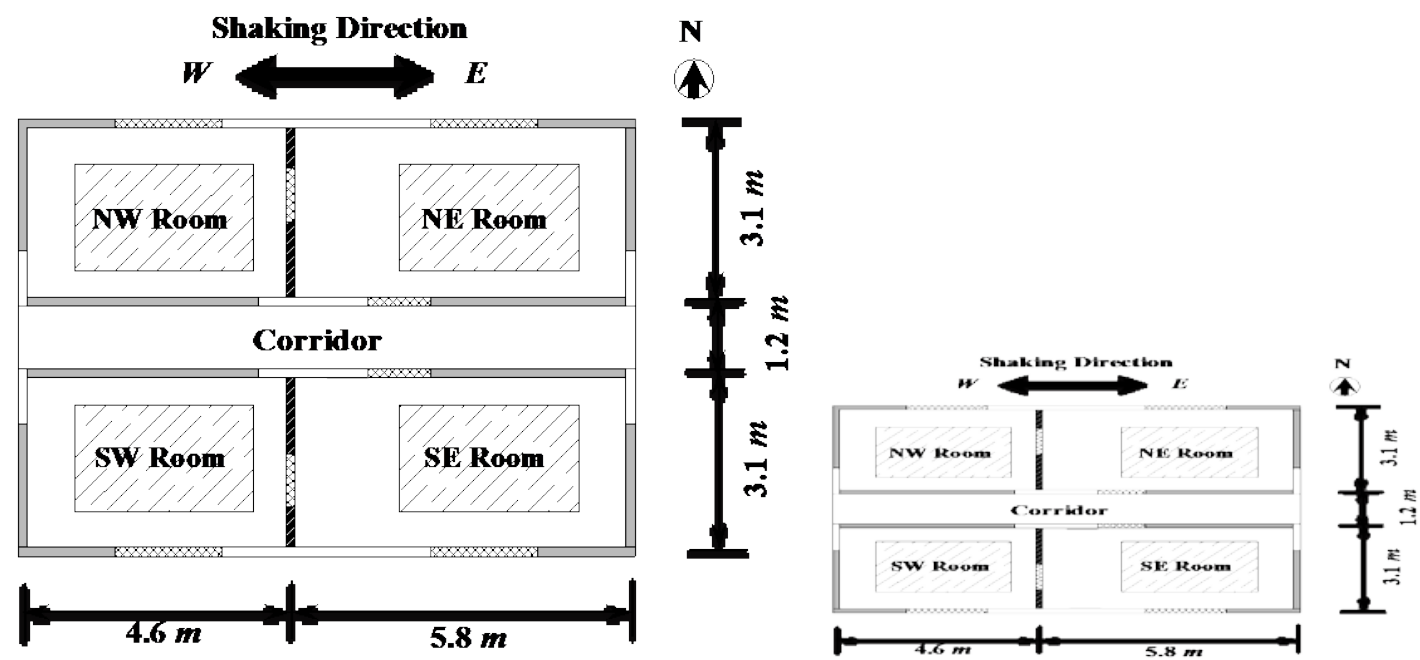

Figure 2: Typical floor plan for six-story building after Xiang [1]. 


\subsubsection{Geometry}

The dimensional details of the single-wall specimens are given in Figure 3. Two studs attached back-to-back provide boundary elements (stud packs) on the ends of the walls (Figure 4) that were used to carry vertical (compression) loads in the six-story building.

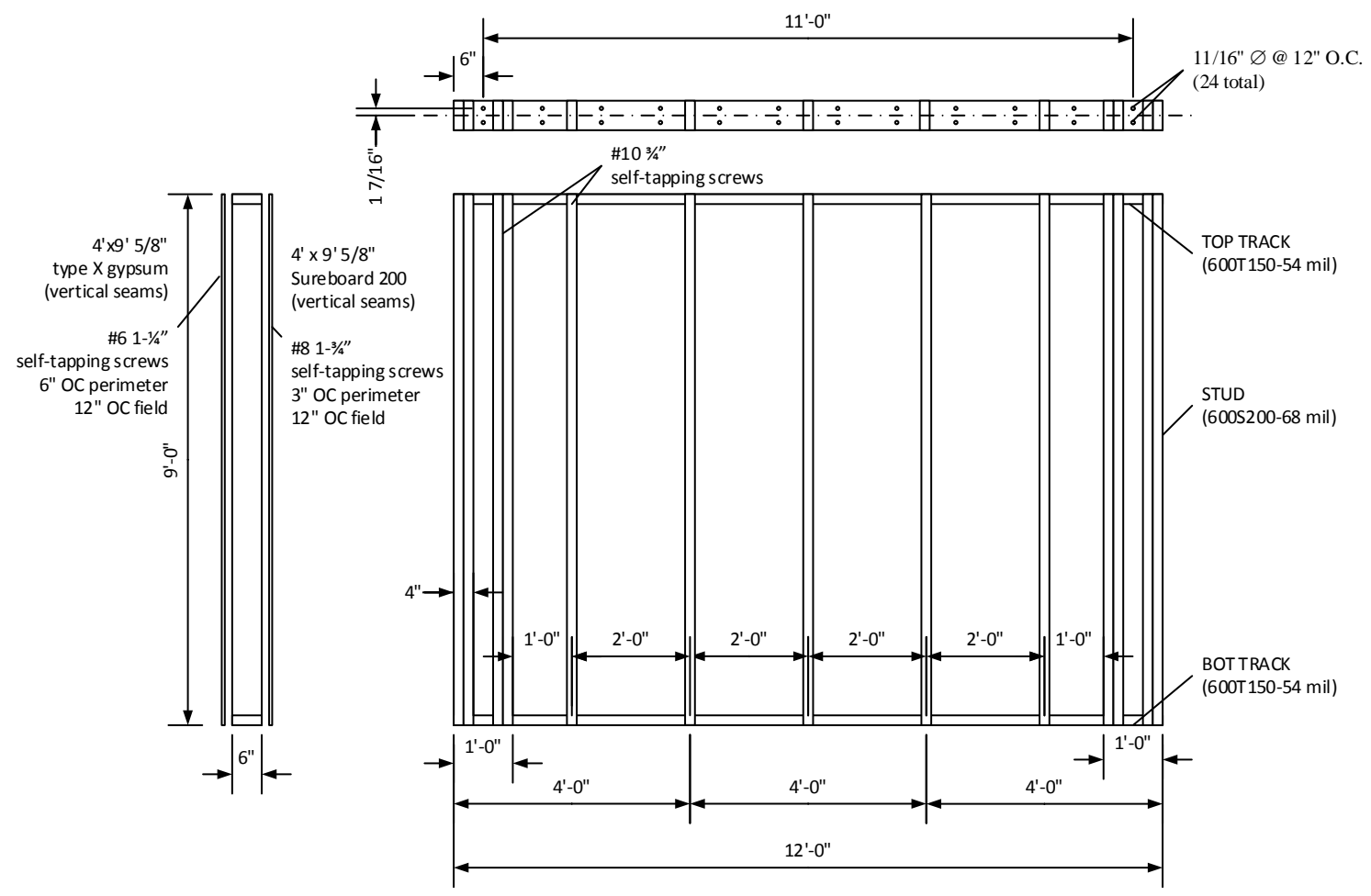

Figure 3: NIST specimen geometry $(1 \mathrm{ft} .=0.3048 \mathrm{~m})$.

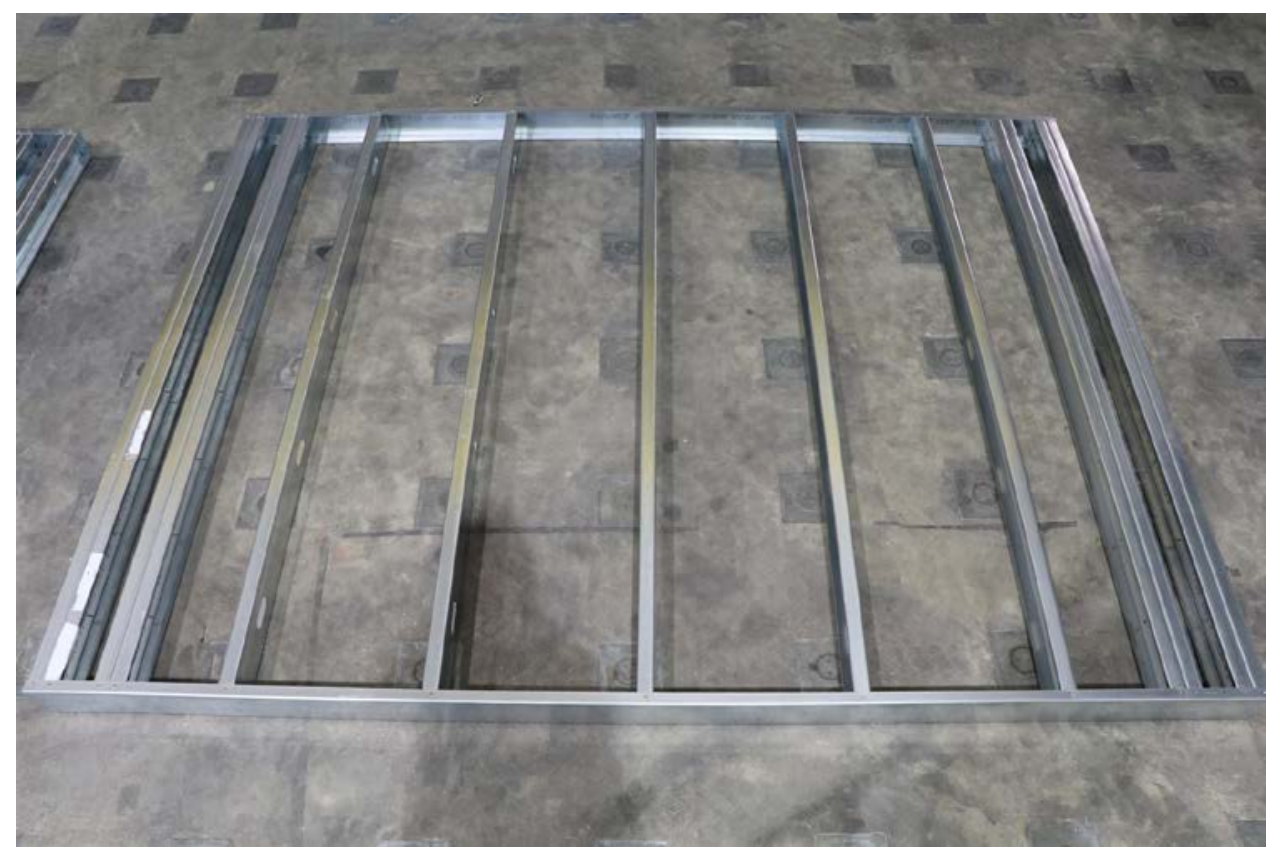

Figure 4: Photograph of specimen framing. 


\subsubsection{Cold-formed steel framing members}

All vertical framing members were 68 mils $(1.7 \mathrm{~mm})$ thick cold-formed steel studs, 600S200-68, 6 in. ( $152 \mathrm{~mm}$ ) wide with a flange width of 2 in. (51 mm). The top and bottom tracks were 54 mils $(1.4 \mathrm{~mm})$ thick cold-formed steel channels, 600T150-54, 6 in. $(152 \mathrm{~mm})$ wide with a flange width of 1-1/2 in. (38 mm). The webs of the top and bottom tracks were drilled with two rows of $\varnothing 11 / 16$ in. $(17.5 \mathrm{~mm})$ holes at 12 in. $(305 \mathrm{~mm})$ on center (Figure 3 ) to allow for attachment to the loading rig. All cold-formed steel sections were Structural Grade 50, Type H (ST50H) conforming to ASTM A653/A653M [2] and ASTM A1003/A1003M [3] with a minimum specified yield strength of $50 \mathrm{ksi}$ (345 MPa).

All fasteners used to connect framing member were \#10 3/4 in. (19 mm) long self-tapping, self-drilling sheet metal screws with shank diameter of $0.190 \mathrm{in}$. (4.8 mm).

The boundary elements were secured together back-to-back with two rows of screws at 12 in. $(305 \mathrm{~mm})$ on center. All other joints had one screw per side where flanges overlapped (Figure 5).

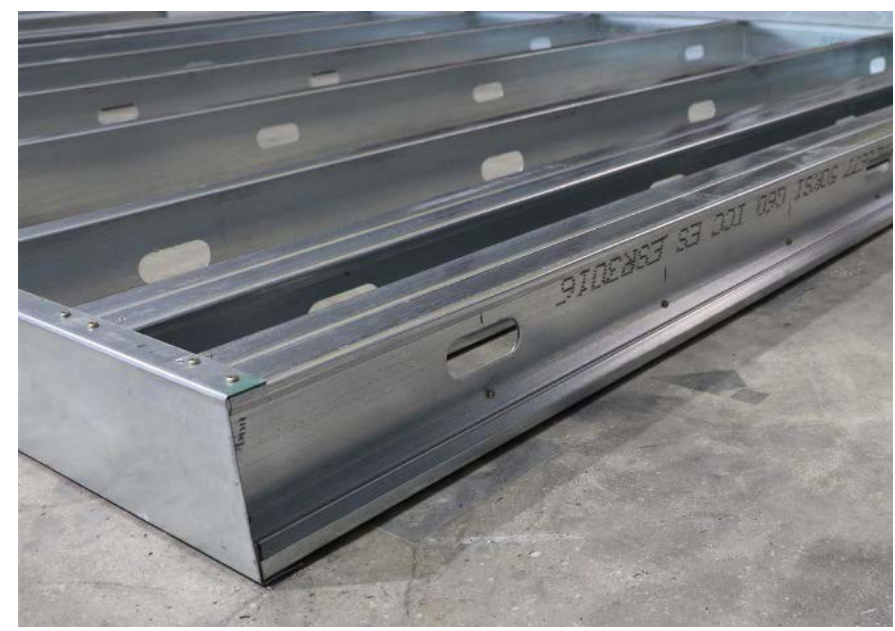

Figure 5: Detail of framing connections.

\subsubsection{Wall panels}

The side of the wall to be fire tested (corridor side) was sheathed with three $9 \mathrm{ft} . \times 4 \mathrm{ft}$. $(2.7 \mathrm{~m} \times 1.2 \mathrm{~m})$ Sure-Board $200^{\circledR}$ panels which consist of 22-gauge sheet metal $(0.686 \mathrm{~mm})$ adhered to 5/8" (16 mm) type X gypsum board. The panels were attached with \#8 1-3/4 in. $(45 \mathrm{~mm})$ long self-tapping, self-drilling sheet metal screws with shank diameter of 0.164 in. $(4.2 \mathrm{~mm})$. The screw spacing was 3 in. (76 mm) on center (OC) on the board perimeter and 12 in. (305 mm) on center in the field.

The opposite side of the wall (cold side) was sheathed with three $9 \mathrm{ft} . \times 4 \mathrm{ft} .(2.7 \mathrm{~m} \times 1.2 \mathrm{~m})$ type X gypsum boards 5/8" (16 mm) thick. The panels were attached with \#6 1-1/4 in. $(32 \mathrm{~mm})$ long self-tapping, self-drilling sheet metal screws with shank diameter of 0.164 in. $(4.2 \mathrm{~mm})$. The screw spacing was 6 in. $(152 \mathrm{~mm})$ on center $(\mathrm{OC})$ on the board perimeter and 12 in. (305 mm) on center in the field. 
The seams were parallel to the studs (vertical) and were collocated on the front and back side of the wall (Figure 6). The panel seams on the side of the wall to be fire tested were covered with paper tape and drywall joint compound and the screw heads were covered with joint compound.

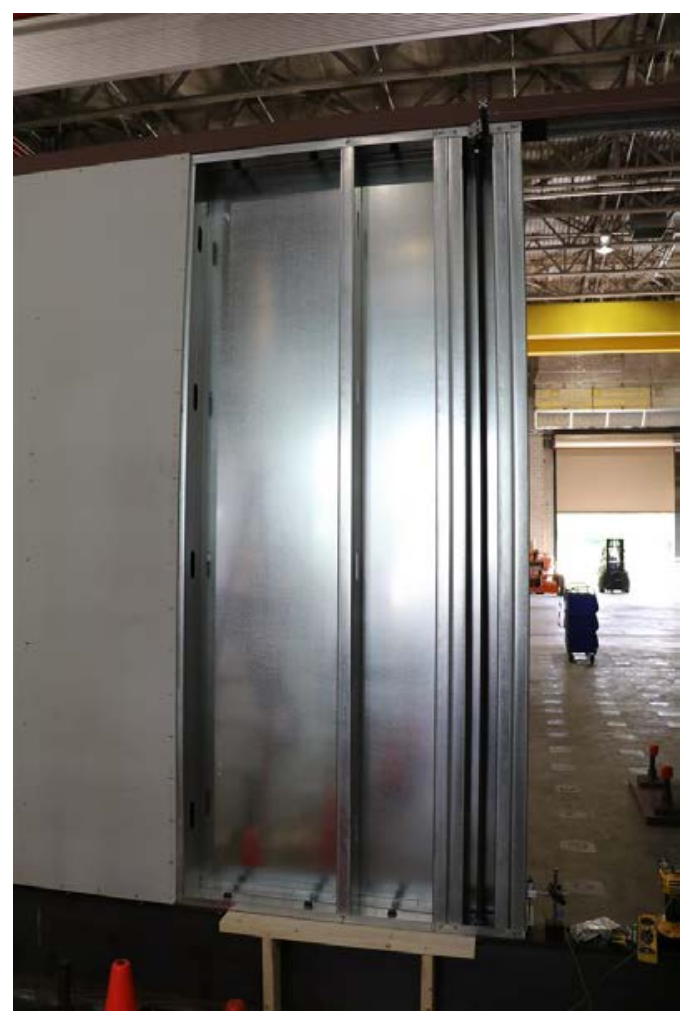

Figure 6: Photograph of test specimen with one gypsum board removed.

\section{2. $\quad$ Test setup}

The test setup was informed by ASTM E2126-11 [4], but deviations were made as required by this test program. A controlling condition for the setup was that a burn compartment on a rolling platform needed to be rolled into position and removed multiple times during testing. This necessitated clear access to the specimen from one side, resulting in a $6 \mathrm{ft} .-4$ in. $(1.9 \mathrm{~m})$ free span of the top loading channel between the specimen and the actuator as shown in the following sections.

\subsubsection{Mechanical}

The test specimens were loaded mechanically by holding the base of the wall fixed and applying a prescribed in-plane deformation to the top of the wall. Out-of-plane movement of the wall was limited by four steel reaction frames place perpendicular to the wall. Figure 7 through Figure 13 provide an overview of the test setup with critical dimensions for the erection of the setup in the NFRL indicted. All reaction frames and the bottom beam (W16 $\times 26)$ were secured to the laboratory strong floor using high-strength rods tensioned to 100 kips $(445 \mathrm{kN})$ each. The wall was attached to the bottom beam by two rows of $5 / 8$ in. $(16 \mathrm{~mm})$ A325 structural bolts (20 total) each pretensioned to $100 \mathrm{ft}-\mathrm{lbs}$ (136 N-m) (Figure 14 to Figure 15). Nonskid tape was used between the beam and the cold-formed steel wall 
track to provide more uniform friction conditions. In between the compression stud packs at each end of the walls, two 5/8 in. (16 mm) diameter Grade 8 steel threaded rods ran from the top of the wall to the bottom (Figure 6). At the bottom the rods passed through a nut and 4.5 in. $\times 6$ in. $\times 3 / 4$ in. $(114 \mathrm{~mm} \times 152 \mathrm{~mm} \times 19 \mathrm{~mm})$ plate washer and were torqued to $100 \mathrm{ft}-\mathrm{lbs}(136 \mathrm{~N}-\mathrm{m})$, fixing the bottom of the rod and cold-formed steel track to the bottom beam. The attachments at the top of the wall were similar, however, the threaded rods were nutted only from above the top channel (MC6×15.3) and torqued to $50 \mathrm{ft}-\mathrm{lbs}(68 \mathrm{~N}-\mathrm{m})$ (Figure 16). The top loading channel was stiffened against vertical bending at the actuator end using a $\mathrm{W} 6 \times 12$ steel section.

Mechanical load was applied to the specimen using a servo-hydraulically controlled actuator with a load capacity of 54 kips $(240 \mathrm{kN})$ when acting in tension and 82 kips $(365 \mathrm{kN})$ when acting in compression. The maximum stroke of the actuator was $30 \mathrm{in}$. (762 mm). The actuator was controlled using a MTS Flextest 100 controller using displacement control during each test.

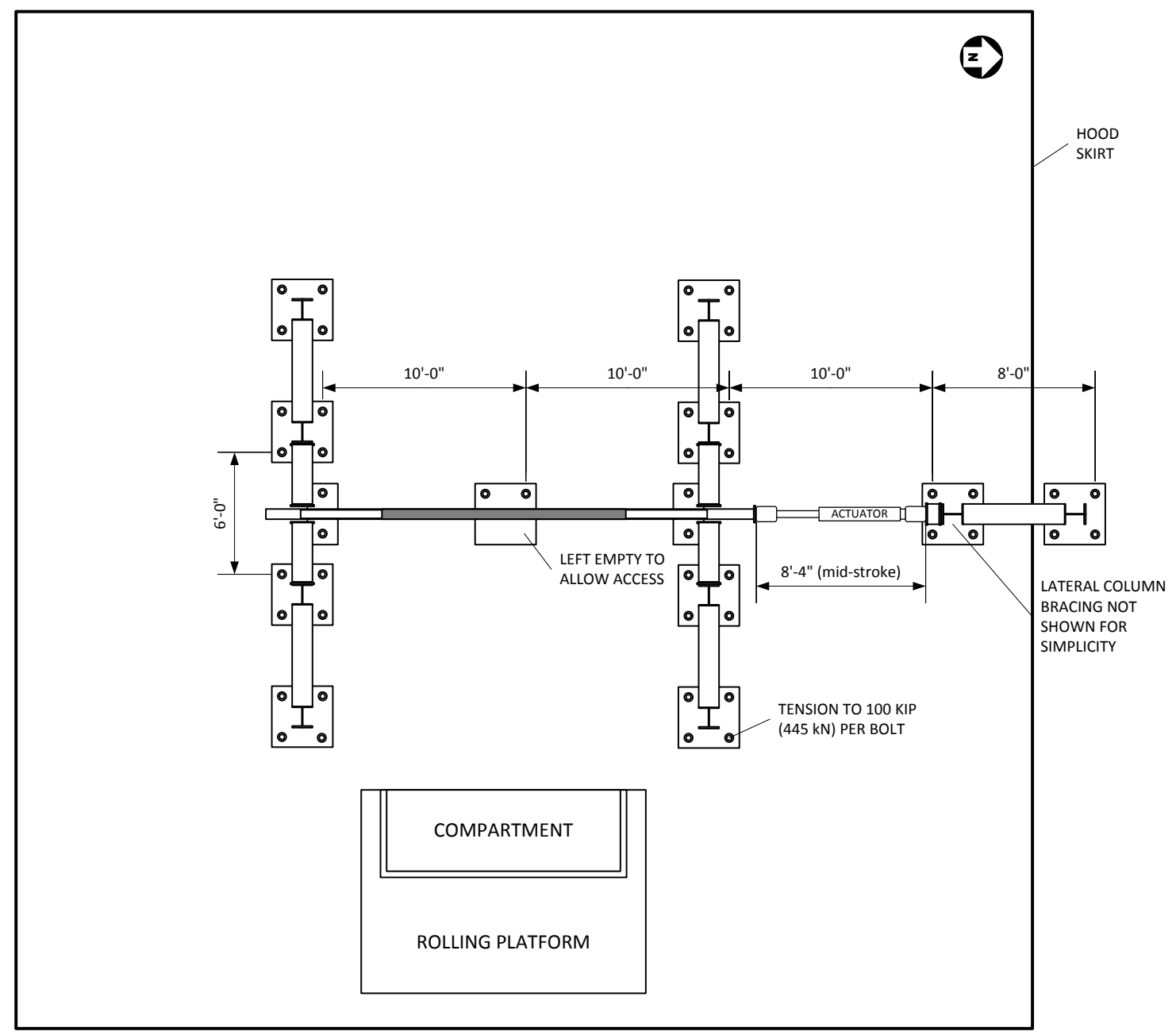

Figure 7: Mechanical loading setup plan view $(1 \mathrm{ft} .=0.3048 \mathrm{~m})$. 


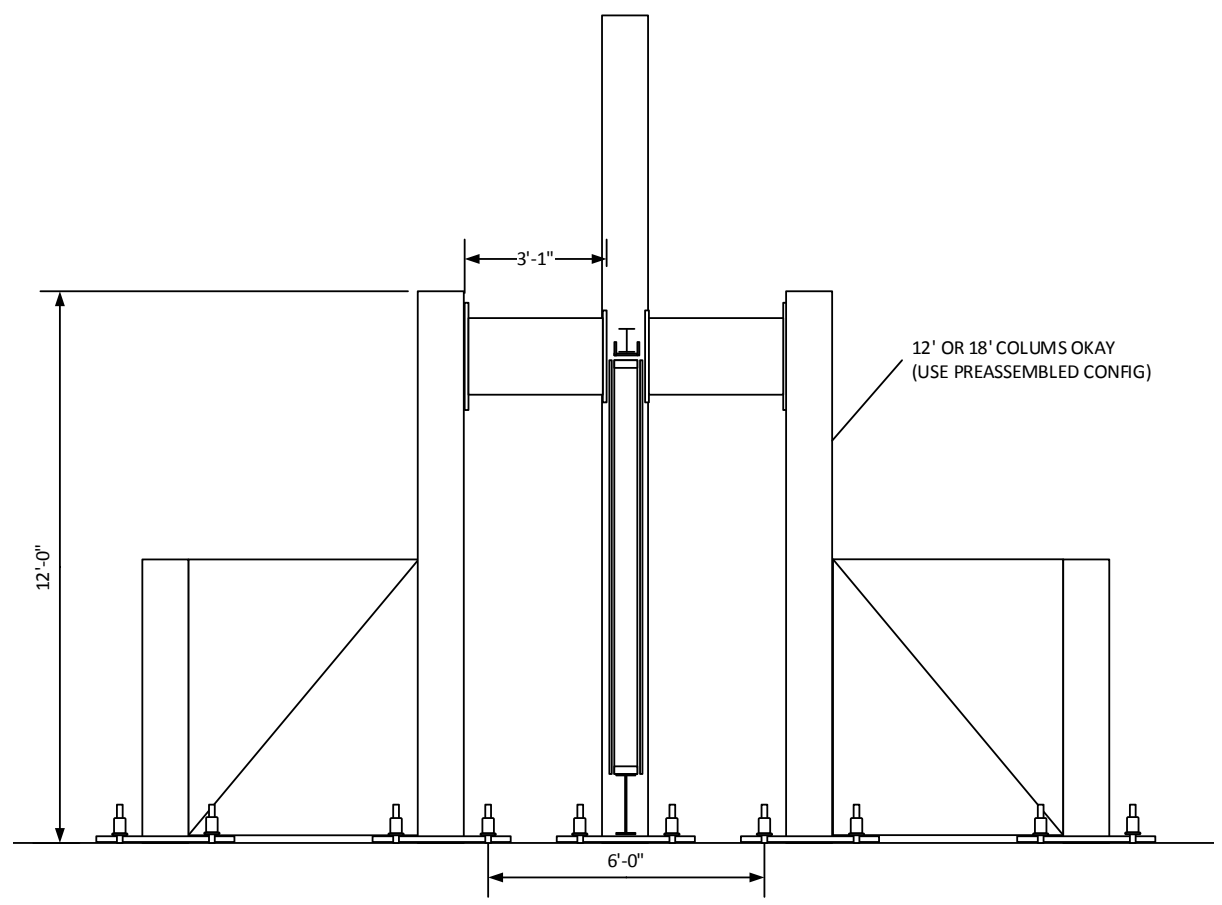

Figure 8: Mechanical loading setup from South $(1 \mathrm{ft} .=0.3048 \mathrm{~m})$.

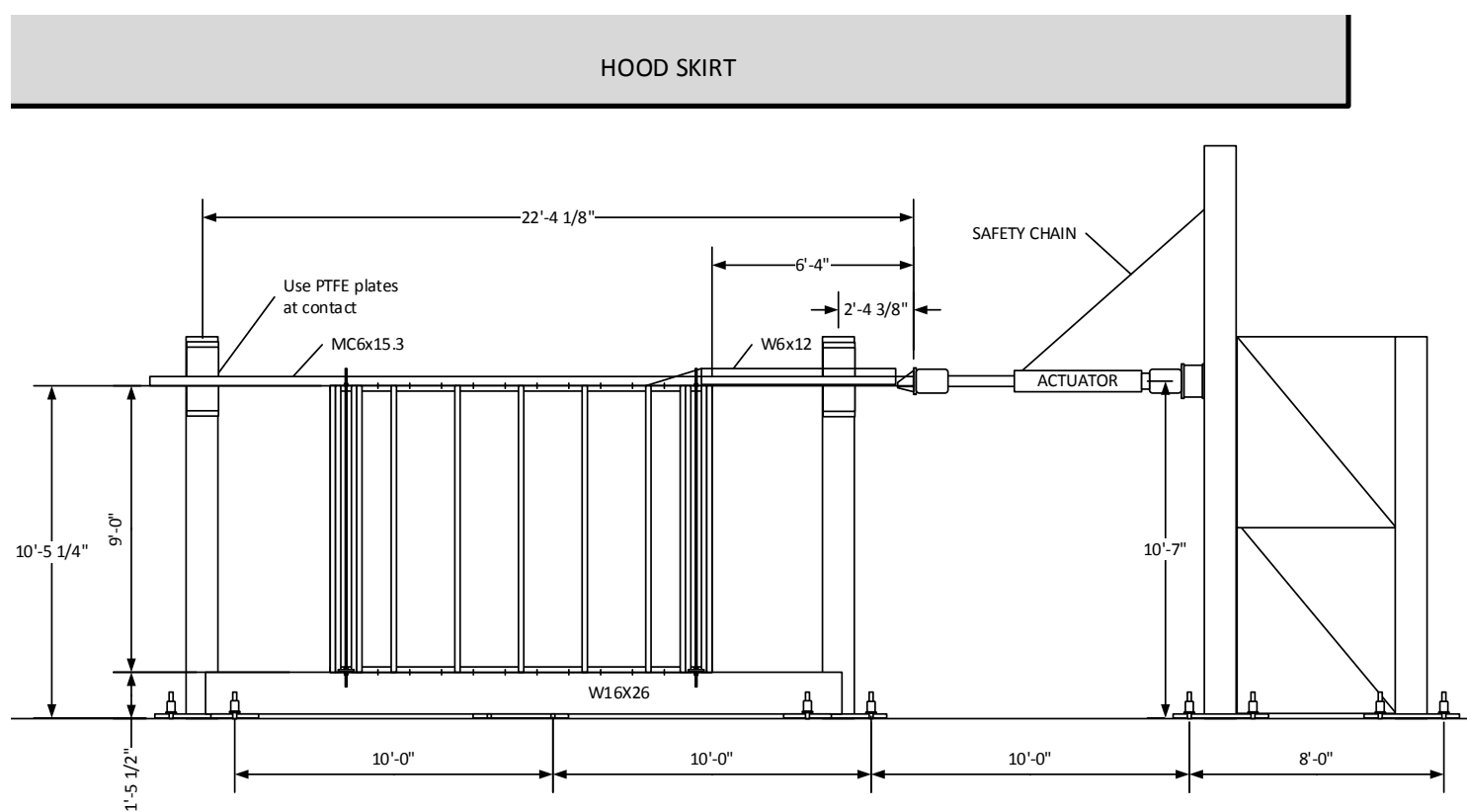

Figure 9: Mechanical loading setup from East (1 ft. $=0.3048 \mathrm{~m})$. 


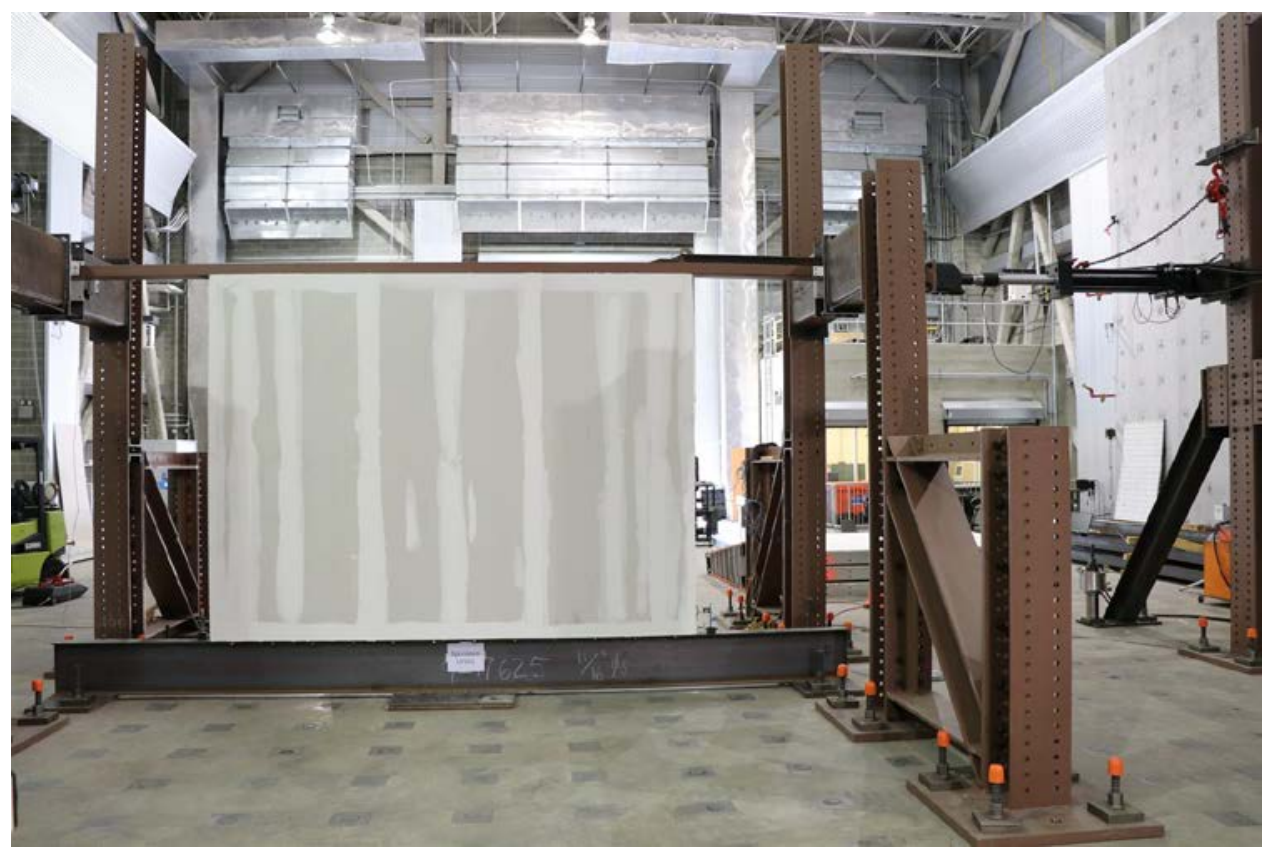

Figure 10: Photograph of mechanical loading setup from the East.

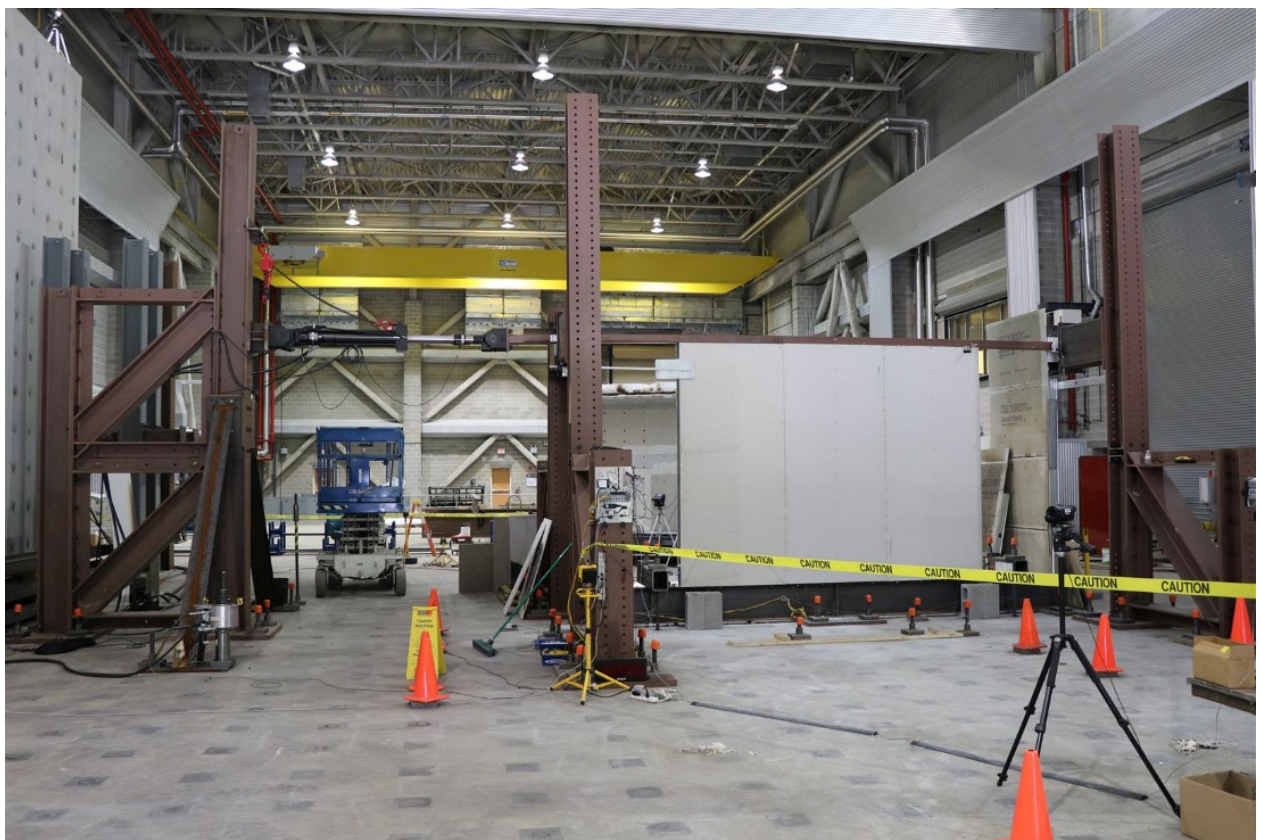

Figure 11: Photograph of mechanical loading setup from the West. 


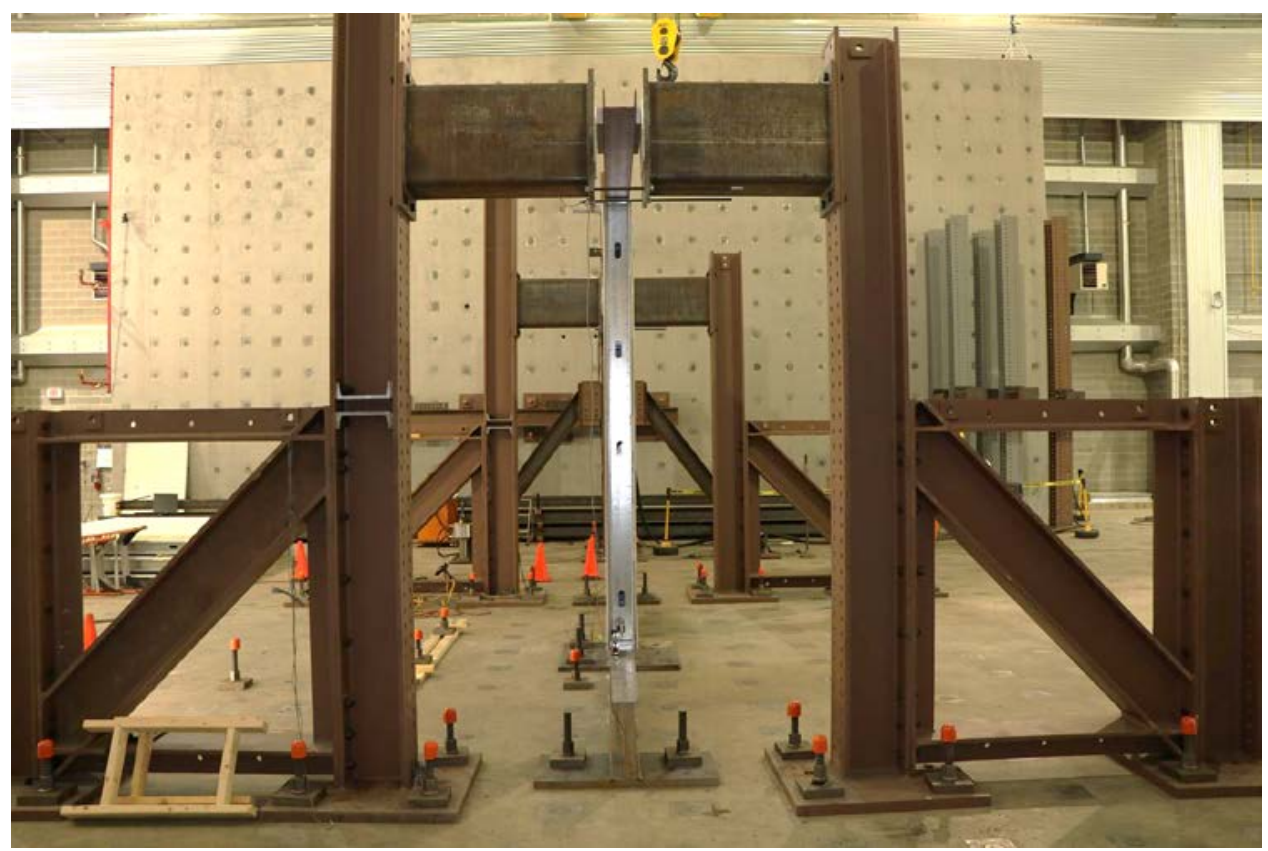

Figure 12: Photograph of mechanical loading setup from the South.

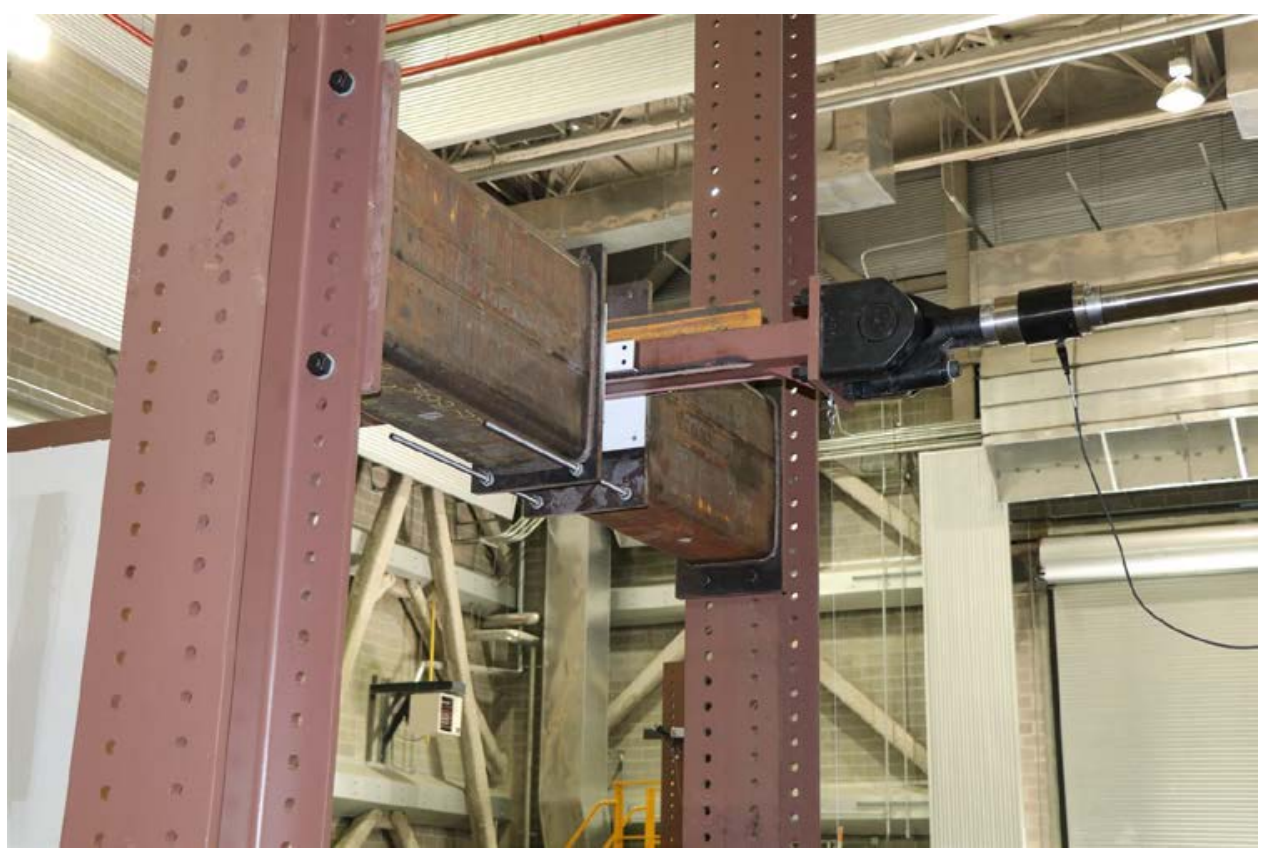

Figure 13: Photograph of Polytetrafluoroethylene (Teflon) glides at actuator to prevent out-of-plane movement. 


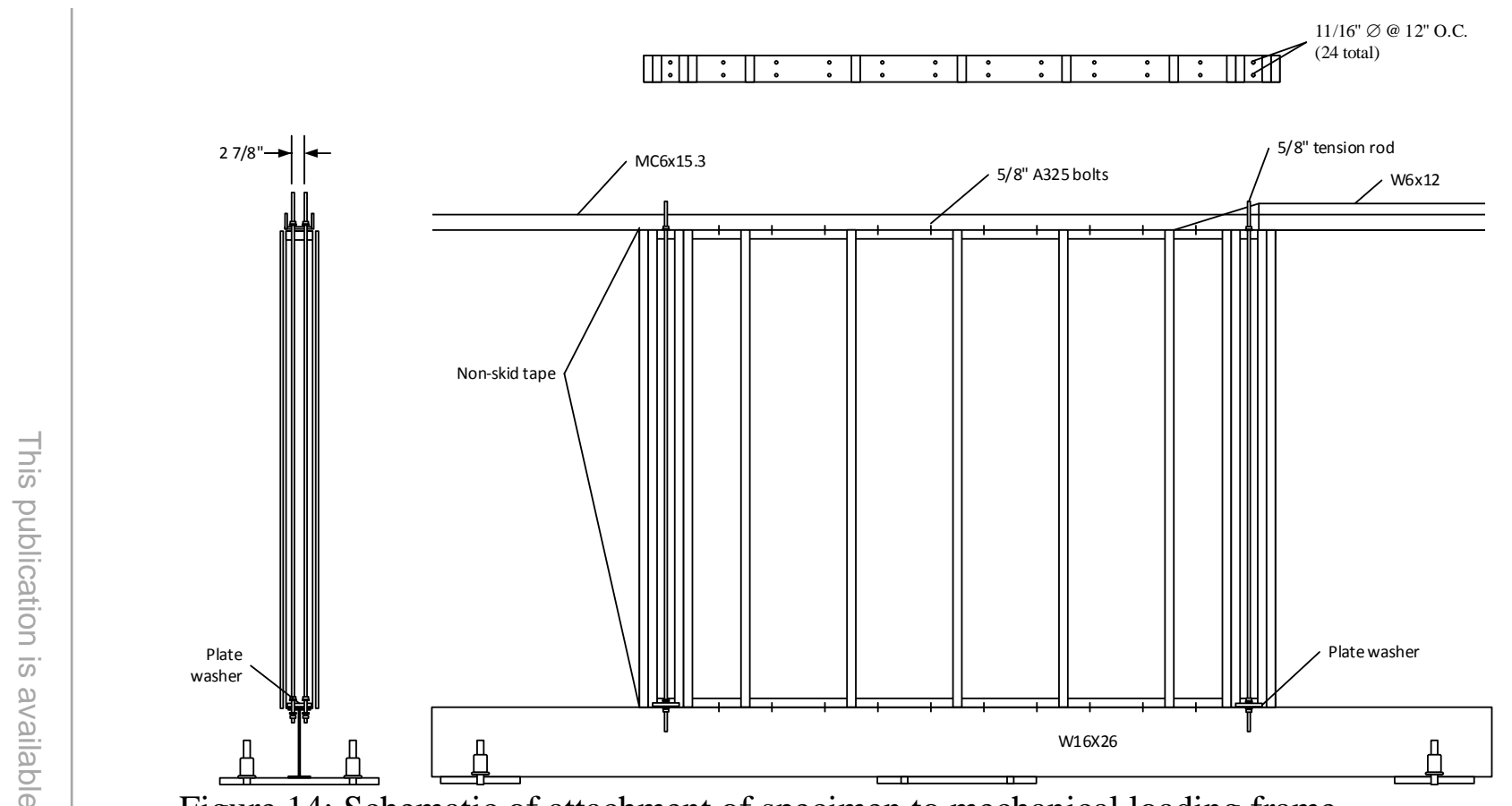

Figure 14: Schematic of attachment of specimen to mechanical loading frame.

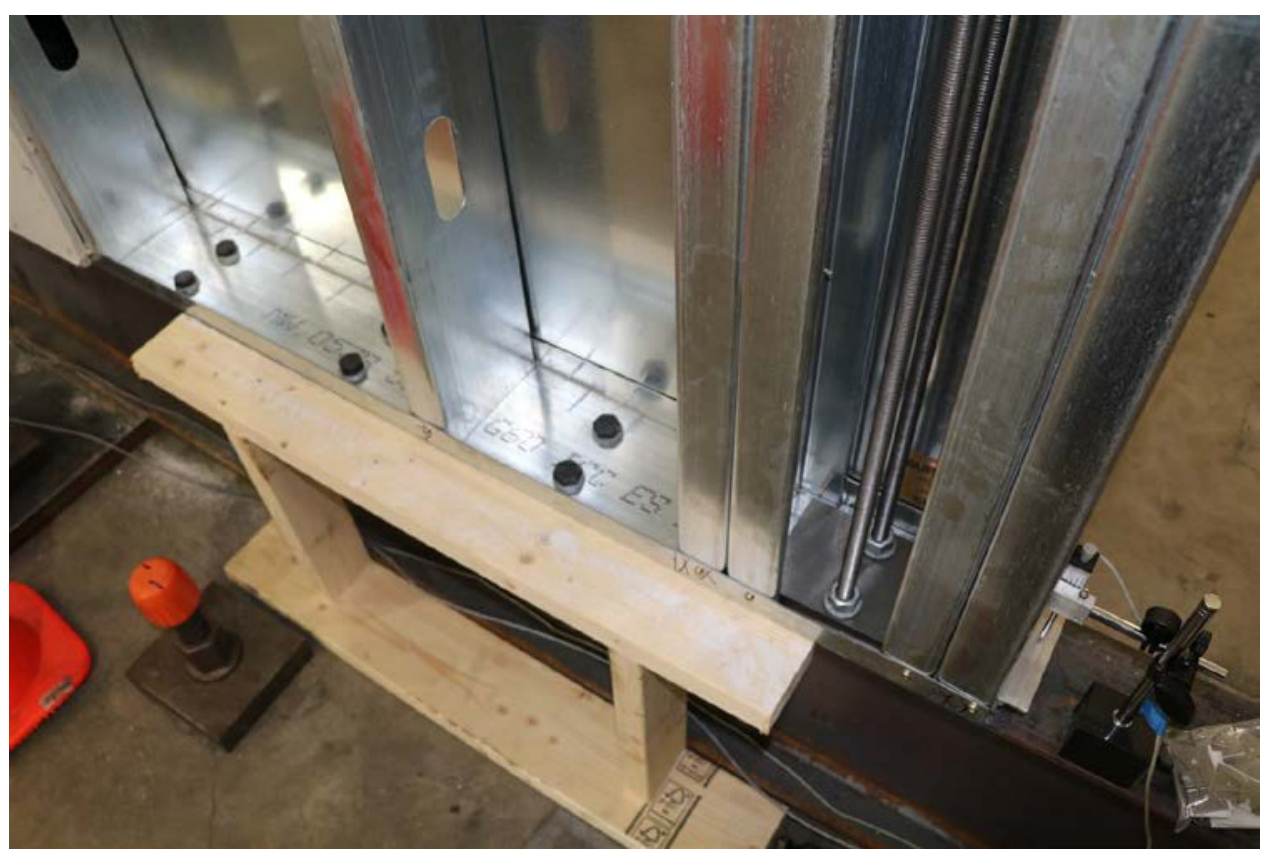

Figure 15: Photograph of plate washer on bottom of tension tie rods. 


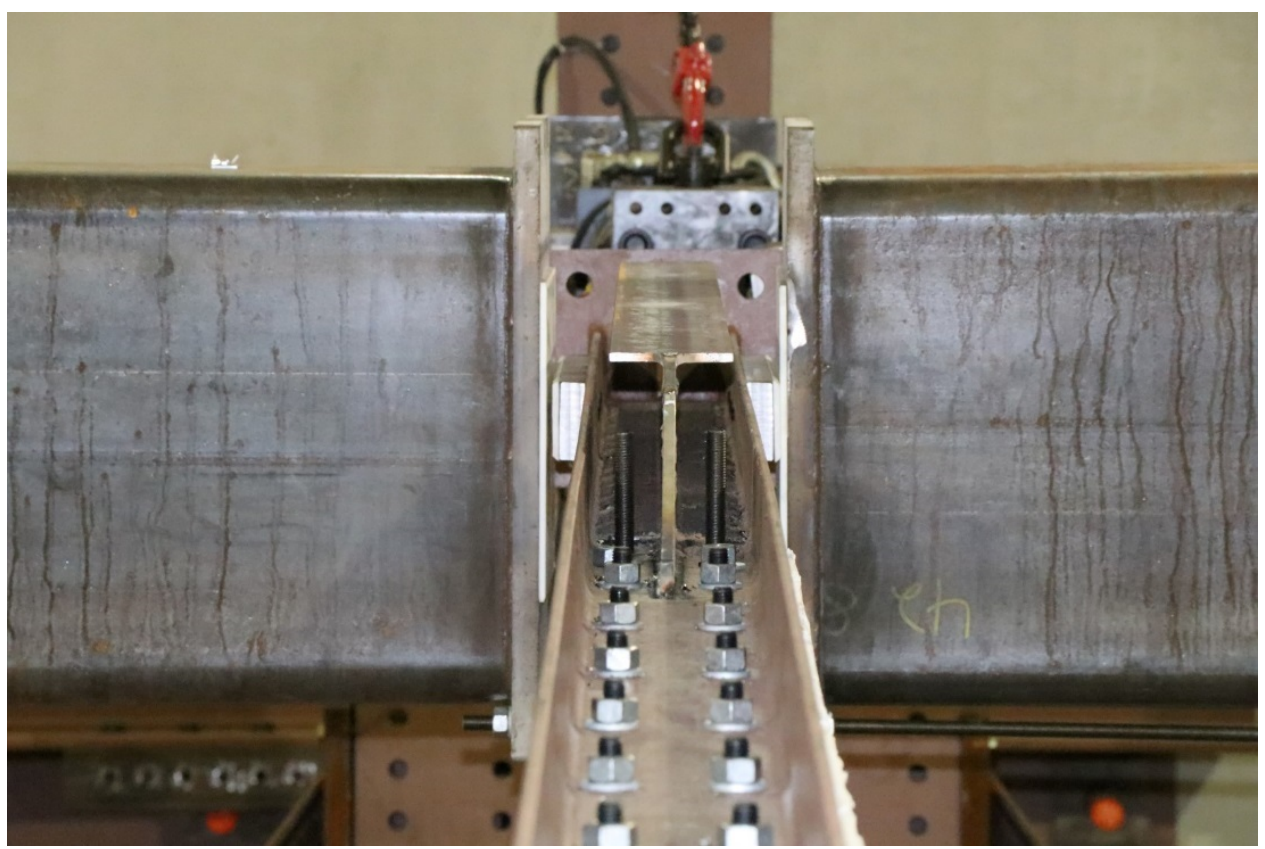

Figure 16: Photograph of top loading beam from above.

\subsubsection{Fire}

The thermal load on the test specimens was provided by a natural gas diffusion burner located in a compartment design to approximate a portion of the center corridor in the sixstory building tested at UCSD. Figure 17 provides the compartment dimensions and Figure 18 shows a photograph of the constructed compartment. The compartment was lined with two layers of 5/8” (16 mm) type C gypsum board. The inner layer was replaced once during the test program as it deteriorated. The open side of the compartment that mated with the test specimen was lined with 1 in. $(25 \mathrm{~mm})$ thick thermal ceramic blanket to provide a seal against smoke and flame leakage (Figure 19). 

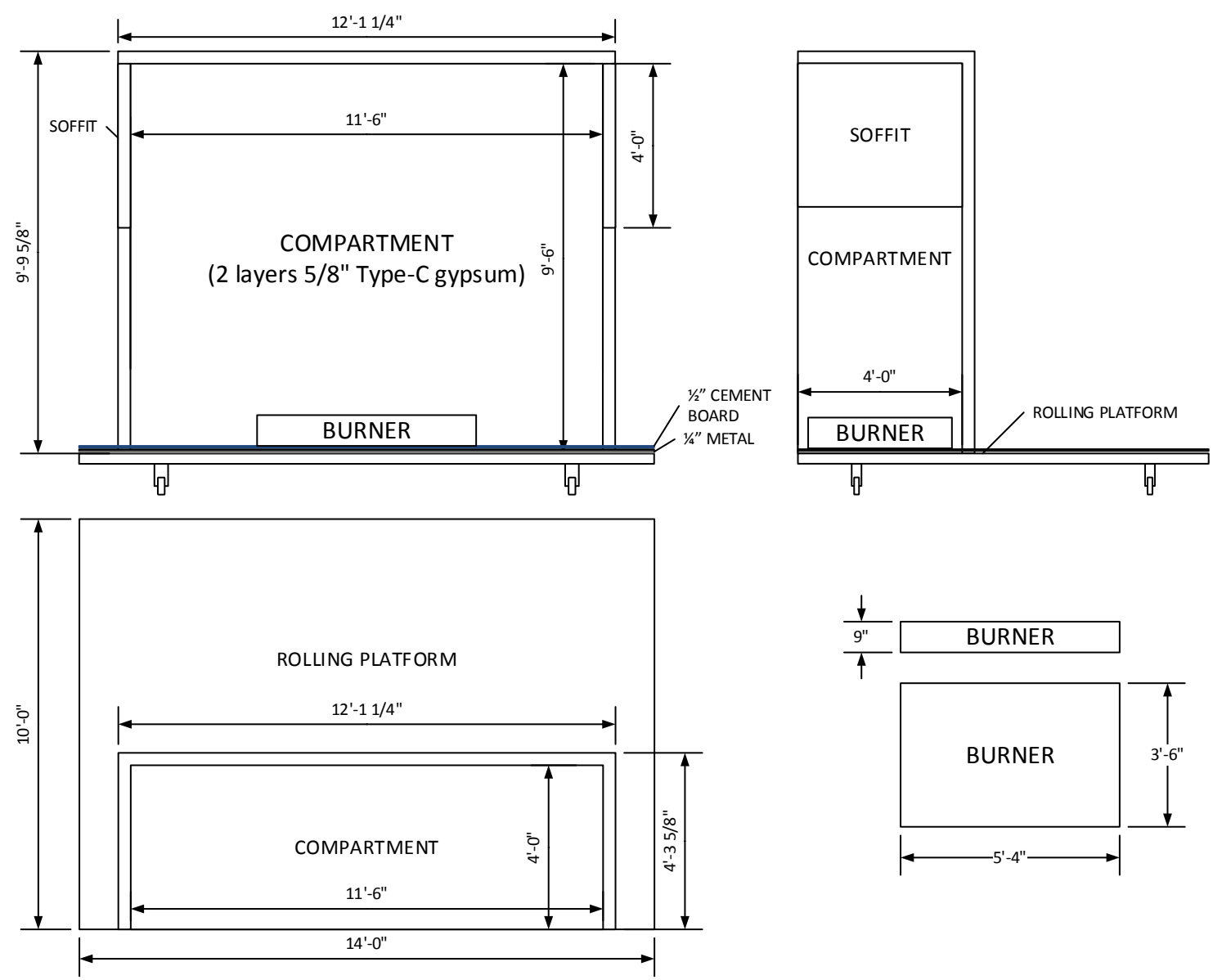

Figure 17: Burn compartment dimensions $(1 \mathrm{ft} .=0.3048 \mathrm{~m})$.

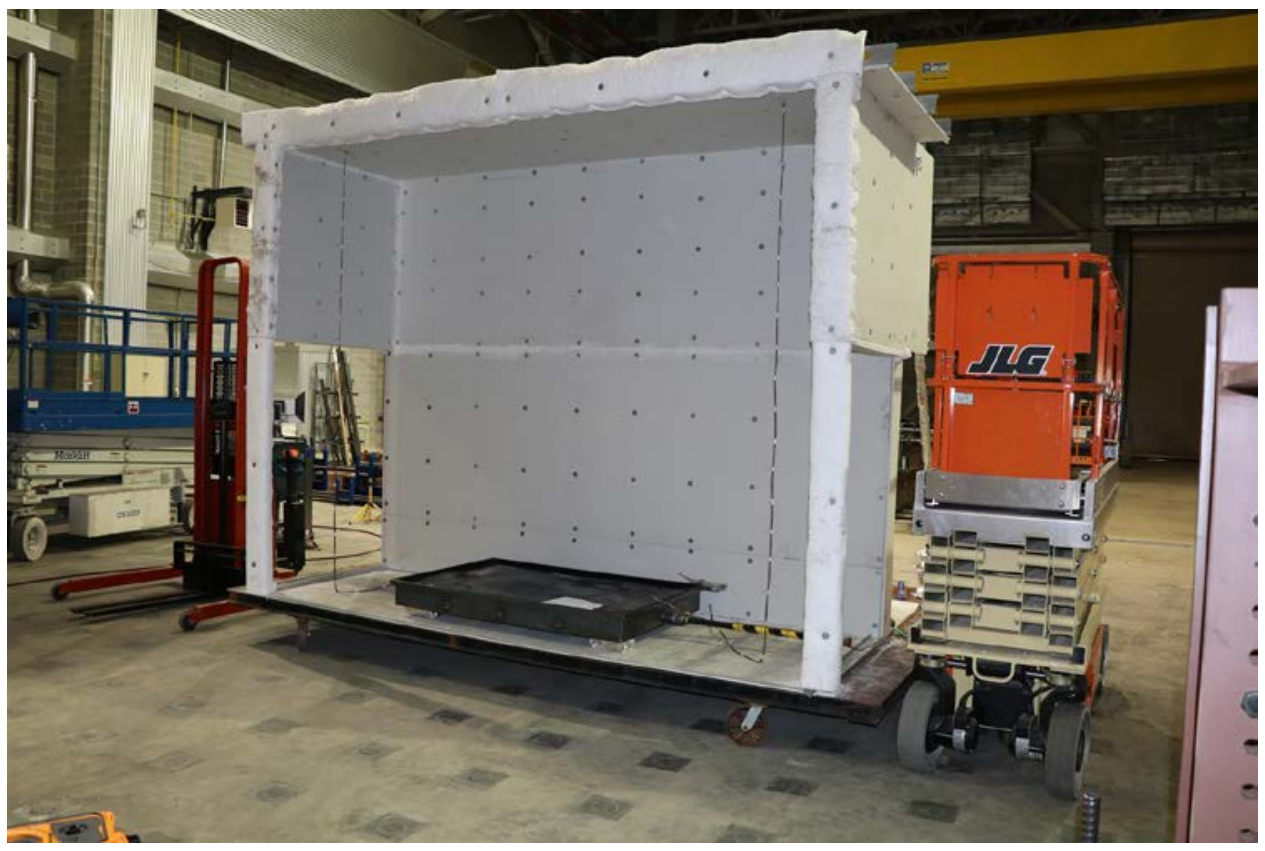

Figure 18: Photograph of burn compartment. 


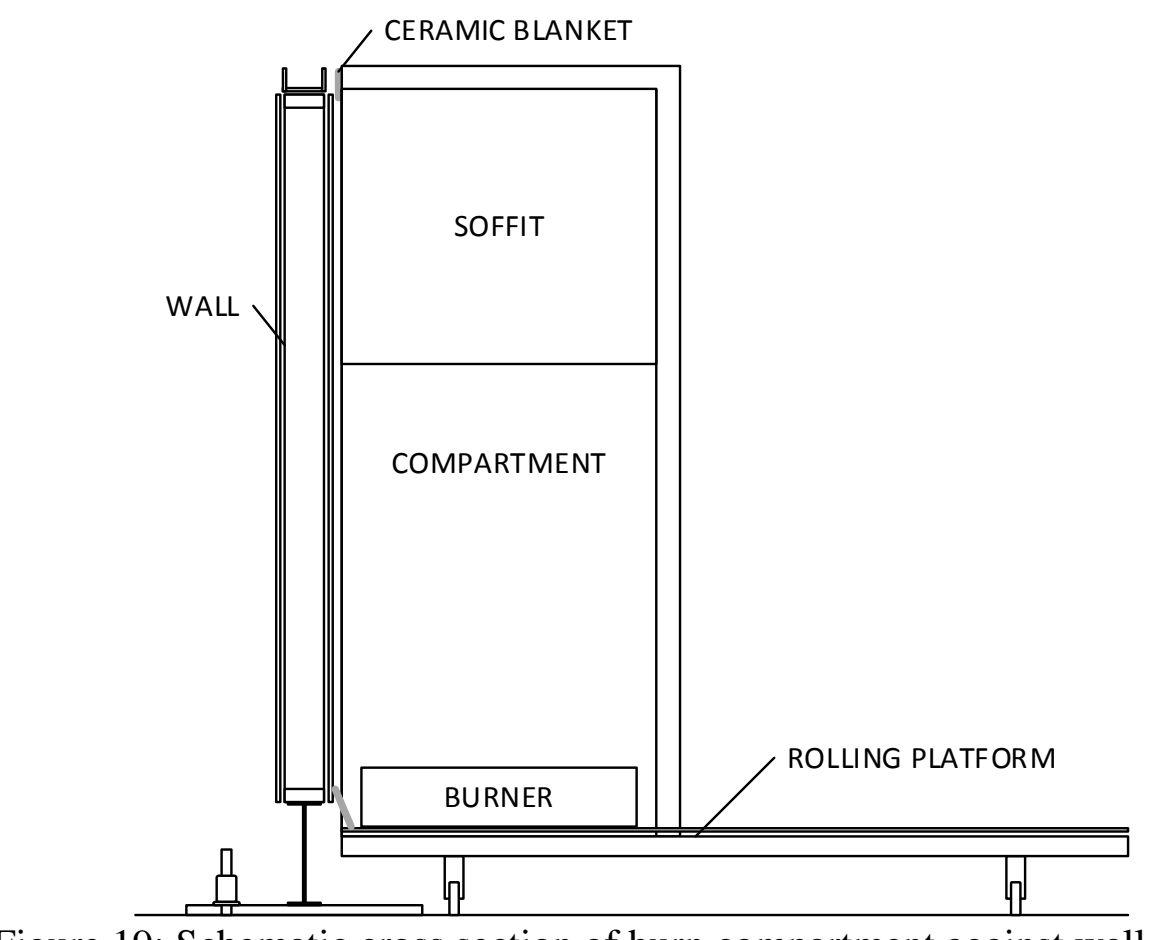

Figure 19: Schematic cross section of burn compartment against wall

\subsection{Test procedure}

\subsubsection{Monotonic loading}

Monotonic load was applied to the top of the wall quasi-statically by controlling the displacement rate of the servo-hydraulic actuator.

\subsubsection{Cyclic loading}

ASTM E2126-11 [4] Method C (CUREE Basic Loading Protocol) was used with a reference deformation $\Delta$ equal to $1.5 \mathrm{in}$. (38.1 mm) for all cyclic tests (CFS02 to CFS06). The loading procedure involves displacement cycles grouped in phases at incrementally increasing displacement levels (Figure 20). The loading history starts with a series of six initiation cycles at small amplitudes (of equal amplitude). Subsequently, each phase of the loading history consists of a primary cycle with amplitude expressed as a fraction (percent) of the reference deformation and subsequent trailing cycles with amplitude of $75 \%$ of the primary one. The reference deformation $\Delta$ was based on the deformation at peak load during the monotonic test (CFS01a). The rate of displacement was selected to be $0.06 \mathrm{in} . / \mathrm{s}$ $(1.524 \mathrm{~mm} / \mathrm{s})$ to minimize inertial influences while maintaining an efficient cyclic test duration (77 minutes total). The schedule of amplitude increments (expressed as percent $\Delta$, absolute amplitude, and drift) along with the step duration are given in Table 2. 


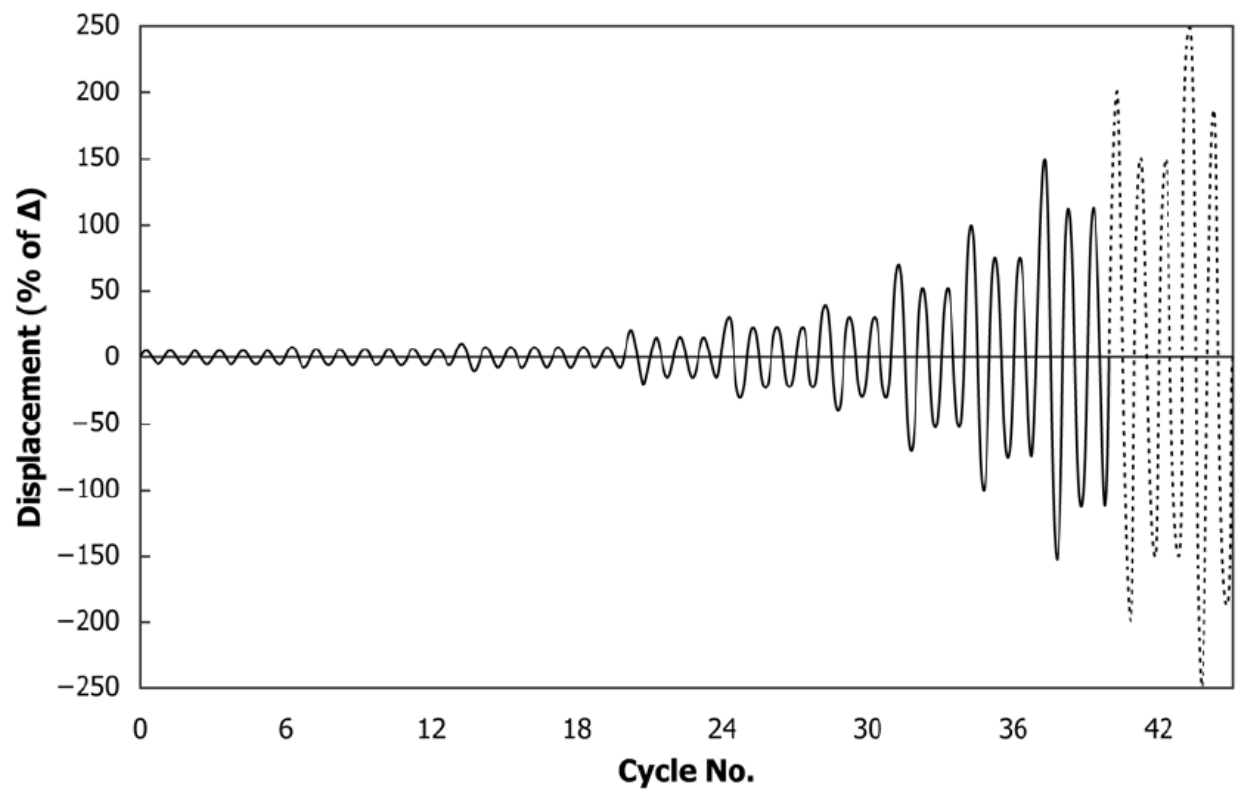

Figure 20: Cyclic displacement pattern (Test Method C) from ASTM E2126-11 [4].

Table 2: Amplitude of primary cycles and step durations.

\begin{tabular}{cccccccc}
\hline Pattern & Step & $\begin{array}{c}\text { Number } \\
\text { of cycles }\end{array}$ & $\begin{array}{c}\text { Amplitude of } \\
\text { primary cycle, } \% \mathbf{\Delta}\end{array}$ & $\begin{array}{c}\text { Amplitude, } \\
\text { in. }\end{array}$ & $\begin{array}{c}\text { Amplitude, } \\
\mathbf{m m}\end{array}$ & $\begin{array}{c}\text { Drift, } \\
\text { \% }\end{array}$ & $\begin{array}{c}\text { Step } \\
\text { duration, } \mathbf{m}\end{array}$ \\
\hline 1 & 1 & 6 & 5 & 0.075 & 1.9 & 0.07 & 10 \\
2 & 2 & 7 & 7.5 & 0.1125 & 2.9 & 0.10 & 12 \\
& 3 & 7 & 10 & 0.15 & 3.8 & 0.14 & 12 \\
3 & 4 & 4 & 20 & 0.3 & 7.6 & 0.28 & 7 \\
& 5 & 4 & 30 & 0.45 & 11.4 & 0.42 & 7 \\
4 & 6 & 3 & 40 & 0.6 & 15.2 & 0.56 & 5 \\
& 7 & 3 & 70 & 1.05 & 26.7 & 0.97 & 5 \\
& 8 & 3 & 100 & 1.5 & 38.1 & 1.39 & 5 \\
& 9 & 3 & 130 & 1.95 & 49.5 & 1.81 & 5 \\
& 10 & 3 & 170 & 2.55 & 64.8 & 2.36 & 5 \\
& 11 & 3 & 200 & 3 & 76.2 & 2.78 & 5 \\
\hline \multicolumn{7}{c}{}
\end{tabular}

\subsubsection{Fire loading}

The fire load was delivered by a single natural gas diffusion burner. The mass flow rate of the natural gas was controlled to match the predicted time versus temperature curves for upper gas layer temperatures in the $2^{\text {nd }}$ floor corridor of the six-story building at UCSD. This was achieved by rapidly increasing (rise time less than 60 seconds) the Heat Release Rate (HRR) from the burner to $1900 \mathrm{~kW}$ and nominally holding the HRR constant for $800 \mathrm{~s}$ (13 m $20 \mathrm{~s}$ ); in test CFS06b the burn duration was doubled. The upper layer gas temperature during the heating phase predicted by the Consolidated Model of Fire and Smoke Transport (CFAST) [5] two-zone fire model is shown in Figure 21. While the fire was more severe 
than the "standard fire test" in American Society of Testing and Materials (ASTM) standard ASTM E119 [6], it was representative of conditions present in residential fires in modern buildings; for example see [7]. Additional details about the fire load development are provided in the Appendices.

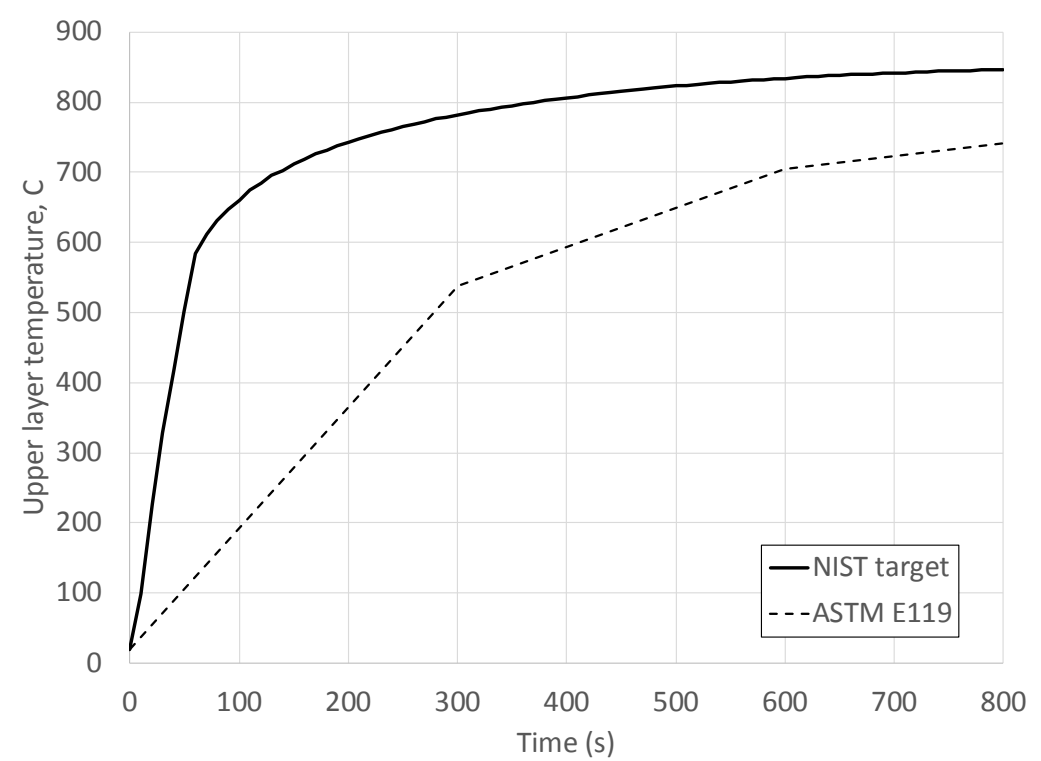

Figure 21: Target upper layer temperature versus time during heating phase predicted by CFAST for the NIST tests (NIST target). ASTM E119 standard fire curve shown for reference.

\subsection{Instrumentation}

Table 3 provides the instrumentation plan. Values shown in bold are reported in this document. The non-bold values were intermediary values that were subsequently scaled or data used for verification and safety purposes during testing. Standard uncertainties (Type B) [8] are provided for each sensor type based on the manufacturers' published data in Table 3. One exception is the burner heat release rate for which the expanded uncertainty is provided from [9].

Data were acquire using two (2) National Instruments cDAQ-9188 chassis; one for channels located on test specimen or the loading frame and a second for channels on the rolling burn compartment. The sensor locations are illustrated in Figure 22 and Figure 23. The directions of the arrows in Figure 22 indicate the directions of the actions in the reported data (actuator compression = positive). Photographs of key sensors are provided in Figure 24 to Figure 26 (also refer to Figure 18). An in-house software developed using LabVIEW was used to allocate channels and control the data acquisition. During load cycling data were recorded at $5 \mathrm{~Hz}$. During fire testing data were recorded at $1 \mathrm{~Hz}$.

Visual data were acquired using photo cameras, video cameras (Figure 27) and a highspeed mid-wavelength infrared camera (FLIR SC8300HD). 
Table 3: Instrumentation plan.

\begin{tabular}{|c|c|c|c|c|c|c|c|c|}
\hline $\begin{array}{c}\text { Output } \\
\text { Column }\end{array}$ & Channel Name & $\begin{array}{l}\text { Type / } \\
\text { Range }\end{array}$ & Units $^{b}$ & $\begin{array}{c}\text { Sensor } \\
\text { Manufacturer }\end{array}$ & $\begin{array}{c}\text { Sensor } \\
\text { Model }\end{array}$ & $\begin{array}{c}\text { Full Scale } \\
\text { Value }^{b}\end{array}$ & $\begin{array}{c}\text { Standard } \\
\text { Uncertainty }\end{array}$ & $\begin{array}{l}\text { Description / } \\
\text { Location }^{\text {b }}\end{array}$ \\
\hline 1 & Test time & MIDAS Time & s & - & - & - & - & Time from start of date acquisition \\
\hline 2 & TC_South_1 & Thermocouple & ${ }^{\circ} \mathbf{C}$ & Omega & GG-K-24 & $1250{ }^{\circ} \mathrm{C}$ & $\pm 0.75 \%^{c}$ & South vent @ 1 in. from ceiling \\
\hline 3 & TC_South_2 & Thermocouple & ${ }^{\circ} \mathbf{C}$ & Omega & GG-K-24 & $1250{ }^{\circ} \mathrm{C}$ & $\pm 0.75 \%^{c}$ & South vent @13 in. from ceiling \\
\hline 4 & TC_South_3 & Thermocouple & ${ }^{\circ} \mathbf{C}$ & Omega & GG-K-24 & $1250{ }^{\circ} \mathrm{C}$ & $\pm 0.75 \%^{c}$ & South vent @ 25 in. from ceiling \\
\hline 5 & TC_South_4 & Thermocouple & ${ }^{\circ} \mathbf{C}$ & Omega & GG-K-24 & $1250{ }^{\circ} \mathrm{C}$ & $\pm 0.75 \%^{c}$ & South vent @ 37 in. from ceiling \\
\hline 6 & TC_South_5 & Thermocouple & ${ }^{\circ} \mathbf{C}$ & Omega & GG-K-24 & $1250{ }^{\circ} \mathrm{C}$ & $\pm 0.75 \%^{c}$ & South vent @ 49 in. from ceiling \\
\hline 7 & TC_South_6 & Thermocouple & ${ }^{\circ} \mathbf{C}$ & Omega & GG-K-24 & $1250^{\circ} \mathrm{C}$ & $\pm 0.75 \%^{c}$ & South vent @61 in. from ceiling \\
\hline 8 & TC_South_7 & Thermocouple & ${ }^{\circ} \mathbf{C}$ & Omega & GG-K-24 & $1250^{\circ} \mathrm{C}$ & $\pm 0.75 \%^{c}$ & South vent @ 73 in. from ceiling \\
\hline 9 & TC_South_8 & Thermocouple & ${ }^{\circ} \mathbf{C}$ & Omega & GG-K-24 & $1250{ }^{\circ} \mathrm{C}$ & $\pm 0.75 \%^{c}$ & South vent @85 in. from ceiling \\
\hline 10 & TC_South_9 & Thermocouple & ${ }^{\circ} \mathbf{C}$ & Omega & GG-K-24 & $1250^{\circ} \mathrm{C}$ & $\pm 0.75 \%^{c}$ & South vent @ 97 in. from ceiling \\
\hline 11 & TC_TopCenter & Thermocouple & ${ }^{\circ} \mathbf{C}$ & Omega & CASS-18U-12 & $1250^{\circ} \mathrm{C}$ & $\pm 0.75 \%^{c}$ & Shielded TC @ 1 in. from ceiling in center \\
\hline 12 & TC_Burner_H2O & Thermocouple & ${ }^{\circ} \mathrm{C}$ & Omega & CASS-18U-12 & $1250^{\circ} \mathrm{C}$ & $\pm 0.75 \%^{c}$ & Cooling water for burner \\
\hline 13 & TC_Compartment_Post & Thermocouple & ${ }^{\circ} \mathrm{C}$ & Omega & GG-K-24 & $1250^{\circ} \mathrm{C}$ & $\pm 0.75 \%^{c}$ & Temperature of compartment front post \\
\hline 14 & TC_North_1 & Thermocouple & ${ }^{\circ} \mathbf{C}$ & Omega & GG-K-24 & $1250^{\circ} \mathrm{C}$ & $\pm 0.75 \%^{c}$ & North vent @ 1 in. from ceiling \\
\hline 15 & TC_North_2 & Thermocouple & ${ }^{\circ} \mathbf{C}$ & Omega & GG-K-24 & $1250{ }^{\circ} \mathrm{C}$ & $\pm 0.75 \%^{c}$ & North vent @13 in. from ceiling \\
\hline 16 & TC_North_3 & Thermocouple & ${ }^{\circ} \mathbf{C}$ & Omega & GG-K-24 & $1250{ }^{\circ} \mathrm{C}$ & $\pm 0.75 \%^{c}$ & North vent@ 25 in. from ceiling \\
\hline 17 & TC_North_4 & Thermocouple & ${ }^{\circ} \mathbf{C}$ & Omega & GG-K-24 & $1250{ }^{\circ} \mathrm{C}$ & $\pm 0.75 \%^{c}$ & North vent@ 37 in. from ceiling \\
\hline 18 & TC_North_5 & Thermocouple & ${ }^{\circ} \mathbf{C}$ & Omega & GG-K-24 & $1250{ }^{\circ} \mathrm{C}$ & $\pm 0.75 \%^{c}$ & North vent @ 49 in. from ceiling \\
\hline 19 & TC_North_6 & Thermocouple & ${ }^{\circ} \mathbf{C}$ & Omega & GG-K-24 & $1250{ }^{\circ} \mathrm{C}$ & $\pm 0.75 \%^{c}$ & North vent @61 in. from ceiling \\
\hline 20 & TC_North_7 & Thermocouple & ${ }^{\circ} \mathbf{C}$ & Omega & GG-K-24 & $1250{ }^{\circ} \mathrm{C}$ & $\pm 0.75 \%^{c}$ & North vent@ 73 in. from ceiling \\
\hline 21 & TC_North_8 & Thermocouple & ${ }^{\circ} \mathbf{C}$ & Omega & GG-K-24 & $1250^{\circ} \mathrm{C}$ & $\pm 0.75 \%^{c}$ & North vent @ 85 in. from ceiling \\
\hline 22 & TC_North_9 & Thermocouple & ${ }^{\circ} \mathbf{C}$ & Omega & GG-K-24 & $1250{ }^{\circ} \mathrm{C}$ & $\pm 0.75 \%{ }^{c}$ & North vent @97 in. from ceiling \\
\hline 23 & TC_VoidTop & Thermocouple & ${ }^{\circ} \mathbf{C}$ & Omega & GG-K-24 & $1250{ }^{\circ} \mathrm{C}$ & $\pm 0.75 \%^{c}$ & Air void in wall @ 18 in. from top \\
\hline 24 & TC_VoidMid & Thermocouple & ${ }^{\circ} \mathbf{C}$ & Omega & GG-K-24 & $1250{ }^{\circ} \mathrm{C}$ & $\pm 0.75 \%^{c}$ & Air void in wall @ mid-height \\
\hline 25 & TC_VoidBot & Thermocouple & ${ }^{\circ} \mathbf{C}$ & Omega & GG-K-24 & $1250{ }^{\circ} \mathrm{C}$ & $\pm 0.75 \%^{c}$ & Air voidin wall @18 in. from bottom \\
\hline 26 & TC_WallTop & Thermocouple & ${ }^{\circ} \mathrm{C}$ & Omega & GG-K-24 & $1250^{\circ} \mathrm{C}$ & $\pm 0.75 \%^{c}$ & SureBoard metal backing @ 18 in. from top \\
\hline 27 & TC_WallMid & Thermocouple & ${ }^{\circ} \mathbf{C}$ & Omega & GG-K-24 & $1250{ }^{\circ} \mathrm{C}$ & $\pm 0.75 \%^{c}$ & SureBoard metal backing @ mid-height \\
\hline 28 & TC_WallBot & Thermocouple & ${ }^{\circ} \mathbf{C}$ & Omega & GG-K-24 & $1250{ }^{\circ} \mathrm{C}$ & $\pm 0.75 \%^{c}$ & SureBoard metal backing @ 18 in. from bottom \\
\hline 29 & TC_WallTopStud & Thermocouple & ${ }^{\circ} \mathbf{C}$ & Omega & GG-K-24 & $1250^{\circ} \mathrm{C}$ & $\pm 0.75 \%^{c}$ & Stud at SureBoard joint @ 18 in. from top \\
\hline 30 & TC_WallMidStud $^{\mathrm{a}}$ & Thermocouple & ${ }^{\circ} \mathrm{C}$ & Omega & GG-K-24 & $1250^{\circ} \mathrm{C}$ & $\pm 0.75 \%^{c}$ & Stud at SureBoard joint @ mid-height \\
\hline 31 & TC_WallBotStud $^{\mathrm{a}}$ & Thermocouple & ${ }^{\circ} \mathbf{C}$ & Omega & GG-K-24 & $1250{ }^{\circ} \mathrm{C}$ & $\pm 0.75 \%^{c}$ & Stud at SureBoard joint @ 18 in. from bottom \\
\hline 32 & Excitation Voltage & $\pm 10 \mathrm{~V}$ RSE & V & - & - & - & - & Used to normalize potentiometer (pot) voltages \\
\hline 33 & V_Disp_Lateral_Top & String pot & $\mathrm{V}$ & UniMeasure & PA30 & $30 \mathrm{in.}$ & $\pm 0.10 \%$ & Top channel out-of-plane at center of specimen \\
\hline 34 & V_Disp_Vertical_Actuator & String pot & $\mathrm{V}$ & UniMeasure & PA30 & $30 \mathrm{in.}$ & $\pm 0.10 \%$ & Vertical movement of actuator @ connection \\
\hline 35 & V_Disp_Longitudinal_SP & String pot & $\mathrm{V}$ & UniMeasure & PA30 & $30 \mathrm{in.}$ & $\pm 0.10 \%$ & Top of specimen in-plane (Drift) \\
\hline 36 & V_Disp_Slip_Track & Linear pot & $\mathrm{V}$ & Novotechnik & TR 25 & $1.0 \mathrm{in}$ & $\pm 0.20 \%$ & Horizontal slip of bottom track at north end \\
\hline 37 & V_Disp_Uplift_N & Linear pot & $\mathrm{V}$ & Novotechnik & TR 25 & $1.0 \mathrm{in}$ & $\pm 0.20 \%$ & Uplift of outer stud pack at north end of wall \\
\hline 38 & V_Disp_Uplift_S & Linear pot & $\mathrm{V}$ & Novotechnik & TR 25 & $1.0 \mathrm{in}$ & $\pm 0.20 \%$ & Uplift of outer stud pack at south end of wall \\
\hline 39 & V_Disp_Slip_Wall_Plate_N & Linear pot & $\mathrm{V}$ & BEI Sensors & 9615 & $1.5 \mathrm{in.}$ & $\pm 2.0 \%$ & Slip of bottom beam relative to floor \\
\hline 40 & V_Disp_Slip_Reaction_Plate_S & Linear pot & $\mathrm{V}$ & BEI Sensors & 9605 & $0.5 \mathrm{in.}$ & $\pm 2.0 \%$ & Slip of actuator frame relative to floor \\
\hline 41 & HRR & HRR & $\mathrm{kW}$ & - & - & - & - & Heat release rate (HRR) from calorimeter \\
\hline 42 & HRR Burner & HRR & kW & - & - & - & $\pm 2.4 \%{ }^{d}$ & Heat release rate (HRR) from gas mass flow \\
\hline 43 & Heat flux timing & N/A & $\mathrm{V}$ & - & - & - & - & Ancillary heat flux for timing \\
\hline 44 & Actuator Force & Load cell & kip & MTS & 201.35TS & $\begin{array}{l}54 \operatorname{kip}(T) \\
82 \operatorname{kip}(C)\end{array}$ & $\pm 0.15 \%$ & Actuator force ( $T=$ tension; $C=$ Compression) \\
\hline 45 & Actuator Disp & Potentiometer & in. & MTS & 201.35TS & $30 \mathrm{in.}$ & $\pm 0.20 \%$ & Actuator displacement \\
\hline 46 & MTS System Tick Count & N/A & - & MTS & - & - & - & Tick counts from MTS controller \\
\hline 47 & Disp_Lateral_Top & Scaled value & in. & UniMeasure & PA30 & $30 \mathrm{in.}$ & $\pm 0.10 \%$ & Top channel out-of-plane at center of specimen \\
\hline 48 & Disp_Vertical_Actuator & Scaled value & in. & UniMeasure & PA30 & $30 \mathrm{in.}$ & $\pm 0.10 \%$ & Vertical movement of actuator@ connection \\
\hline 49 & Disp_Longitudinal_SP & Scaled value & in. & UniMeasure & PA30 & $30 \mathrm{in.}$ & $\pm 0.10 \%$ & Top of specimen in-plane (Drift) \\
\hline 50 & Disp_Slip & Scaled value & in. & Novotechnik & TR 25 & 1.0 in & $\pm 0.20 \%$ & Horizontal slip of bottom track at north end \\
\hline 51 & Disp_Uplift_N & Scaled value & in. & Novotechnik & TR 25 & $1.0 \mathrm{in}$ & $\pm 0.20 \%$ & Uplift of outer stud pack at north end of wall \\
\hline 52 & Disp_Uplift_S & Scaled value & in. & Novotechnik & TR 25 & 1.0 in & $\pm 0.20 \%$ & Uplift of outer stud pack at south end of wall \\
\hline 53 & Disp_Slip_Wall_Plate_N & Scaled value & in. & BEI Sensors & 9615 & $1.5 \mathrm{in.}$ & $\pm 2.0 \%$ & Slip of bottom beam relative to floor \\
\hline 54 & Disp_Slip_Reaction_Plate_S & Scaled value & in. & BEI Sensors & 9605 & $0.5 \mathrm{in.}$ & $\pm 2.0 \%$ & Slip of actuator reaction frame relative to floor \\
\hline
\end{tabular}

${ }^{a}$ Channel not include in tests CFS01a, CFS01b, CFS02, CFS03a or CFS03b.

${ }^{\mathrm{b}} 1$ in. $=25.4 \mathrm{~mm} ; 1 \mathrm{kip}=1000 \mathrm{lbs}=4.5 \mathrm{kN}$.

${ }^{\mathrm{C}} 2.2^{\circ} \mathrm{C}$ for temperatures less than $293^{\circ} \mathrm{C}$. Uncertainties valid for temperatures above $0^{\circ} \mathrm{C}$

${ }^{\mathrm{d}}$ Expanded uncertainty.

Items shown in bold are reported in the appendicies. 


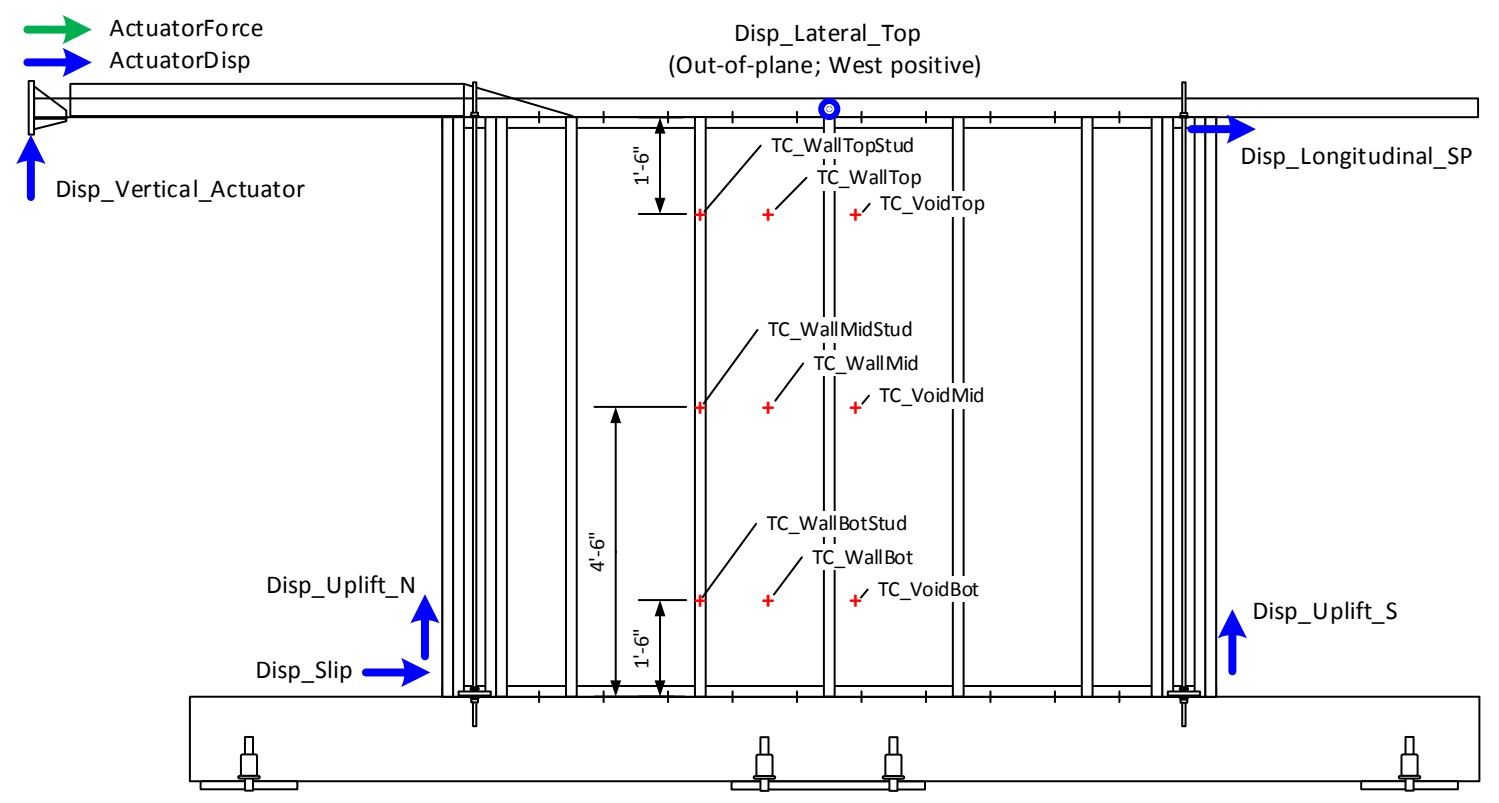

Figure 22: Sensor locations on specimen and loading frame $(1 \mathrm{ft} .=0.3048 \mathrm{~m})$.

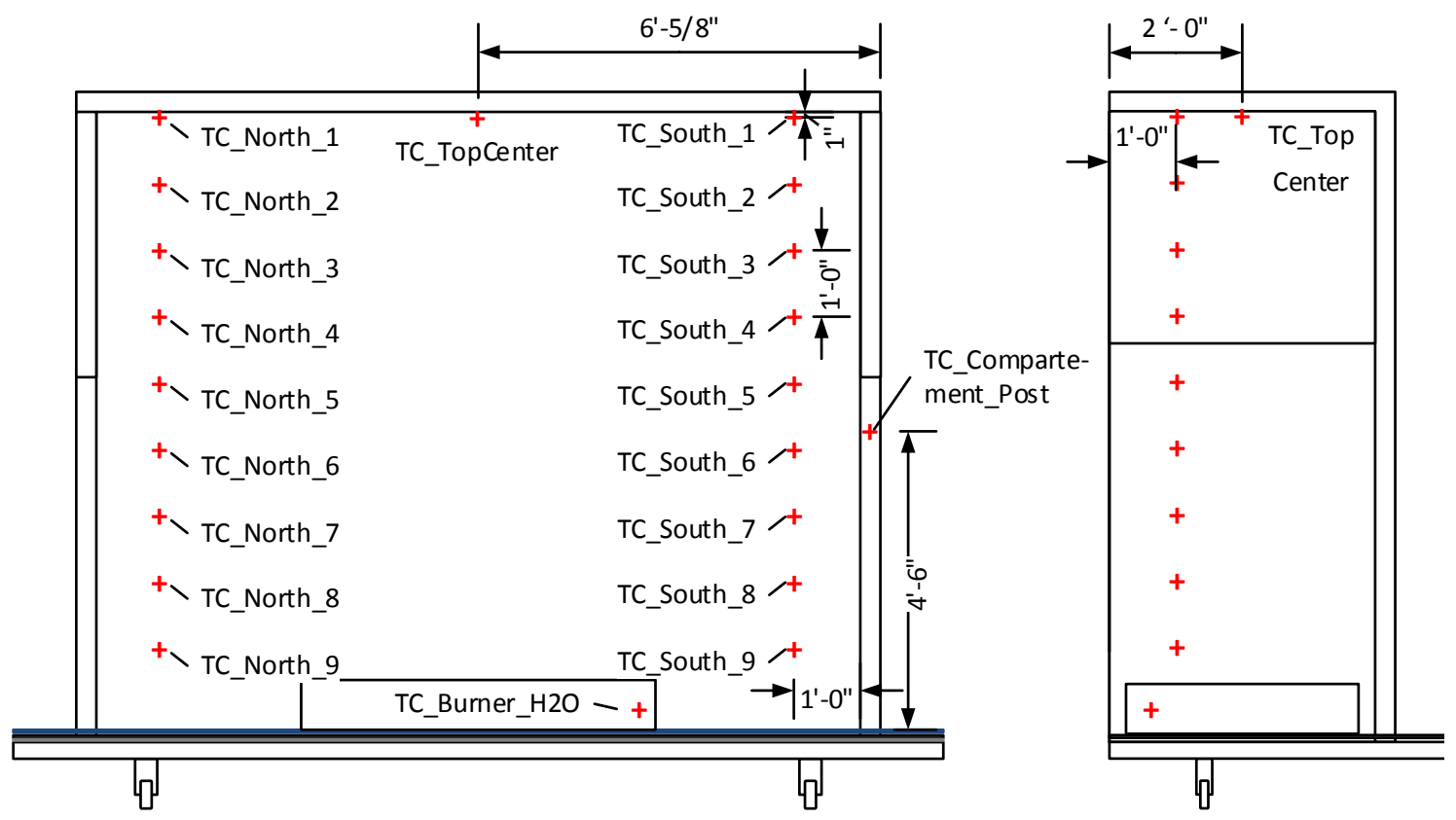

Figure 23: Sensor locations on burn compartment $(1 \mathrm{ft} .=0.3048 \mathrm{~m})$. 


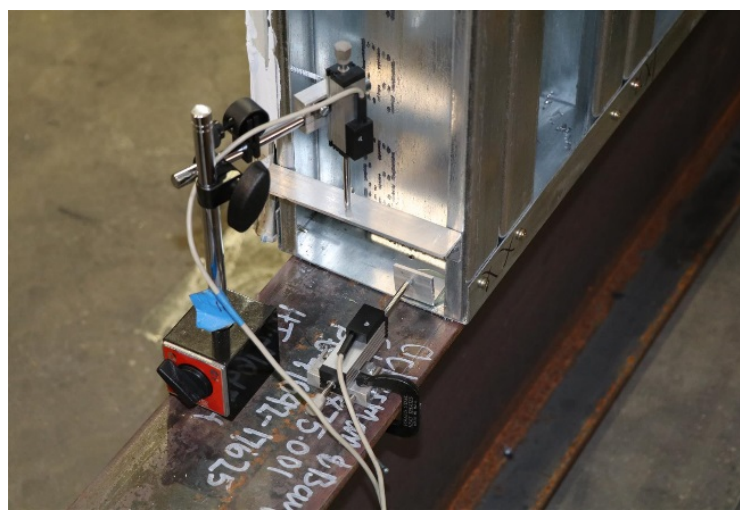

(a)

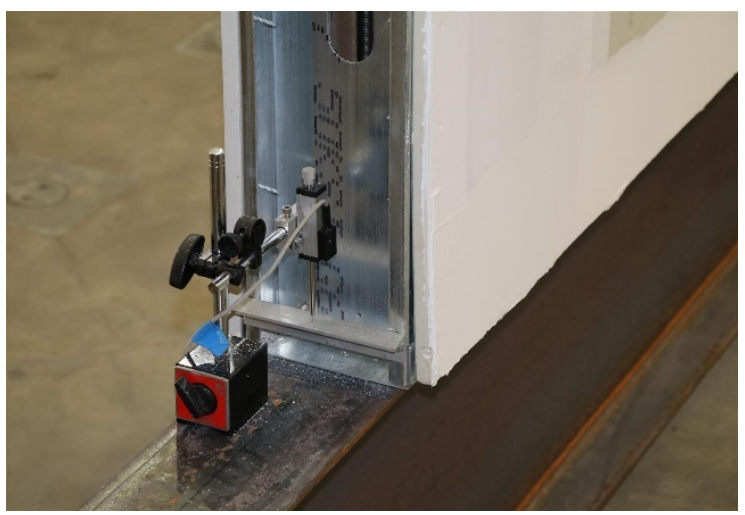

(b)

Figure 24: Photographs linear potentiometers to measure wall uplift and slip: (a) North end; (b) South end.

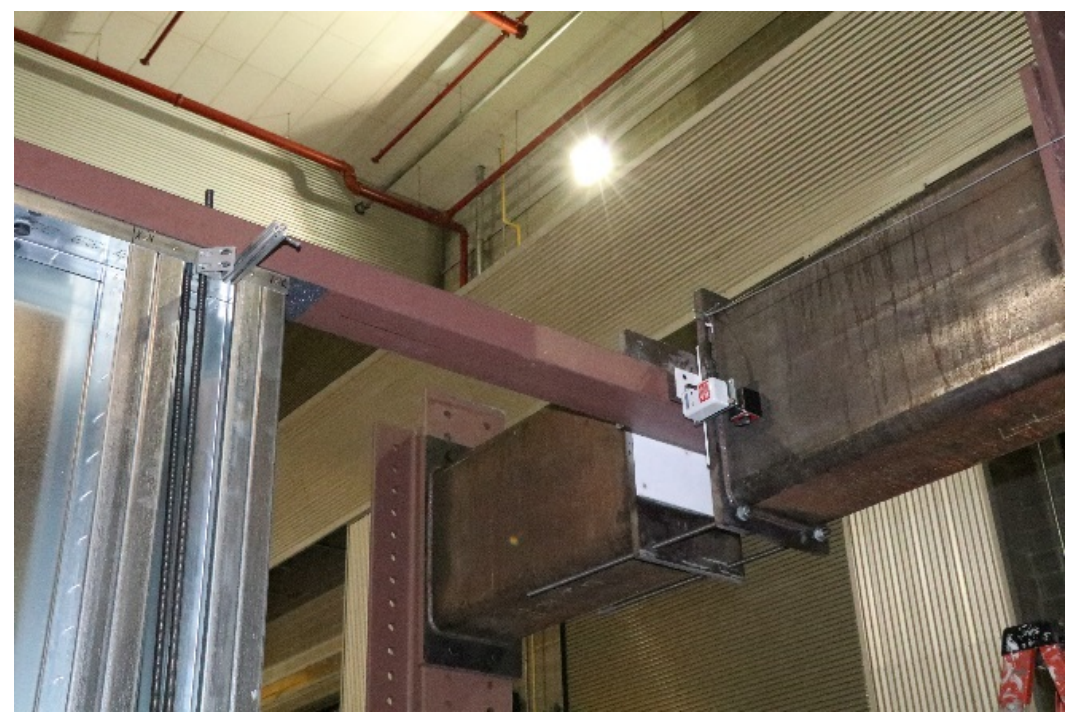

Figure 25: Photograph of string potentiometer to measure top wall drift.

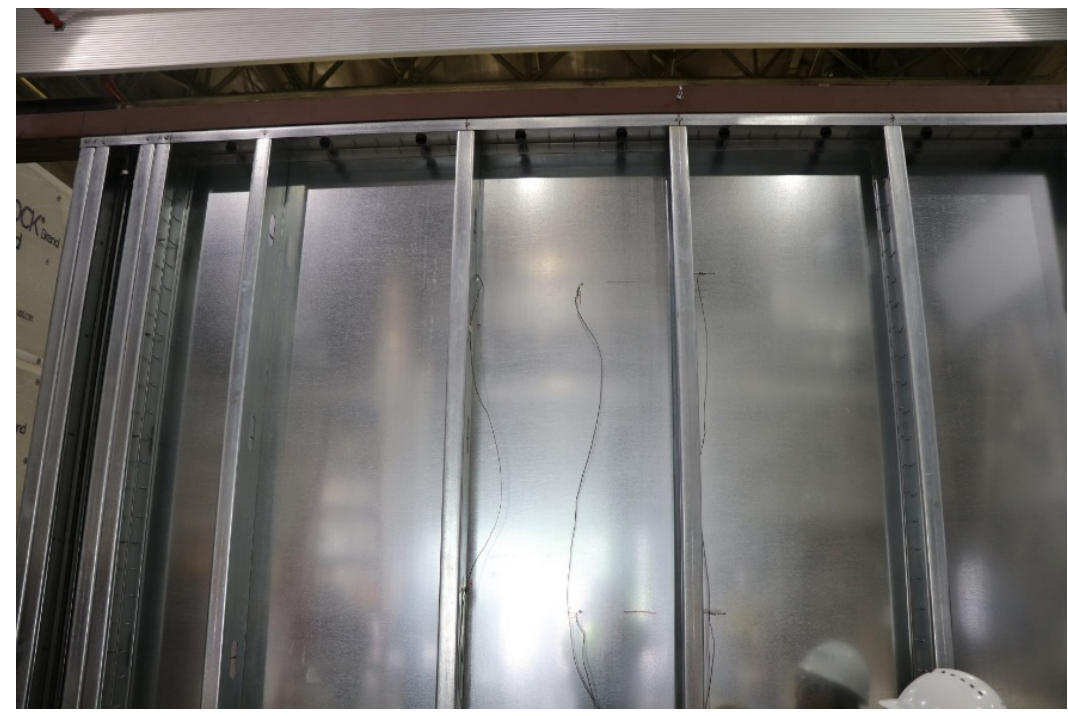

Figure 26: Photograph of thermocouples in specimen. 


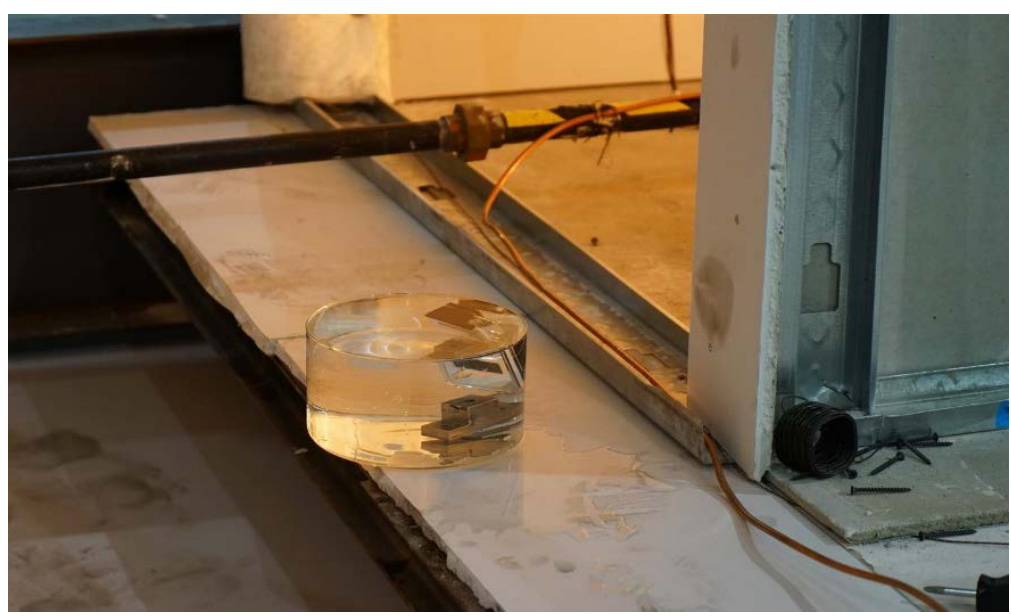

Figure 27: Photograph of GoPro video camera in water bath used to acquire footage during fire loading.

\section{Results Summary}

Detailed results for each test series are provided in the Appendices. The enveloping curves ("backbones") extracted from the peak values of applied force versus drift for the five cyclic tests are compared in this section. Displacements (drifts) measured at the top of the specimens are converted to percent interstory drift by dividing by the specimen height ( $9 \mathrm{ft}$. $(2.7 \mathrm{~m}))$. Figure 28 and Table 4 provide results in U.S. Customary Units. Figure 29 and Table 5 provide results in SI Units. The portions of the curves in Figure 28 and Figure 29 indicated by dashed lines occurred after fire loading was applied.

Test CFS02 represents the stiffness and capacity of the wall under ambient conditions. Test CFS05 represents the stiffness and capacity of the specimen after the metal sheathed side has been subjected to the investigated fire load for $13 \mathrm{~m} 20 \mathrm{~s}$ (without any pre-damage by lateral loading). The reduction in peak load capacity was $35 \%$ (in compression) and the response was roughly symmetric for tension and compression cycles. The reduction in the peak load was accompanied by a shift in failure mode of the specimens from local buckling of the sheet metal near the corners of the panel and tear-out of the screws (Figure 30a) to field buckling of the sheet metal (Figure 30b). The fire severely damaged the gypsum on the burned side, reducing the out-of-plane stiffness of the panels (provided by composite action between the steel and gypsum) and also eliminating the out-of-plane restraint provided by the screw heads. This, in effect, changed the specimen to a sheet metal shear wall (without adhered gypsum) with reduced constraint around the panel boundaries.

Pre-damaging the specimen by cycling it to $1 \%$ (CFS03) or $1.8 \%$ (CFS04) drift prior to the fire loading had no noticeable influence on the residual capacity of the wall after the fire. The fire load alone was the trigger to shift the load-displacement behavior between a sheet metal wall with adhered gypsum (CFS02) to that of a sheet metal wall without adhered gypsum (CFS05).

Doubling the burn time to $26 \mathrm{~m} 40 \mathrm{~s}$ caused additional reduction (11\% to $18 \%$ in compression and tension, respectively) of the post-fire load capacity. This is believed to be 
due to the damage to the nonstructural gypsum board on the unexposed side of the wall in the longer burn (Figure 31) which was not present in the shorter burn tests. However, additional testing is recommended to confirm this hypothesis.

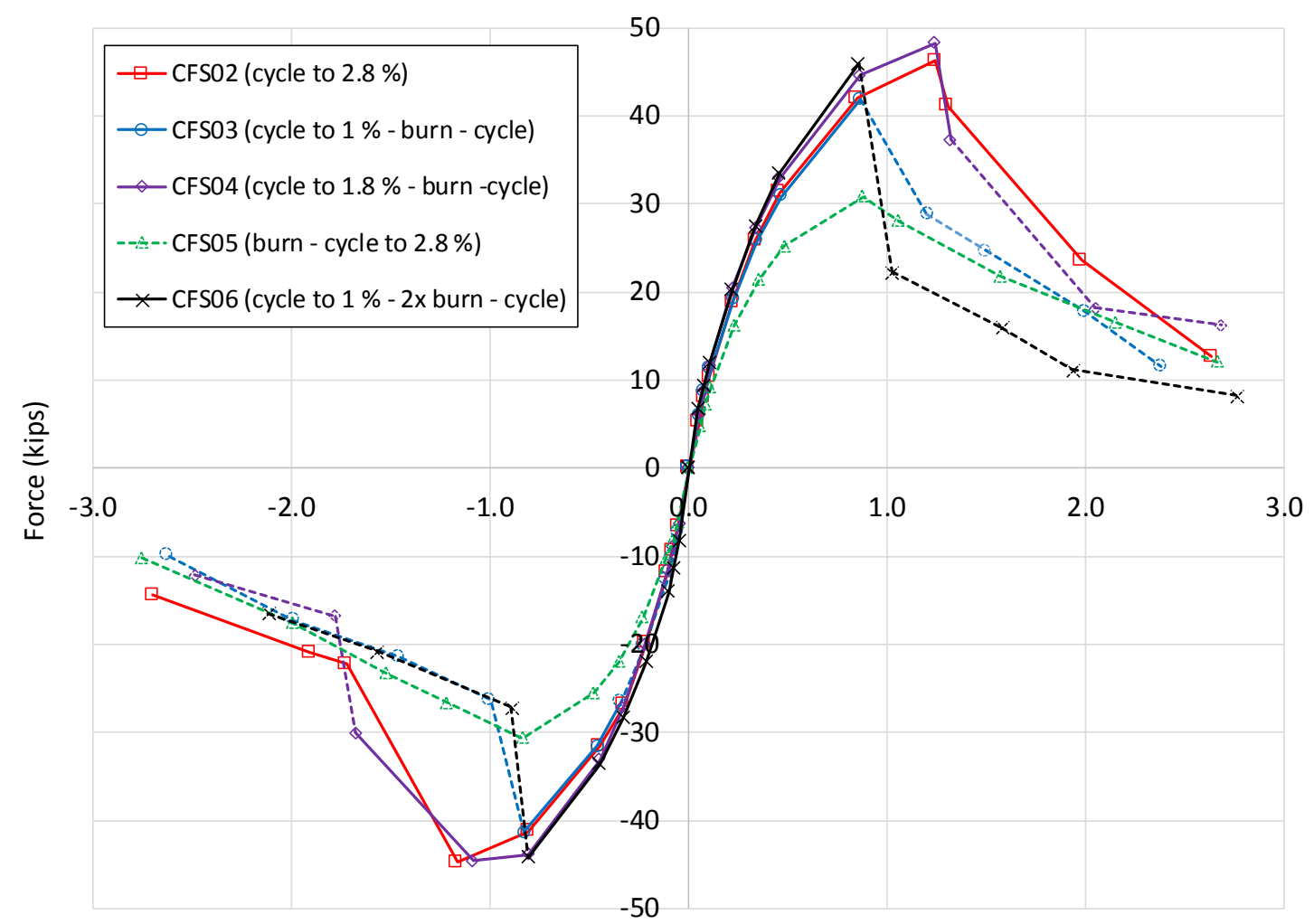

Interstory drift (\%)

Figure 28: Backbone curves for CFS02 to CFS06 (U.S. Customary Units).

Table 4: Backbone curve data for CFS02 to CFS06

(U.S. Customary Units; standard uncertainty $\pm 0.15 \%$ on forces and $\pm 0.10 \%$ for drift).

\begin{tabular}{|c|c|c|c|c|c|c|c|c|c|c|c|c|c|c|c|c|c|c|c|c|}
\hline \multirow{4}{*}{$\begin{array}{c}\text { Primary } \\
\text { cycle } \\
\text { amplitude, } \\
\% \\
\end{array}$} & \multicolumn{20}{|c|}{ Force and Interstory drift } \\
\hline & \multicolumn{4}{|c|}{ CFSO2 } & \multicolumn{4}{|c|}{ CFSO3 } & \multicolumn{4}{|c|}{ CFSO4 } & \multicolumn{4}{|c|}{ CFS05 } & \multicolumn{4}{|c|}{ CFSO6 } \\
\hline & \multicolumn{2}{|c|}{ Pos } & \multicolumn{2}{|c|}{ Neg } & \multicolumn{2}{|c|}{ Pos } & \multicolumn{2}{|c|}{ Neg } & \multicolumn{2}{|c|}{ Pos } & \multicolumn{2}{|c|}{ Neg } & \multicolumn{2}{|c|}{ Pos } & \multicolumn{2}{|c|}{ Neg } & \multicolumn{2}{|c|}{ Pos } & \multicolumn{2}{|c|}{ Neg } \\
\hline & kip & $\%$ & kip & $\%$ & kip & $\%$ & kip & $\%$ & kip & $\%$ & kip & $\%$ & kip & $\%$ & kip & $\%$ & kip & $\%$ & kip & $\%$ \\
\hline 0.07 & 5.2 & 0.05 & -6.6 & -0.05 & 6.0 & 0.05 & -7.3 & -0.05 & 6.0 & 0.05 & -6.3 & -0.05 & 4.8 & 0.06 & -6.1 & -0.05 & 6.7 & 0.05 & -8.2 & -0.05 \\
\hline 0.10 & 8.0 & 0.08 & -9.4 & -0.08 & 8.8 & 0.08 & -10.0 & -0.08 & 8.9 & 0.08 & -9.0 & -0.08 & 7.2 & 0.08 & -8.3 & -0.08 & 9.3 & 0.08 & -11.4 & -0.08 \\
\hline 0.14 & 0.4 & 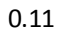 & 1.8 & -0.11 & .3 & 0.11 & -12.6 & -0.11 & 1.7 & 0.11 & -11.6 & -0.11 & 9.2 & 0.11 & -10.2 & -0.11 & 11.9 & 0.10 & -14.0 & -0.10 \\
\hline 0.28 & 18.8 & 0.22 & -19.9 & -0.22 & 9.2 & 0.23 & -20.2 & -0.22 & 20.5 & 0.22 & -20.1 & -0.22 & 16.2 & 0.23 & -16.9 & -0.23 & 20.3 & 0.22 & -22.0 & -0.21 \\
\hline 0.42 & 25.8 & 0.34 & -26.8 & -0.33 & 5.8 & 0.34 & -26.5 & -0.34 & 27.3 & 0.34 & -27.2 & -0.33 & 21.5 & 0.36 & -22.0 & -0.35 & 27.5 & 0.34 & -28.4 & -0.33 \\
\hline 0.56 & L.3 & 0.46 & -31.5 & -0.45 & 30.8 & 0.47 & -31.5 & -0.46 & 32.9 & 0.46 & -33.1 & -0.45 & 25.2 & 0.48 & -25.5 & -0.48 & 33.5 & 0.46 & -33.6 & -0.45 \\
\hline 1.0 & 42.0 & 0.85 & -41.2 & -0.81 & 41.9 & 0.87 & -41.3 & -0.83 & 44.6 & 0.86 & -43.9 & -0.81 & 30.8 & 0.88 & -30.6 & -0.83 & 45.9 & 0.85 & -44.2 & -0.81 \\
\hline 1.39 & 46.2 & 1.24 & -44.7 & -1.17 & 28.9 & 1.20 & -26.3 & -1.00 & 48.3 & 1.24 & -44.6 & -1.09 & 28.0 & 1.06 & -26.6 & -1.22 & 22.2 & 1.02 & -27.2 & -0.89 \\
\hline 1 & 1.1 & 1.31 & -22.3 & -1.72 & 24.7 & 1.49 & -21.4 & -1.46 & 37.2 & 1.32 & -30.0 & -1.68 & 21.8 & 1.57 & -23.3 & -1.52 & 16.0 & 1.58 & -20.7 & -1.57 \\
\hline 2.36 & 23.5 & 1.98 & -20.9 & -1.91 & 17.8 & 1.99 & -17.3 & -1.99 & 18.2 & 2.05 & -16.8 & -1.78 & 16.5 & 2.15 & -17.6 & -1.99 & 11.2 & 1.93 & -16.5 & -2.12 \\
\hline 0 & 12.6 & 2.63 & -14.4 & -2.70 & 11.6 & 2.38 & -9.9 & -2.62 & 16.2 & 2.68 & -12.1 & -2.49 & 12.1 & 2.66 & -10.2 & -2.76 & 8.3 & 2.76 & -13.9 & -2.38 \\
\hline Max & 46.2 & 2.6 & -44.7 & -2.7 & 41.9 & 2.4 & -41.3 & -2.6 & 48.3 & 2.7 & -44.6 & -2.5 & 30.8 & 2.7 & -30.6 & -2.8 & 45.9 & 2.8 & -44.2 & -2.4 \\
\hline
\end{tabular}




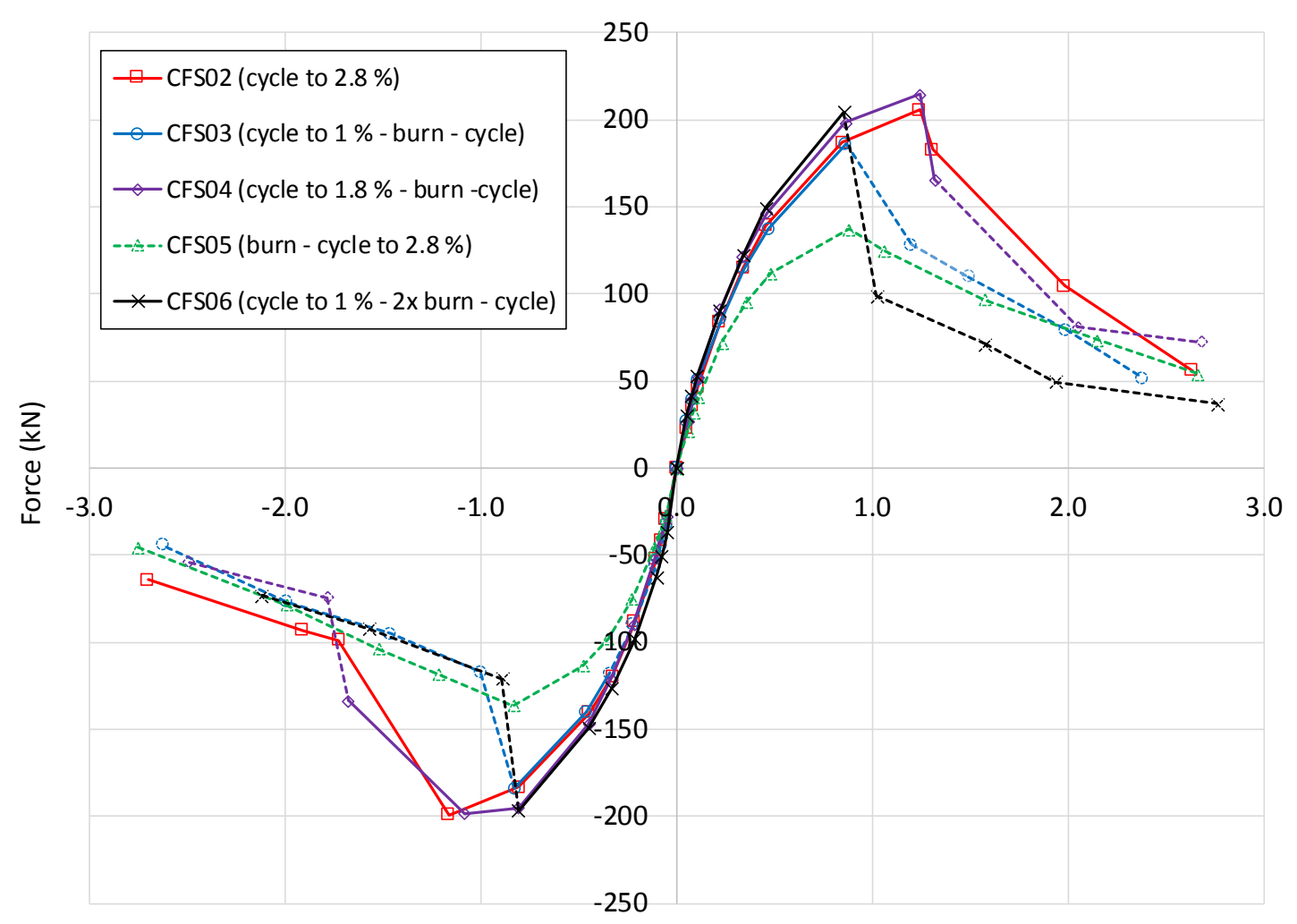

Interstory drift (\%)

Figure 29: Backbone curves for CFS02 to CFS06 (SI Units).

Table 5: Backbone curve data for CFS02 to CFS06

(SI Units; standard uncertainty $\pm 0.15 \%$ on forces and $\pm 0.10 \%$ for drift).

\begin{tabular}{|c|c|c|c|c|c|c|c|c|c|c|c|c|c|c|c|c|c|c|c|c|}
\hline \multirow{4}{*}{$\begin{array}{c}\text { Primary } \\
\text { cycle } \\
\text { amplitude, } \\
\%\end{array}$} & \multicolumn{20}{|c|}{ Force and Interstory drift } \\
\hline & \multicolumn{4}{|c|}{ CFSO2 } & \multicolumn{4}{|c|}{ CFSO3 } & \multicolumn{4}{|c|}{ CFSO4 } & \multicolumn{4}{|c|}{ CFSO5 } & \multicolumn{4}{|c|}{ CFSO6 } \\
\hline & \multicolumn{2}{|c|}{ Pos } & \multicolumn{2}{|c|}{ Neg } & \multicolumn{2}{|c|}{ Pos } & \multicolumn{2}{|c|}{ Neg } & \multicolumn{2}{|c|}{ Pos } & \multicolumn{2}{|c|}{ Neg } & \multicolumn{2}{|c|}{ Pos } & \multicolumn{2}{|c|}{ Neg } & \multicolumn{2}{|c|}{ Pos } & \multicolumn{2}{|c|}{ Neg } \\
\hline & $\mathrm{kN}$ & $\%$ & kN & $\%$ & kN & $\%$ & kN & $\%$ & kN & $\%$ & kN & $\%$ & $\mathbf{k N}$ & $\%$ & kN & $\%$ & $k N$ & $\%$ & kN & $\%$ \\
\hline 0.07 & 23 & 0.05 & -30 & -0.05 & 27 & 0.05 & -33 & -0.05 & 27 & 0.05 & -28 & -0.05 & 21 & 0.06 & -27 & -0.05 & 30 & 0.05 & -36 & -0.05 \\
\hline 0.1 & 36 & 0.08 & -42 & -0.08 & 39 & 0.08 & -45 & -0.08 & 40 & 0.08 & -40 & 08 & 32 & .08 & -37 & -0.08 & 41 & .08 & -51 & 0.08 \\
\hline 0.14 & 46 & 0.11 & -52 & -0.11 & 50 & 0.11 & -56 & -0.11 & 52 & 0.11 & -51 & -0.11 & 41 & 0.11 & -45 & -0.11 & 53 & 0.10 & -62 & -0.10 \\
\hline 0.28 & 84 & 0.22 & -88 & -0.22 & 85 & 0.23 & -90 & -0.22 & 91 & 0.22 & -89 & -0.22 & 72 & 0.23 & -75 & -0.23 & 90 & 0.22 & -98 & -0.21 \\
\hline 0.42 & 115 & 0.34 & -119 & -0.33 & 115 & 0.34 & -118 & -0.34 & 121 & 0.34 & -121 & -0.33 & 96 & 0.36 & -98 & -0.35 & 122 & 0.34 & -126 & -0.33 \\
\hline 0.56 & 139 & 0.46 & -140 & -0.45 & 137 & 0.47 & -140 & -0.46 & 146 & 0.46 & -147 & -0.45 & 112 & 0.48 & -114 & -0.48 & 149 & 0.46 & -149 & -0.45 \\
\hline 1.0 & 187 & 0.85 & -183 & -0.81 & 186 & 0.87 & -184 & -0.83 & 198 & 0.86 & -195 & -0.81 & 137 & 0.88 & -136 & -0.83 & 204 & 0.85 & -197 & -0.81 \\
\hline 1.39 & 206 & 1.24 & -199 & -1.17 & 128 & 1.20 & -117 & -1.00 & 215 & 1.24 & -198 & -1.09 & 125 & 1.06 & -118 & -1.22 & 99 & 1.02 & -121 & -0.89 \\
\hline 1.8 & 183 & 1.31 & -99 & -1.72 & 110 & 1.49 & -95 & -1.46 & 166 & 1.32 & -134 & -1.68 & 97 & 1.57 & -104 & -1.52 & 71 & 1.58 & -92 & -1.57 \\
\hline 2.36 & 105 & 1.98 & -93 & -1.91 & 79 & 1.99 & -77 & -1.99 & 81 & 2.05 & -75 & -1.78 & 74 & 2.15 & -78 & -1.99 & 50 & 1.93 & -73 & -2.12 \\
\hline 2.8 & 56 & 2.63 & -64 & -2.70 & 51 & 2.38 & -44 & -2.62 & 72 & 2.68 & -54 & -2.49 & 54 & 2.66 & -45 & -2.76 & 37 & 2.76 & -62 & -2.38 \\
\hline ax & 206 & 2.6 & -199 & -2.7 & 186 & 2.4 & -184 & -2.6 & 215 & 2.7 & -198 & -2.5 & 137 & 2.7 & -136 & -2.8 & 204 & 2.8 & -197 & -2.4 \\
\hline
\end{tabular}




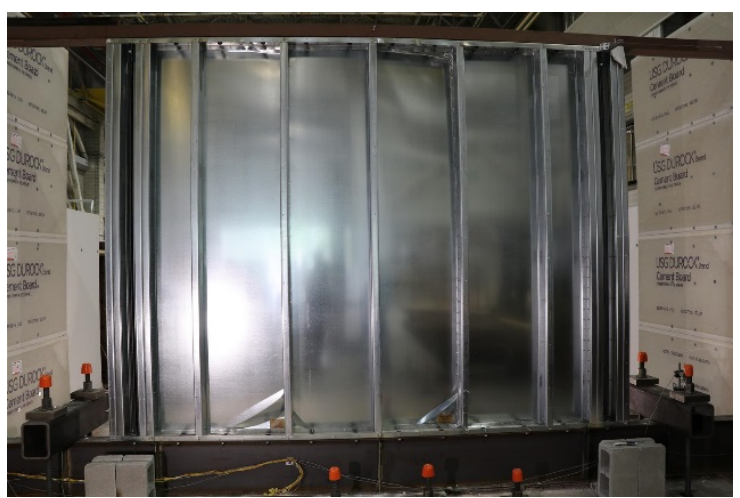

(a)

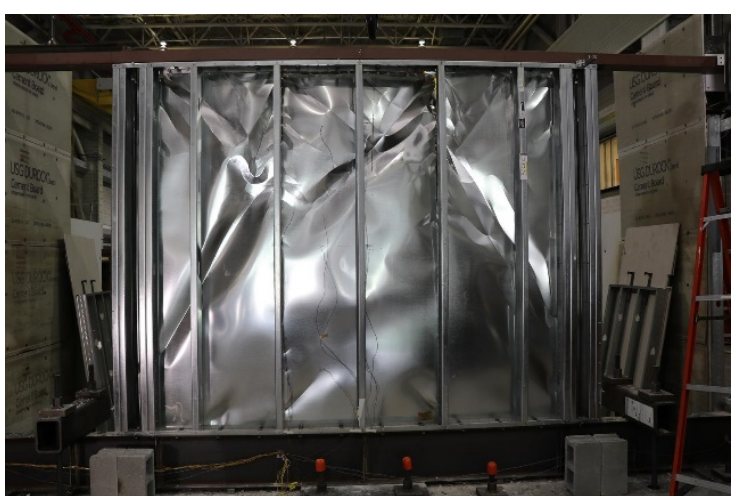

(b)

Figure 30: Photograph of back of metal sheathed side of wall after mechanical loading to 2.8 \% drift; nonstructural gypsum removed: (a) unburned wall; (b) wall after burning.

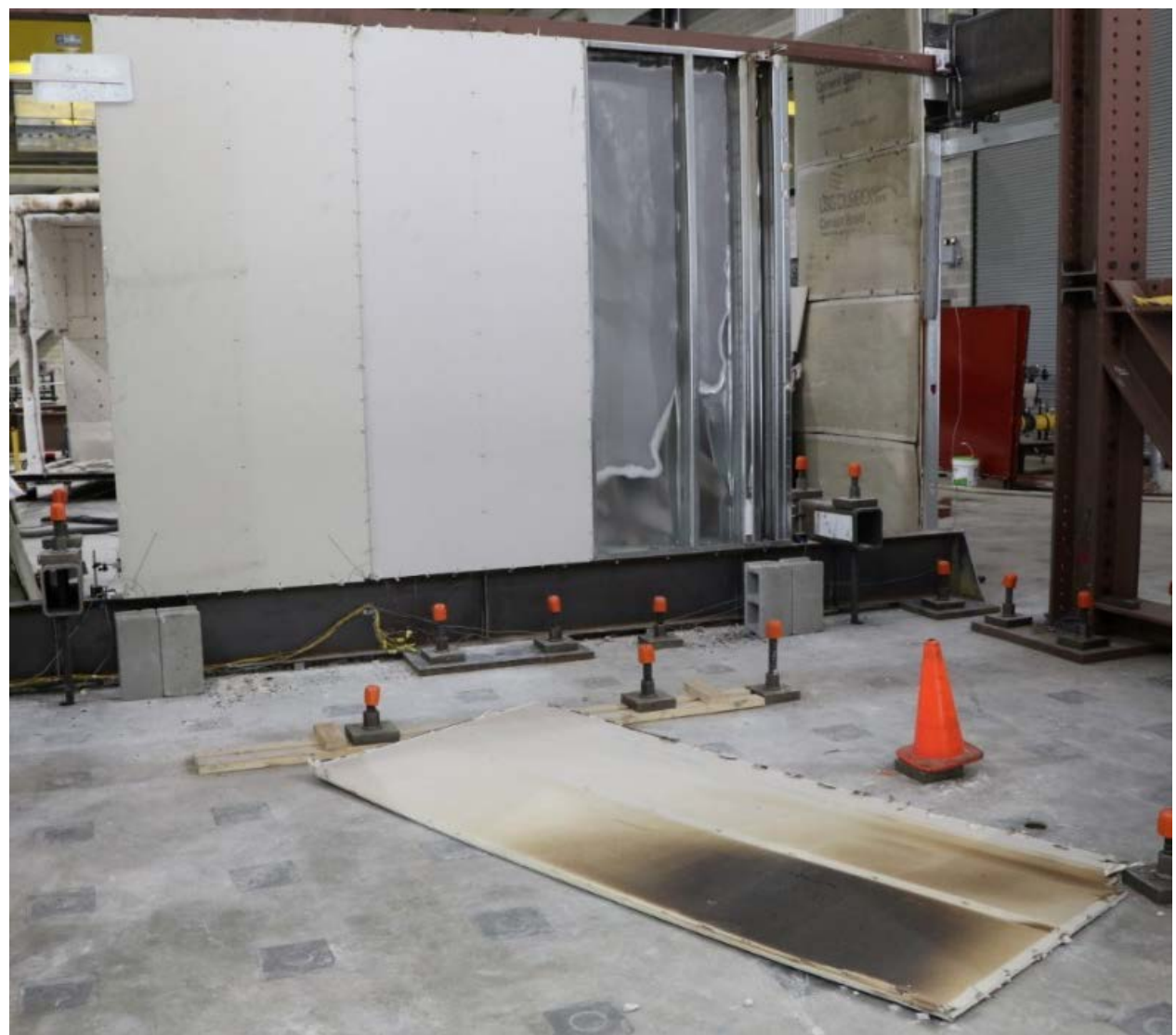

Figure 31: Photograph of back of metal sheathed side of wall after fire loading for $26 \mathrm{~m}$ $40 \mathrm{~s}$ and mechanical loading to $2.8 \%$ drift. 


\section{References}

[1] X. Wang, T. C. Hutchinson, G. Hegemier, S. Gunisetty, P. Kamath, and B. Meacham, "Earthquake and fire performance of a mid-rise cold-formed steel framed building - test program and test results: rapid release (preliminary) report (SSRP-2016/07),” San Diego, CA, 2016.

[2] ASTM International, “ASTM A653/A653M-15 Standard Specification for Steel Sheet , Zinc-Coated (Galvanized) or Zinc-Iron Alloy- Coated (Galvannealed) by the Hot-Dip Process,” West Conshohocken, PA, 2015.

[3] ASTM International, “ASTM A1003/A1003M-15 Standard Specification for Steel Sheet, Carbon, Metallic- and Nonmetallic-Coated for Cold-Formed Framing Members,” West Conshohocken, PA, 2015.

[4] ASTM International, “ASTM E2126-11 Standard Test Methods for Cyclic (Reversed) Load Test for Shear Resistance of Vertical Elements of the Lateral Force Resisting Systems for Buildings,” West Conshohocken, PA, 2011.

[5] R. D. Peacock, K. B. McGrattan, P. A. Reneke, and G. P. Forney, "CFAST Consolidated Model of Fire Growth and Smoke Transport (Version 7) Volume 1: Technical Reference Guide,” Gaithersburg, MD, Dec. 2015.

[6] ASTM International, “ASTM E119-16a Standard Test Methods for Fire Tests of Building Construction and Materials,” West Conshohocken, PA, 2016.

[7] S. Kerber, "Analysis of Changing Residential Fire Dynamics and Its Implications on Firefighter Operational Timeframes,” Fire Technol., vol. 48, no. 4, pp. 865891, Oct. 2012.

[8] B. N. Taylor and C. E. Kuyatt, "Guidelines for Evaluating and Expressing the Uncertainty of NIST Measurement Results,” 1994.

[9] M. Bundy, A. Hamins, E. L. Johnsson, S. C. Kim, G. H. Ko, and D. B. Lenhert, "Measurements of Heat and Combustion Products in Reduced-Scale VentilationLimited Compartment Fires,” 2007. 


\section{Appendix A. Fabrication Drawings}

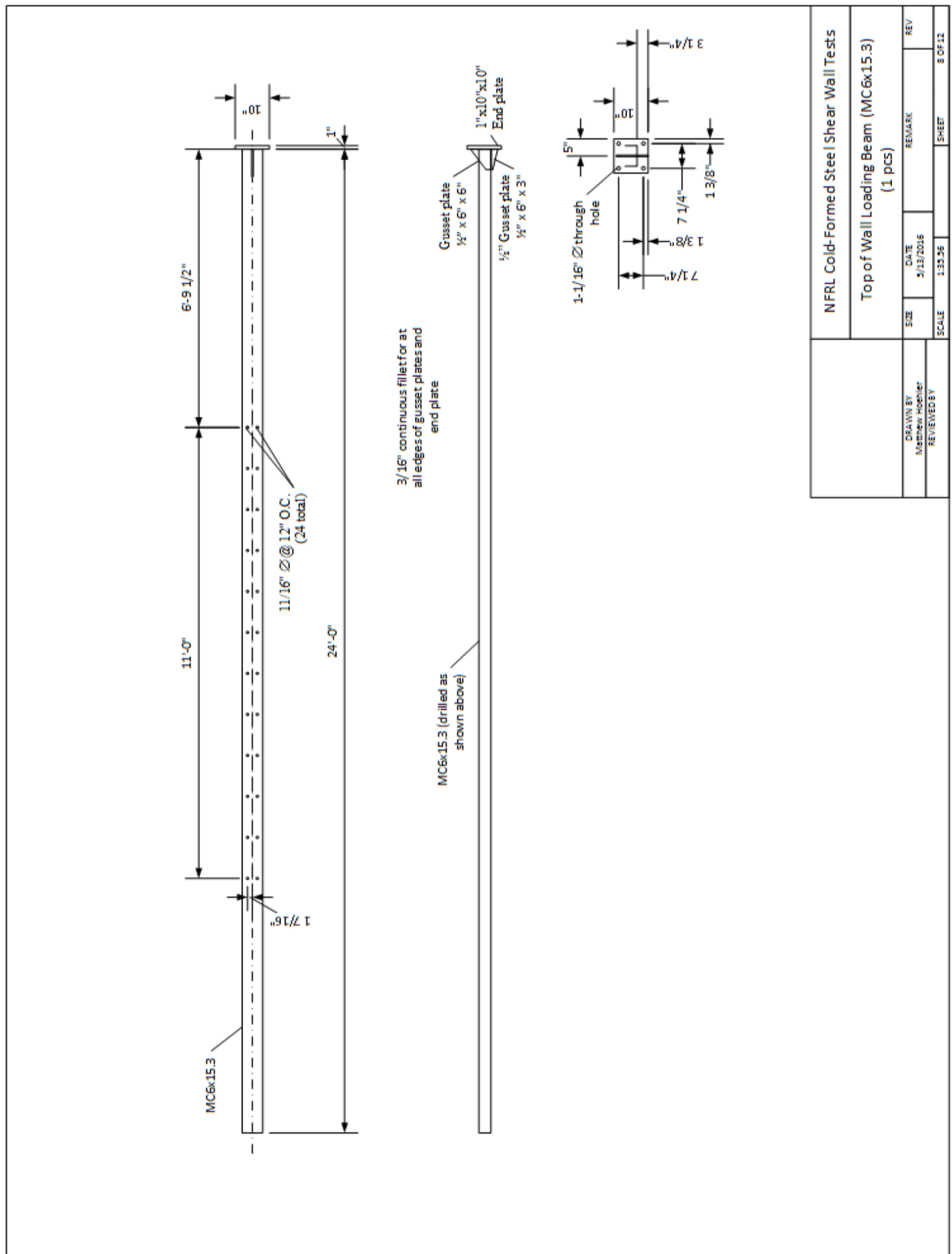

Figure 32: Fabrication drawing for top beam $(1 \mathrm{ft} .=0.3048 \mathrm{~m})$. 


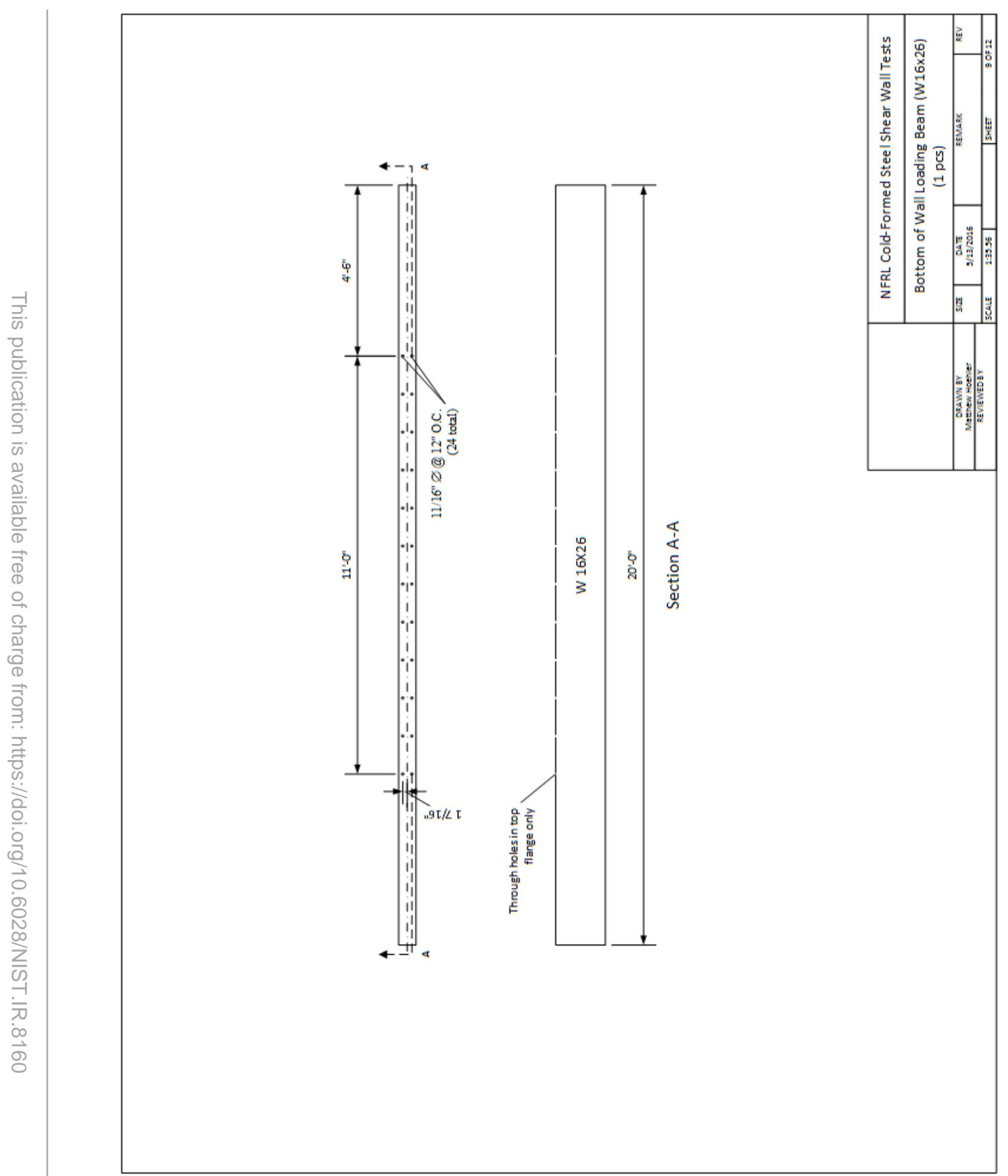

Figure 33: Fabrication drawing for bottom beam $(1 \mathrm{ft} .=0.3048 \mathrm{~m})$. 


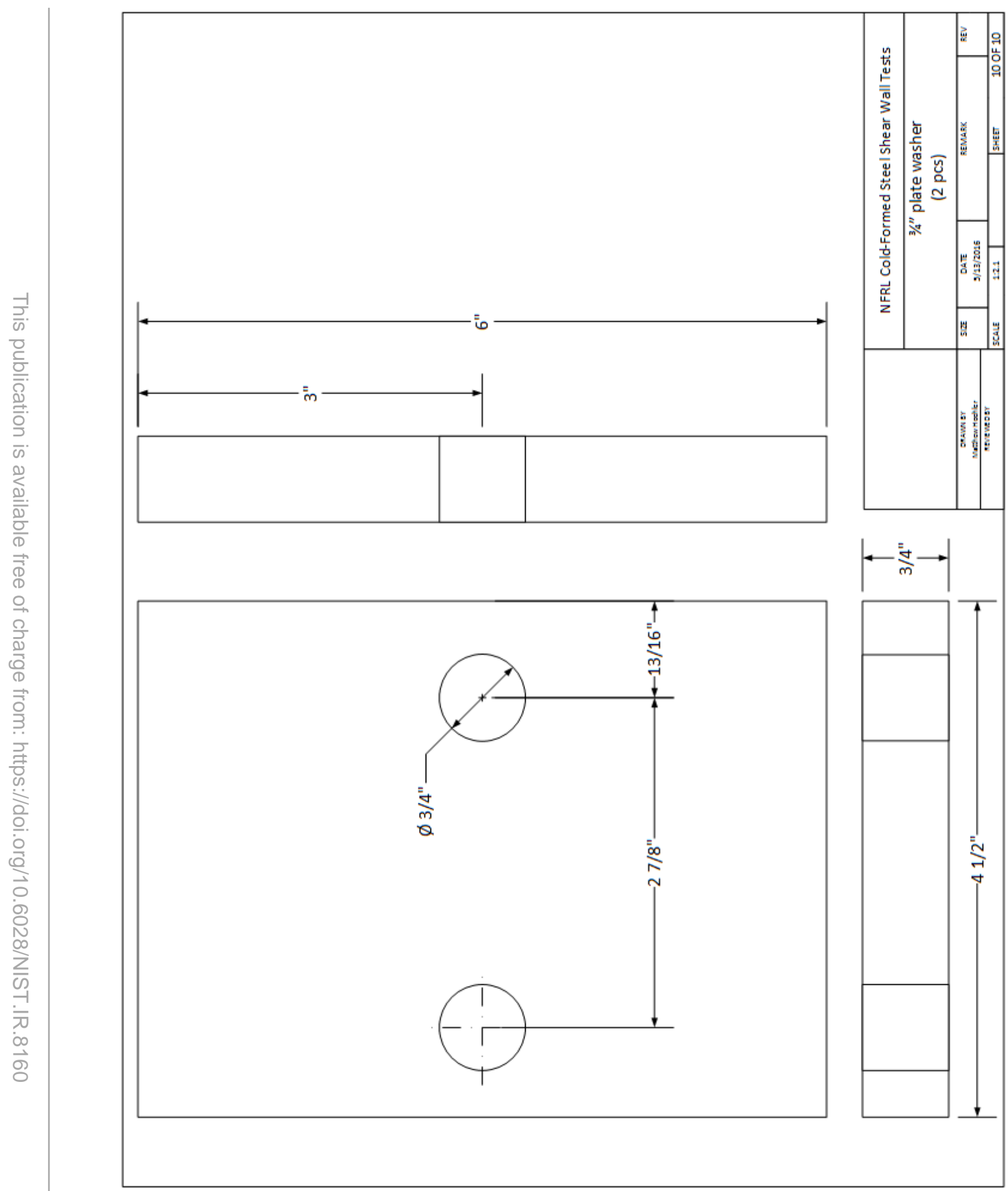

Figure 34: Fabrication drawing for plate washers $(1$ in. $=25.4 \mathrm{~mm})$. 


\section{Appendix B. Fire Load Development}

The experiments presented in this report were conducted prior to the six-story building tests at UCSD. Multiple burns in various compartments were planned for the six-story building using liquid heptane fuel [1]. The fuel load for the UCSD tests was selected to be representative of typical modern rooms and furnishings. The fuel type and duration of the burns was limited by the local fire authorities in San Diego because the tests were to be performed outdoors and close to the start of the dry season in Southern California. The authors' goal for the fire load development was to approximately match the expected upper layer gas time-temperature curve for the NIST tests to the anticipated curve in the six-story building.

The NIST test was designed to approximate one third of the corridor on the $2^{\text {nd }}$ floor of the six-story building ("Burn area" in Figure 35). To determine the required heat release rate for the NIST burner, the full corridor in the UCSD building with inside dimensions of $34 \mathrm{ft}$. $\times 3 \mathrm{ft} .-6$ in. $\times 9 \mathrm{ft}$. $(10.4 \mathrm{~m} \times 1.0 \mathrm{~m} \times 2.7 \mathrm{~m})$ was first simulated using a Consolidated Model of Fire and Smoke Transport (CFAST) [5] two-zone fire model. The corridor was lined with $5 / 8$ in. $(16 \mathrm{~mm})$ thick Type $\mathrm{X}$ gypsum board and had $5 \mathrm{ft}$. $(1.5 \mathrm{~m})$ high openings (floor vents) the width of the corridor extending up from the floor at both ends (Figure 36). Initially, four 16 in. $\times 25$ in. $(0.4 \mathrm{~m} \times 0.6 \mathrm{~m})$ pans of heptane were prescribed. An exploratory test of the heptane pool fire conducted by Worcester Polytechnic Institute (WPI) indicated a heat of combustion of $44.6 \mathrm{MJ} / \mathrm{kg}$ and a mass loss rate of $8.01 \mathrm{~g} / \mathrm{s}$ in an open room (fully ventilated, no re-radiation). This resulted in an estimated heat release rate equal to $360 \mathrm{~kW}$ per pan and total burn duration of approximately 13 minutes. This information applied to the CFAST model of the UCSD corridor results in the upper layer time-temperature curve (dashed-dot) shown in Figure 37. Since an upper layer temperature exceeding $850{ }^{\circ} \mathrm{C}$ by the end of the heating phase was desired for the UCSD tests, the number of heptane pans was increased to five and then six pans.

The NIST compartment - with inside dimensions of $11 \mathrm{ft} .-6 \mathrm{in} . \times 4 \mathrm{ft} . \times 9 \mathrm{ft} .-6 \mathrm{in}$. $(3.5 \mathrm{~m} \times 1.2 \mathrm{~m} \times 2.9 \mathrm{~m})$ lined with $5 / 8$ in. $(16 \mathrm{~mm})$ thick Type $\mathrm{X}$ gypsum board with $5 \mathrm{ft}$.6 in. $(1.7 \mathrm{~m})$ high floor vents at each end - was then simulated using CFAST. The single, natural gas burner used as the fuel source for the NIST tests had plan dimensions of approximately 42 in. $\times 60$ in. $(1 \mathrm{~m} \times 1.5 \mathrm{~m})$. Through iteration of the simulations a heat release rate from the burner of $1900 \mathrm{~kW}$ applied for 13 minutes and 20 seconds produced the desired upper layer temperature at the end of the heating phase (see NIST target in Figure 37).

The predicted upper layer temperatures and lower layer temperatures at the end of the heating phase (800 seconds) are provide in Table 6 . Figure 38 shows visualizations of the CFAST results for the two compartments near the end of the heating phases. 


\section{Level 2}

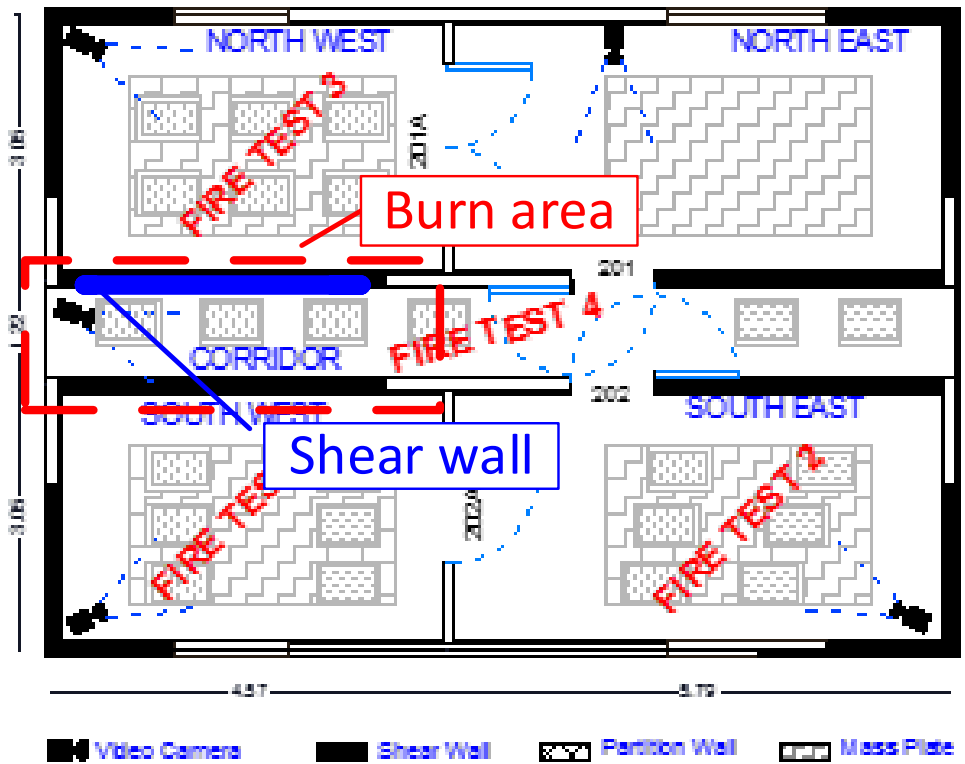

Figure 35: Approximate burn area for NIST investigations after Xiang [1].

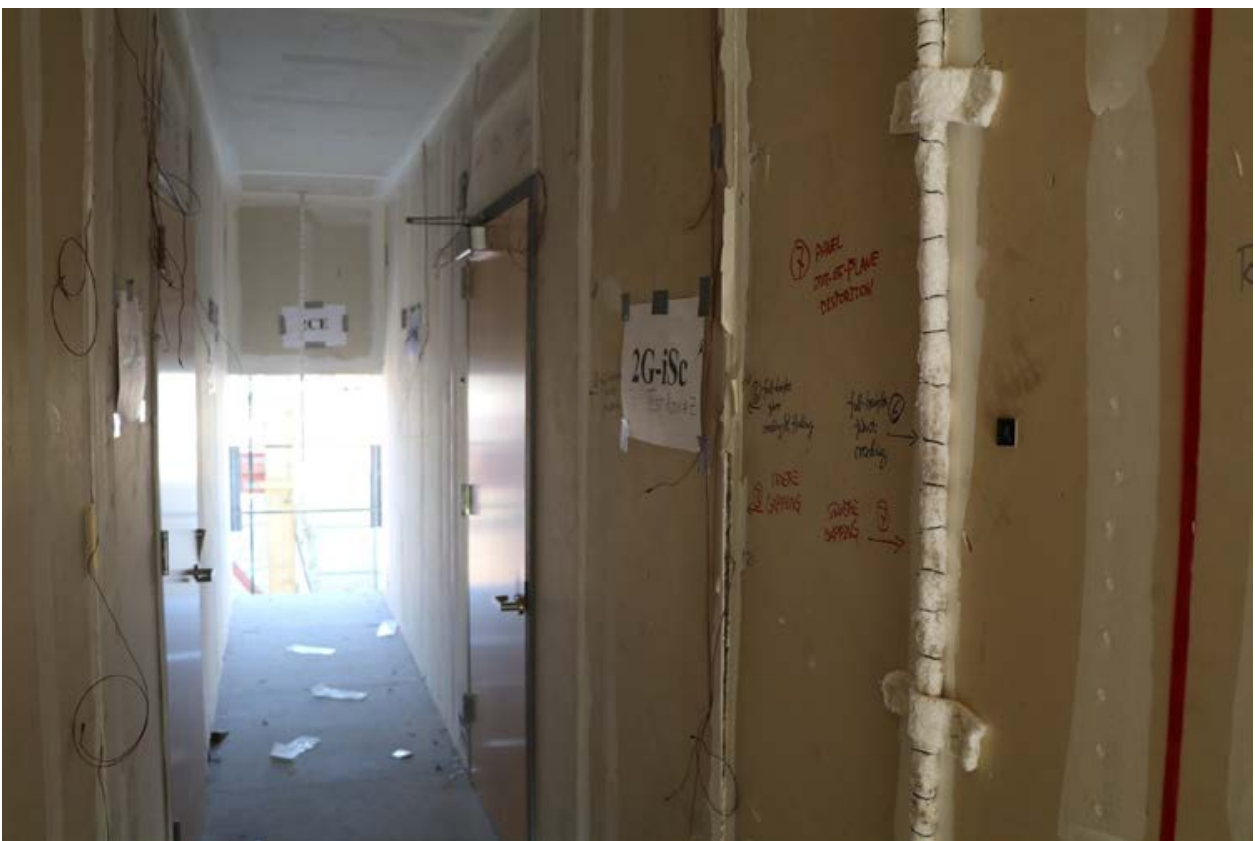

Figure 36: Photo (looking East) of $2^{\text {nd }}$ level showing opening at end of corridor in the six-story building. 


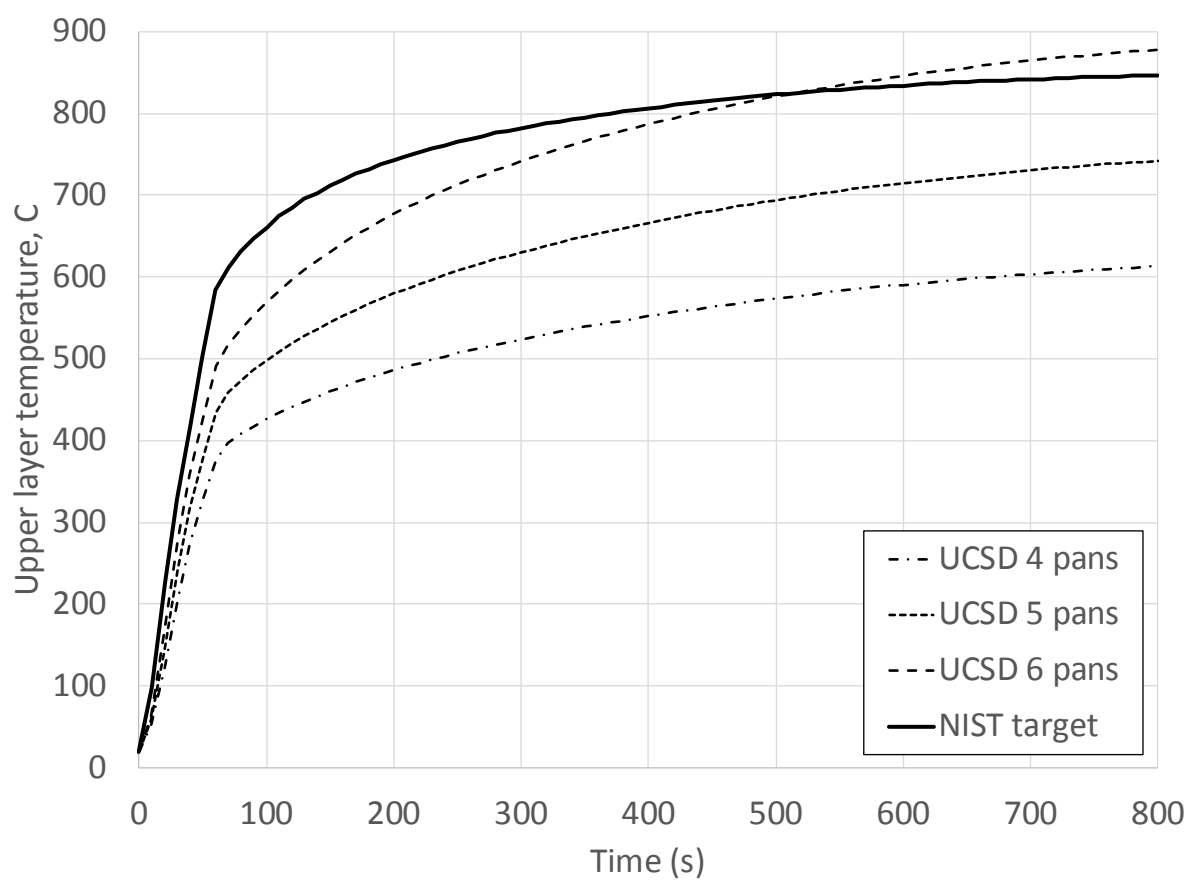

Figure 37: Upper layer temperature versus time predicted by CFAST for four, five and six pans of heptane in the UCSD corridor along with target curve for the NIST compartment.

Table 6: Predicted temperature from CFAST models.

\begin{tabular}{cccccc}
\hline Specimen & Fuel & Case & $\begin{array}{c}\text { Heat Release } \\
\text { Rate, kW }\end{array}$ & $\begin{array}{c}\text { Upper Layer } \\
\text { Temperature, C }\end{array}$ & $\begin{array}{c}\text { Lower Layer } \\
\text { Temperature, C }\end{array}$ \\
\hline \multirow{2}{*}{ UCSD corridor } & Heptane & 4 pans & 1440 & 613 & 197 \\
& & 5 pans & 1800 & 742 & 260 \\
& 6 pans & 2160 & 878 & 340 \\
\hline NIST & Natural & Target & 1900 & 846 & 154 \\
Compartment & gas & & & & \multirow{2}{*}{ Targer } \\
\hline
\end{tabular}

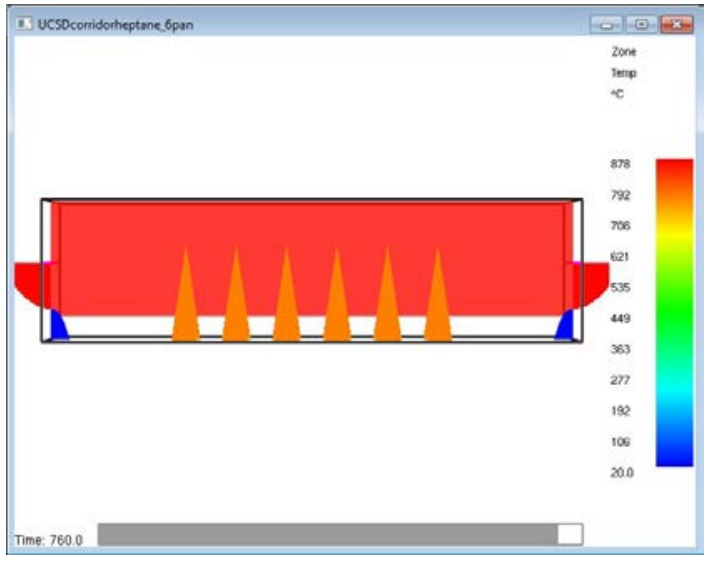

(a)

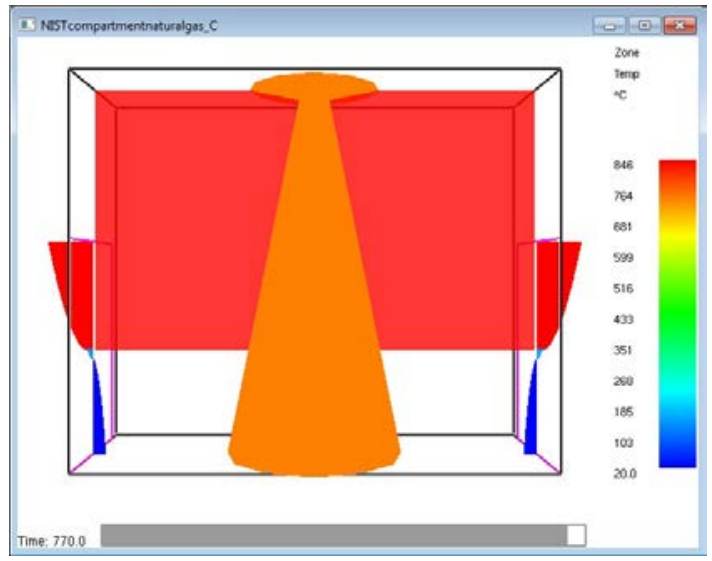

(b)

Figure 38: Smokeview visualizations of CFAST models: (a) UCSD $2^{\text {nd }}$ floor corridor with 6 pans of heptane; (b) NIST compartment with HRR selected to match UCSD results. 


\section{Appendix C. CFS01 Test Data}

CFS01a:

- The actuator was inclined slightly downward prior to test. Slotted holes on mounting plate were added for subsequent tests for better alignment with top of the specimen.

- Direction of uplift sensors was reversed in this test only (corrected in plots below).

- Stroke on uplift sensors must be better centered in subsequent tests so they do not go out of range.

- Compression end of bottom beam rolled significantly during loading (Figure 45) leading to an increase in apparent in drift. Add end plates to W16x26. Add stiffeners and blocks below compression posts and at center of clear spans. Tension W16x26 down near specimen ends.

- A large release of elastic energy occurred after peak and the test was terminated.

- Peak (actuator compression) load indicated by circle in Figure 39.

\section{CFS01b:}

- Stepped up to $1900 \mathrm{~kW}$ manually. Held for about 10 minutes. The test was terminated when the fire protection for reaction frames failed. The fire protection for the reaction frames was redesigned for subsequent tests.

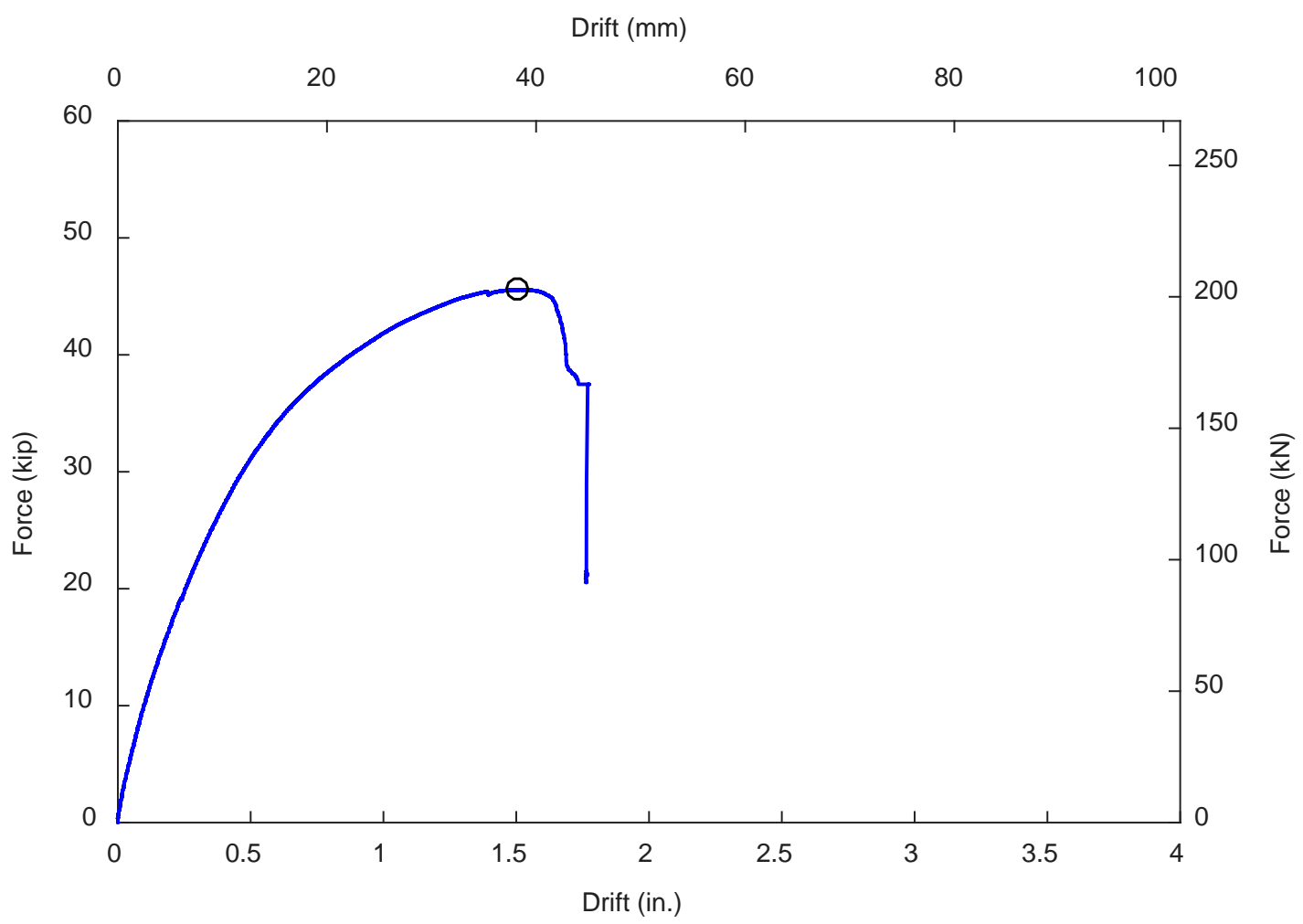

Figure 39: CFS01 - Lateral load (Actuator Force) versus drift (Disp_Longitudinal_SP) during mechanical loading. 


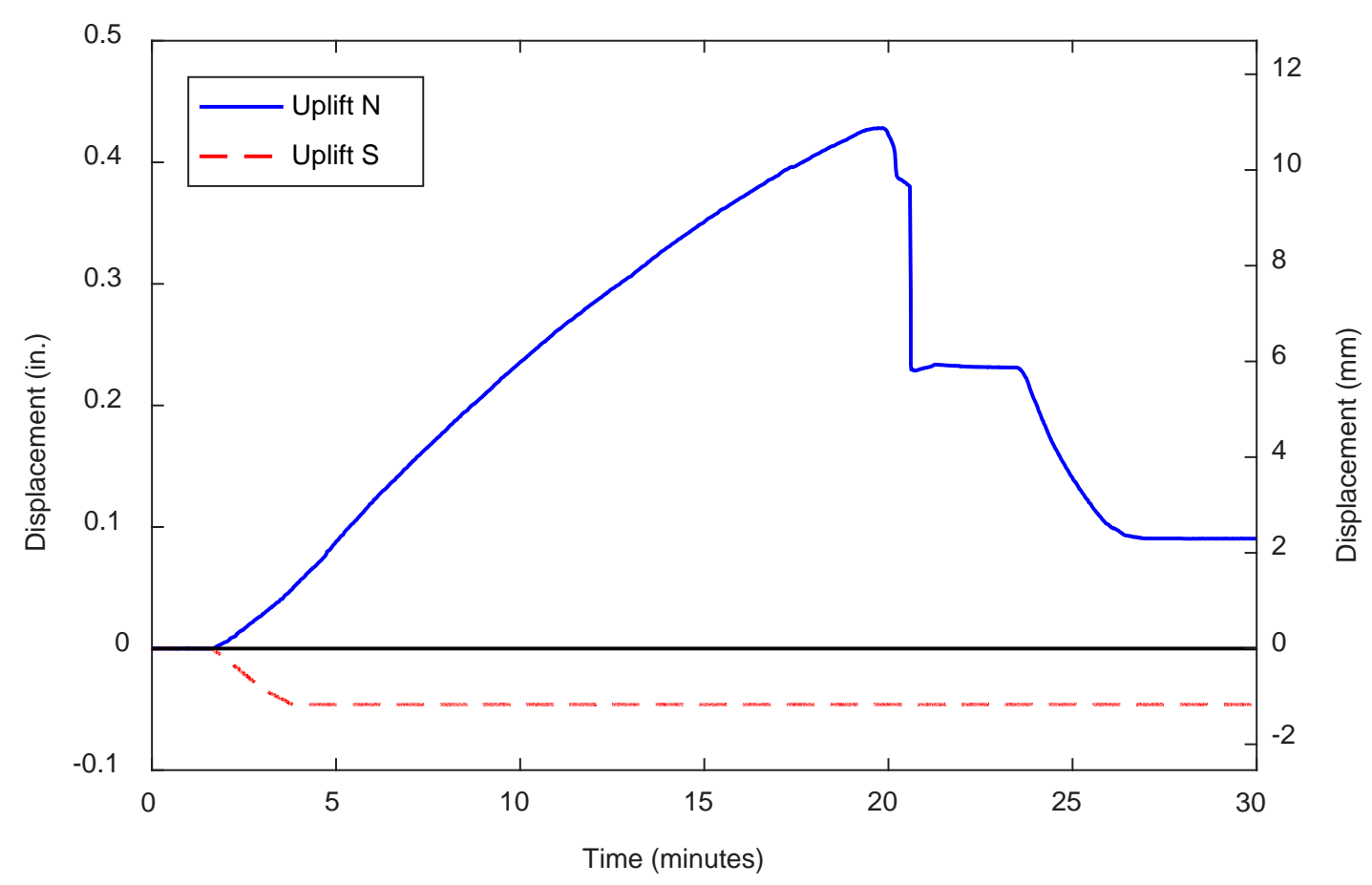

Figure 40: CFS01 - Uplift at bottom of specimen during mechanical loading.

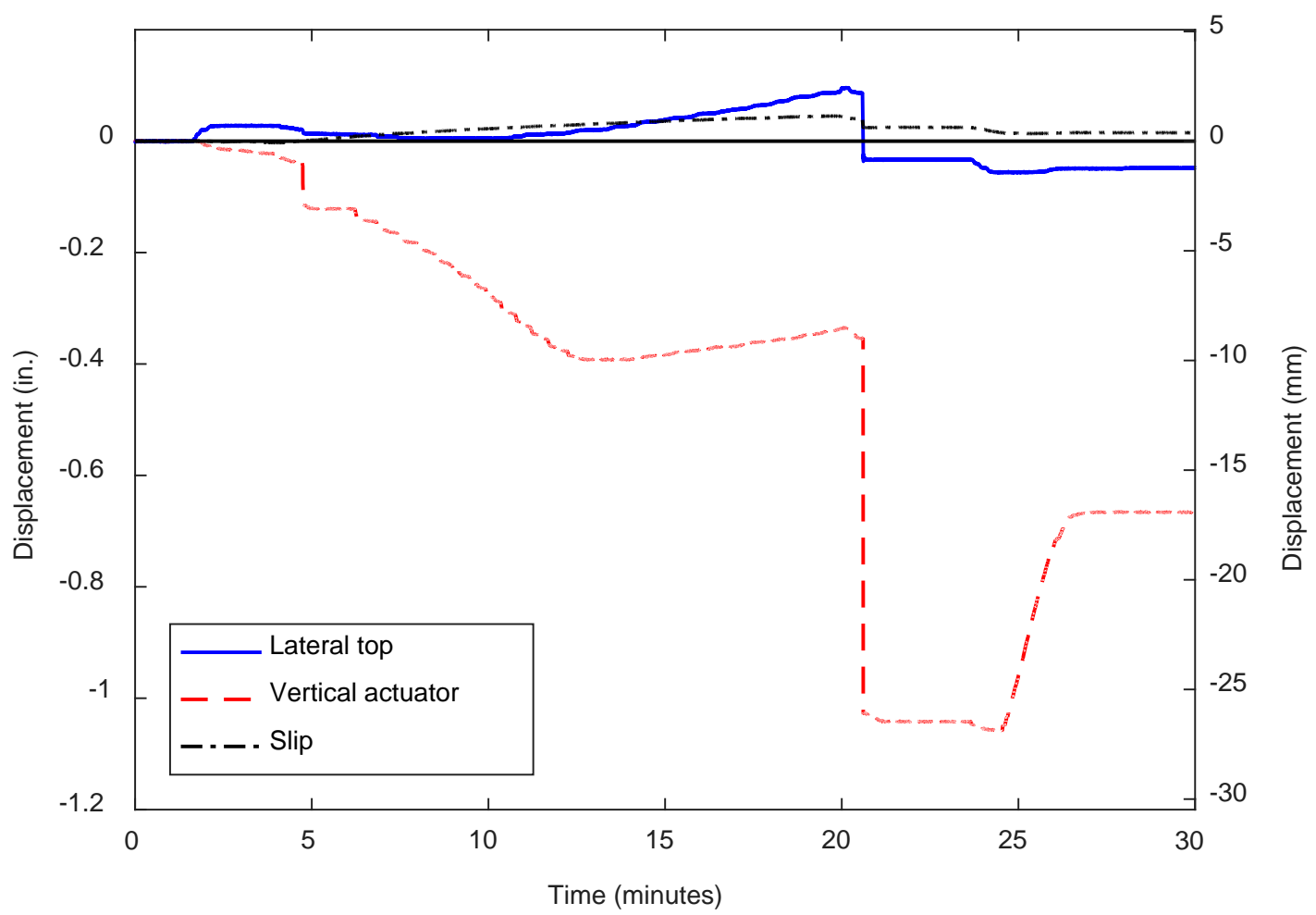

Figure 41: CFS01 - Ancillary displacement measurements during mechanical loading. 


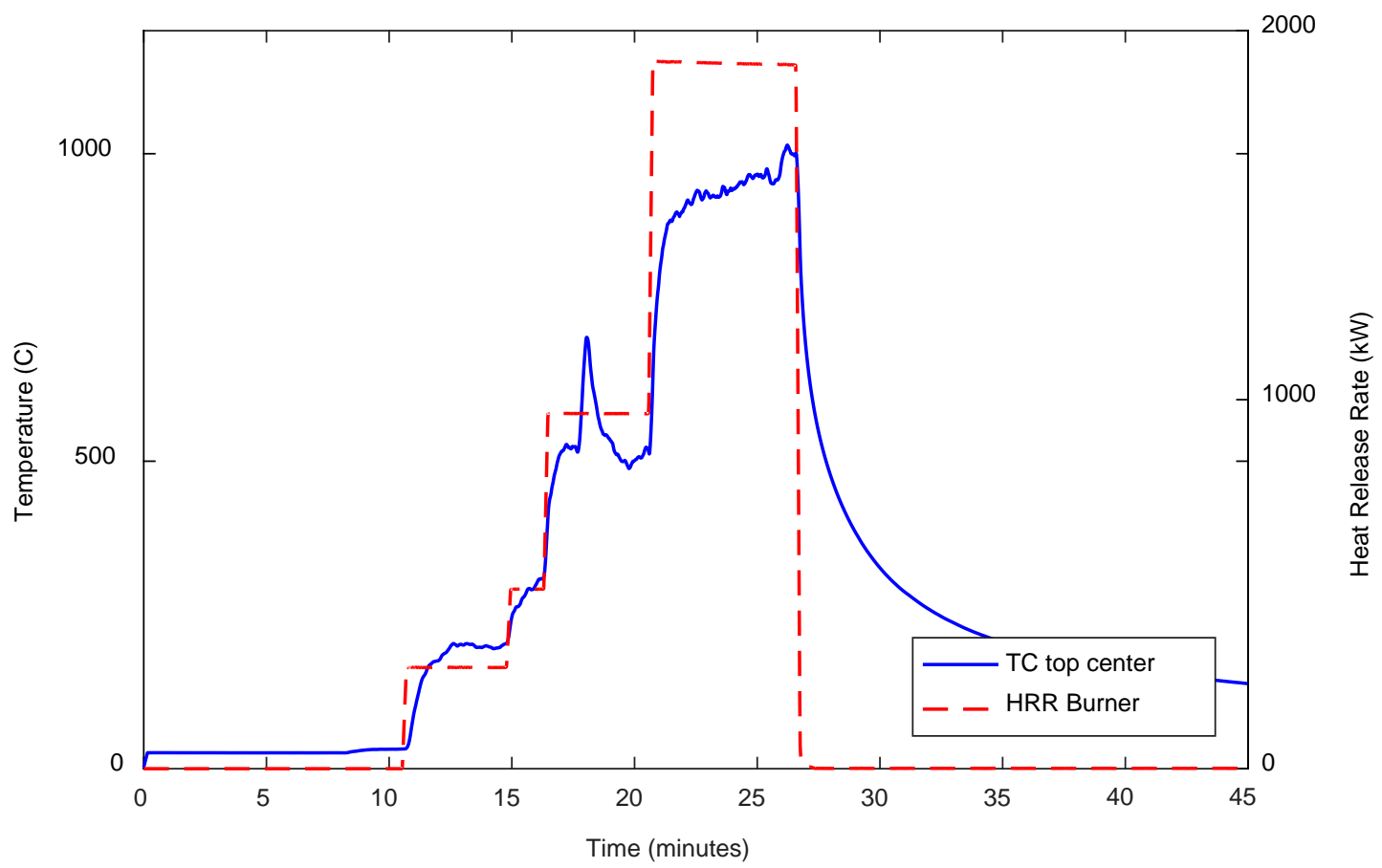

Figure 42: CFS01 - Burner heat release rate and upper layer temperature during fire loading.

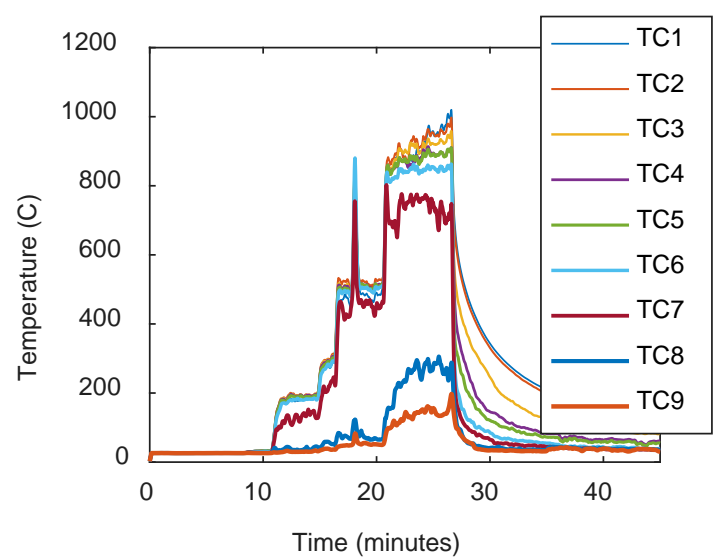

(a)

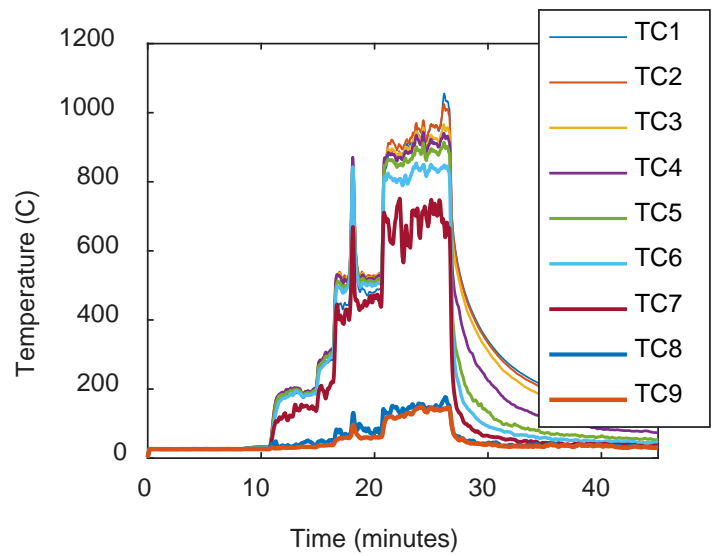

(b)

Figure 43: CFS01 - Compartment temperatures during fire loading: (a) North thermocouple tree; (b) South thermocouple tree. 


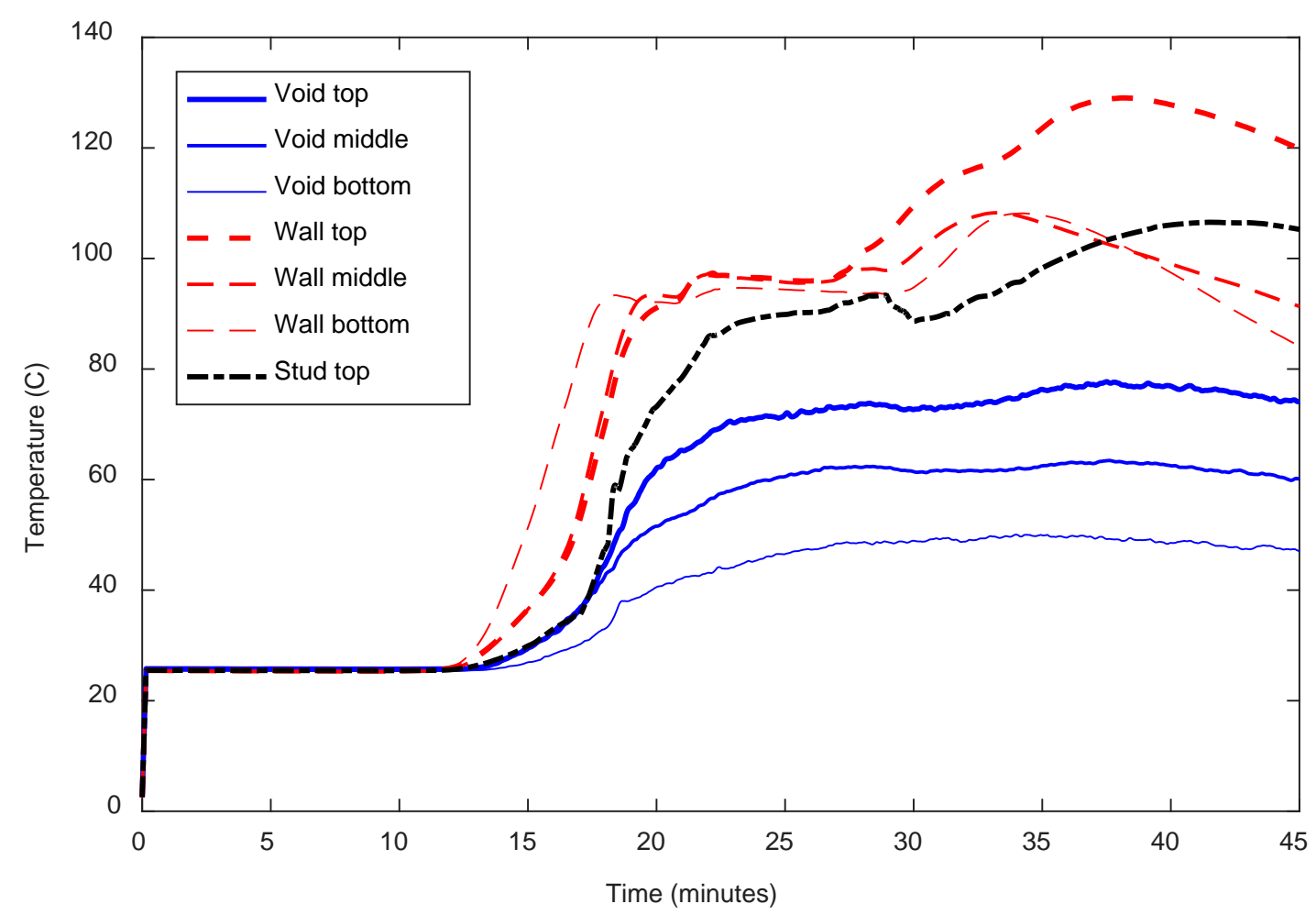

Figure 44: CFS01 - Specimen temperatures during fire loading.

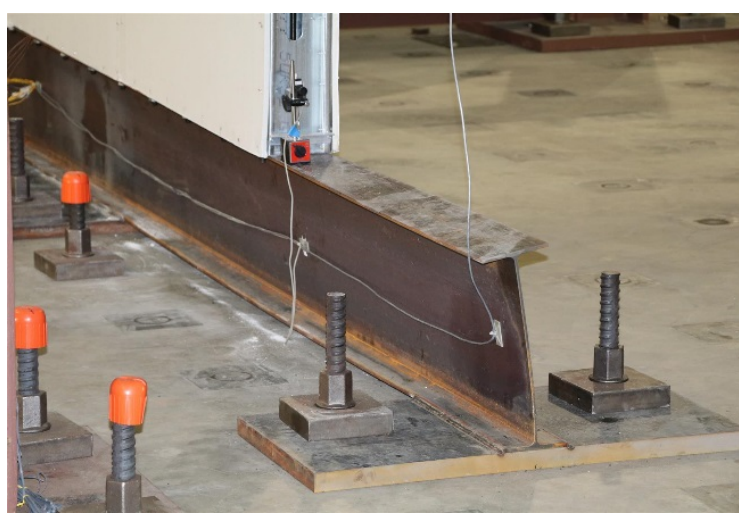

(a)

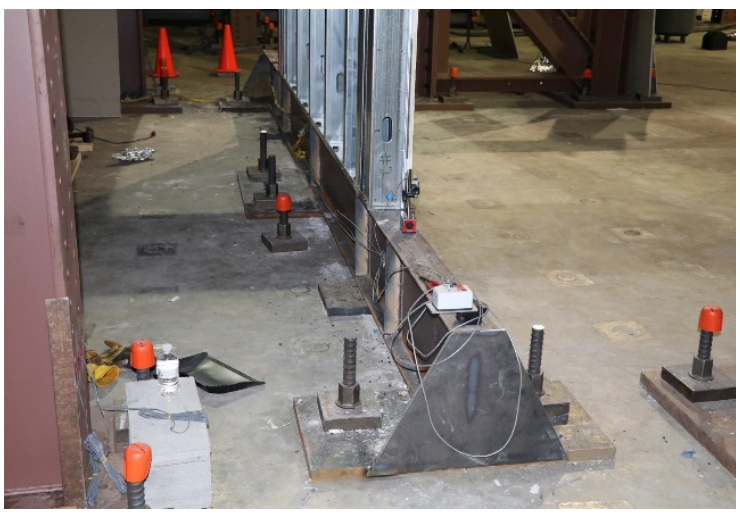

(b)

Figure 45: CFS01 - Photograph of bottom framing beam: (a) during test; (b) retrofit for all subsequent tests. 


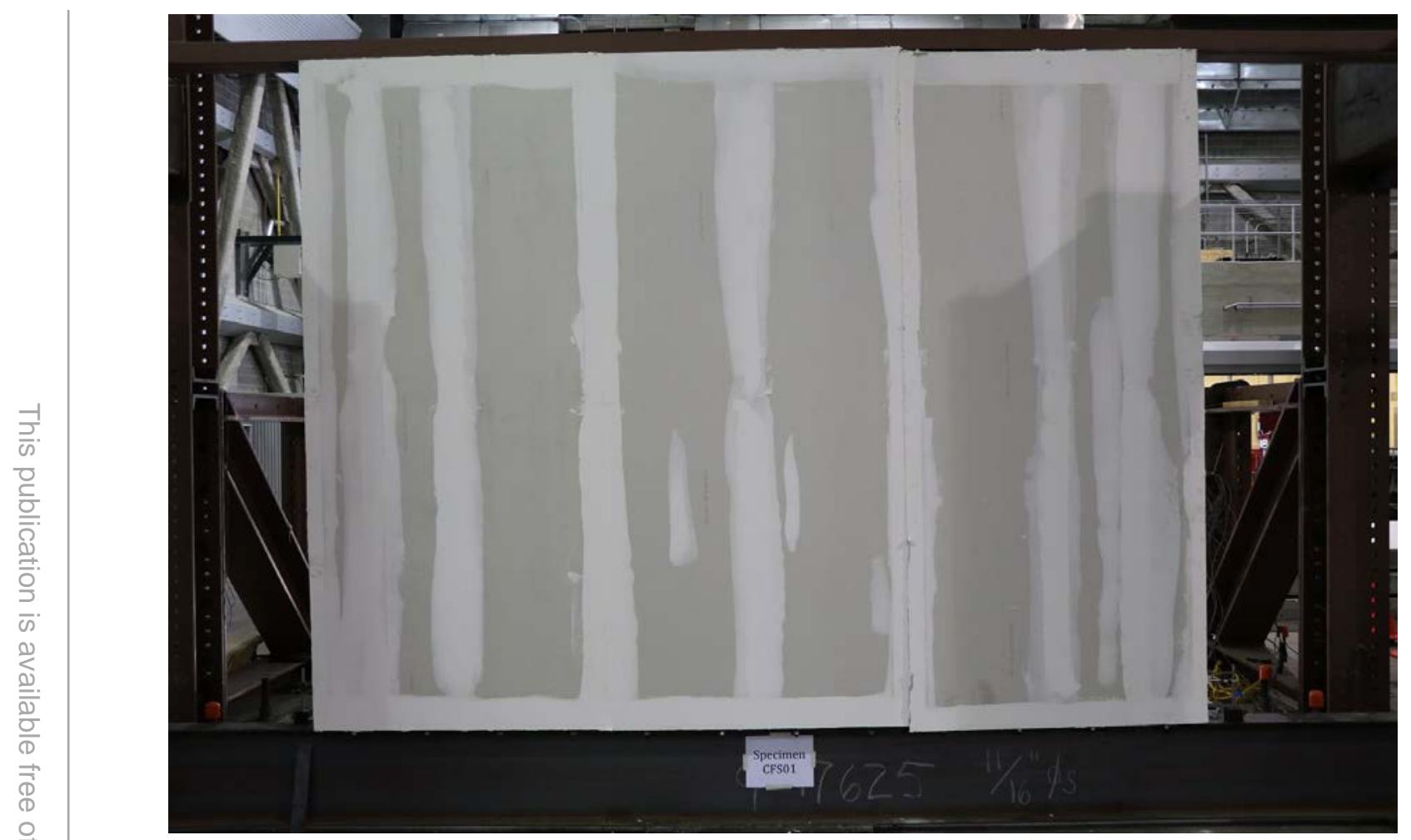

Figure 46: CFS01 - Photograph of metal sheathed side of wall after mechanical loading (CFS01a).

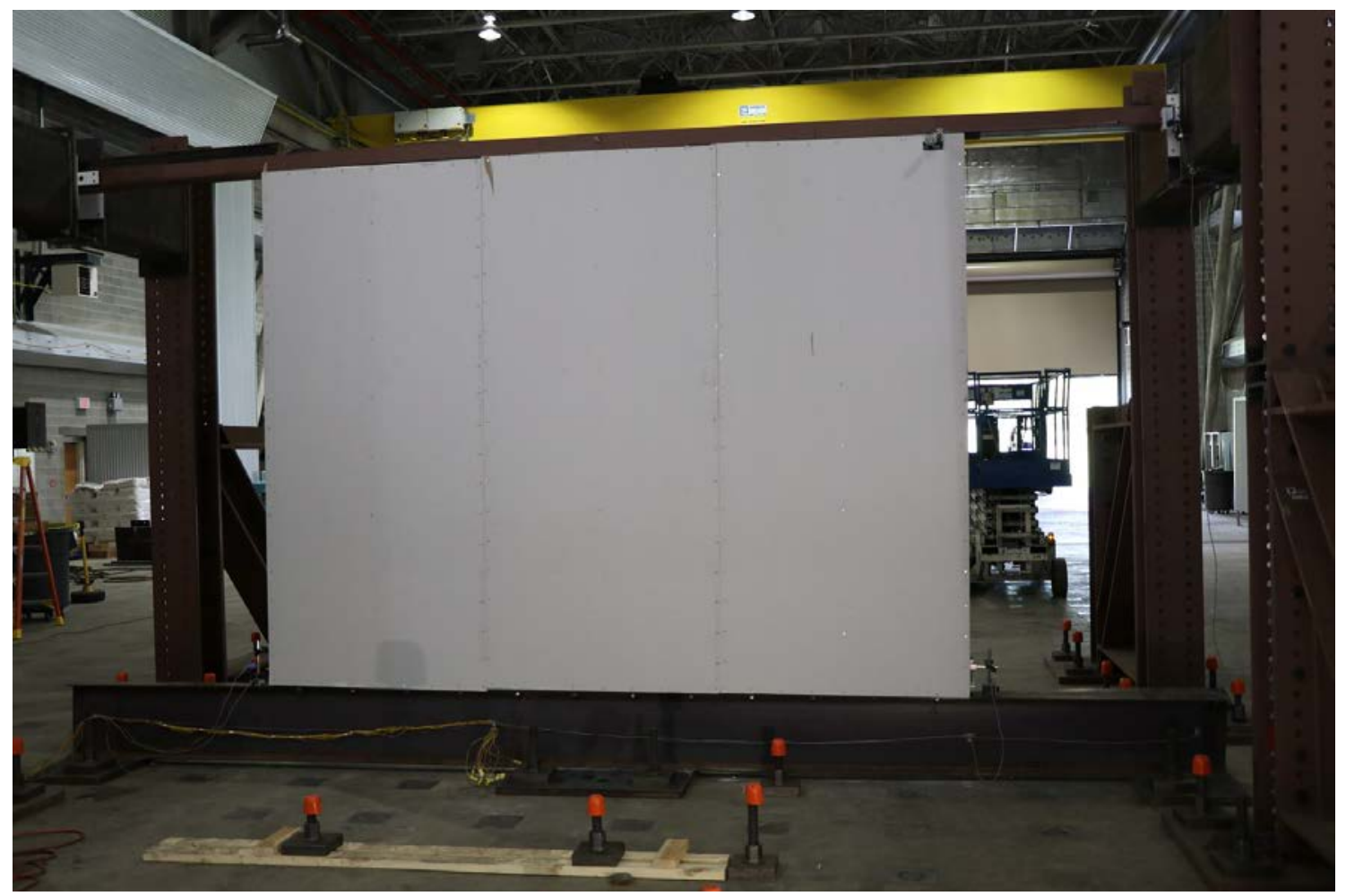

Figure 47: CFS01 - Photograph of gypsum sheathed side of wall after mechanical loading (CFS01a). 


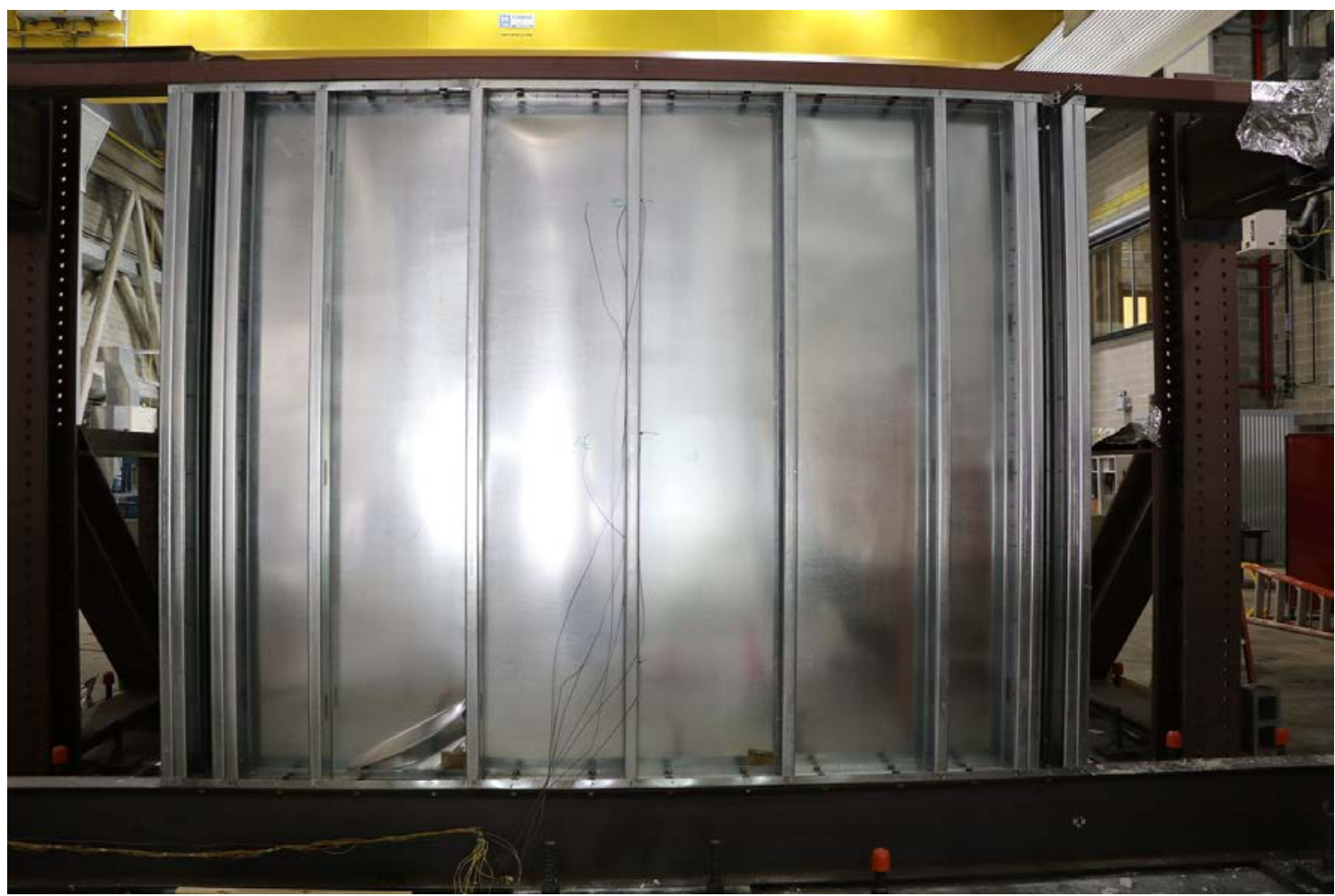

Figure 48: CFS01 - Photograph of back of metal sheathed side of wall after mechanical loading; nonstructural gypsum removed.

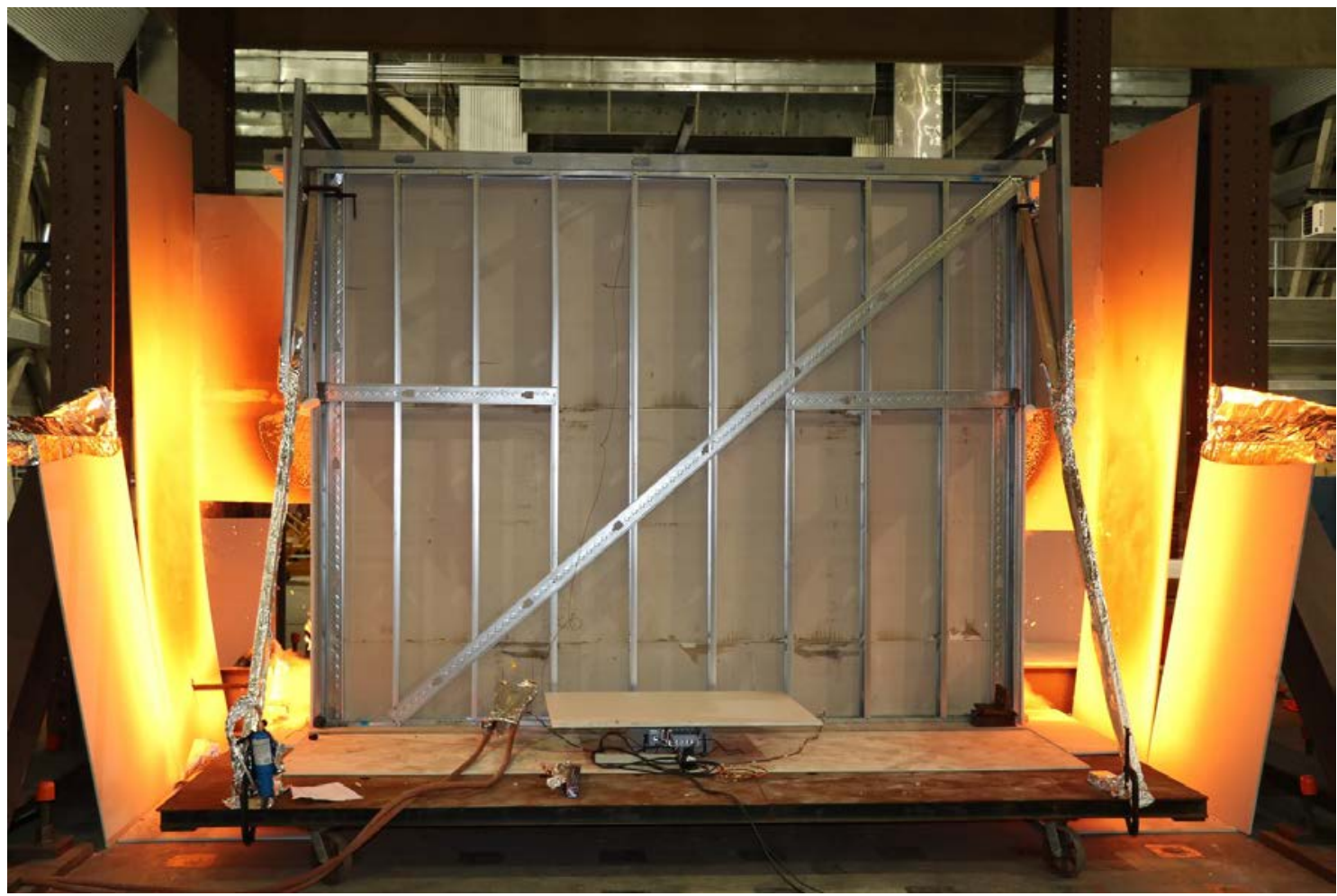

Figure 49: CFS01 - Photograph of back of compartment during fire loading (CFS01b). 


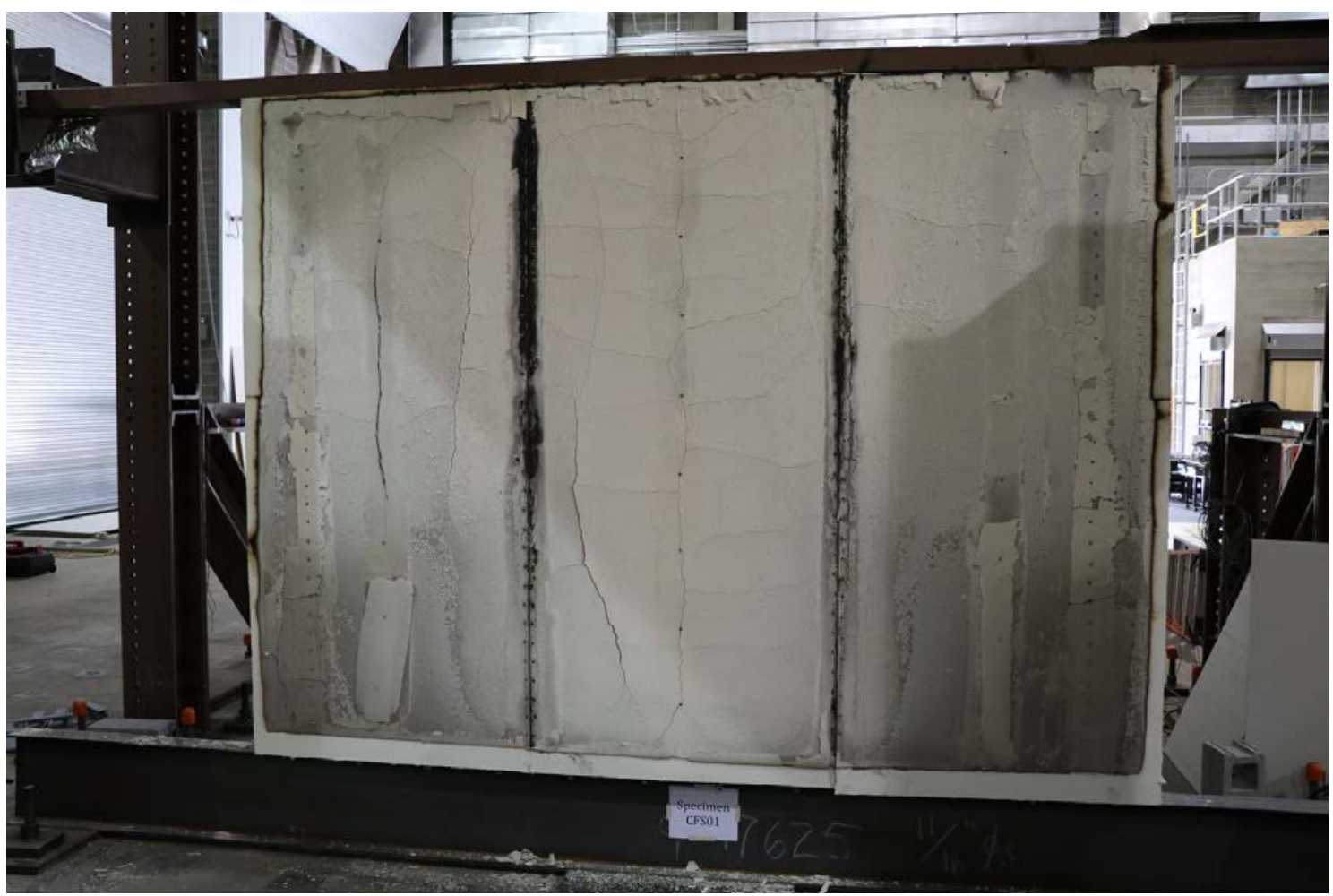

Figure 50: CFS01 - Photograph of metal sheathed side of wall after fire loading (CFS01b).

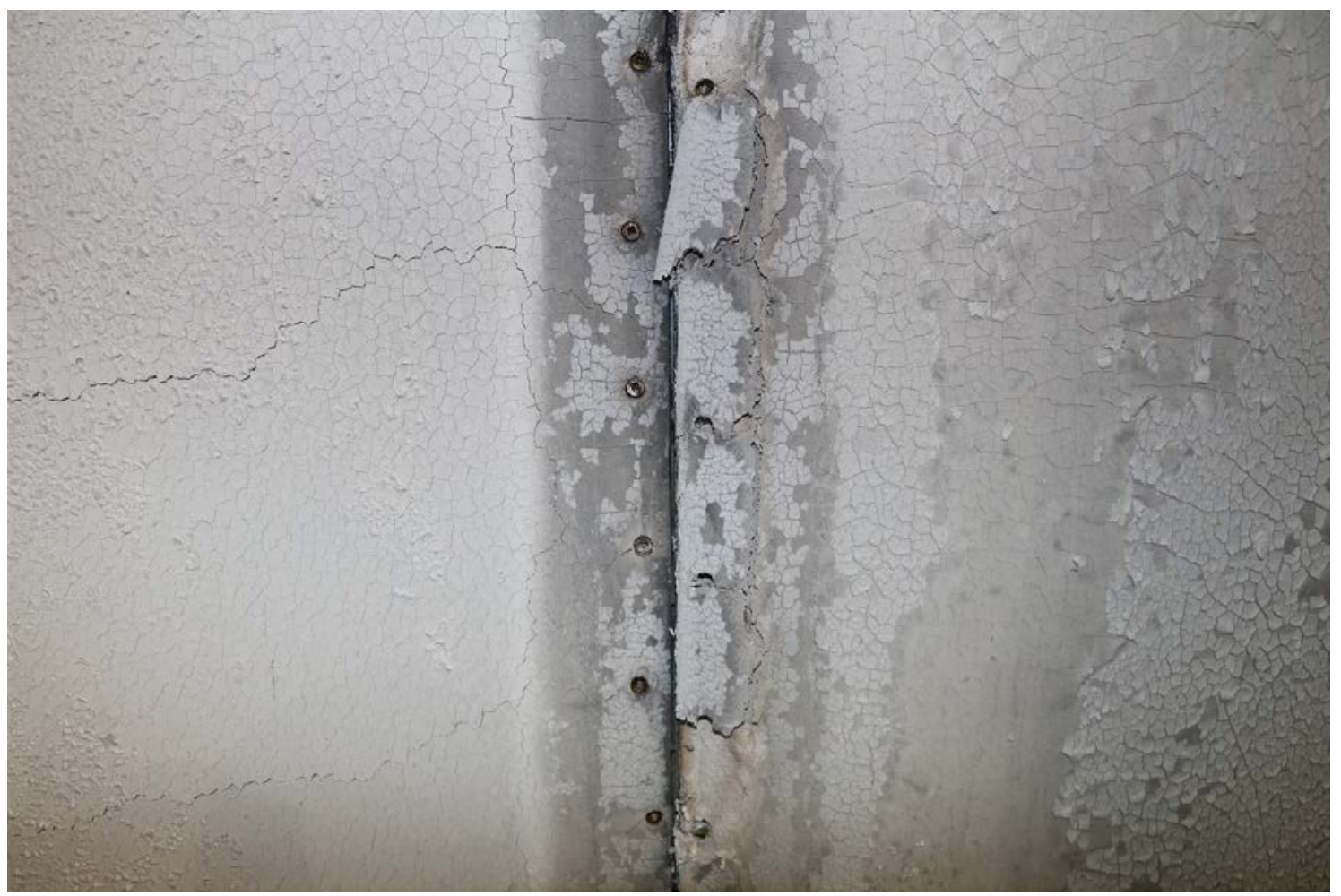

Figure 51: CFS01 - Photograph of joint detail of metal sheathed side of wall after fire loading (CFS01b). 


\section{Appendix D. CFS02 Test Data}

CFS02a:

- Stiffening of bottom framing beam (W16x26) resolved rolling problem observed in CFS01a. The top loading channel still flexed about \pm 1.5 in. (38 mm) which allows for vertical movement of top of wall that may not be representative of the six-story building. Damage to the specimen was only visible during post-peak cycling; localized to panel seams. Upon removal of nonstructural drywall following the test, local bucking of sheet steel at bottom of wall was observed; primarily on north most panel. Numerous screws sheared ( $>25 \%$ ) on nonstructural gypsum, however, no board fracture occurred.

- Uplift sensors were removed after 14 minutes to avoid damage to the sensors.

- Circles (squares) in the force versus drift figures indicate the peak compression (tension) load achieved at a given drift level.

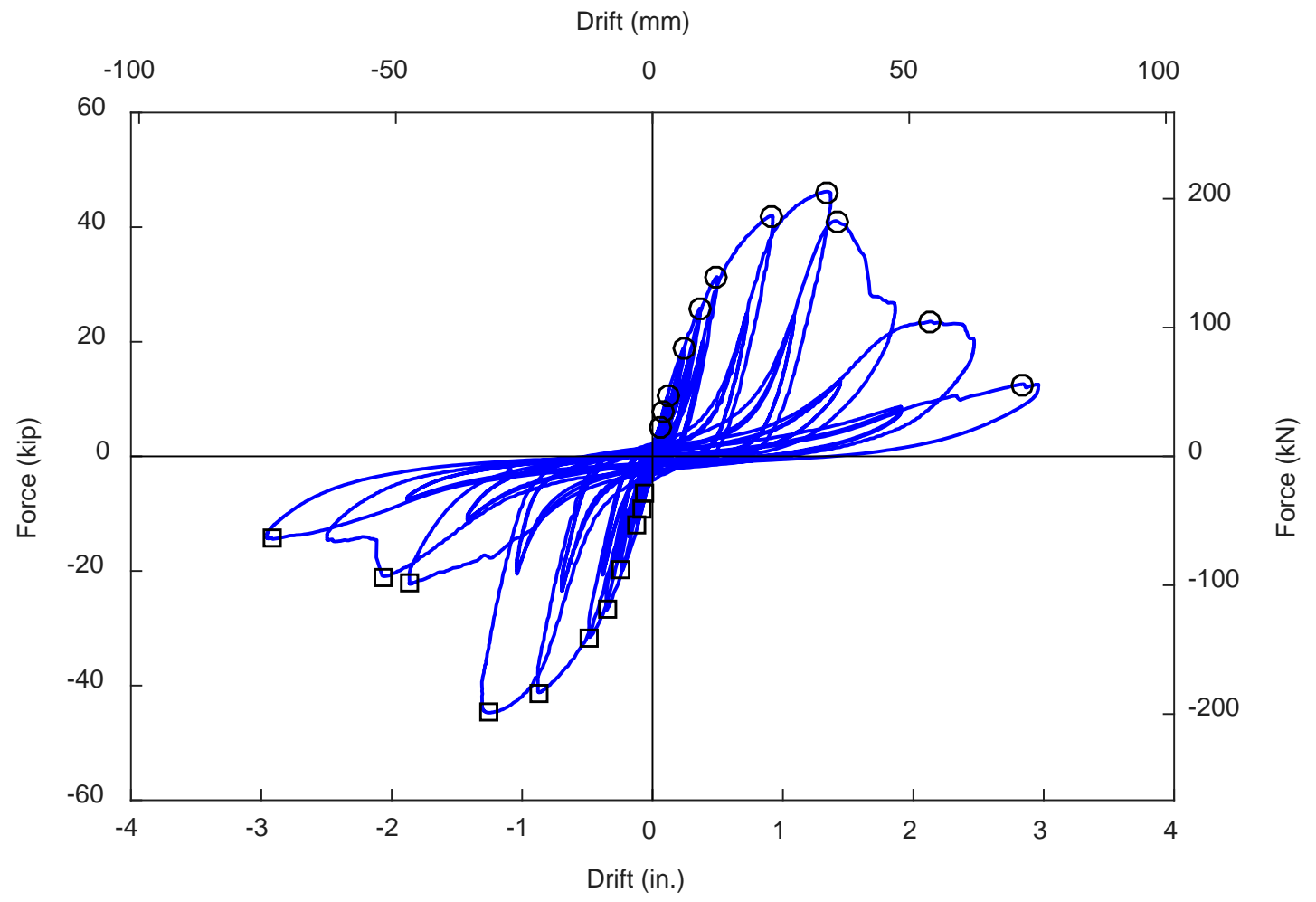

Figure 52: CFS02 - Lateral load (Actuator Force) versus drift (Disp_Longitudinal_SP) during mechanical loading. 


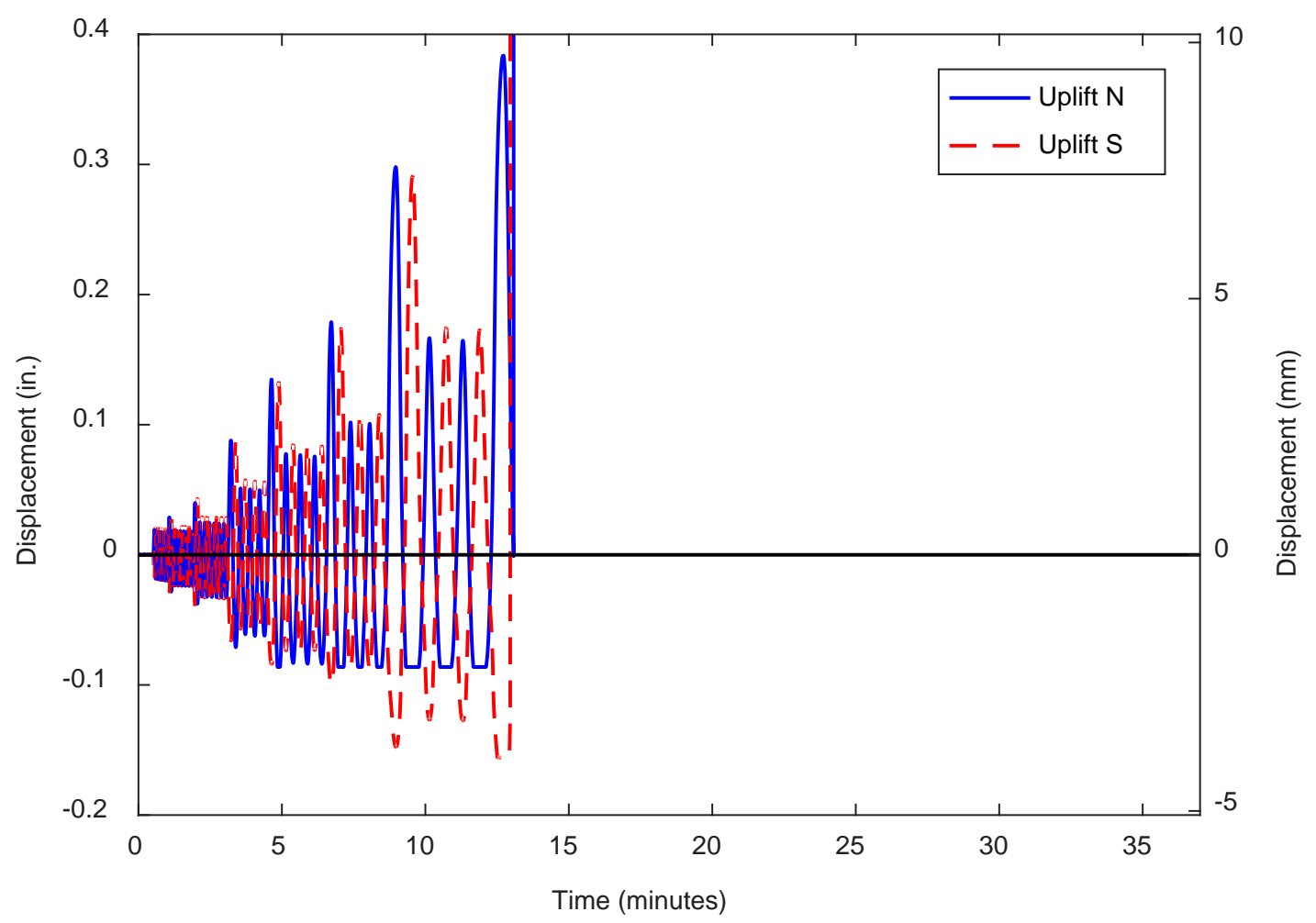

Figure 53: CFS02 - Uplift at bottom of specimen during mechanical loading.

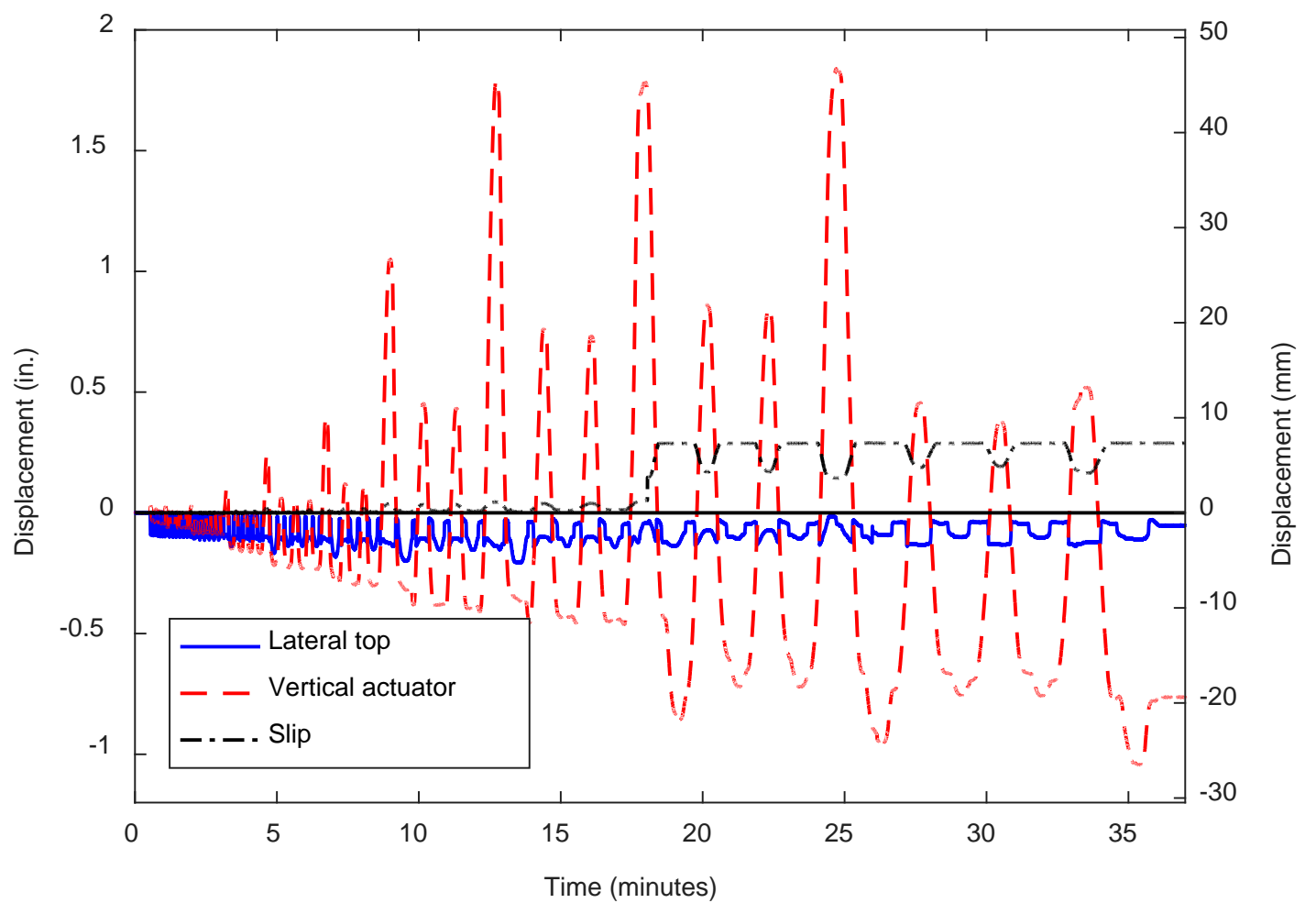

Figure 54: CFS02 - Ancillary displacement measurements during mechanical loading. 


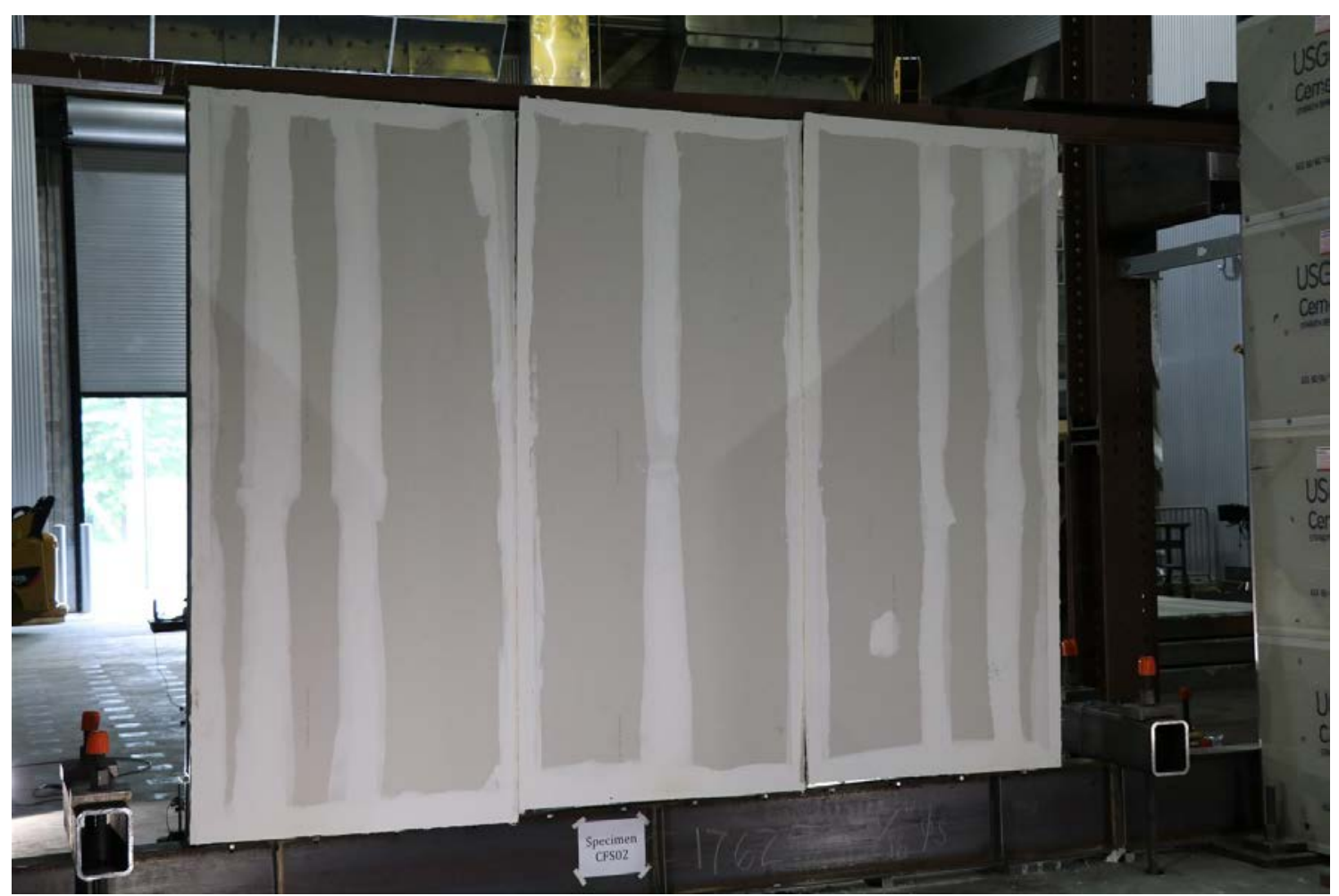

Figure 55: CFS02 - Photograph of metal sheathed side of wall after mechanical loading to $2.8 \%$ drift (CFS02a).

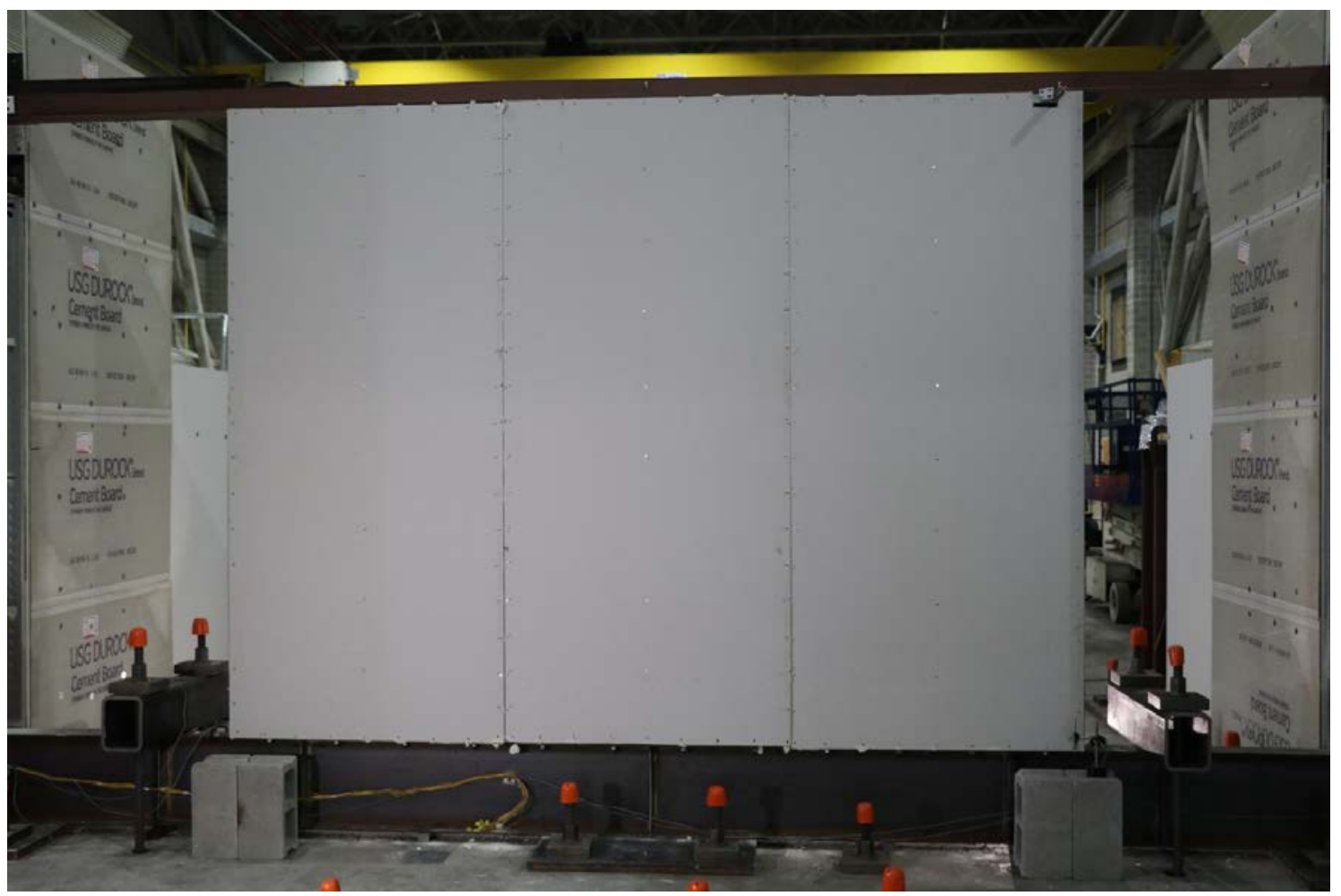

Figure 56: CFS02 - Photograph of gypsum sheathed side of wall after mechanical loading to $2.8 \%$ drift (CFS02a). 


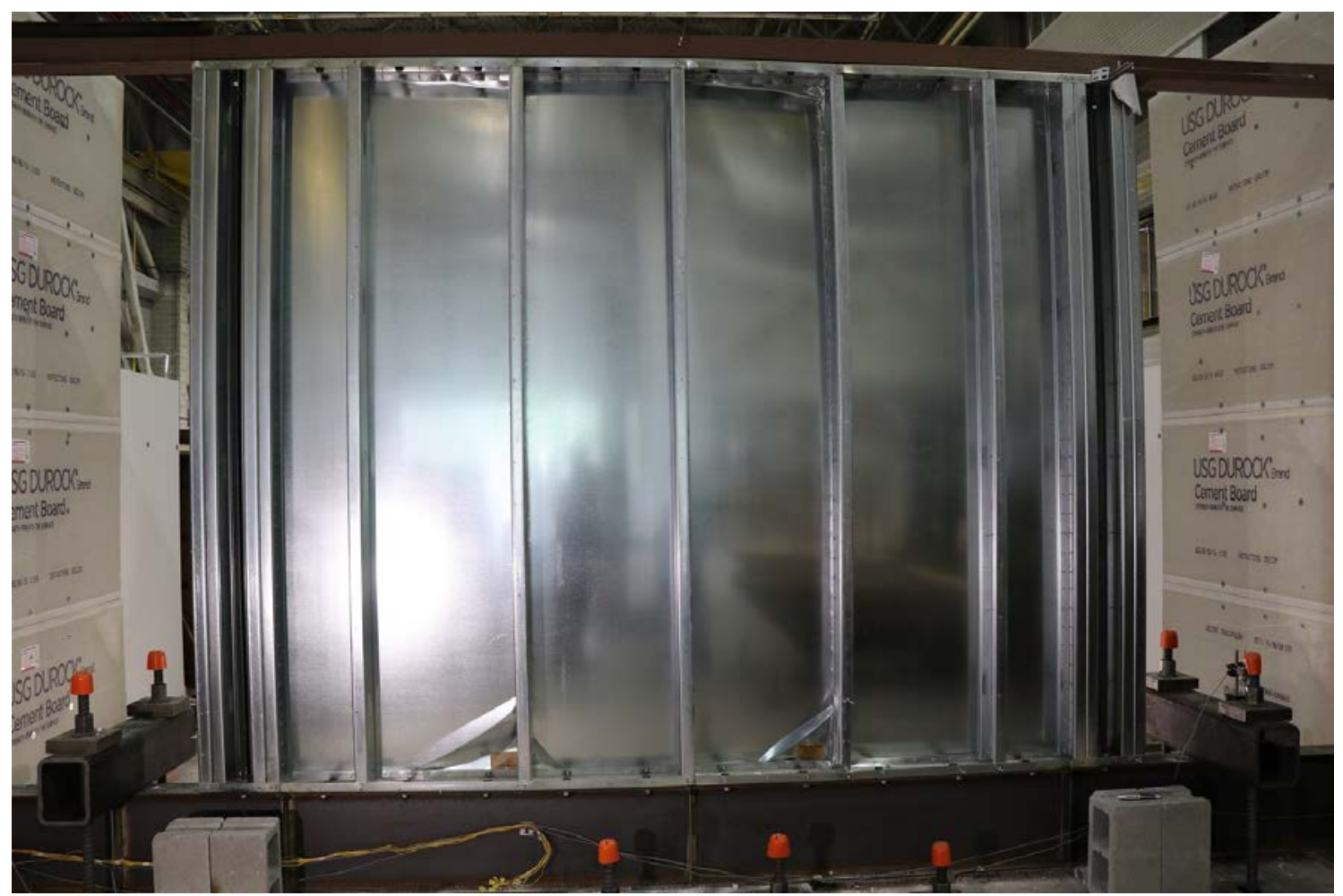

Figure 57: CFS02 - Photograph of back of metal sheathed side of wall after mechanical loading to $2.8 \%$ drift (CFS02a); nonstructural gypsum removed.

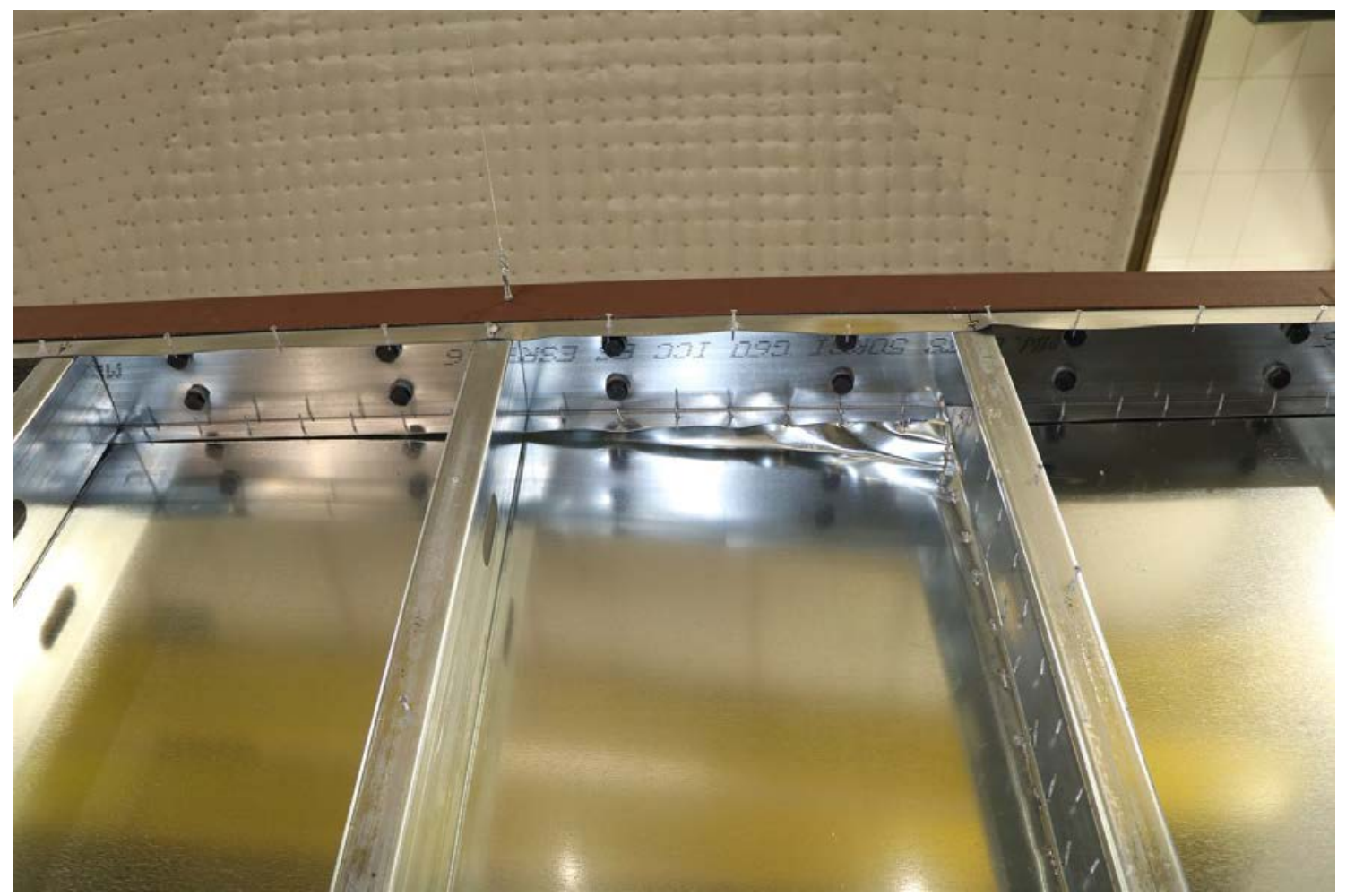

Figure 58: CFS02 - Photograph of back of metal sheathed side of wall after mechanical loading to $2.8 \%$ drift (CFS02a) highlighting corner damage. 


\section{Appendix E. CFS03 Test Data}

CFS03a:

- Damage was limited to tearing of joint compound and paper tape along seams.

\section{CFS03b:}

- $\quad$ Severe damage to drywall on compartment side observed during the fire test. Loss of adhesion of the drywall from sheet metal.

\section{CFS03c:}

- Added TC_WallMidStud and TC_WallBotStud to data acquisition program. They were not used in this test, but are present in this and all subsequent data files.

- Buckling of the sheet metal followed by tear out of the screws from the sheet metal.

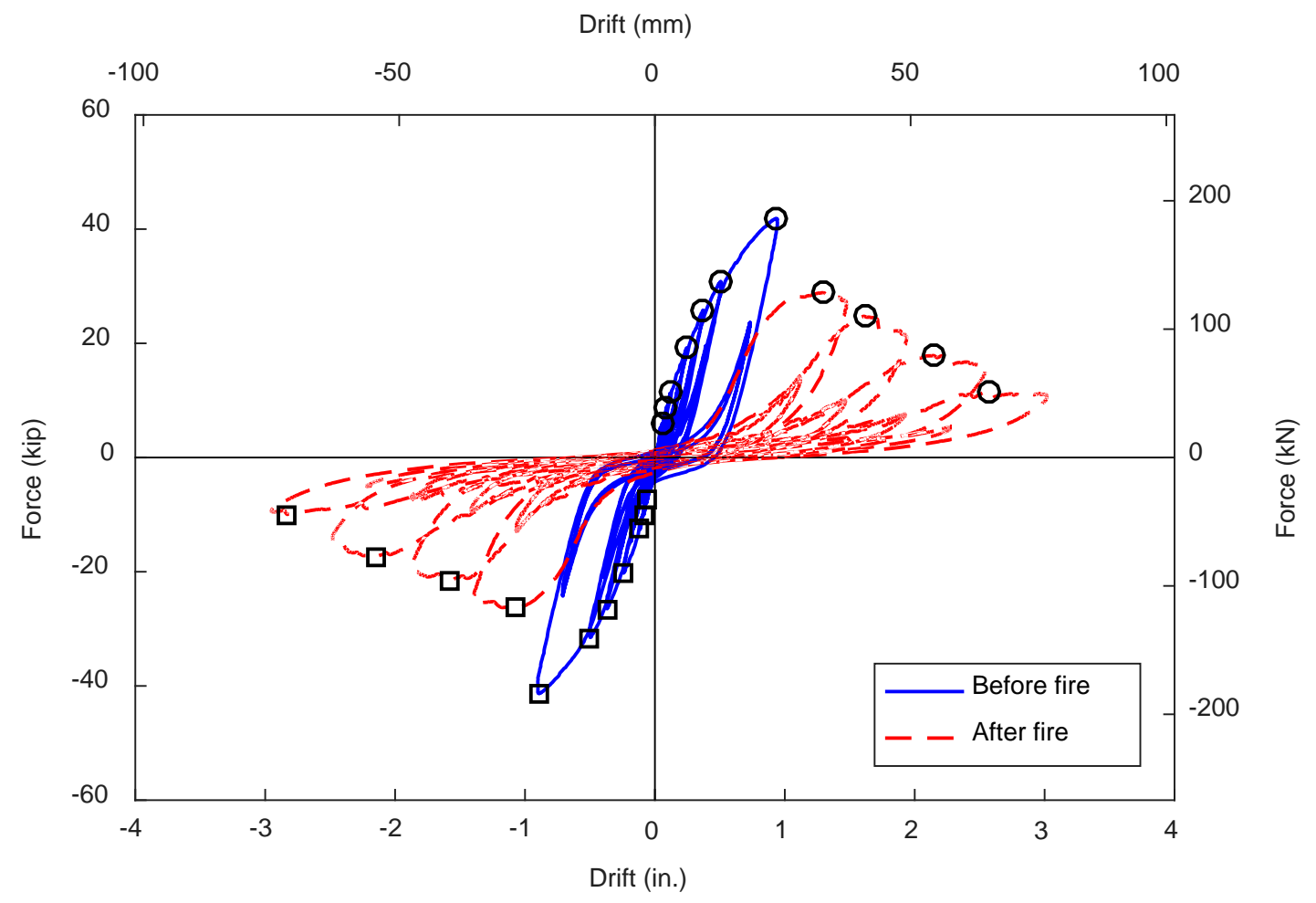

Figure 59: CFS03 - Lateral load (Actuator Force) versus drift (Disp_Longitudinal_SP) during mechanical loading. 


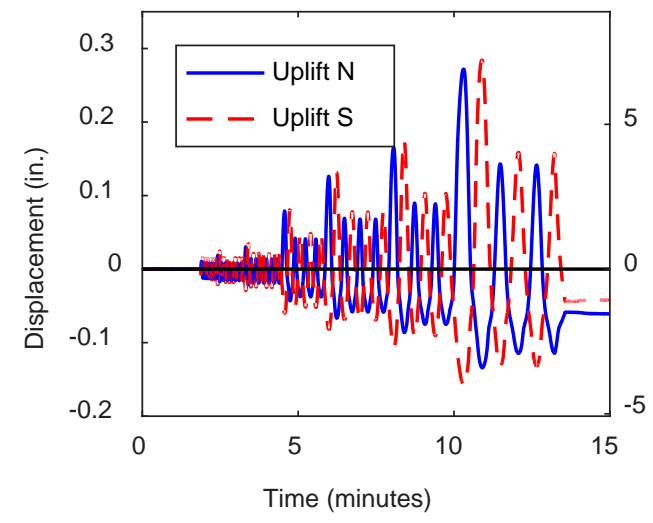

(a)

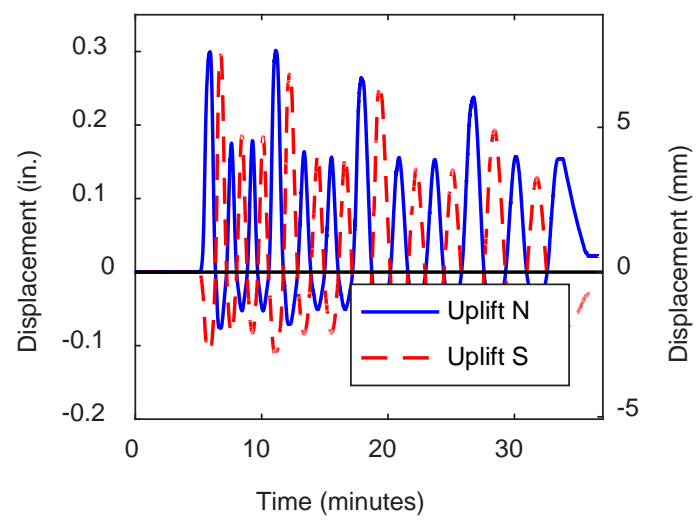

(b)

Figure 60: CFS03 - Uplift at bottom of specimen during mechanical loading: (a) Before fire; (b) After fire.

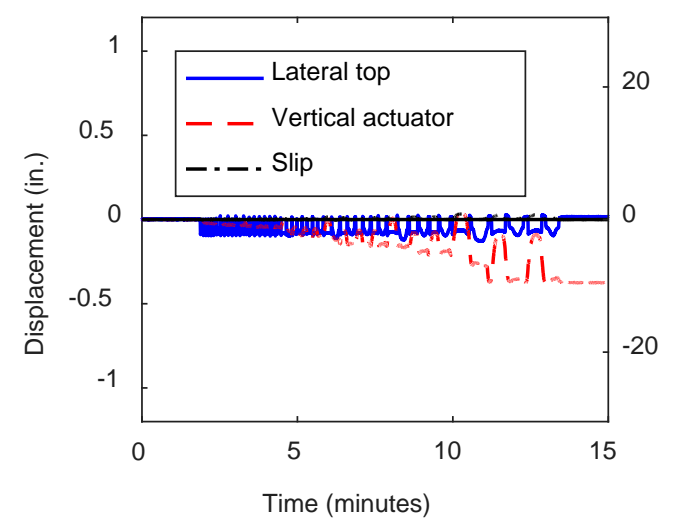

(a)

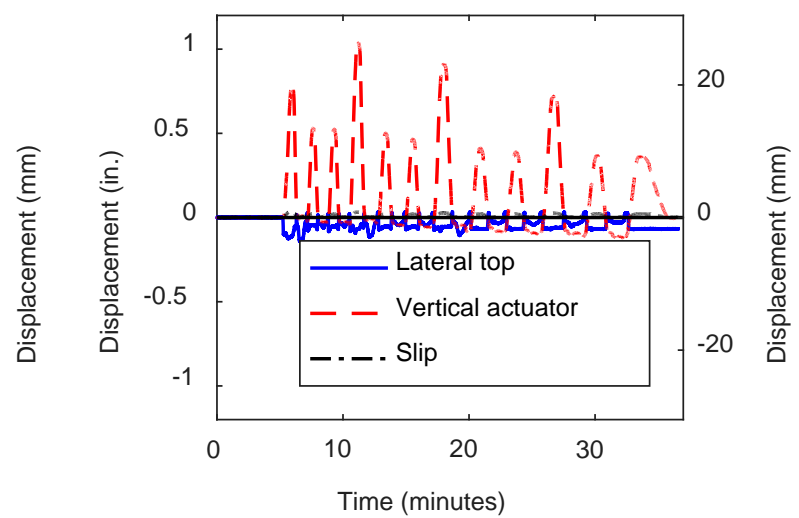

(b)

Figure 61: CFS03 - Ancillary displacement measurements during mechanical loading: (a) Before fire; (b) After fire. 


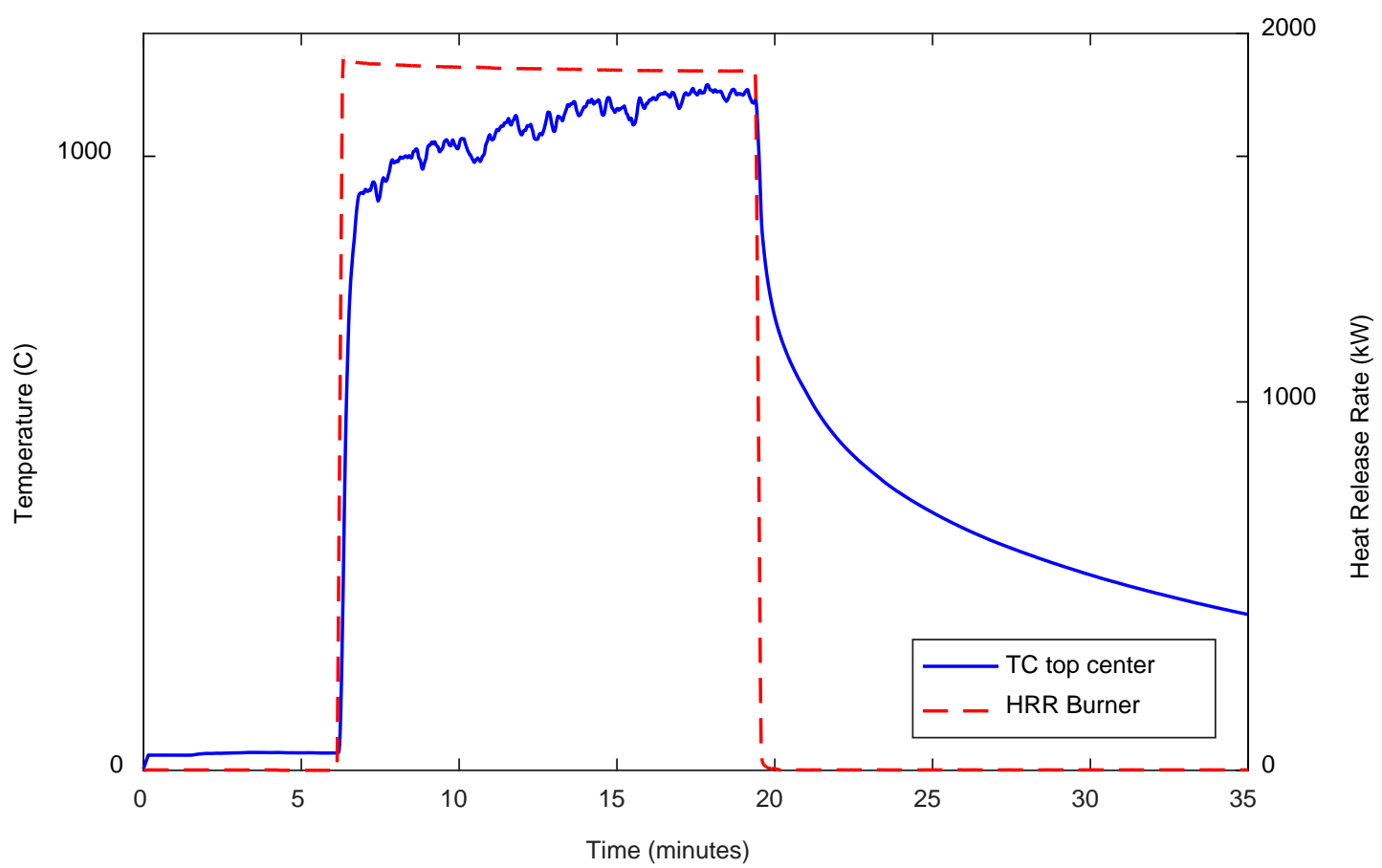

Figure 62: CFS03 - Burner heat release rate and upper layer temperature during fire loading.

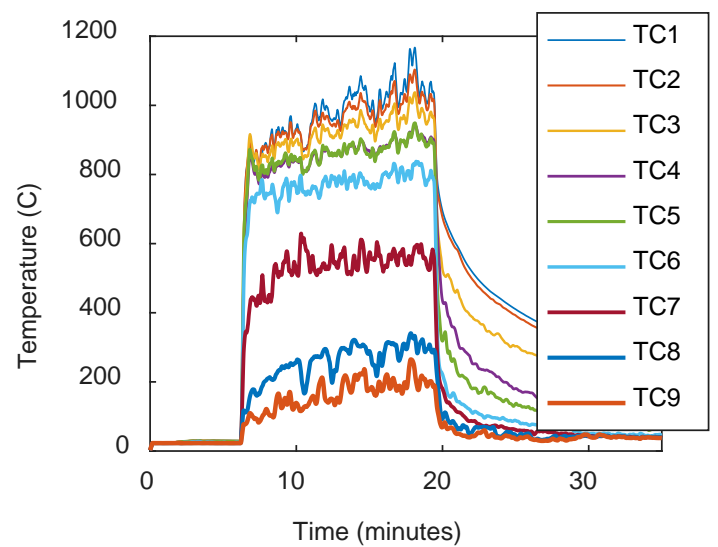

(a)

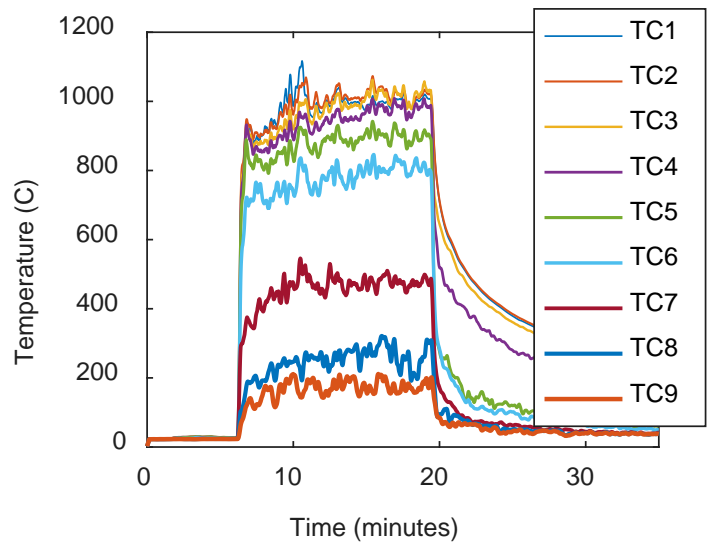

(b)

Figure 63: CFS03 - Compartment temperatures during fire loading: (a) North thermocouple tree; (b) South thermocouple tree. 


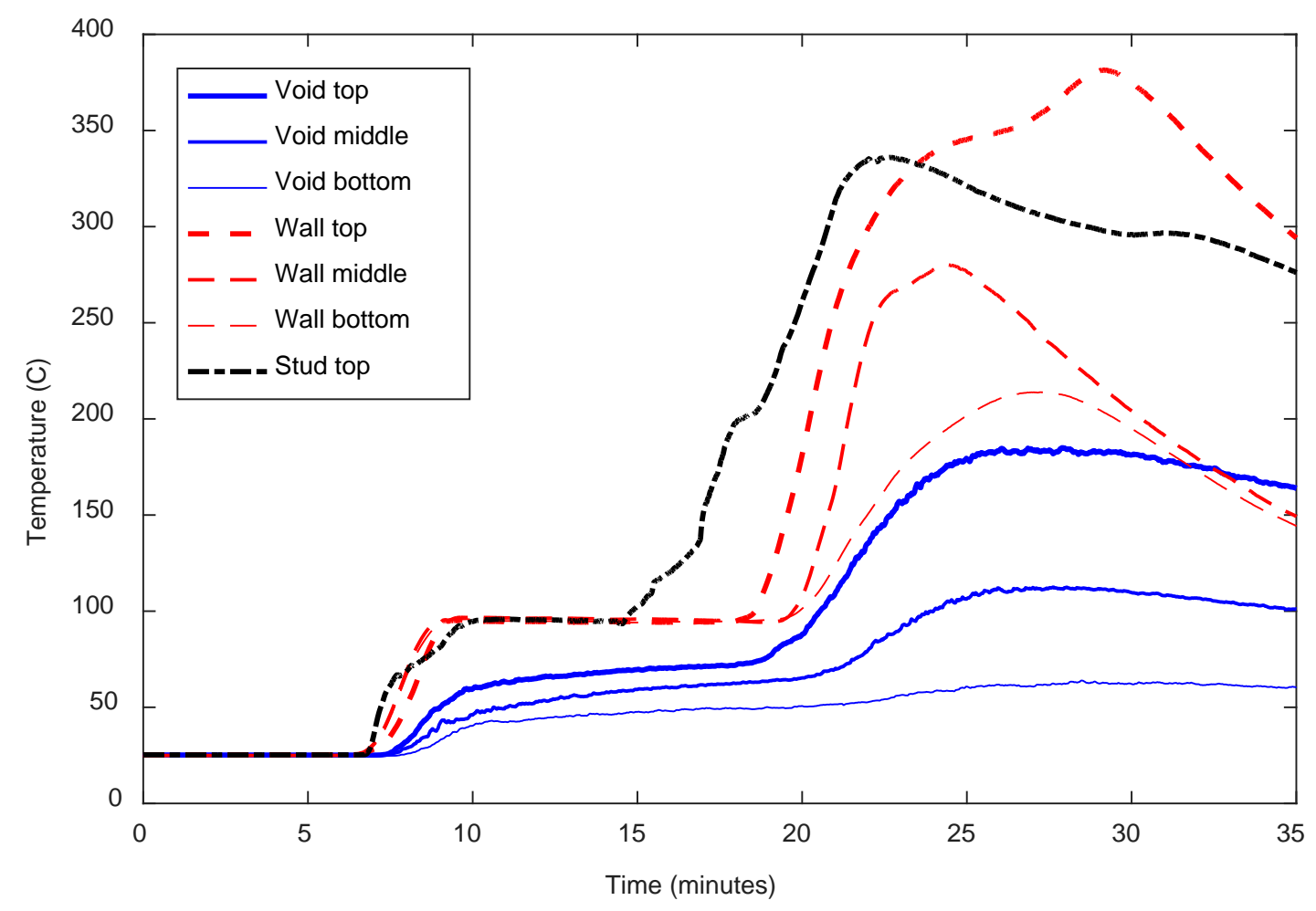

Figure 64: CFS03 - Specimen temperatures during fire loading.

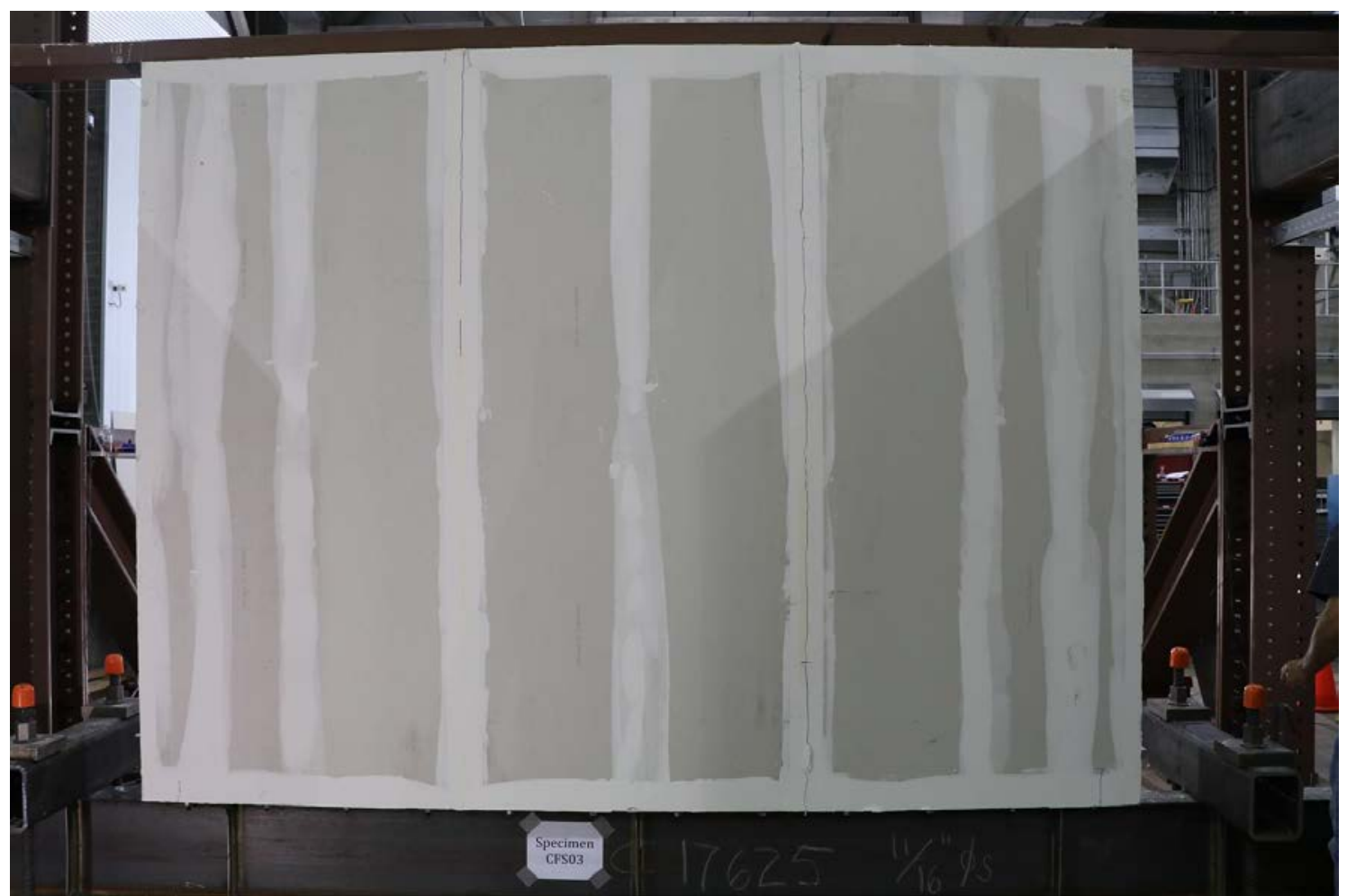

Figure 65: CFS03 - Photograph of metal sheathed side of wall after mechanical loading to $1.0 \%$ drift (CFS03a). 


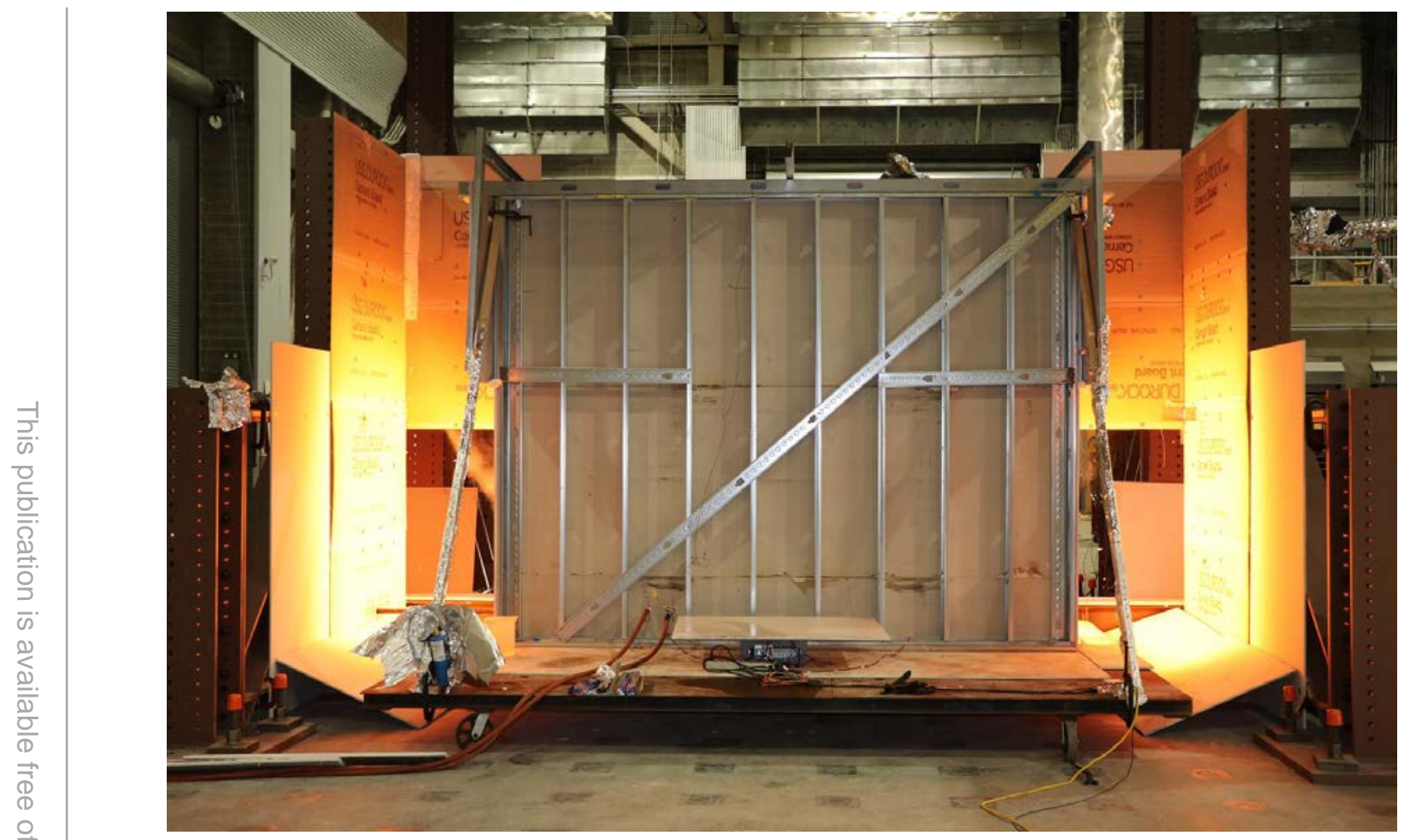

Figure 66: CFS03 - Photograph of back of compartment with redesigned fire protection for reaction frames during fire loading (CFS03b).

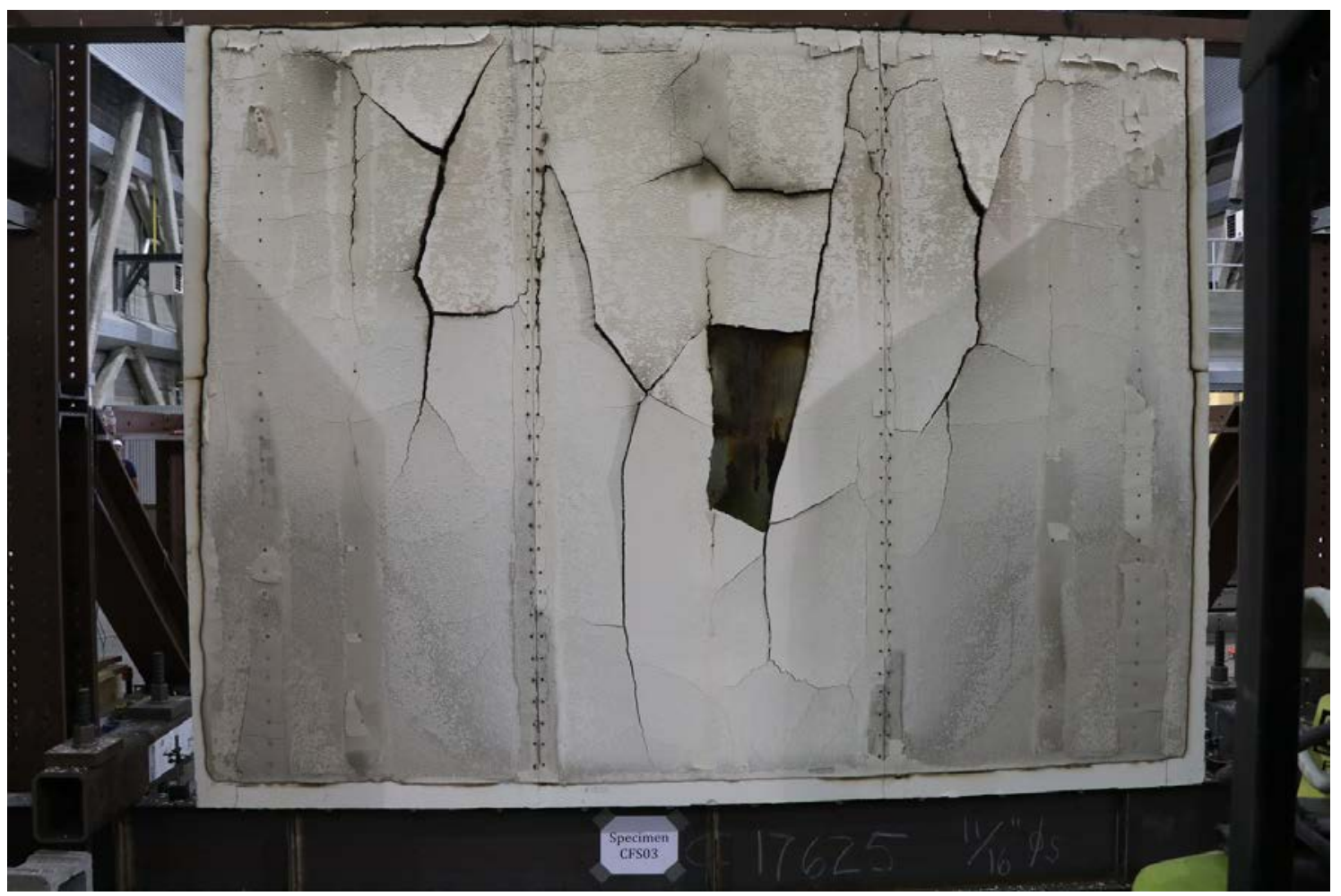

Figure 67: CFS03 - Photograph of metal sheathed side of wall after fire loading (CFS03b). 


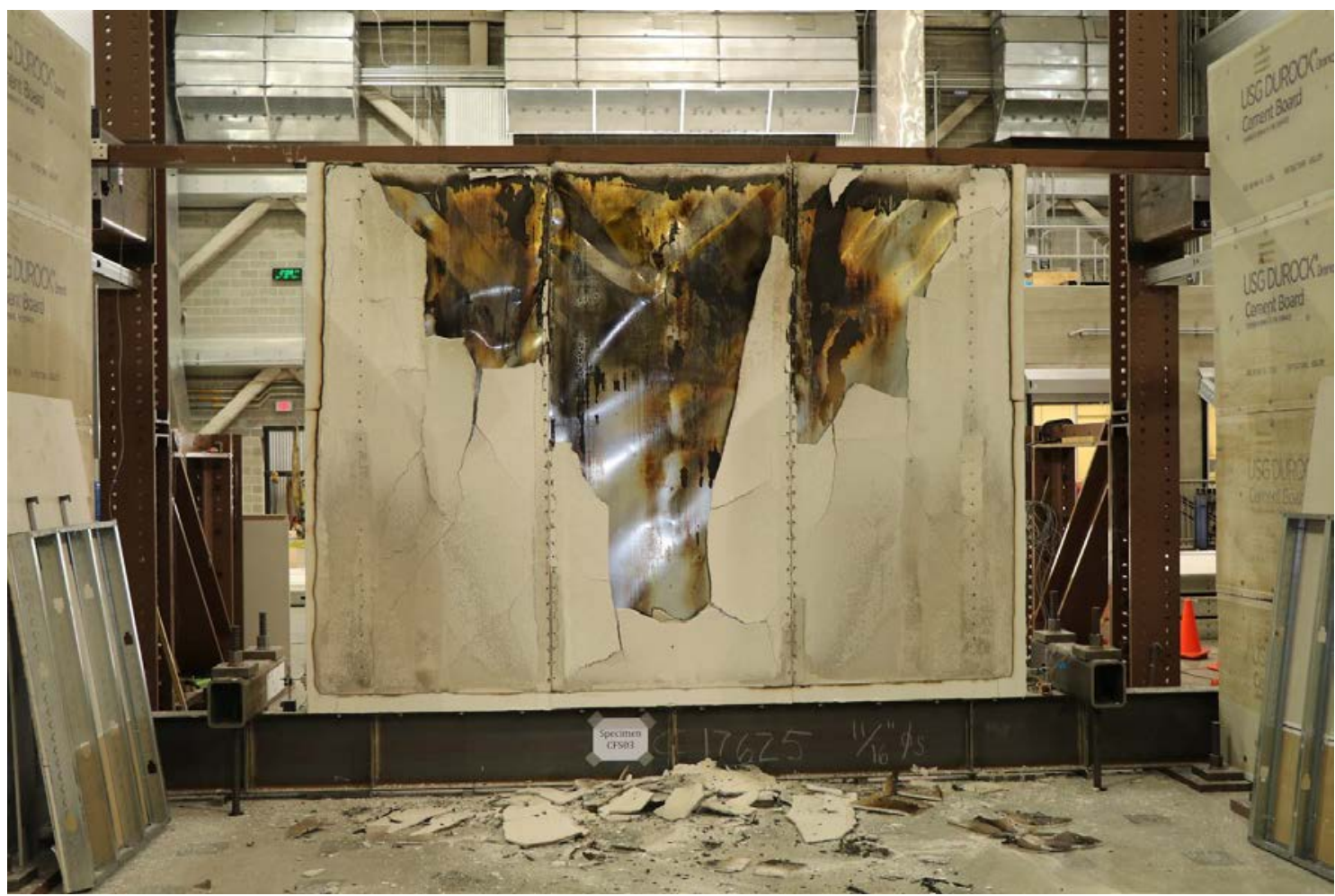

Figure 68: CFS03 - Photograph of metal sheathed side of the burned wall after mechanical loading to $2.8 \%$ drift (CFS03c).

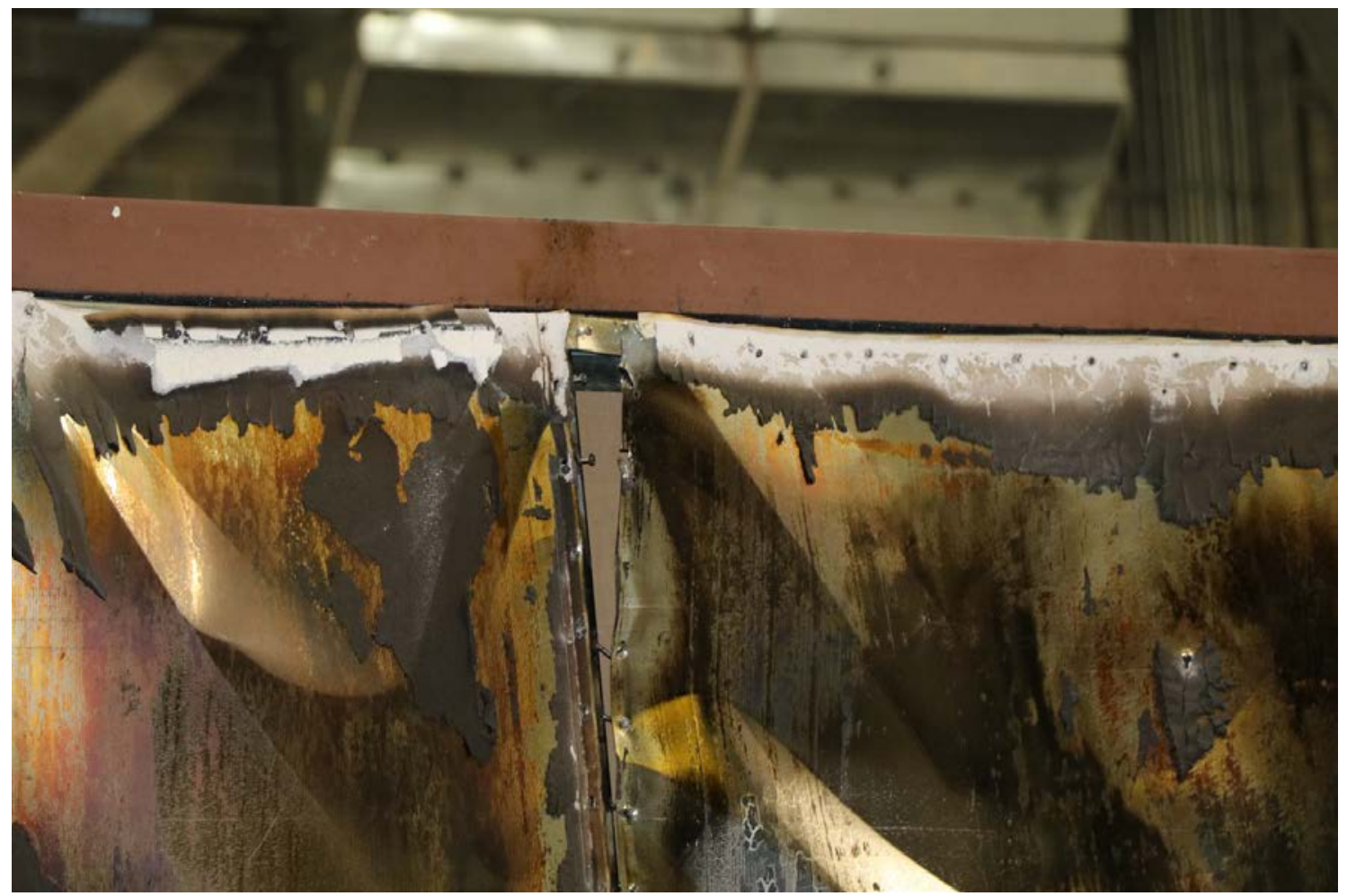

Figure 69: CFS03 - Photograph of metal sheathed side of the burned wall after mechanical loading to $2.8 \%$ drift (CFS03c) highlighting tearing of sheet metal. 


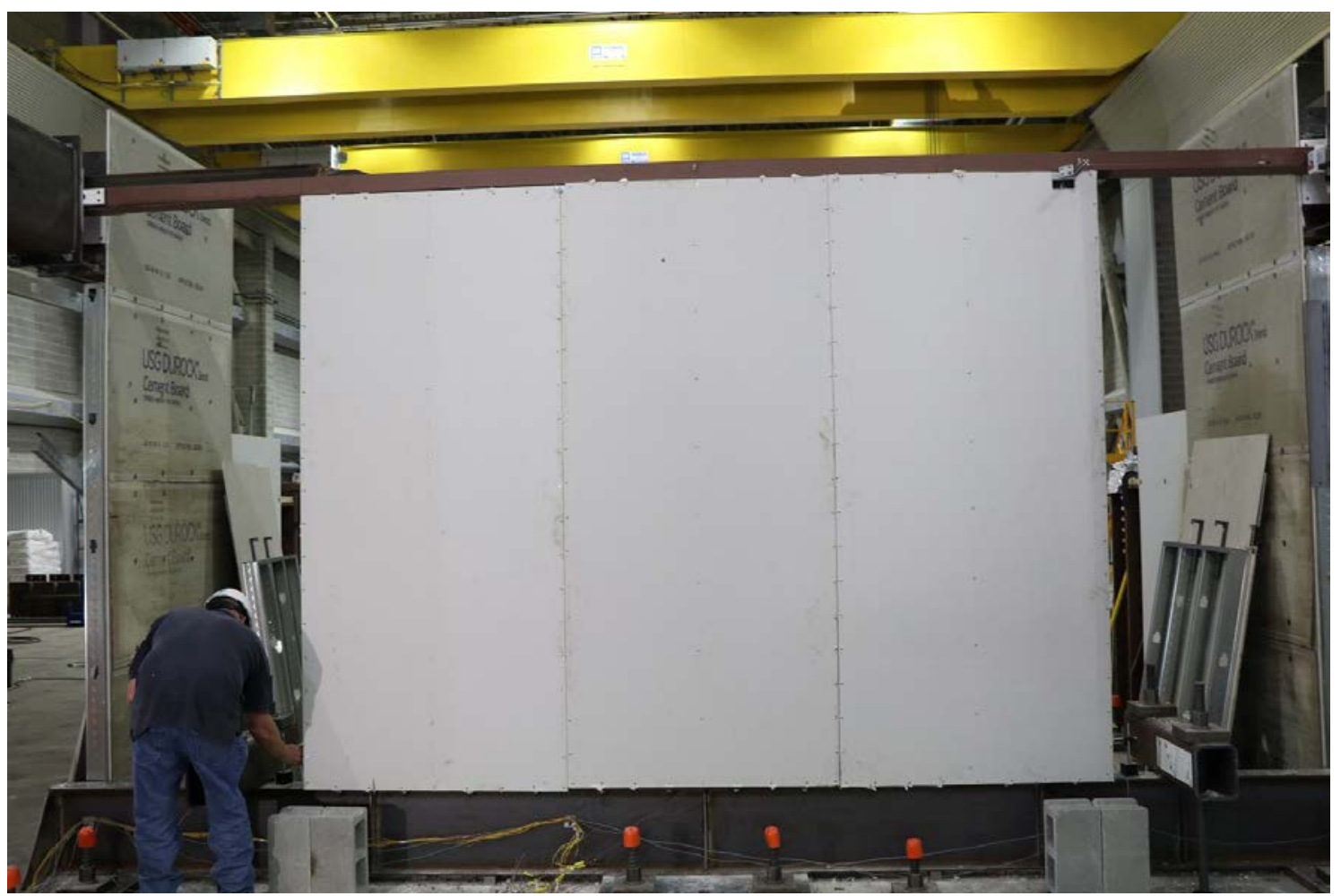

Figure 70: CFS03 - Photograph of gypsum sheathed side of wall after mechanical loading to $2.8 \%$ drift (CFS03c).

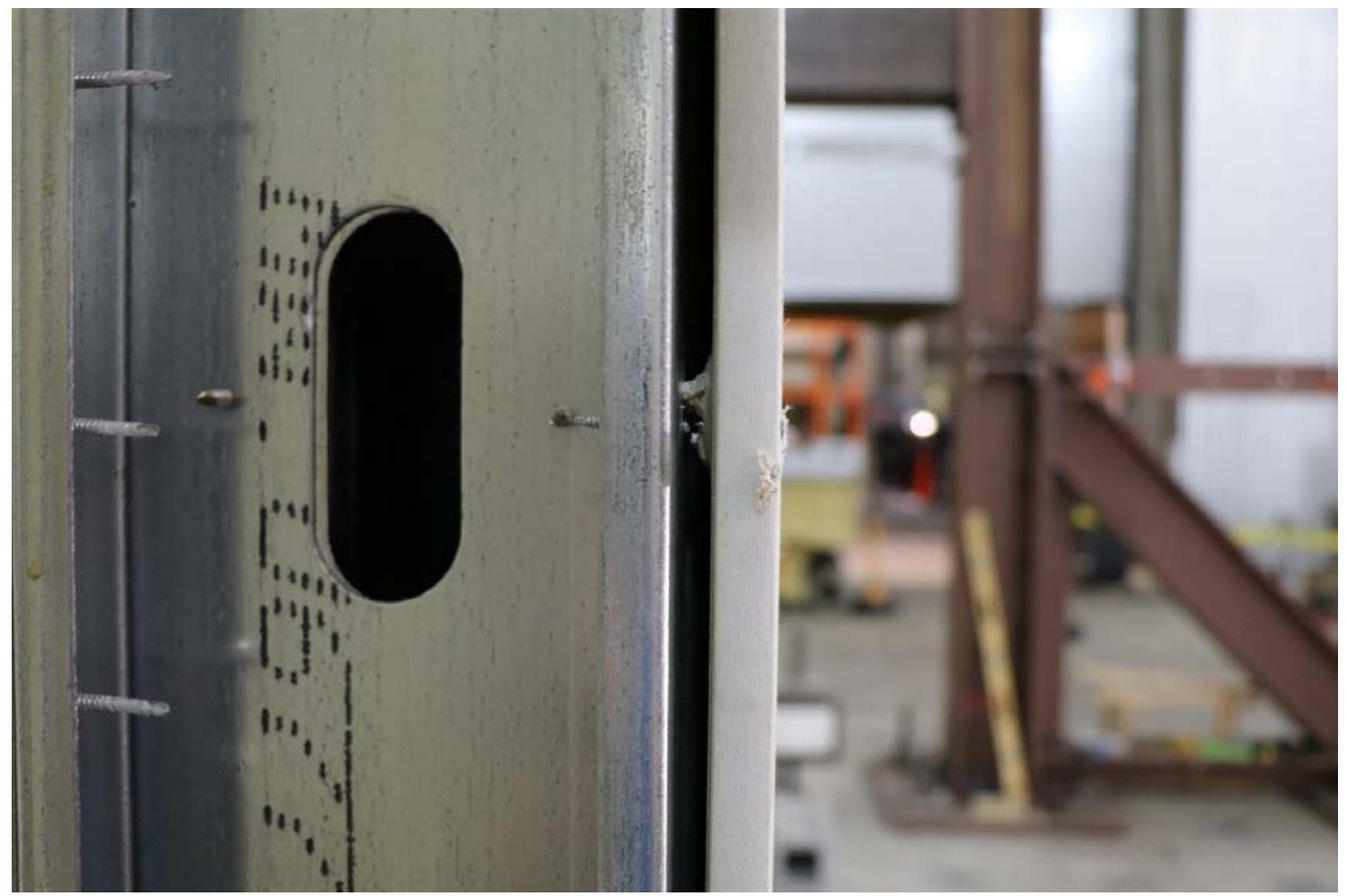

Figure 71: CFS03 - Photograph of gypsum sheathed side of wall after mechanical loading to $2.8 \%$ drift (CFS03c) highlighting screw shearing. 


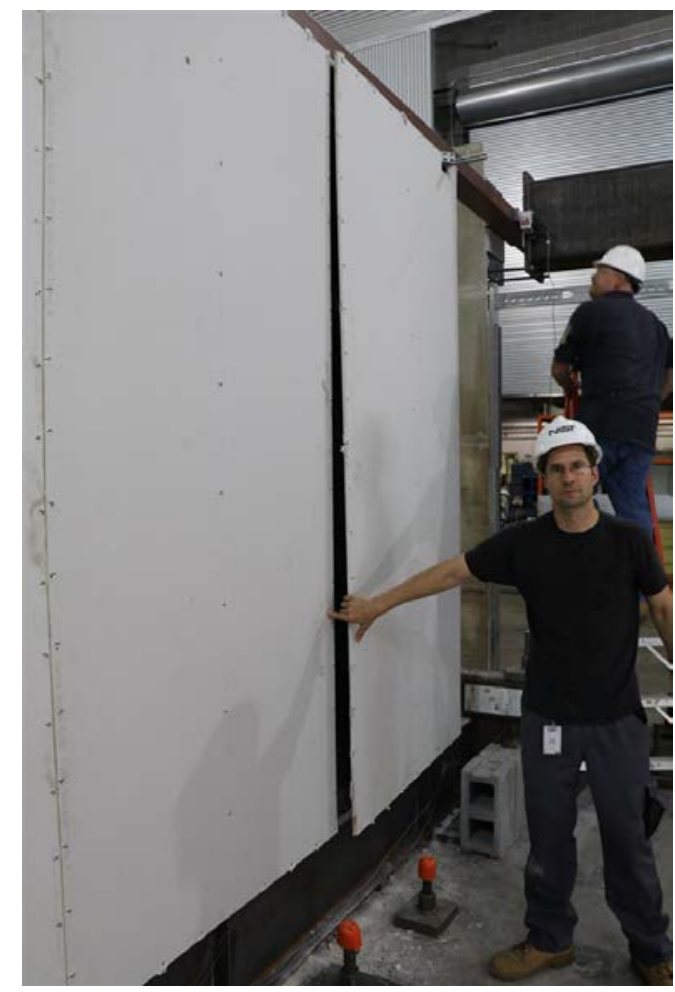

Figure 72: CFS03 - Photograph of gypsum sheathed side of wall after mechanical loading to $2.8 \%$ drift (CFS03c) highlighting board detachment.

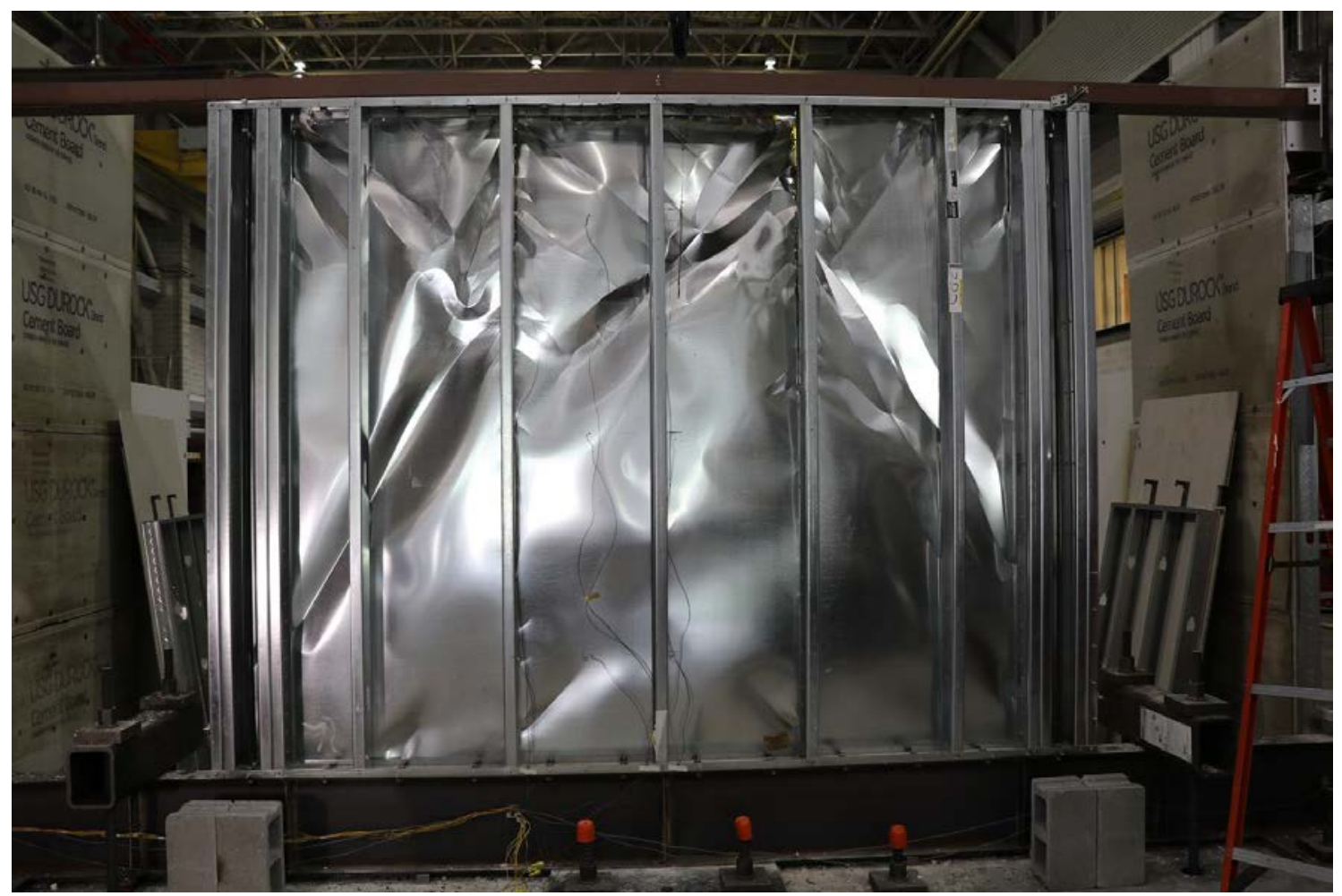

Figure 73: CFS03 - Photograph of back of metal sheathed side of the burned wall after mechanical loading to $2.8 \%$ drift (CFS03c); nonstructural gypsum removed 


\section{Appendix F. CFS04 Test Data}

CFS04a:

- No comments.

\section{CFS04b:}

- No comments.

CFS04c:

- No comments.

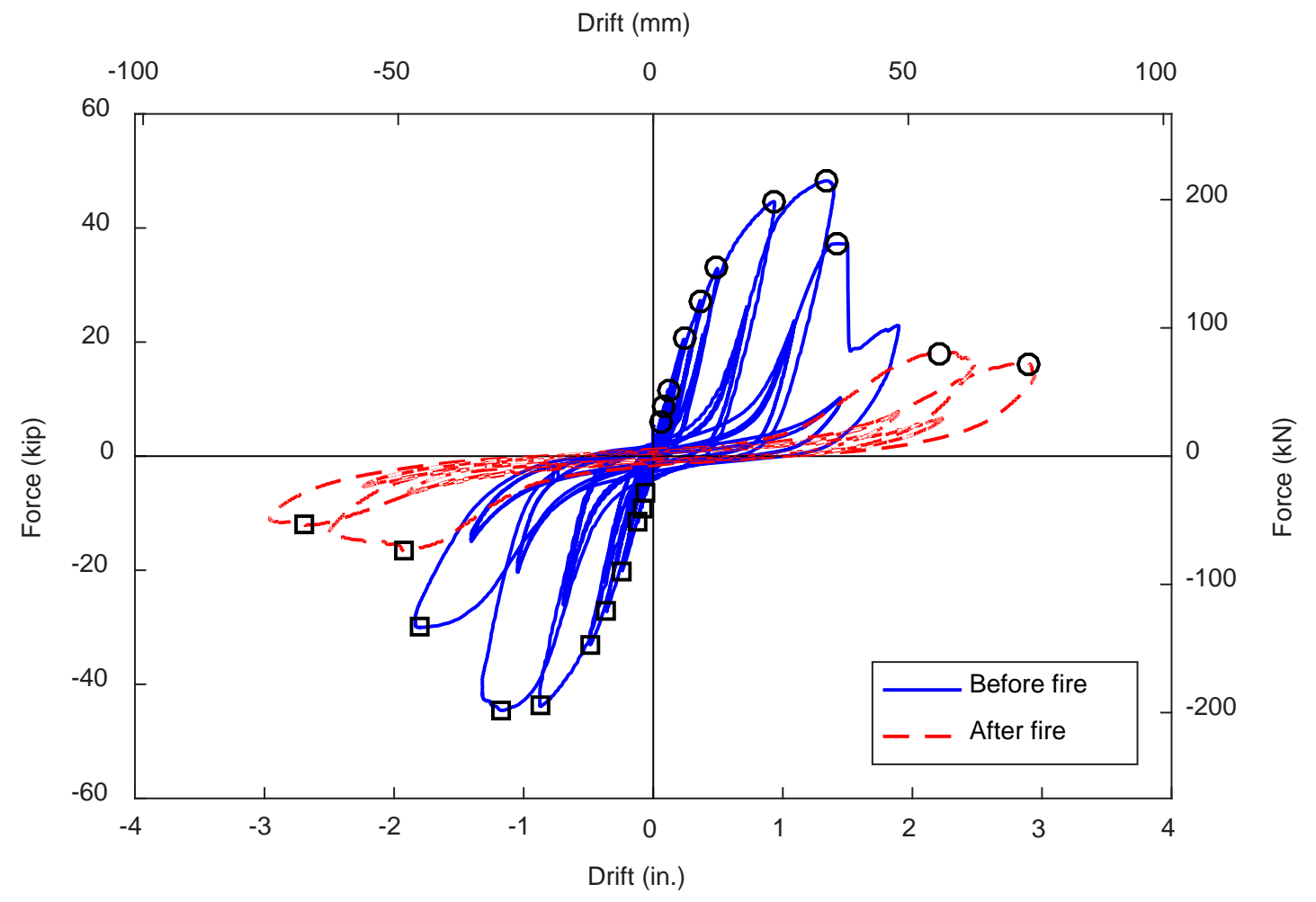

Figure 74: CFS04 - Lateral load (Actuator Force) versus drift (Disp_Longitudinal_SP) during mechanical loading. 


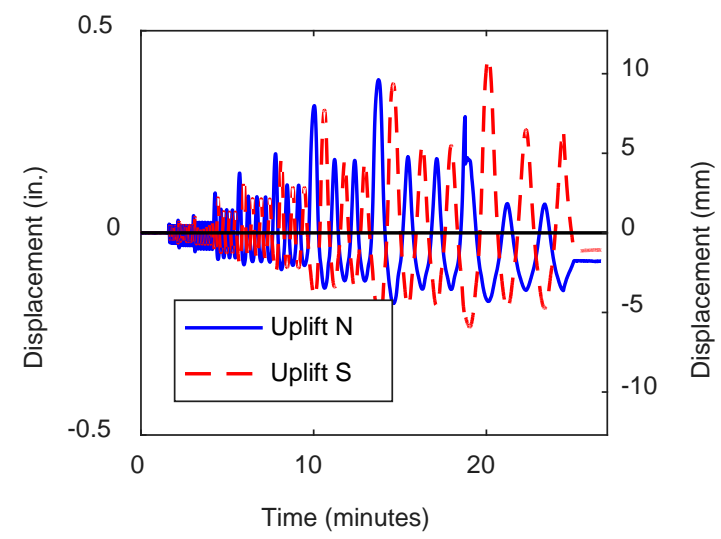

(a)

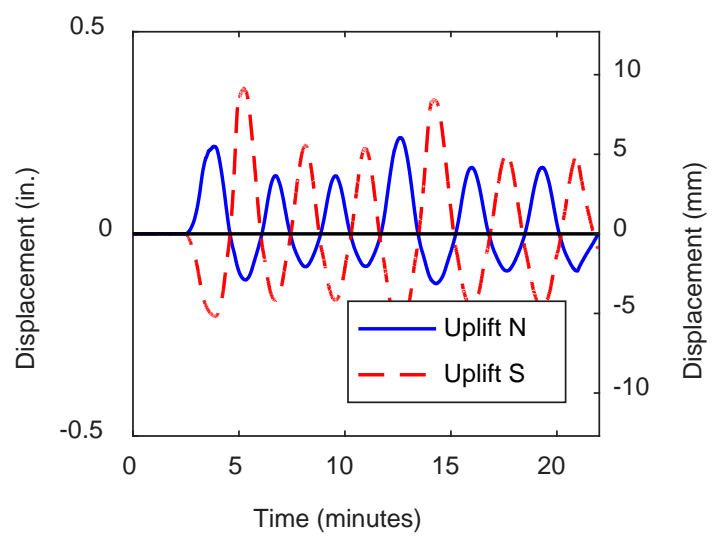

(b)

Figure 75: CFS04 - Uplift at bottom of specimen during mechanical loading: (a) Before fire; (b) After fire.

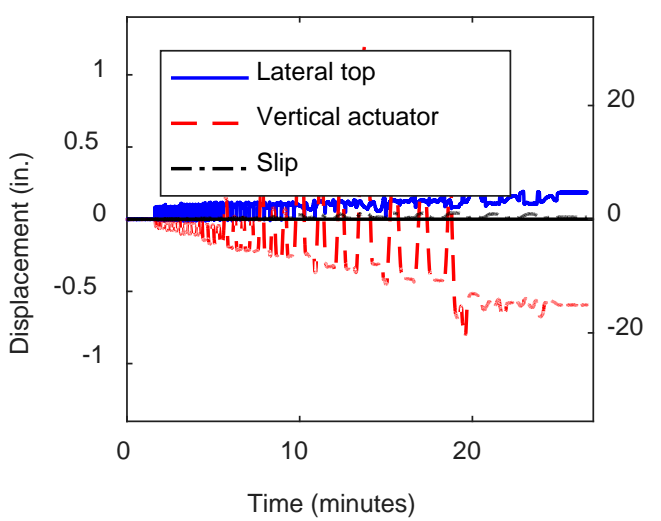

(a)

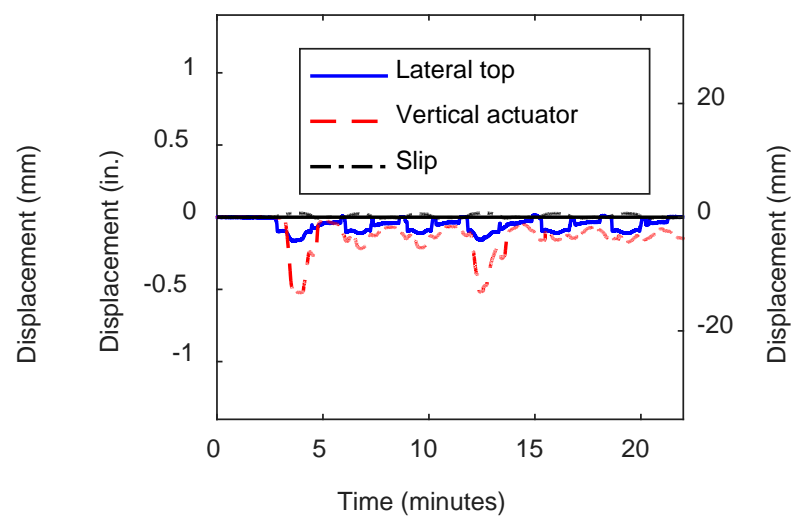

(b)

Figure 76: CFS04 - Ancillary displacement measurements during mechanical loading: (a) Before fire; (b) After fire. 


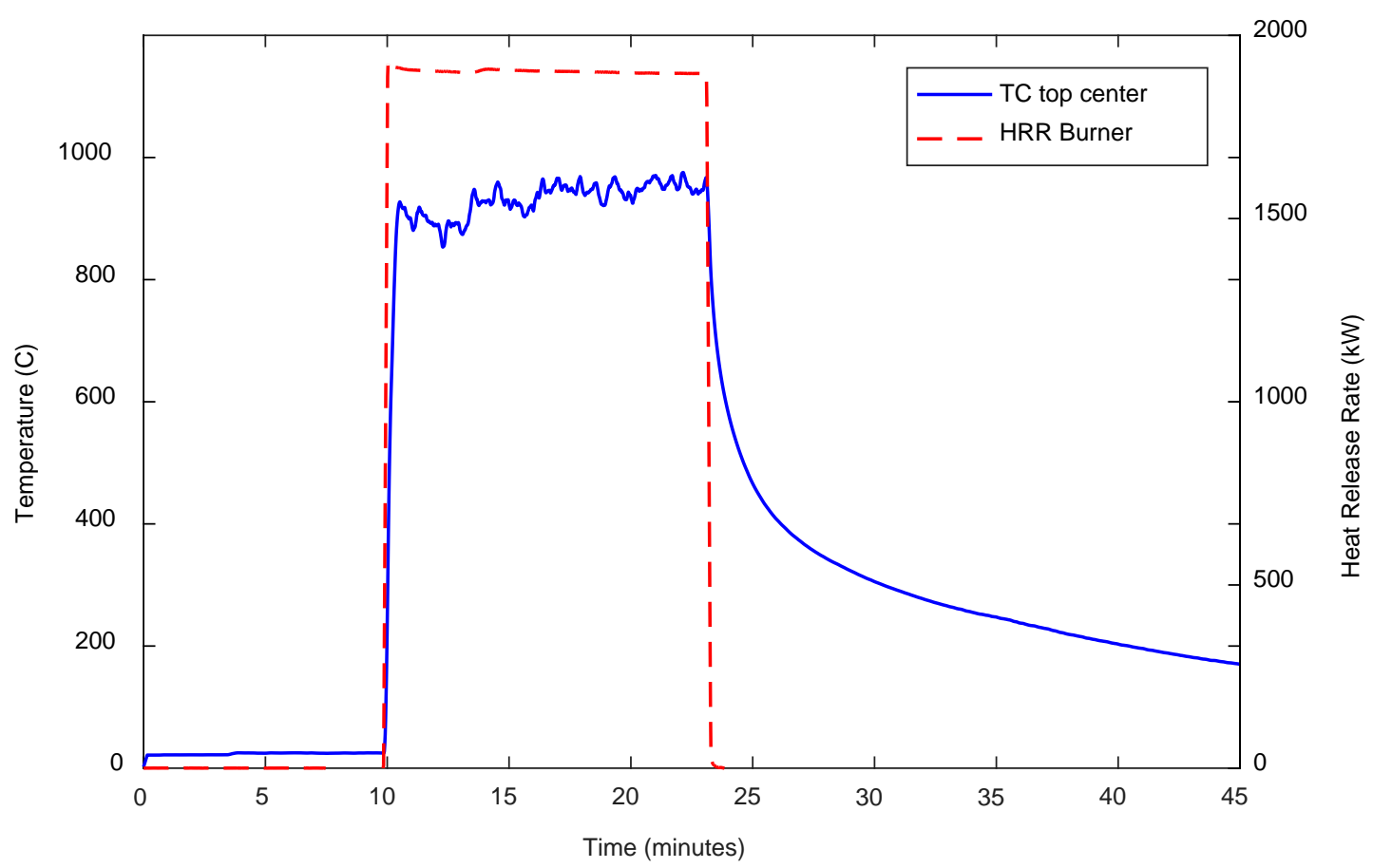

Figure 77: CFS04 - Burner heat release rate and upper layer temperature during fire loading.

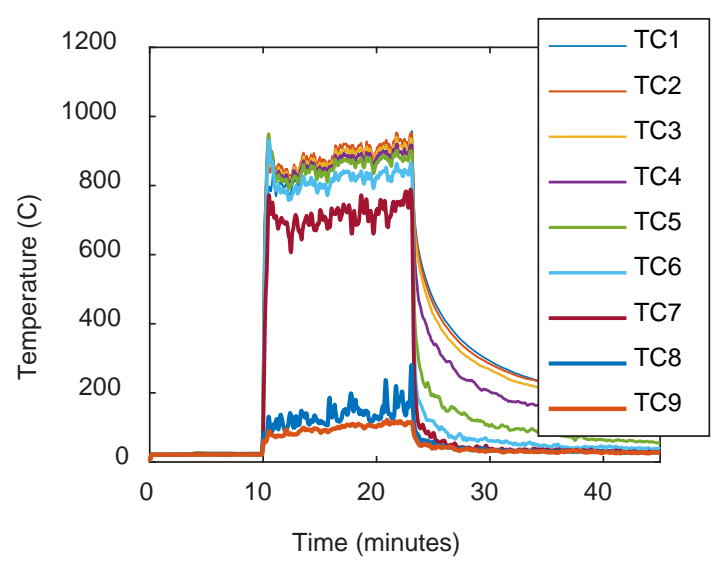

(a)

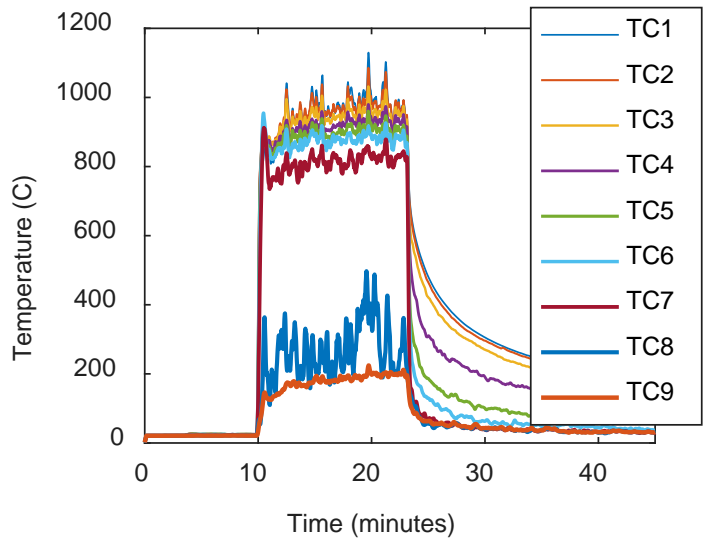

(b)

Figure 78: CFS04 - Compartment temperatures during fire loading: (a) North thermocouple tree; (b) South thermocouple tree. 


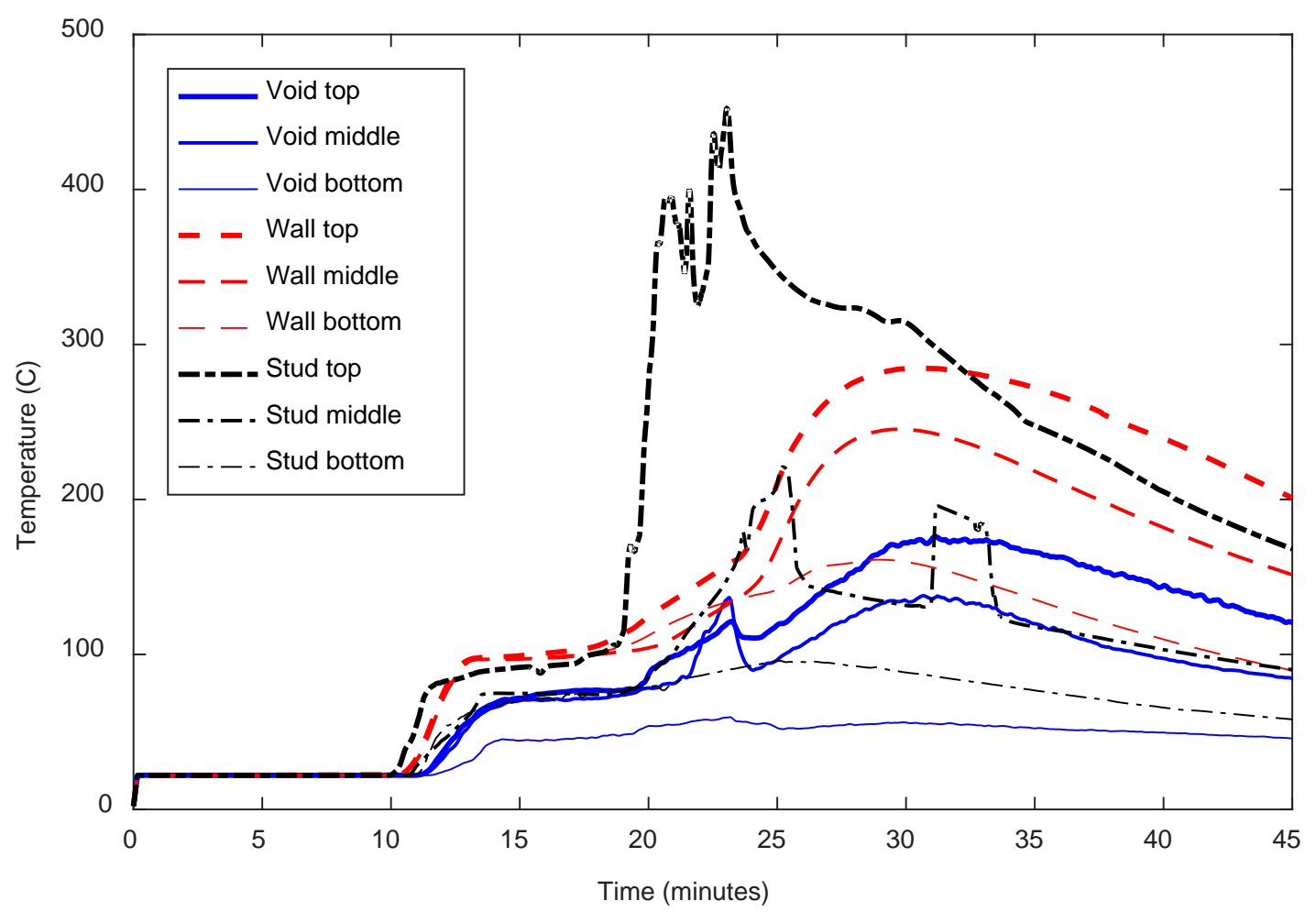

Figure 79: CFS04 - Specimen temperatures during fire loading.

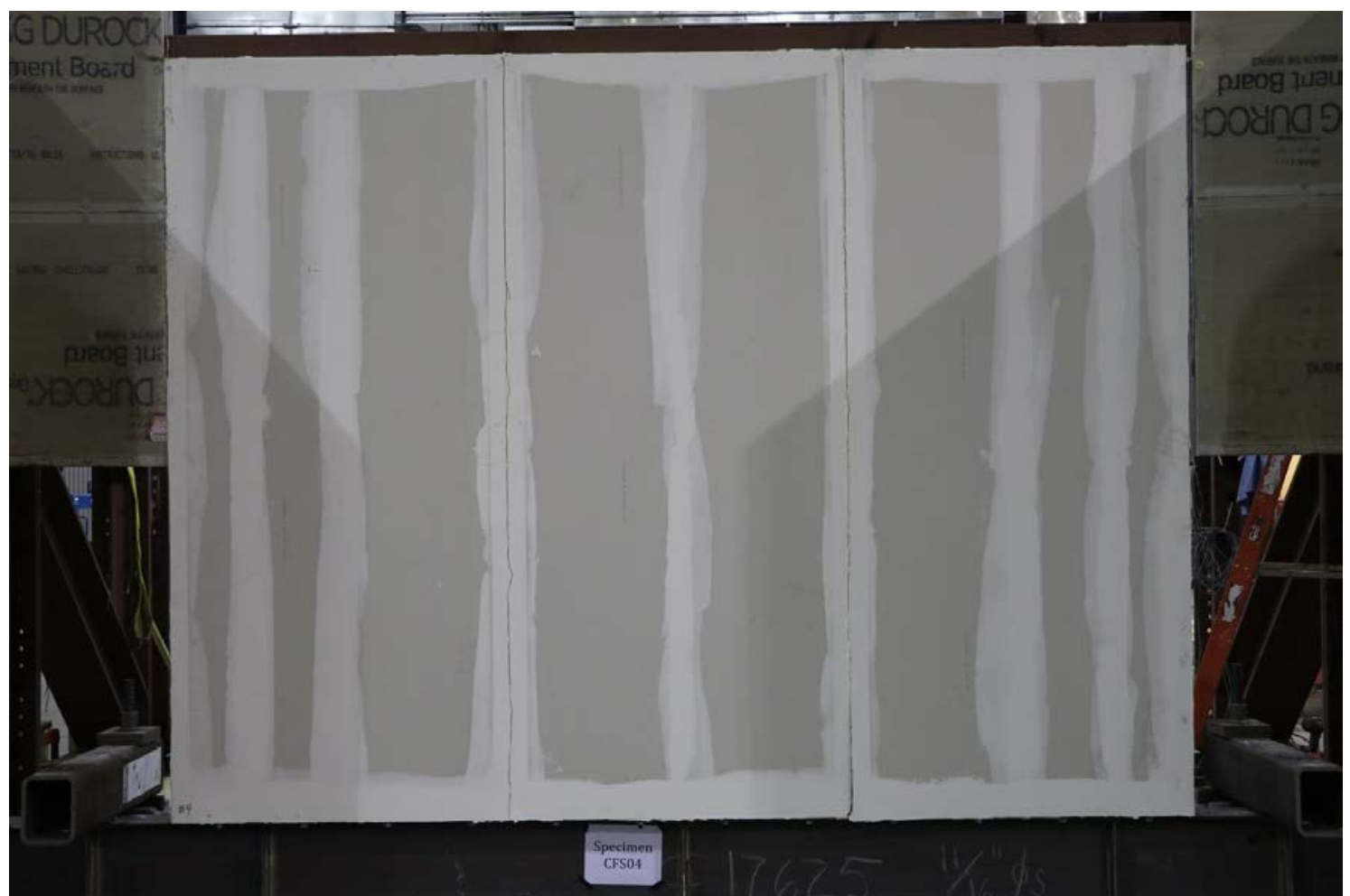

Figure 80: CFS04 - Photograph of metal sheathed side of wall after mechanical loading to $1.8 \%$ drift (CFS04a). 


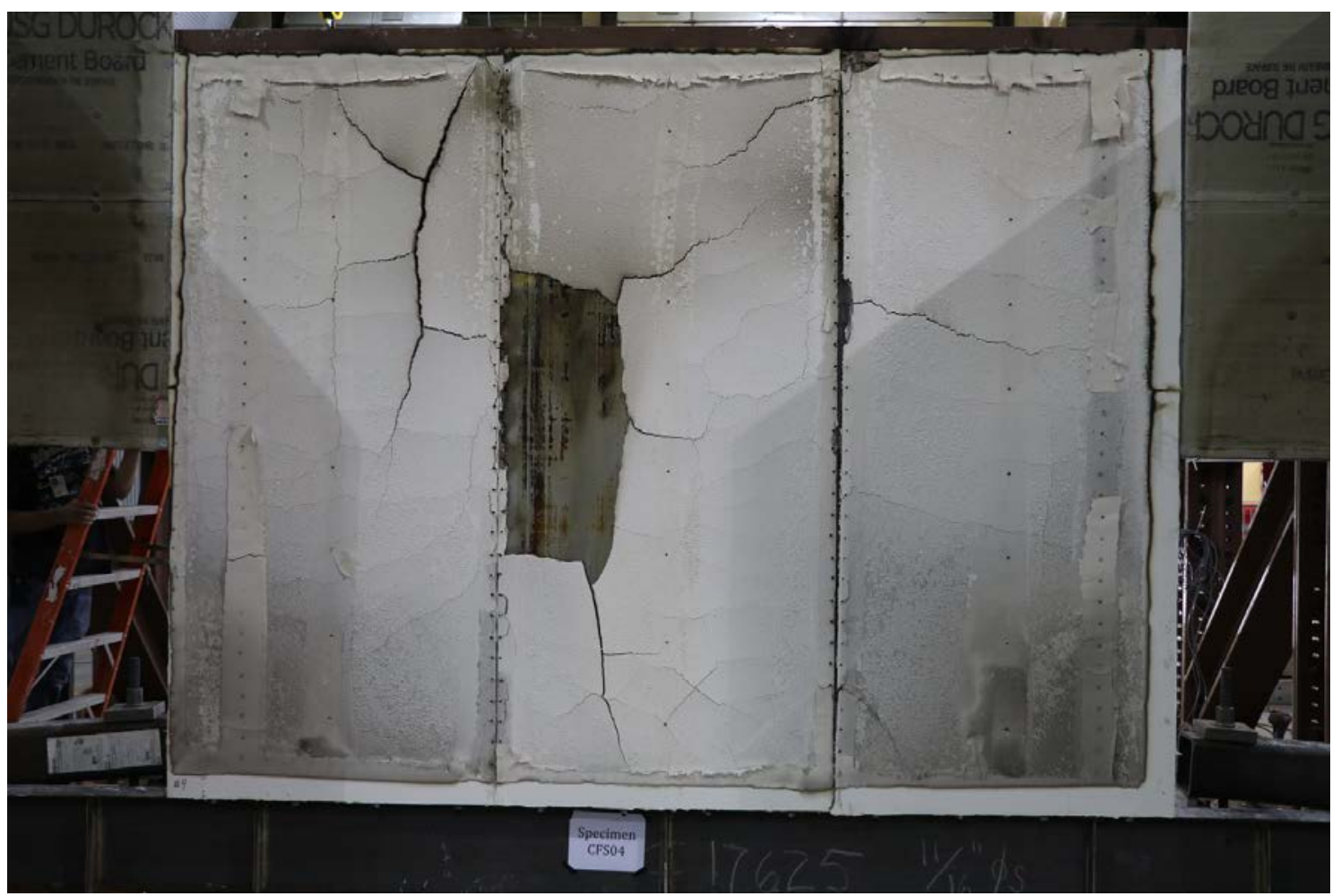

Figure 81: CFS04 - Photograph of metal sheathed side of wall after fire loading (CFS04b).

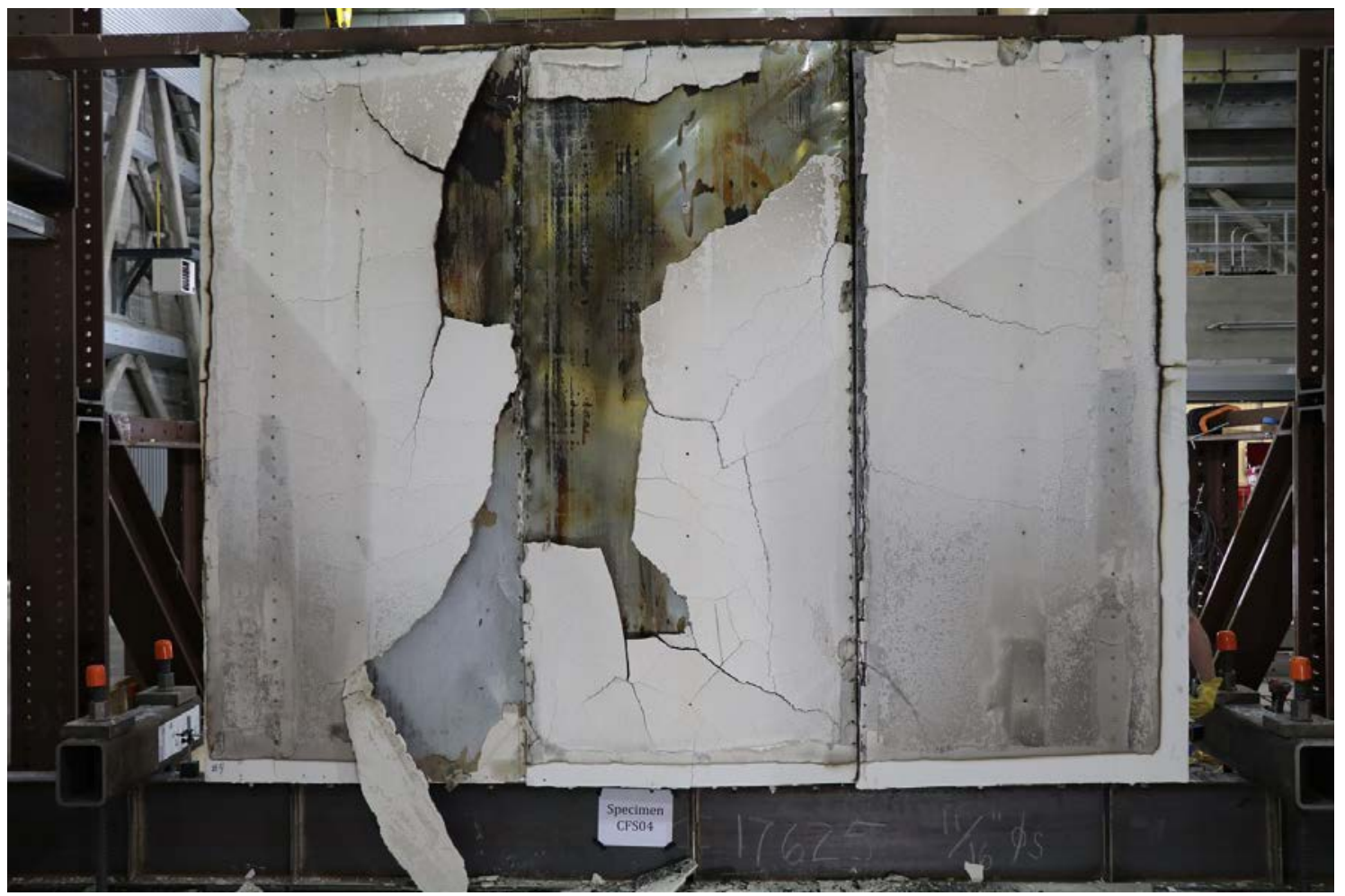

Figure 82: CFS04 - Photograph of metal sheathed side of the burned wall after mechanical loading to $2.8 \%$ drift (CFS04c). 


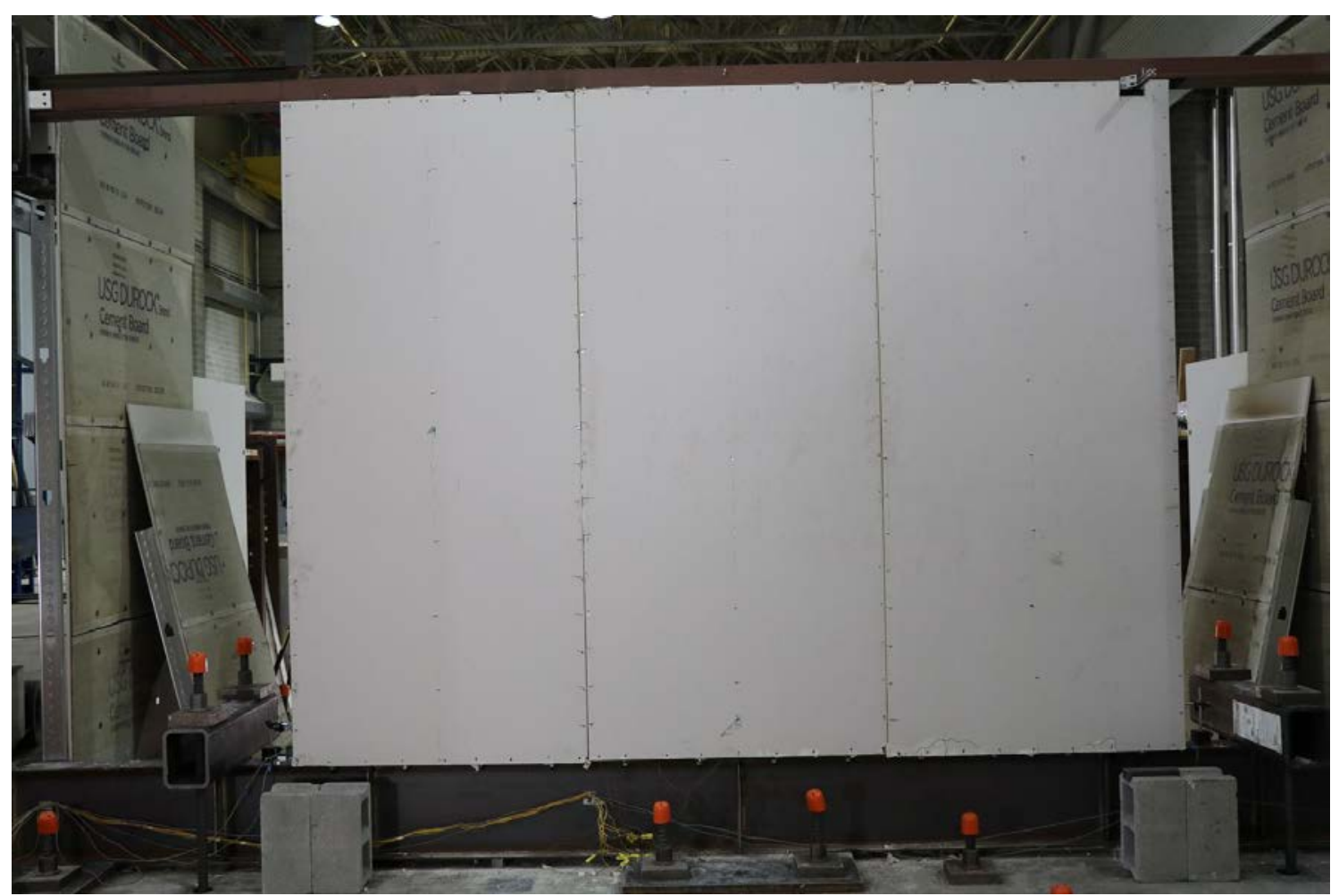

Figure 83: CFS04 - Photograph of gypsum sheathed side of wall after mechanical loading to $2.8 \%$ drift (CFS04c).

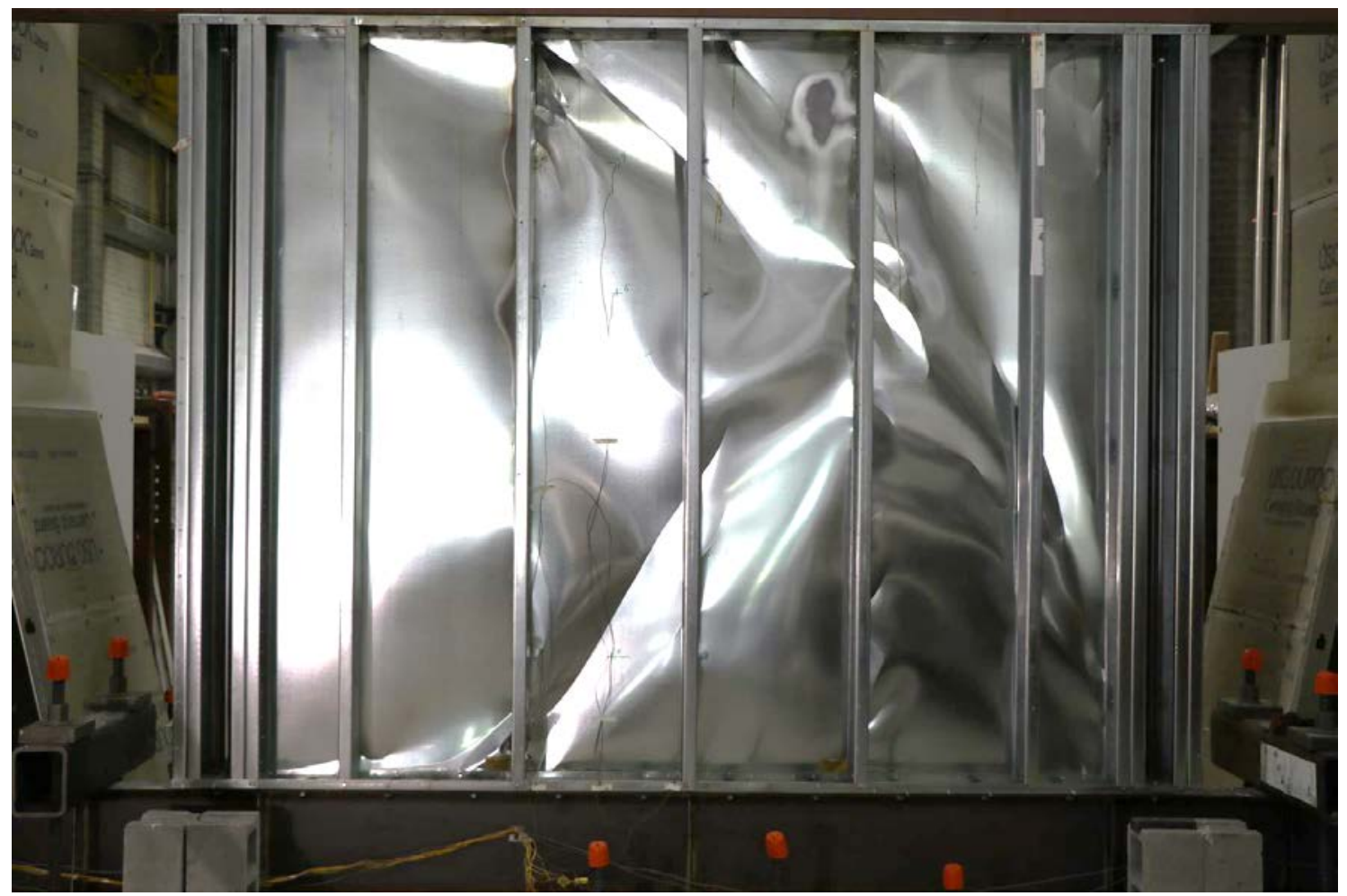

Figure 84: CFS04 - Photograph of back of metal sheathed side of the burned wall after mechanical loading to $2.8 \%$ drift (CFS04c); nonstructural gypsum removed. 


\section{Appendix G. CFS05 Test Data}

CFS05a:

- Gypsum delaminated from metal backing during fire except around protected edges where the adhesive remained intact.

CFS05b:

- Less slotting of screw holes compared to CFS03a and CFS04a.

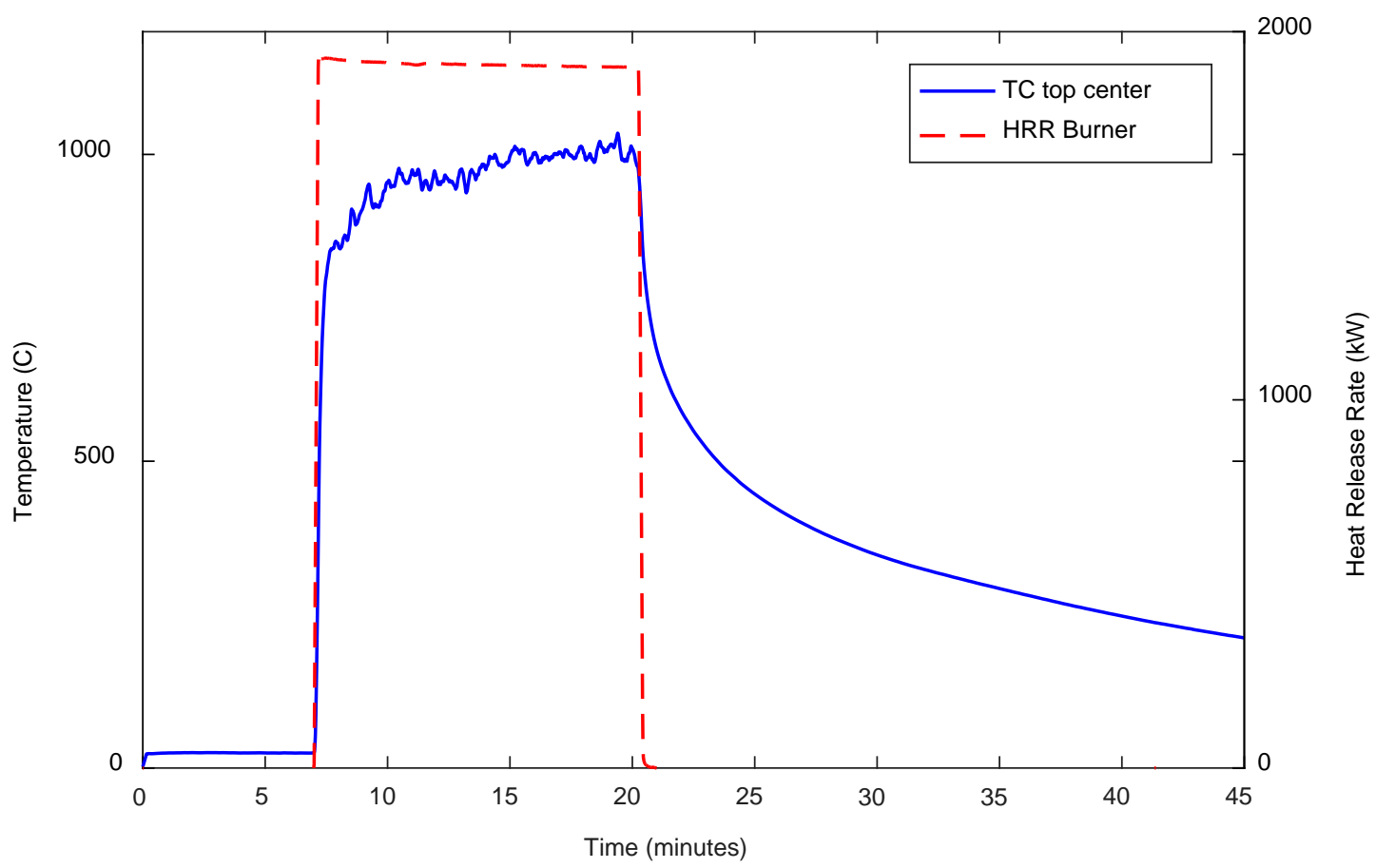

Figure 85: CFS05 - Burner heat release rate and upper layer temperature during fire loading.

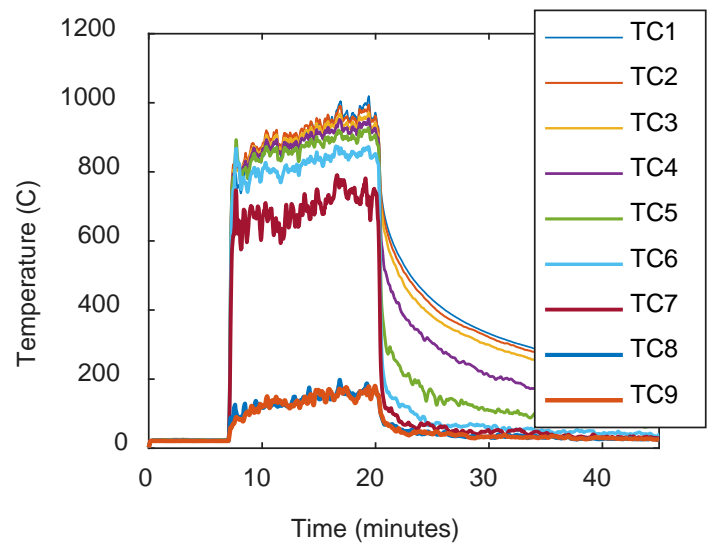

(a)

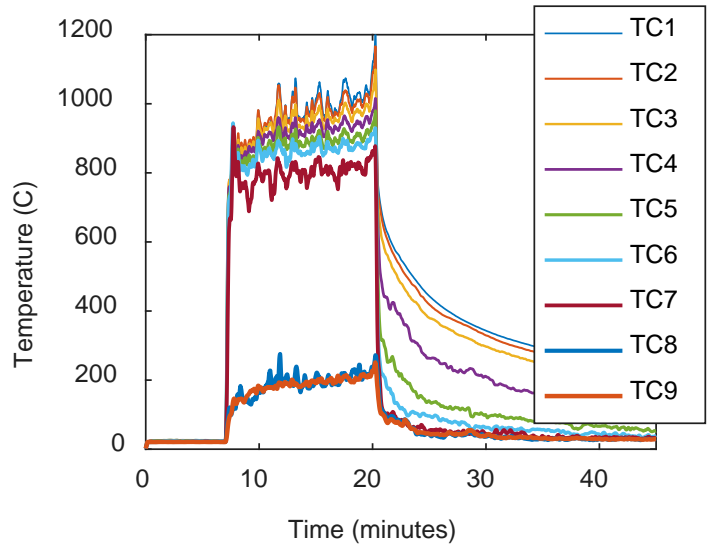

(b)

Figure 86: CFS05 - Compartment temperatures during fire loading: (a) North thermocouple tree; (b) South thermocouple tree. 


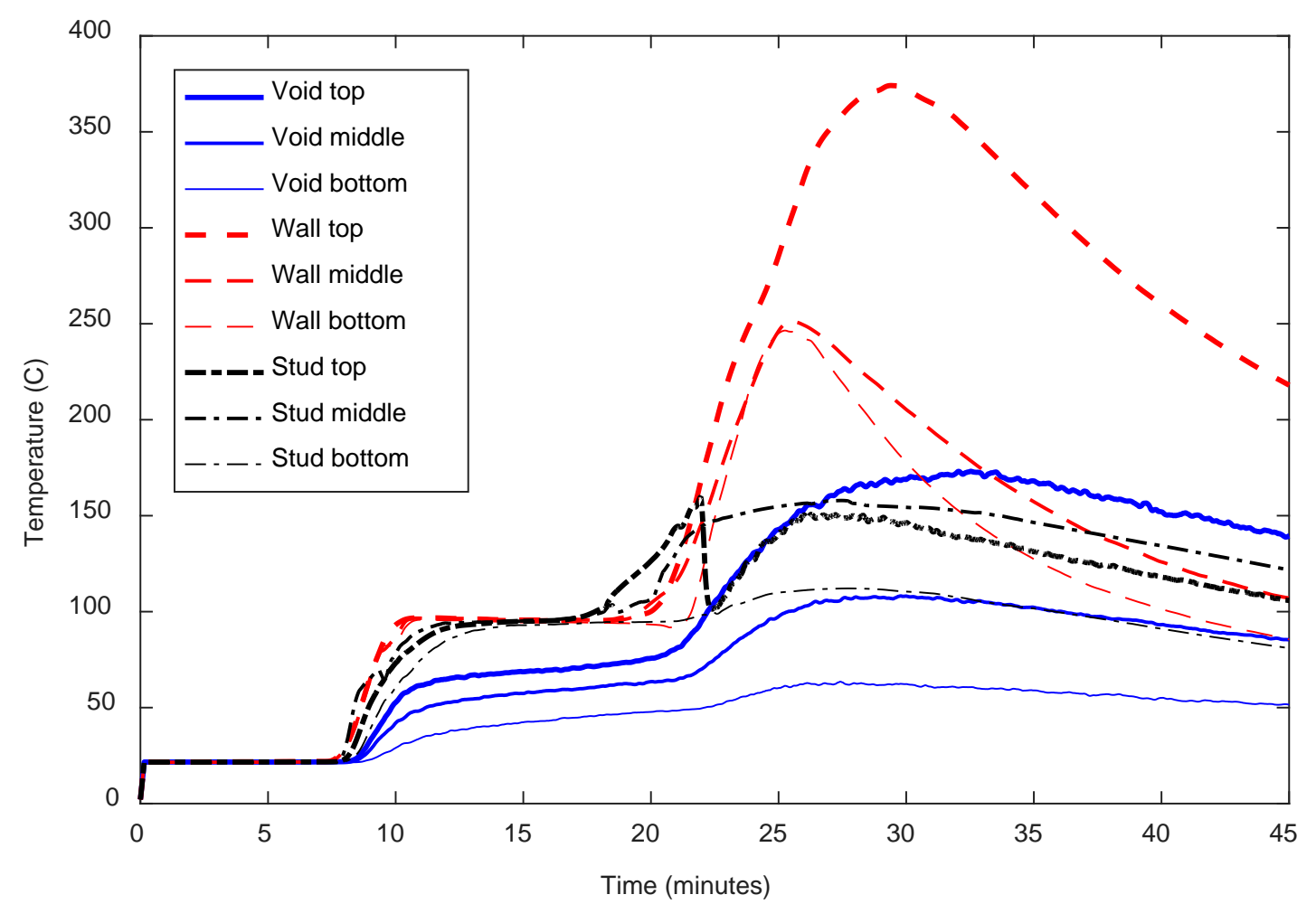

Figure 87: CFS05 - Specimen temperatures during fire loading.

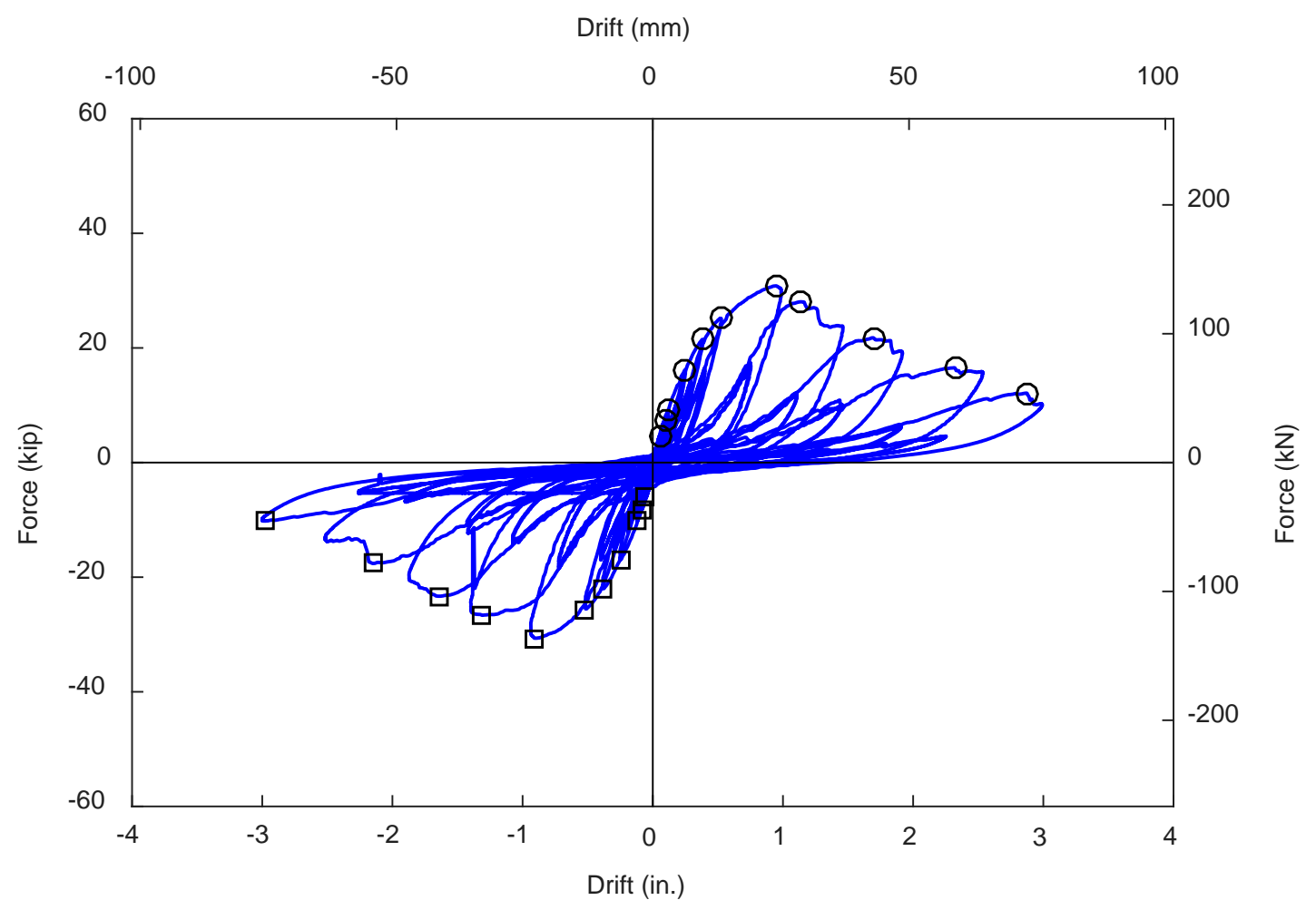

Figure 88: CFS05 - Lateral load (Actuator Force) versus drift (Disp_Longitudinal_SP) during mechanical loading. 


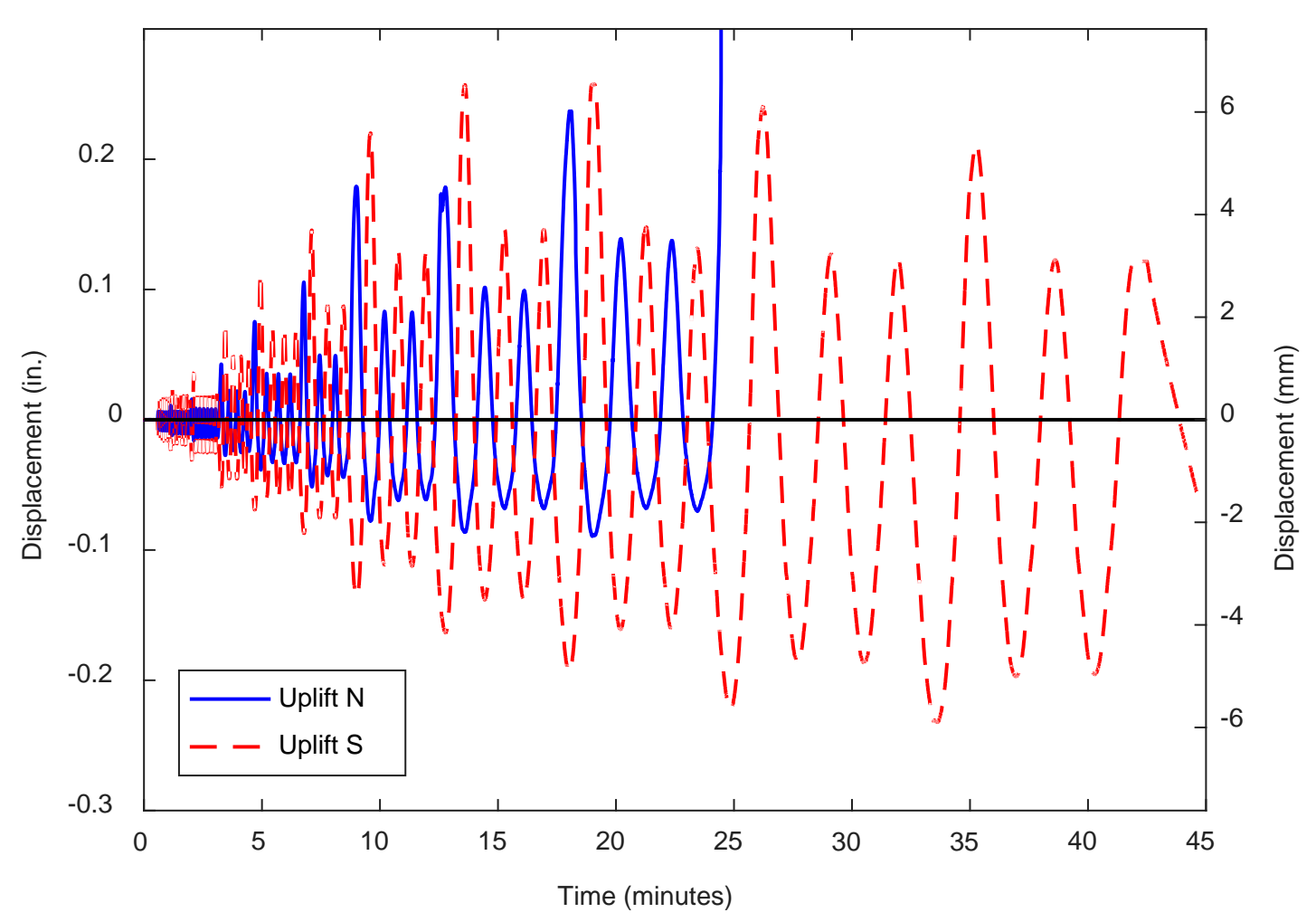

Figure 89: CFS05 - Uplift at bottom of specimen during mechanical loading.

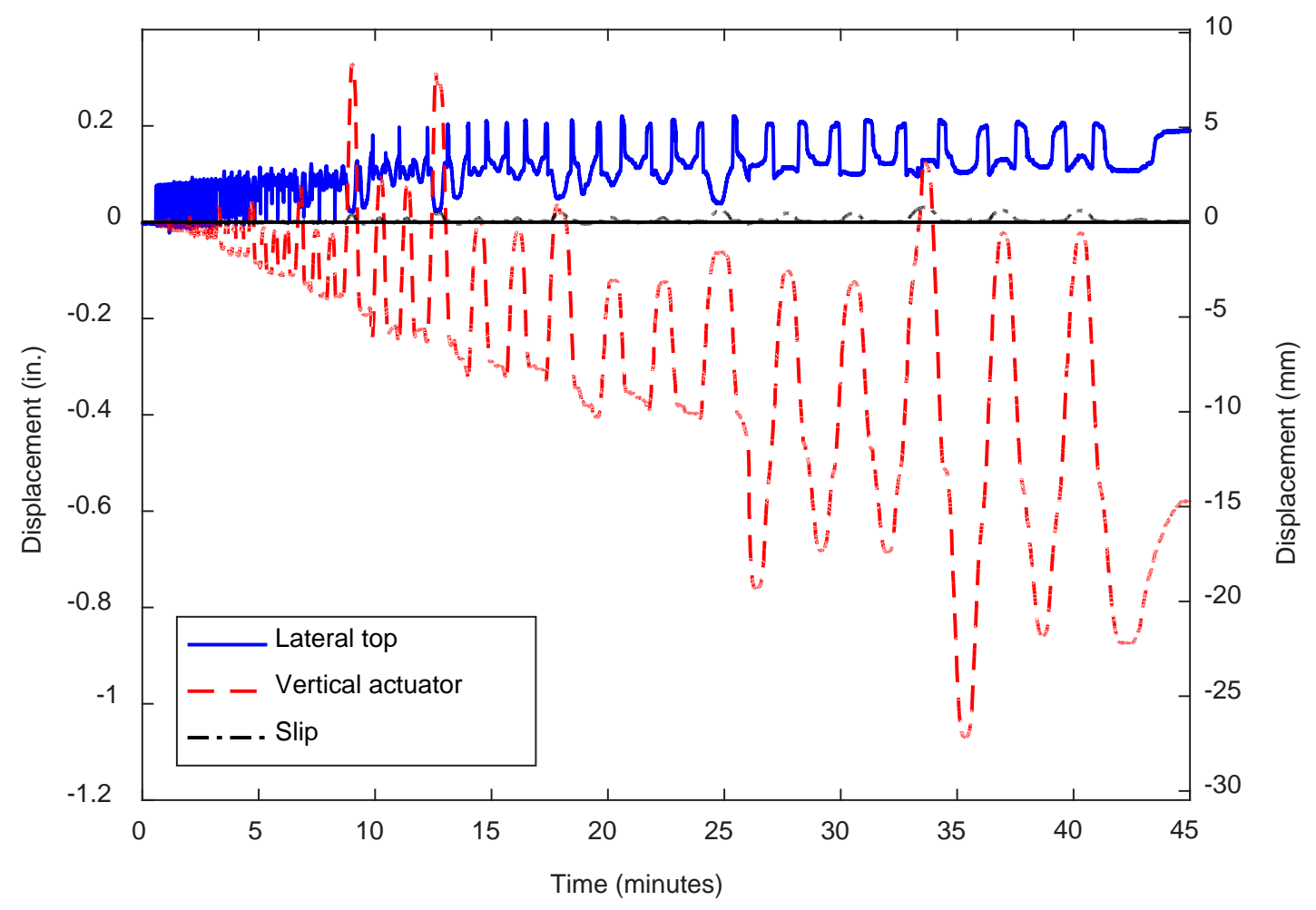

Figure 90: CFS05 - Ancillary displacement measurements during mechanical loading. 


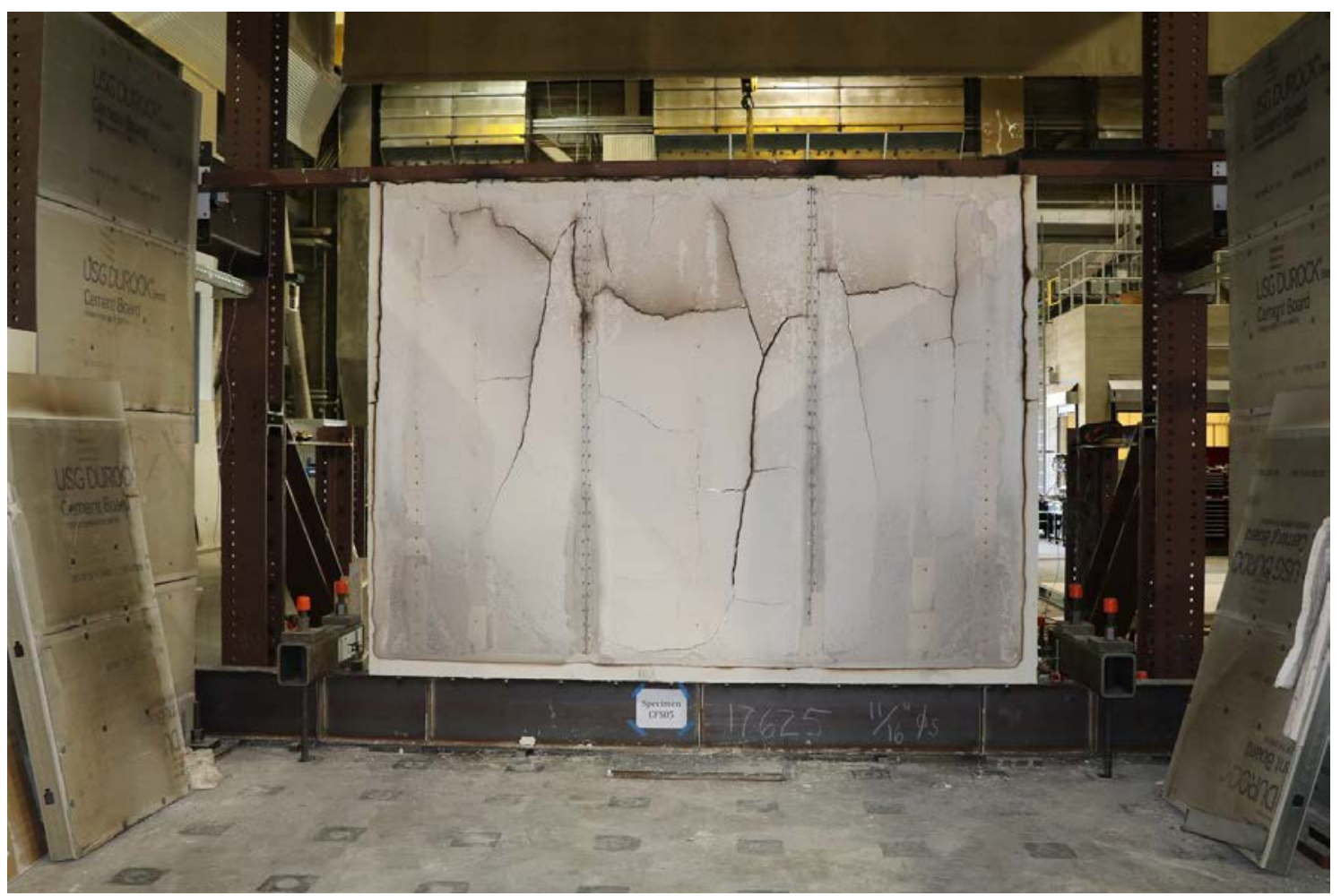

Figure 91: CFS05 - Photograph of metal sheathed side of wall after fire loading (CFS05a).

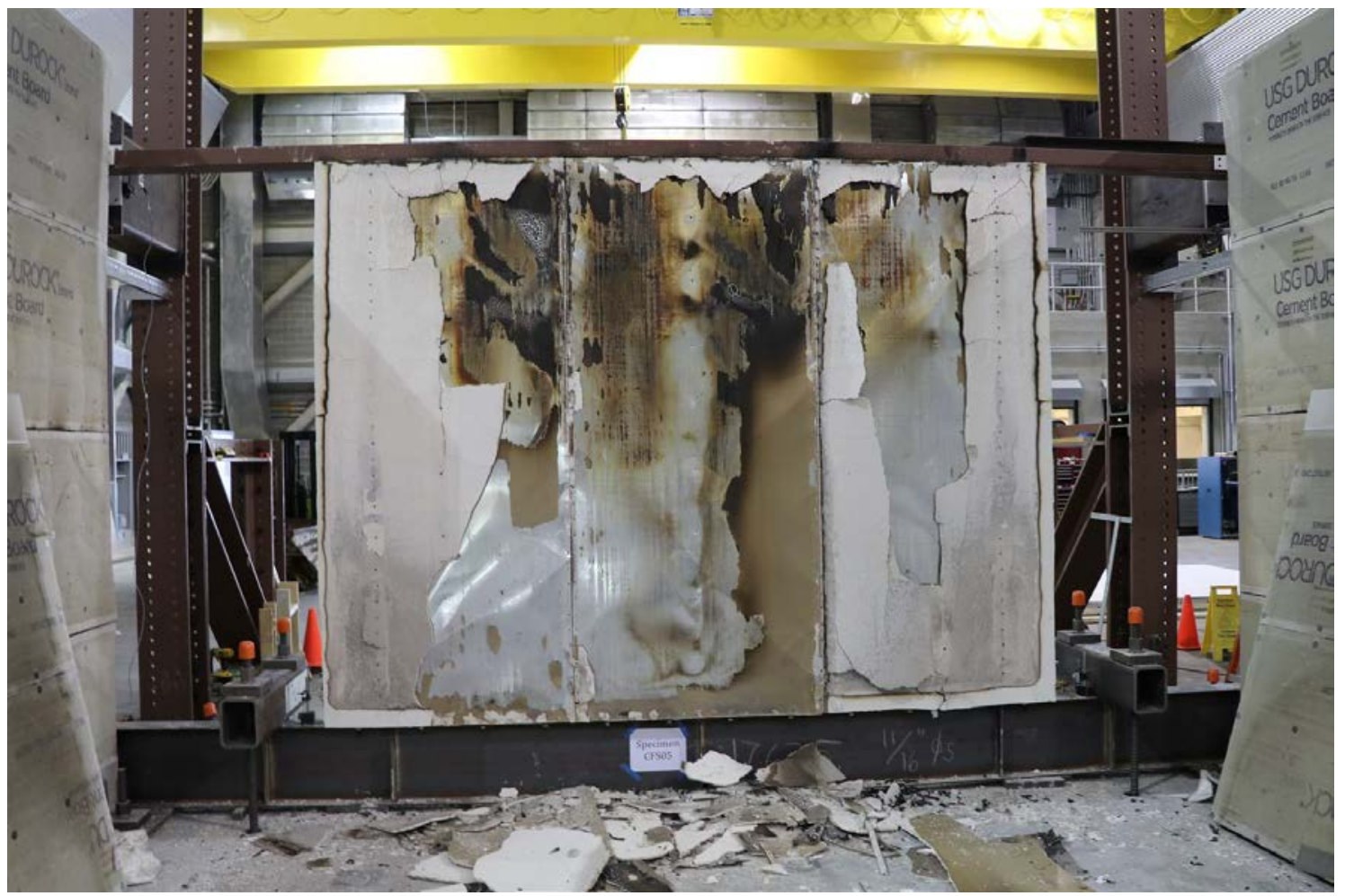

Figure 92: CFS05 - Photograph of metal sheathed side of the burned wall after mechanical loading to $2.8 \%$ drift (CFS05b). 


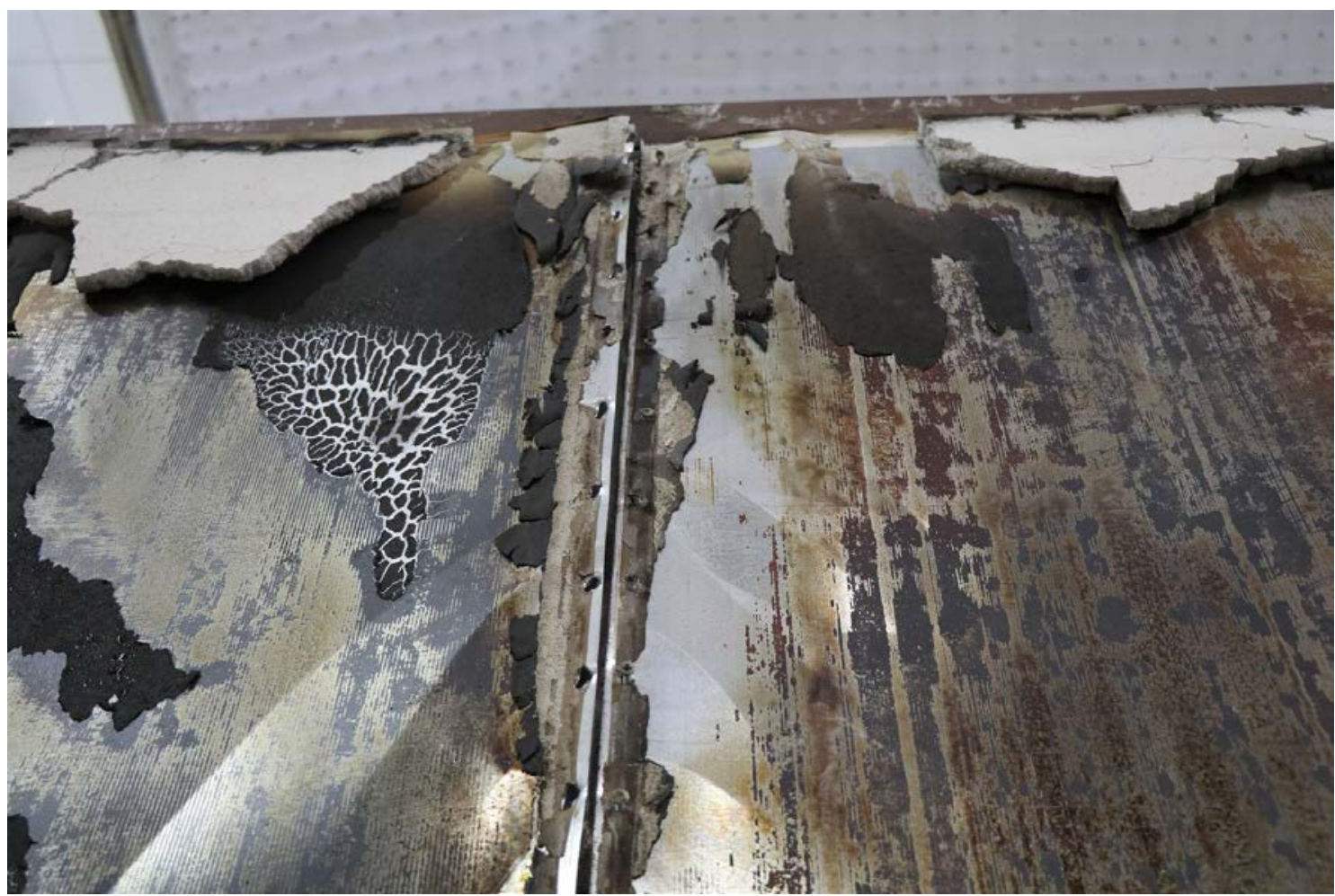

Figure 93: CFS05 - Photograph of metal sheathed side of the burned wall after mechanical loading to $2.8 \%$ drift (CFS05b) highlighting sheeting damage.

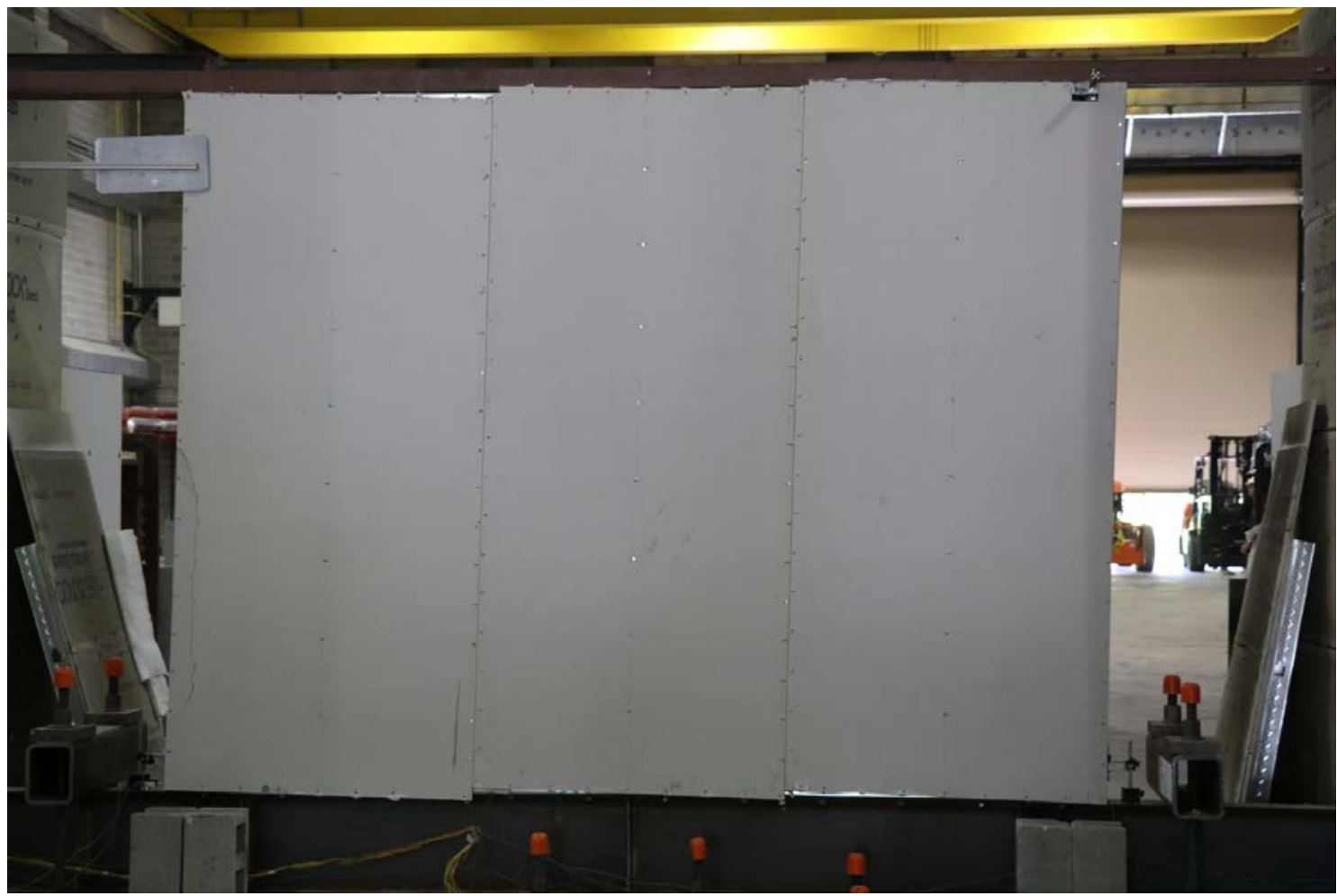

Figure 94: CFS05 - Photograph of gypsum sheathed side of wall after mechanical loading to $2.8 \%$ drift (CFS05b). 


\section{Appendix H. CFS06 Test Data}

CFS06a:

- Damage was limited to tearing of joint compound and paper tape along seams.

\section{CFS06b:}

- Drywall moisture was driven off after about 12 minutes of heating. The specimen temperatures plateaued again at about $500{ }^{\circ} \mathrm{C}$.

- $\quad$ North TC tree fell during cooling at around 50 minutes.

\section{CFS06c:}

- More damage to nonstructural gypsum; panels nearly detached during cycling, burning of paper on cavity side of board, screws at top of wall where the gypsum was thermally degraded pulled through gypsum and screws at the bottom (colder portion) were sheared off at the stud.

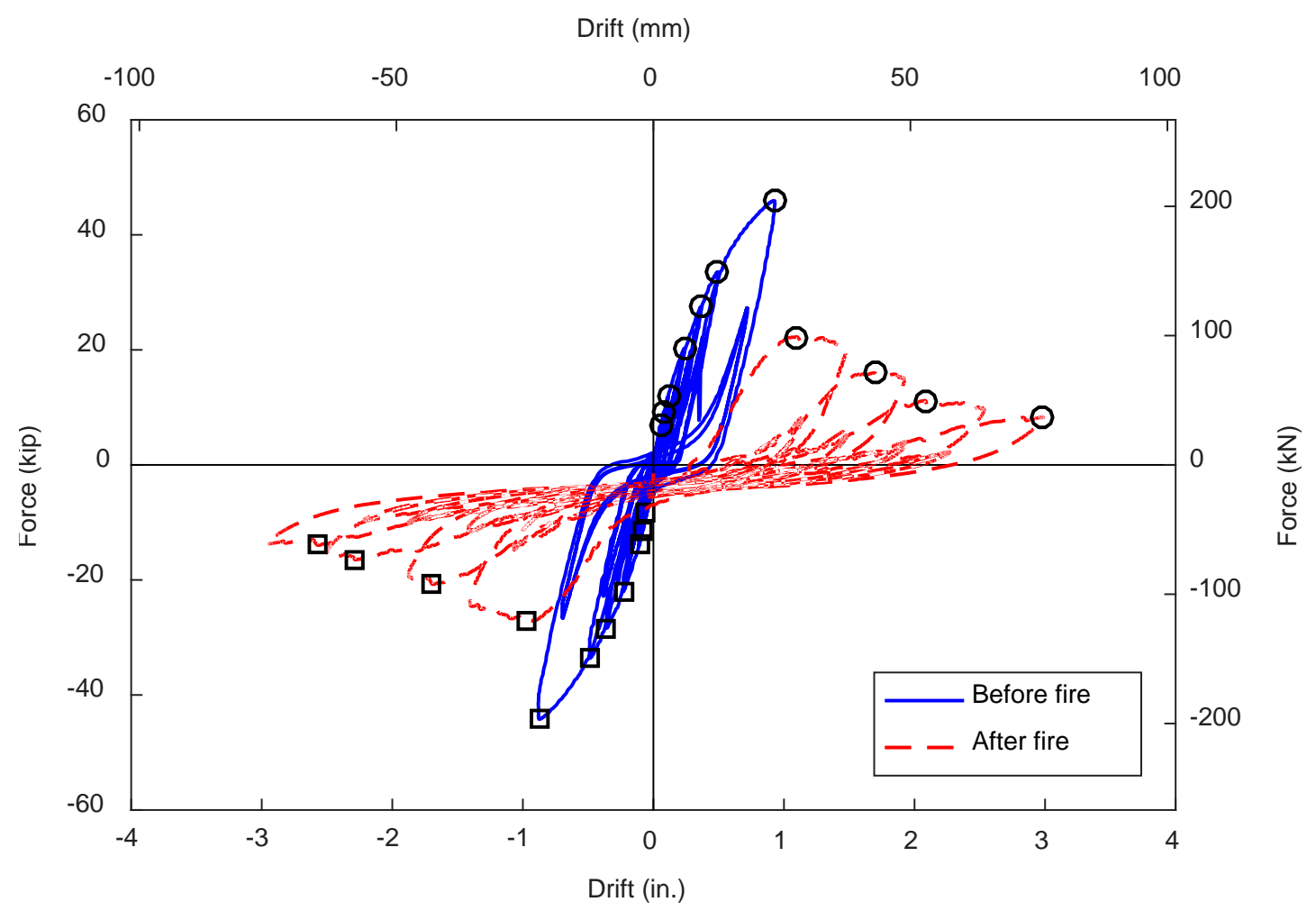

Figure 95: CFS06 - Lateral load (Actuator Force) versus drift (Disp_Longitudinal_SP) during mechanical loading. 


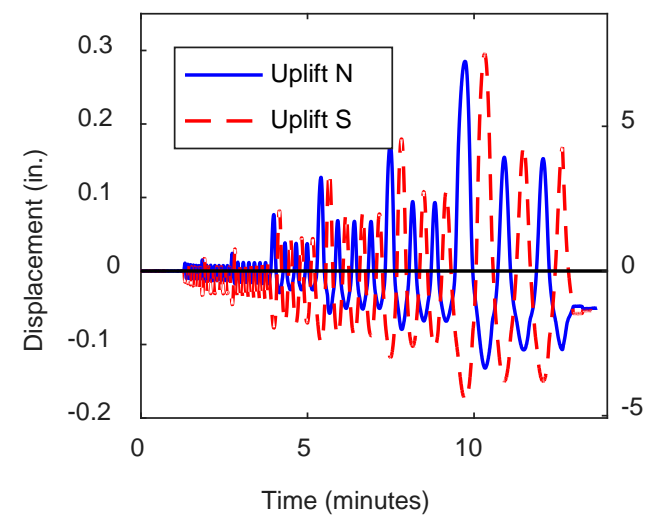

(a)

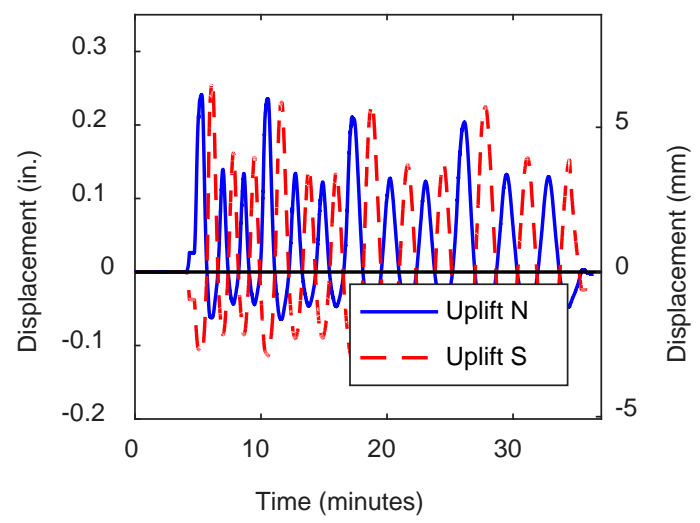

(b)

Figure 96: CFS06 - Uplift at bottom of specimen during mechanical loading: (a) Before fire; (b) After fire.

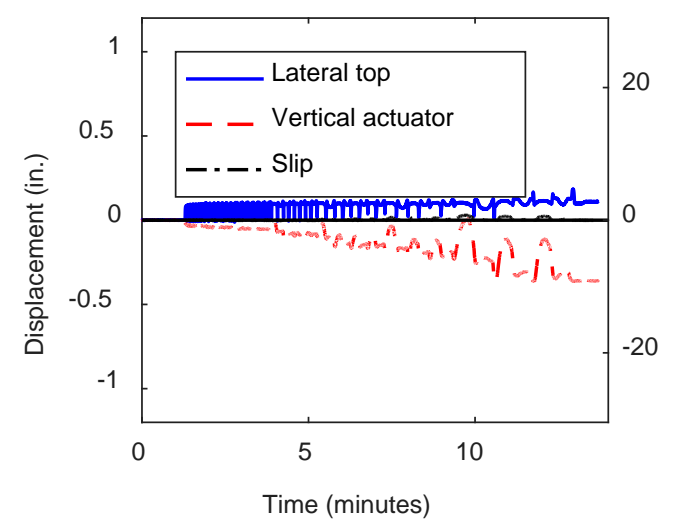

(a)

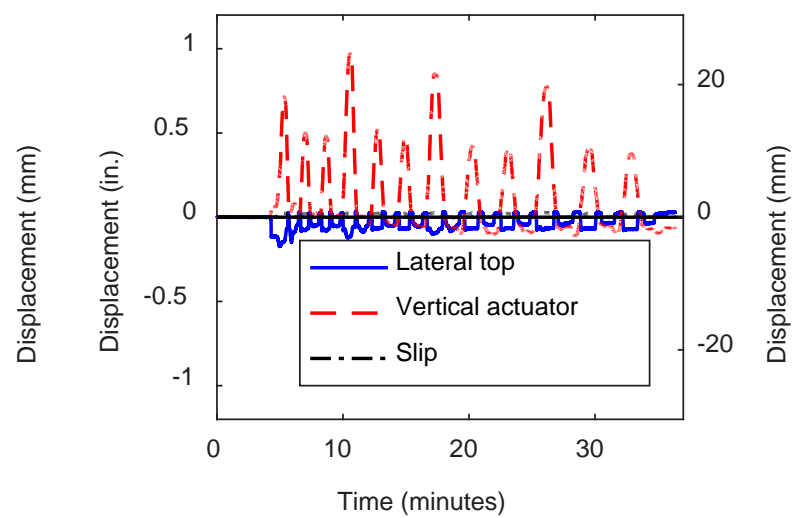

(b)

Figure 97: CFS06 - Ancillary displacement measurements during mechanical loading: (a) Before fire; (b) After fire. 


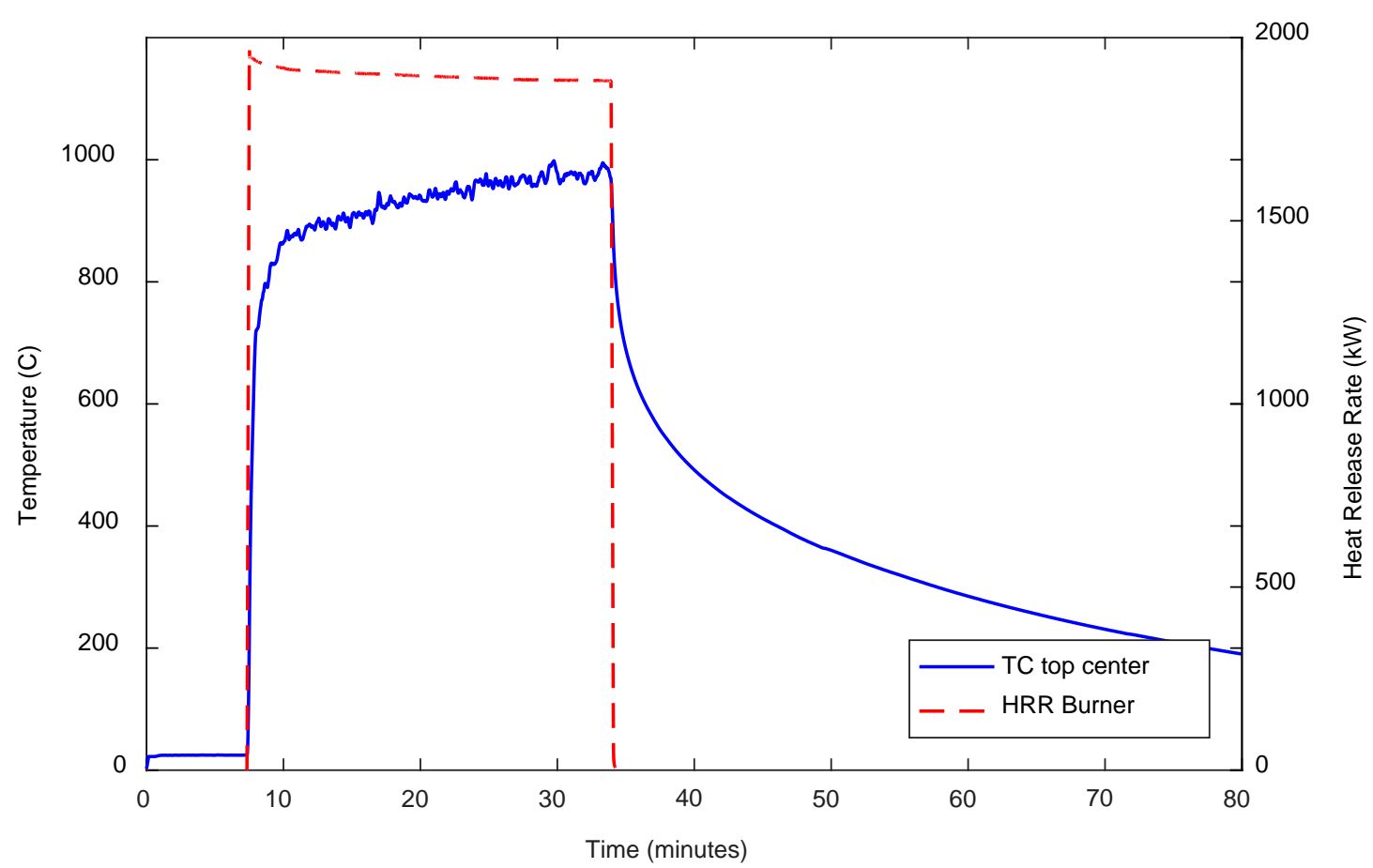

Figure 98: CFS06 - Burner heat release rate and upper layer temperature during fire loading.

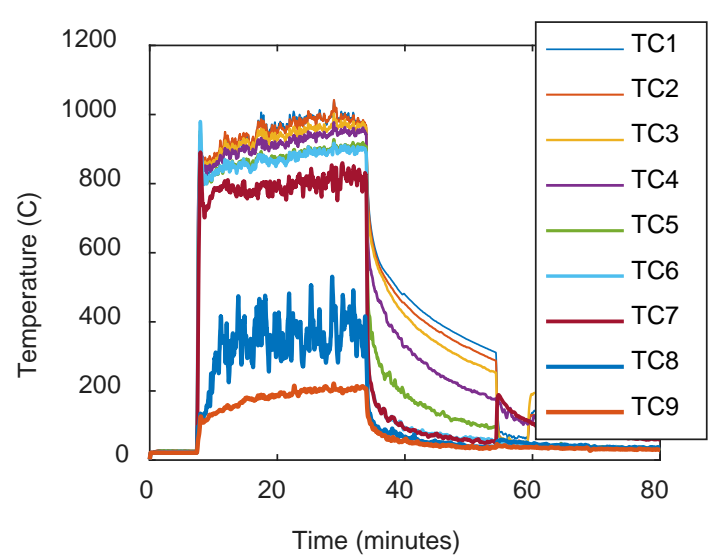

(a)

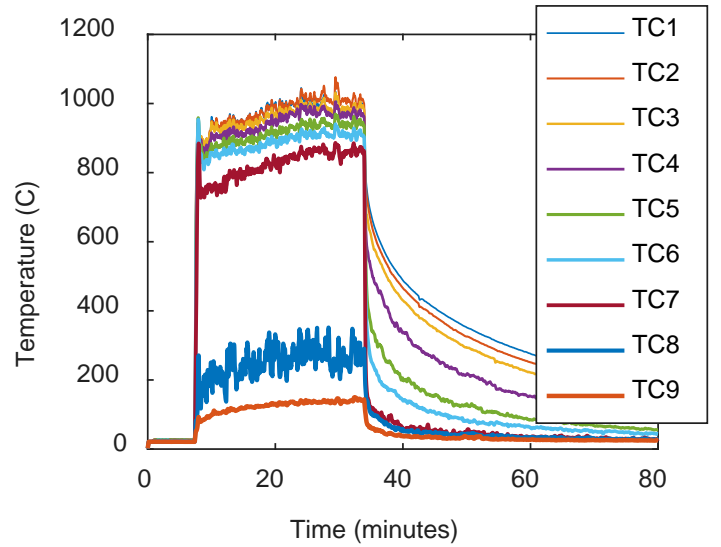

(b)

Figure 99: CFS06 - Compartment temperatures during fire loading: (a) North thermocouple tree; (b) South thermocouple tree. 


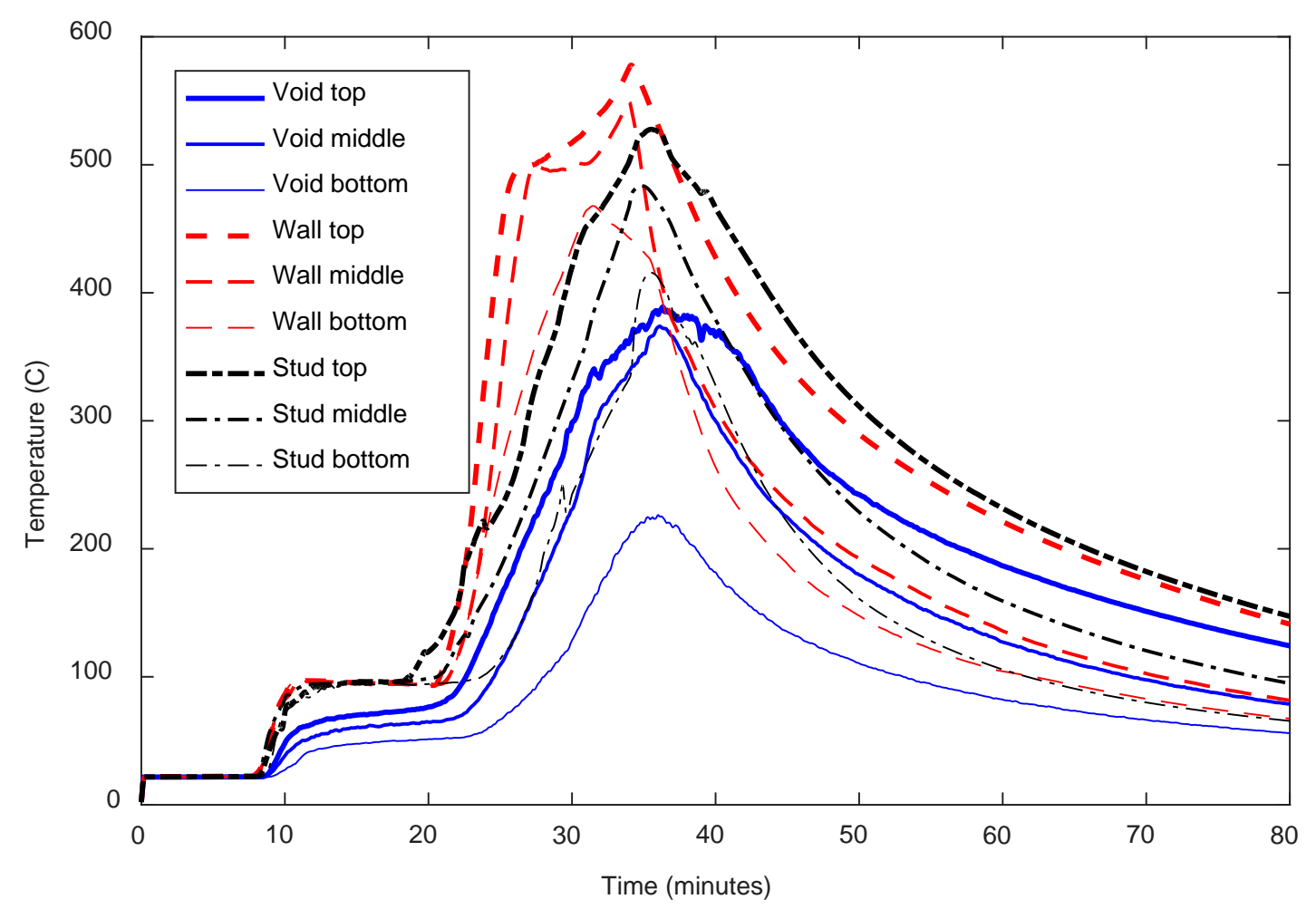

Figure 100: CFS06 - Specimen temperatures during fire loading.

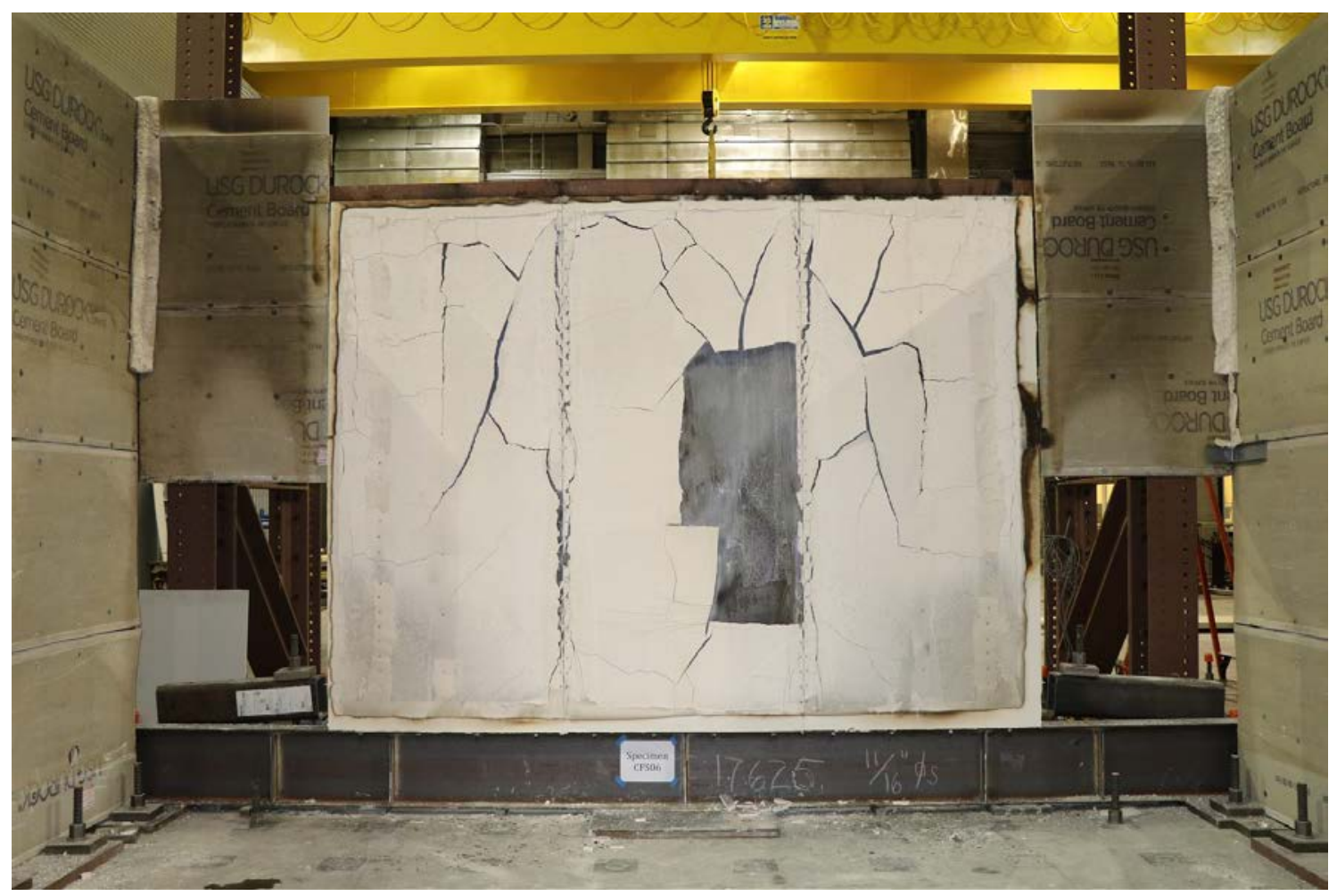

Figure 101: CFS06 - Photograph of metal sheathed side of wall after fire loading (CFS06b). 


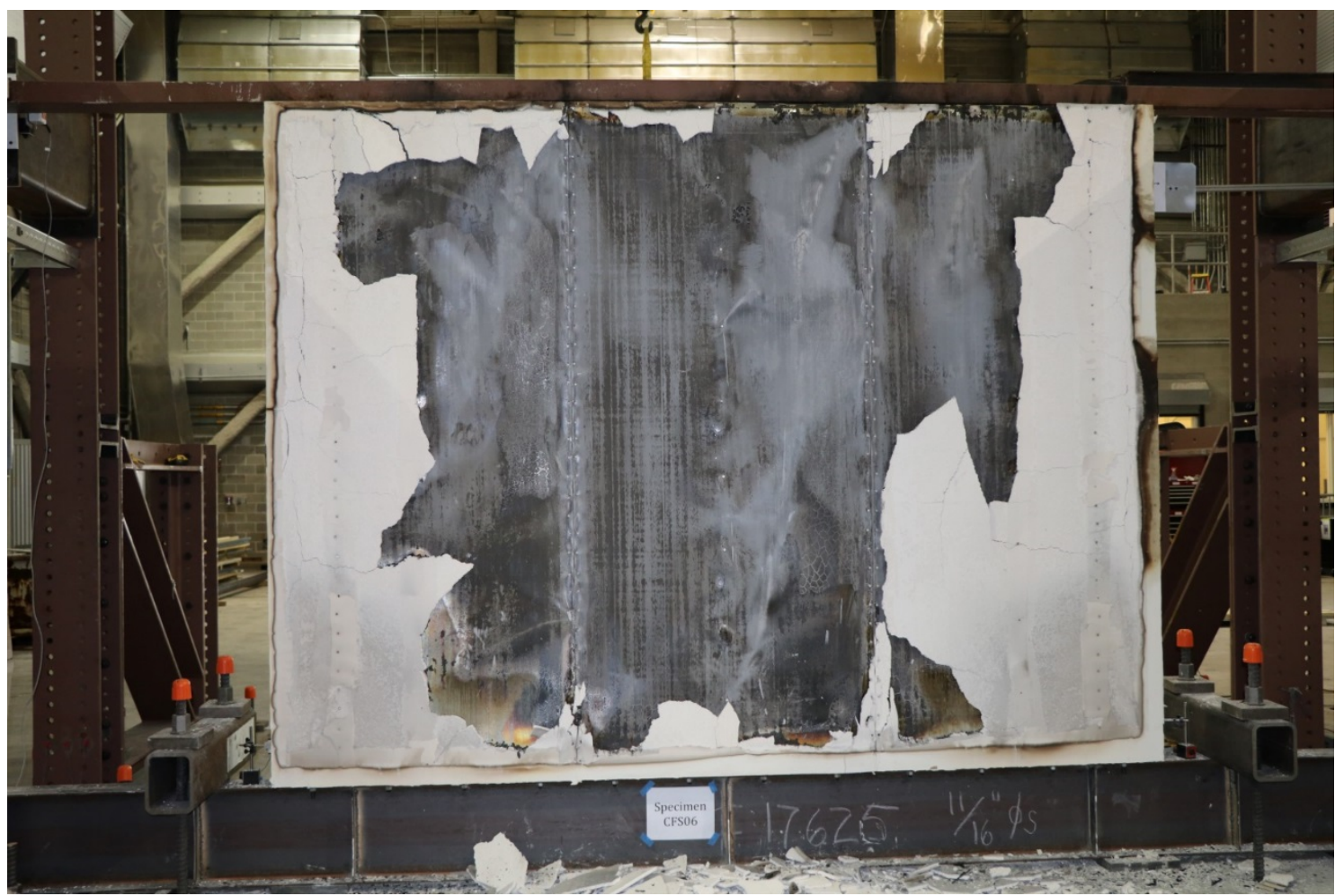

Figure 102: CFS06 - Photograph of metal sheathed side of the burned wall after mechanical loading to $2.8 \%$ drift (CFS06c).

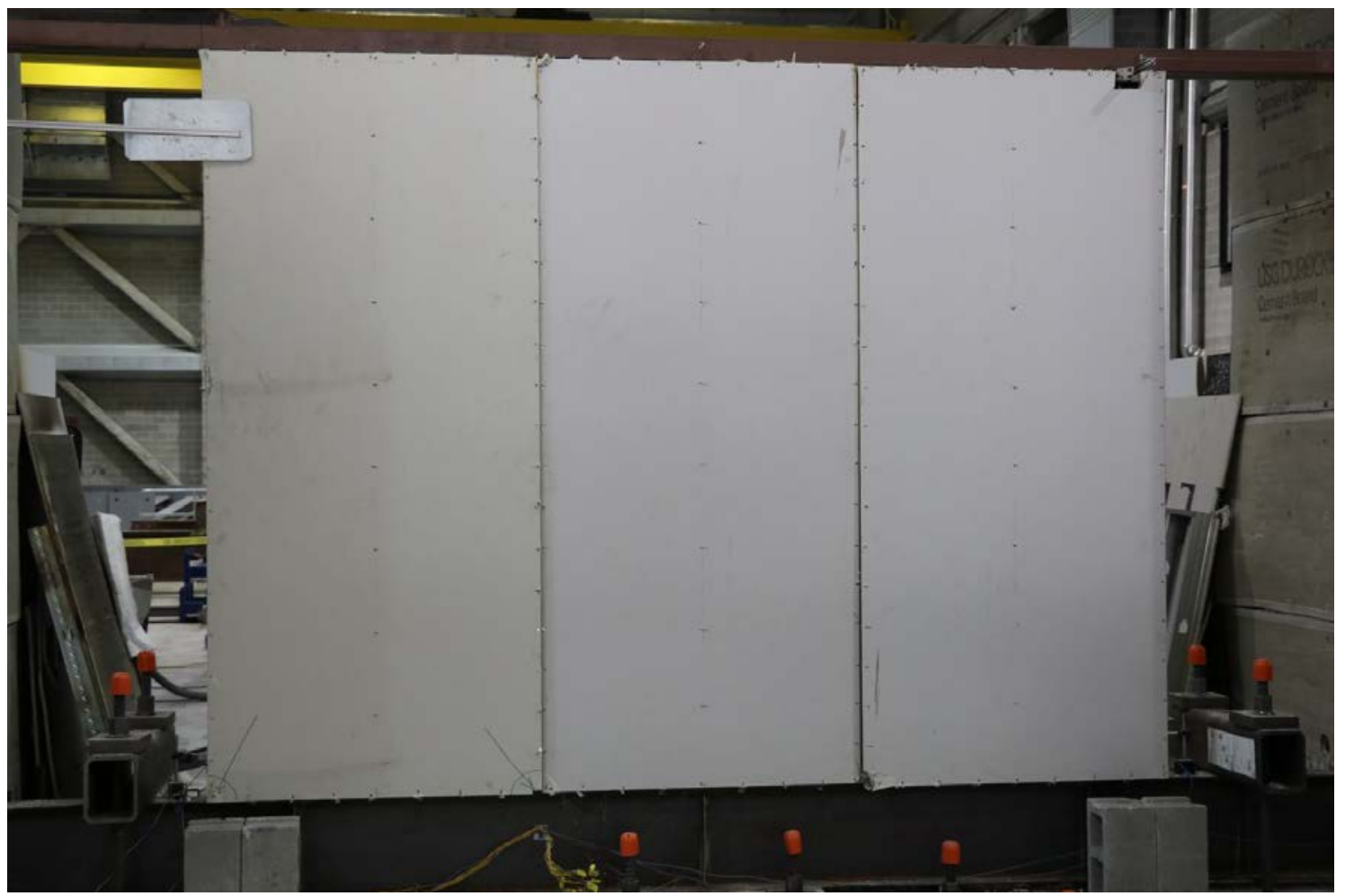

Figure 103: CFS06 - Photograph of gypsum sheathed side of wall after mechanical loading to $2.8 \%$ drift (CFS06c). 


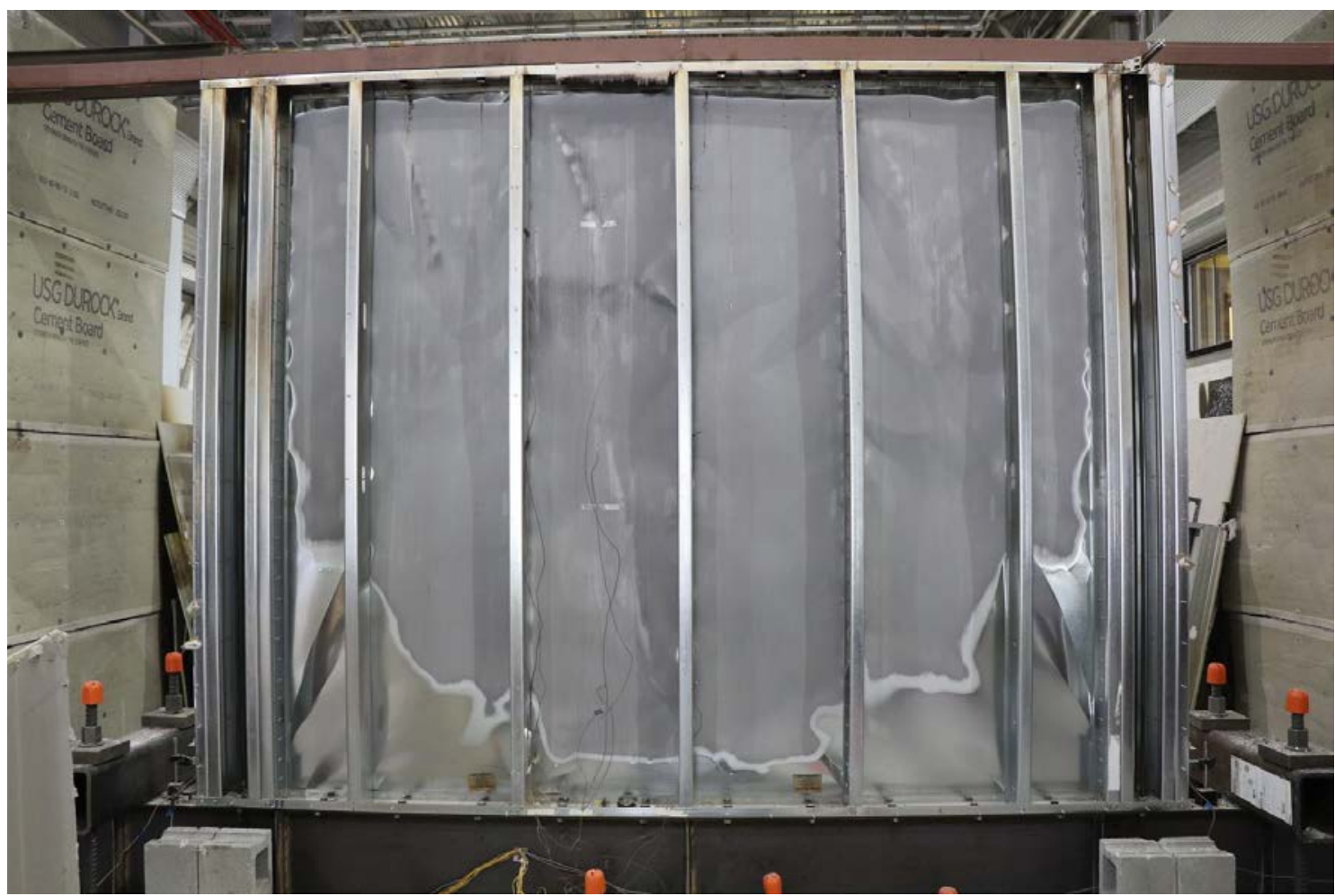

Figure 104: CFS06 - Photograph of back of metal sheathed side of the burned wall after mechanical loading to $2.8 \%$ drift (CFS06c); nonstructural gypsum removed.

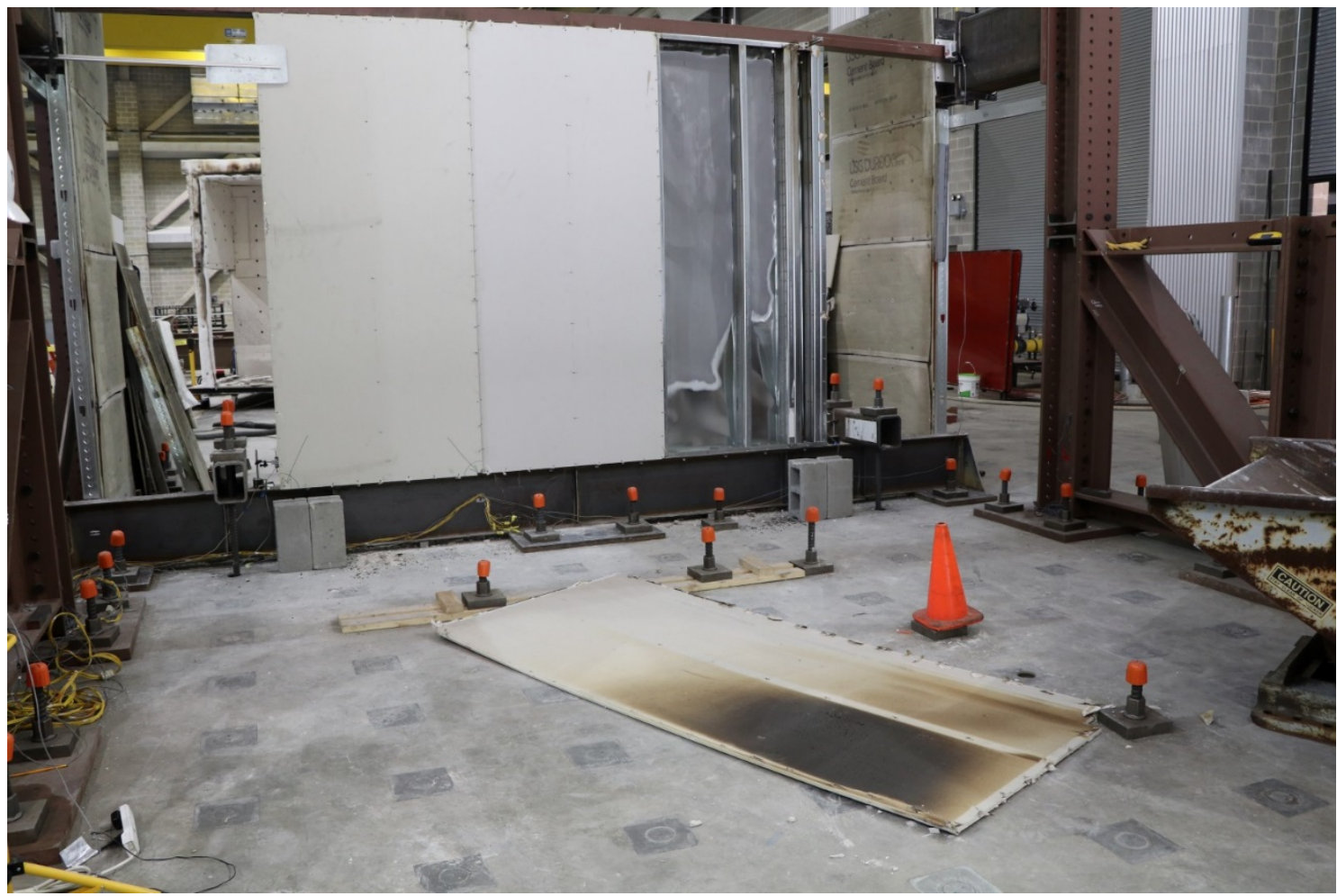

Figure 105: CFS06 - Photograph of back of metal sheathed side of wall after mechanical loading to $2.8 \%$ drift (CFS06c) highlighting charring of gypsum board. 